Check for updates

Cite this: Sens. Diagn., 2022, 1, 10

\title{
Explorations in a galaxy of sialic acids: a review of sensing horizons, motivated by emerging biomedical and nutritional relevance
}

\author{
Saurav K. Guin, (D)*abc Trinidad Velasco-Torrijos (iD ${ }^{\text {ad }}$ and Eithne Dempsey (iD *ad
}

\begin{abstract}
Sialic acid (Sia) is widely distributed in free, polymeric and conjugated forms in living creatures and humans. It serves various roles in human physiology including brain development, function of central nervous system, the immune system, lactation and infant cognition. Sia is over- or under-expressed in human cells, tissues and fluids during physiological disorders and the onset of cancers. Furthermore, the exploitation of Sia by several bacteria and viruses including SARS-CoV-2 to cause human infections has been recently revealed. A special chemical form of Sia and 3'- and 6'-sialyllactose have recently received regulatory approval for use in commercial food products as nutrition additives. Therefore, Sia production and assay have immense clinical and industrial interests. However, sensing or analytical approaches to Sia measurement in complex clinical and food samples are less developed due to lack of a comprehensive review covering both fundamental and perspectives to general readers working at the periphery of Sia. This review provides a carefully balanced and comprehensive collation of key aspects of the monosaccharide family of Sia, covering their sources, synthesis, biological significance, role in disease and human health and nutrition, culminating in a robust account of their analysis in complex matrices.
\end{abstract}

Received 21st September 2021, Accepted 3rd November 2021

DOI: $10.1039 / \mathrm{d} 1 \mathrm{sd} 00023 \mathrm{c}$

rsc.li/sensors reported as 2.6 and thus in the physiological conditions (i.e., at $\mathrm{pH}$ 7.4), it exists as an anionic pyranose form (Fig. 1[C]). ${ }^{1}$ About $92-95 \%$ of free $\mathrm{Sia}$ at equilibrium exists in the thermodynamically stable $\beta$-pyranose form. The anomeric carbon (C-2) is involved in the formation of glycosidic linkages and thus bound Sia predominantly exists in the $\alpha$-pyranose form (Fig. 1[C]). Sia is generally part of oligosaccharides bonded to glycoproteins and glycolipids through either $\alpha 2,3-$ or $\alpha 2,6$-glycosidic bond. They can also be connected through either $\alpha 2,9$ - or $\alpha 2,8$-bond to other Sia units i.e. oligo-(2-7 units of Sia) and poly- $(\geq 8$ units of Sia) sialic acid (polySia) as a linear polysaccharide chain. ${ }^{2}$

It is important to mention that several research groups around the world independently identified Sia in a range of biological sources and unintentionally named them differently. In 1935, Klenk's research group in Germany extracted and identified a new monosaccharide from human brain glycolipid and named it "neuraminic acid". ${ }^{3-5}$ In the following year, Blix's research group in Sweden extracted a similar compound from the mucin of submaxillary gland of bovine and named that as "kohlenhydrat $\Gamma^{, 6,7}$ Yamakawa's research group in Japan extracted a similar compound from equine blood stroma glycolipid in 1951 and designated it as "hemataminic acid". ${ }^{8}$ In the same year, Gottschalk in Australia extracted a similar compound from homogeneous mucoproteins by using an influenza virus enzyme and named as "N-substituted-isoglucosamine". ${ }^{9}$ György's research group, in 
USA in 1953, extracted a similar type of monosaccharide from the nondialyzable fraction of skimmed human milk and called it "gynaminic acid". 10,11 A similar type of compound was extracted by Richard et al. in Germany in 1954 from the mucoprotein fraction of bovine colostrum and was identified as "lactaminic acid". ${ }^{12}$ In 1955, Gottschalk identified the structural similarity among the above-mentioned compounds. ${ }^{13}$ In order too avoid the global confusion in the identification and reporting of this group of monosaccharides, he in association with Blix and Klenk, provided a unique nomenclature "sialic acid" that was unanimously accepted in $1957 .{ }^{14}$

Sia is a "shy" sugar unlike glucose and fructose and is thus relatively less known. Sia is endogenously synthesised de novo via an anabolic mechanism in the cytosol of eukaryotic cells. The uridine diphosphate- $N$-acetylglucosamine (UDP-GlcNAc), which is a nucleotide sugar, successively undergoes enzymatic reactions with UPD-GlcNAc-2-epimerase (EC: 5.1.3.14), $N$-Acetyl-D-mannosamine (ManNAc) kinase (EC: 2.7.1.60), Neu5Ac- $g$-phosphate synthetase (EC: 2.5.1.57) and Neu5Ac-9-phosphatase (EC: 3.1.3.29) to produce Neu5Ac inside the nucleus where it is activated by cytidine- $5^{\prime}$ monophospho (CMP)-Neu5Ac synthetase (EC: 2.7.7.43) as
CMP-Neu5Ac. The CMP-Neu5Ac transporter transports CMPNeu5Ac from the nucleus back to the cytosol for the following catabolic cycle. The bifunctional GNE enzyme (i.e., UPDGlcNAc-2-epimerase and ManNAc kinase) regulates the anabolic enzymatic reaction through feedback action. ${ }^{15,16}$ CMP- $N$-acetylneuraminic acid hydroxylase (EC: 1.14.18.2) hydroxylates CMP-Neu5Ac and produces CMP-Neu5Gc for the catabolic cycle. ${ }^{17}$ This enzyme is absent in humans, ferrets and new world monkeys as a result of an independent inactivating mutation and thus Neu5Gc is not endogenously synthesised in their body. ${ }^{18-20}$ Recently, it was experimentally observed that the distribution and concentration of Neu5Gc in other mammals depend on the type of species and tissues. For example, the skeletal muscle of goat was found enriched with Neu5Gc $\left(166 \pm 48.70 \mu \mathrm{g} \mathrm{g}^{-1}\right.$ of protein), while it was found to be absent in the skeletal muscles of dog and kangaroo. The lung, heart, liver, kidney and spleen of female deer had negligible (in the range $0.31-0.61 \mu \mathrm{g} \mathrm{g}^{-1}$ of protein) amount of Neu5Gc, but it was considerably $(36.89 \pm 42.60 \mu \mathrm{g}$ $\mathrm{g}^{-1}$ of protein) present in skeletal muscle. Similarly, the large$(851.50 \pm 314.20 \mu \mathrm{g}$ bound Neu5Gc per $\mathrm{g}$ of protein; $79.76 \pm$ $57.11 \mu \mathrm{g}$ free Neu5Gc per $\mathrm{g}$ of protein) and small-intestines of sheep $(760.52 \pm 295.08 \mu \mathrm{g}$ bound Neu5Gc per $\mathrm{g}$ of protein;

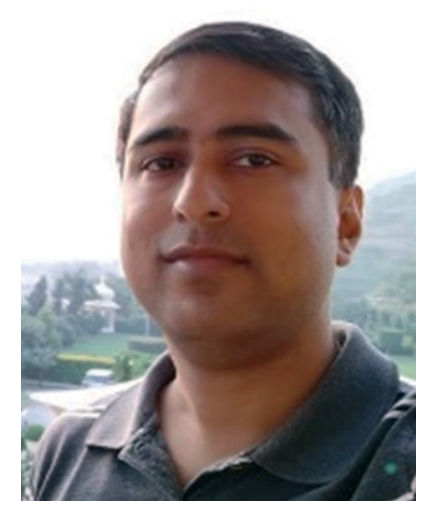

Saurav K. Guin
Dr. Saurav K. Guin is an earlycareer Scientist working in the domain of electrosynthesis, electrocatalysis and electroanalysis for more than 14 years in the Fuel Chemistry Division, Bhabha Atomic Research Centre, Department of Atomic Energy, Government of India. $\mathrm{He}$ is an Assistant Professor of Chemical Sciences in Homi Bhabha National Institute, Mumbai, India. At present time, he is working as a Marie Skłodowska-Curie Fellow and Career Fit PLUS Fellow at the Department of Chemistry, National University of Ireland Maynooth (Maynooth University) in Ireland on the development of biosensors for the determination of sialic acids in complex clinical samples, commercial foods and drinks. He worked in the Ulm University, Germany (2016) and National University of Singapore (2009) as visiting research fellow availing international fellowships. He is (co)author of 19 peer-reviewed articles published in international peer-reviewed journals and 44 other scientific publications. He is recipient of several competitive international research-fellowships, travel-grants and presentation-awards in international conferences. He has published a peer-reviewed Special Issue as a Guest Editor in 'Electroanalysis (Wiley)'. He served Indian Society for ElectroAnalytical Chemistry as the Secretary for 6 years. He is also member of reputed academic societies.

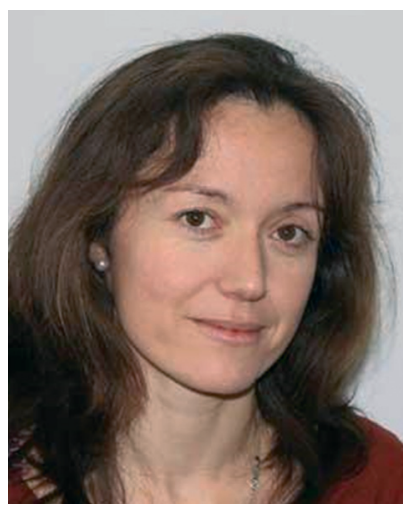

Dr. Trinidad Velasco-Torrijos is currently an Associated Professor and coordinator of $B S c$ in Pharmaceutical and Biomedical Chemistry program at the Department of Chemistry, Maynooth University (Ireland). Trinidad received her $P h D$ in from the University of Bristol (UK) under the supervision of Prof. Tony Davis in the field of carbohydrate recognition and supramolecular Chemistry. She pursued post-doctoral research at Ghent University (Belgium) with Prof. Annemieke Madder. She then joined the group of Prof. Paul Murphy at University College Dublin (Ireland) as a Marie Curie Postdoctoral Fellow (2003-2005). Trinidad's current research interests include the synthesis of glycomimetics and carbohydrate-based soft materials for biomedical applications. 
$65.96 \pm 49.34 \mu \mathrm{g}$ free Neu5Gc per $\mathrm{g}$ of protein) had the highest concentration of Neu5Gc amongst all organs. The concentration of bound Neu5Gc in the commercial cuts of lamb/mutton varied in the range $\sim 31-77 \mu \mathrm{g} \mathrm{g}{ }^{-1}$ of protein. ${ }^{21}$ Although KDN is highly abundant in bacteria and lower vertebrates, it is highly expressed on ovarian tumour tissue and in the foetal haemoglobin of humans. ${ }^{22}$ Sia is also found in some viruses, bacteria, fungi, protozoa, insects, mollusca, sea urchin, and different organs and cells of humans. ${ }^{23}$ The edible bird's nest (EBN) of Asian swiftlet showed significantly high concentration of Sia due to the involvement of Sia rich saliva secreted from the sublingual glands of Asian swiftlets during nest formation. ${ }^{24-26}$ The presence of Sia in plants and fruits is usually rare and mainly originated from extraneous contaminants. ${ }^{27-29}$ However, recently Sun et al. reported the presence of a considerable amount of Neu5Ac in pea seedlings. ${ }^{30}$ Furthermore, Xia et al. extracted Sia from the sialylated glycoprotein from the root of a Tibetan plant Potentilla anserina $\mathrm{L}^{31}$ Hence, the present state of art is not able to confirm that Sia is absent in all parts of the plants.

It would be a mistake to ignore the biological importance of Sia. Schauer and Kamerling published a book chapter in 2018 exploring the world of Sia, covering their discovery, structural analysis and some biological roles. ${ }^{32}$ In 2021, Yang et al. has published a review article emphasising the biosynthesis, metabolism and various means of production

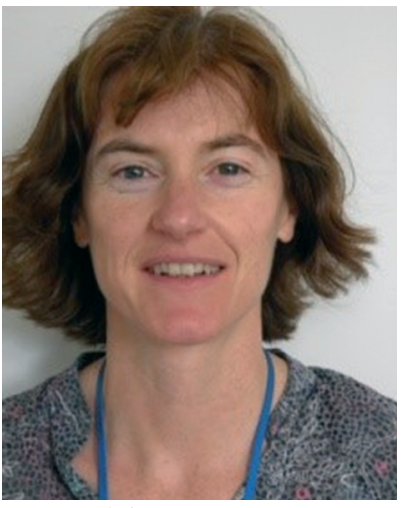

Eithne Dempsey
Dr. Eithne Dempsey received a $\mathrm{PhD}$ in Electroanalytical Chemistry from Dublin City University followed by postdoctoral research at St. Vincent's Hospital, Dublin. She then took up a position as Lecturer in Chemistry at Technological University Dublin - Tallaght Campus where she managed the Centre for Research in Electroanalytical Technologies. She was appointed visiting Professor of Chemistry at the University of the Western Cape, Capetown, South Africa in 2012 and recently (2017) took up a position at Maynooth University, currently as Associate Professor (since 2020) in Dept. Chemistry. Her core research objective is to address electroanalytical challenges using bespoke (nano)materials integrated with biosensing systems suitable for onsite deployment in multiple application scenarios. This includes nanoassembly and characterisation with use of modern electrochemical and surface based techniques, utilisation of electrocatalytic materials in biomedical and environmental science and the design and fabrication of integrated fluidics/sensor microsystems which exploit electrocatalytic/nanomaterials for biomedical diagnostics. of $\mathrm{Sia}^{33}$ Furthermore, a couple of interesting reviews have been published in 2020-2021 covering the progress and promises of free Sia storage disorder, ${ }^{34}$ development of the entry inhibitors for Sia targeting viruses, ${ }^{35}$ the role of Sia as a receptor of various pathogens, ${ }^{36}$ role in human immune regulation and therapeutic potentials ${ }^{37}$ and utilisation of Sia for identifying tumours. ${ }^{38}$ In 2010, Lacomba et al. published a review emphasising analytical methodologies for Sia and gangliosides in the biological and dairy products. ${ }^{39}$ In 2021, Cheeseman et al. published another review on the identification and quantification of Sia covering the traditional colorimetric, fluorometric, enzymatic and chromatographic methods. ${ }^{40}$ It is important to mention here, that the European Commission has recently approved inclusion of Sia as a supplement in infant and follow-up formula and other food products under regulation EC/258/ 97. ${ }^{41}$ However, the beneficial or inhibiting role of Sia in the present pandemic caused by the COVID-19 disease is yet an open question. ${ }^{42-44}$ Hence, this serendipitous review has the intriguing ambition to concisely outline the universe of Sia to both general and expert readers covering Sia's involvement in human biochemistry; its role in human health, the immune system, pathogenicity and disease; dietary regulations and commercial production and most importantly the evolution of analytical methods from traditional to the latest emerging techniques for assays of Sia in complex biological and food matrices.

\section{Biological relevance of Sia}

The CMP-sialic acid transporter (viz. CMP-Neu5Ac transporter) transports CMP-Sia to the lumen of the Golgi body, where Sia becomes associated with glycoproteins, glycolipids and oligosaccharides by various silyl transferases. The sialylated glycoproteins/glycolipids/oligosaccharides and poly- or oligo- sialic acids are distributed in the lysosome, cytosol, outer-plasma membrane and intra-cellular cell compartment membrane, where exo- $\alpha$-sialidase (EC: 3.2 .1 .18 ) releases the terminal Sia unit in the cell. Sialic acid aldolase (EC: 4.1.3.3) then splits Sia into pyruvate and ManNAc in the cell. In this catabolic cycle both free Sia and ManNAc may be salvaged to the appropriate stage of the anabolic cycle. ${ }^{45}$ The absence of (CMP)-Neu5Ac synthetase and sialic acid aldolase in human milk helps in the accumulation of free Neu5Ac in human milk.

\subsection{Diverse biological functions of Sia in healthy humans}

Sia is generally present on the human cell glycocalyx, which is a sugar-coat or a thick $(\sim 500 \mathrm{~nm})$ network of glycans on the surface of human cells. The glycocalyx not only protects the cells, but it also interacts with other cells and outercellular environment. Neu5Ac is a major occupant of stroma of human erythrocytes i.e., red blood cell (RBC) and it eventually helps in the dispersion of RBC in blood owing to electrostatic repulsions as shown in Fig. 2[A]. ${ }^{46}$ Furthermore, the podocalyxin epithelial polyanions consist of negatively 
[A]

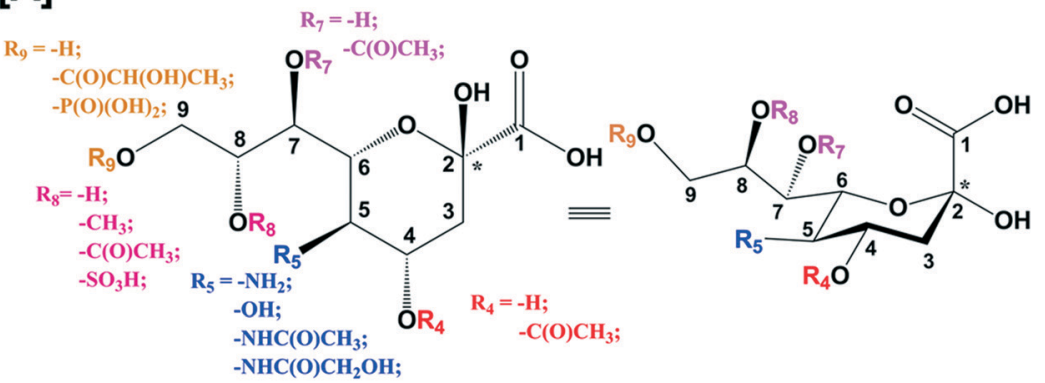

In Haworth Projection In Chair Configuration

Family Members of Sias
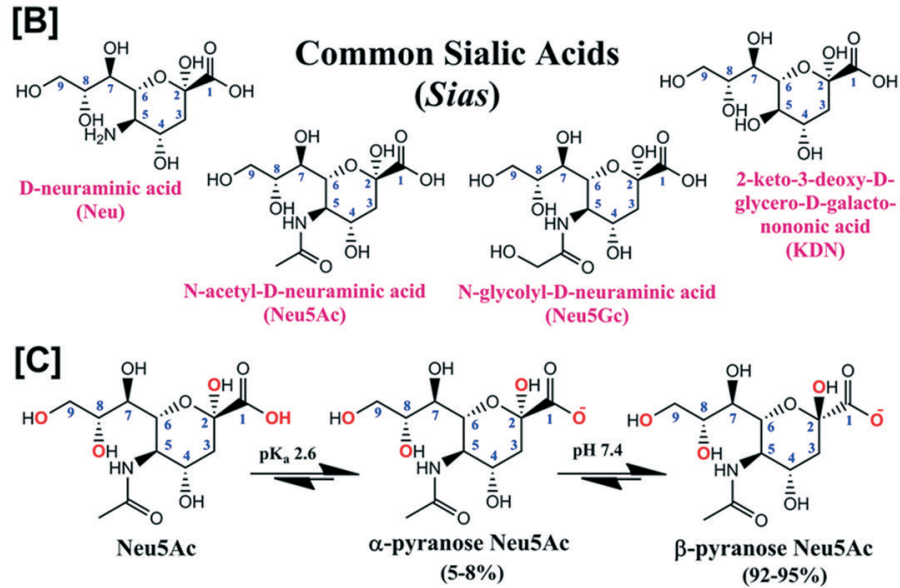

Fig. 1 [A] Generic molecular structure of Sia. [B] Molecular structures of common Sia i.e. D-neuraminic acid, N-acetyl-D-neuraminic acid (Neu5AC), $\mathrm{N}$-glycolyl-D-neuraminic acid (Neu5GC) and 2-keto-3-deoxy-D-glycero-D-galacto-nononic acid (KDN). [C] Anomeric forms of free Neu5Ac at physiological pH (7.4).

charged Sia (as shown in Fig. 2[B]), sulphated oligosaccharides and glycopeptides control the glomerular filtration in the kidneys in association with phosphorylated ezrin and $\mathrm{Na}^{+} / \mathrm{H}^{+}$exchanger regulatory factor $2 .{ }^{47}$ On the other hand, glycans are covalent linear and branched oligosaccharide chains, whose monosaccharide component includes Neu5Ac, glucose, galactose, mannose, fucose, $\mathrm{N}$-acetyl-glucosamine (GlcNAc) and $\mathrm{N}$-acetyl-galactosamine (GalNAc). Glycans are attached to glycoproteins (by either $N$ or $O$-linkage) and glycolipids on the glycocalyx and extracellular fluids and matrices.

2.1.1 Immune system regulation. The human immune system can identify antigens and cell-damages by different types of molecular patterns known as pathogen- and dangerassociated molecular pattern, respectively, by the pattern recognition receptors viz. toll-like receptors, C-type lectin receptors, etc. Following this, the immune network triggers the release of inflammatory cytokines for consolidated immunological actions to encounter antigens. However, chronic and prolonged inflammation can eventually damage the healthy cells, tissues and organs. Hence, the regulation of inflammation inside the cells is a critical process, where Sia plays an important role.
The sialoglycans on the glycocalyx of healthy cells usually form specific self-associated molecular pattern (SAMP). ${ }^{48}$ The sialoglycan-SAMP is recognised by sialic acid-binding immunoglobulin type lectin (Siglec) protein receptors on the surface of immune cells (such as monocytes, macrophages, dendritic cells, natural killer cells, B lymphocytes, neutrophils and eosinophils), myelin, myeloid progenitors, trophoblasts and osteoclasts. Siglec discriminates the body's own and foreign antigens and can interact with Sia of the same as well as different cells. A total number of 15 human Siglecs $(1-12,14-16)$ have been identified so far and it is believed that Siglec-13 and -17 genes have been inactivated during the course of human evolution. ${ }^{49}$ Siglec-1 (also known as sialoadhesin), -2 (also known as CD22), -4 (also known as myelin-associated glycoprotein) and -15 are found in all mammals and thus are known as conserved classic Siglecs. The other Siglecs have rapidly evolved in humans and are categorised as Siglec-3 (also known as CD-33) related Siglecs. On the other hand, Siglecs are often classified as per their functionality such as inhibitory (2, 3, 5-12), activating (14-16) and non-signalling $(1,4)$ Siglecs.

The binding of Sia by the inhibitory-type Siglecs induces the Src family kinases by the immunoreceptor tyrosine-based 
inhibitory motif or its alike tyrosine present in the cytoplasmic domain and eventually it down-regulates the proinflammation caused by toll-like receptors (Fig. 2[C]). ${ }^{50}$ This phenomenon prevents the pro-inflammatory damage of the self-antigens and healthy cells. On the other hand, the transmembrane DNAX activation protein 12 of the activatingtype Siglec electrostatically binds with negatively charged Sia and stimulates pro-inflammatory responses through mitogenactivated protein kinase and AKT pathways to destroy the pathogens having specific sialoglycan-SAMPs to circumvent inhibitory Siglecs (Fig. 2[C]). ${ }^{51}$ The Siglec-2, -6, -14 and -15 bind $\alpha 2,6-N e u 5 A c$, whereas Siglec- 5 and -11 bind $\alpha 2,3-N e u 5 A c$ and $\alpha 2,8-\mathrm{Neu} 5 \mathrm{Ac}$, respectively. The Siglec- 9 and -10 do not show any preference to $\alpha 2,3-$ and $\alpha 2,6-N e u 5 A c$; but Siglec-1, 4 and -8 preferentially bind $\alpha 2,3$-Neu5Ac over $\alpha 2,6$-Neu5Ac and the reverse is true for Siglec-3. On the other hand, Siglec7 preferentially binds to $\alpha 2,8$ - over $\alpha 2,6$ - and $\alpha 2,3$-Neu5Ac. ${ }^{52}$
The $\alpha 2,3-N e u 5 A c-S A M P$ is recognised by the serum complement factor $\mathrm{H}$ of the alternate pathway of innate immune system to identify and protect "self" cells. ${ }^{53,54}$

The selectins are a family of calcium-dependent (C-type) lectins also involved in immune cell adhesion to endothelial cells. They mediate access to lymphoid organs and sites of inflammation. Sialylated tetrasaccharides, i.e., sialyl Lewis ${ }^{x}$ $\left(\right.$ sLe $^{x}$, Neu5Ac $\alpha 2-3 G a l \beta 1-4(F u c \alpha 1-3)$ GlcNAc) and sialyl Lewis ${ }^{a}$ (sLe ${ }^{\mathrm{a}}$, Neu5Ac $\alpha 2-3 \mathrm{Gal} \beta 1-3$ (Fuc $\left.\alpha 1-4\right)$ GlcNAc) are among the best described ligands for the selectins but they can also have high-affinity interactions with sulfatides and non-sialylated glycosphingolipids (Fig. 2[C]). ${ }^{55}$ The selectin family can be subdivided in three main groups: P-selectins, expressed on platelets; E-selectins, expressed on endothelial cells and Lselectin, expressed on leukocytes. The biological function and ligand selectivity of these three selectins sub-families are also different. L-selectin is involved in leukocyte trafficking.

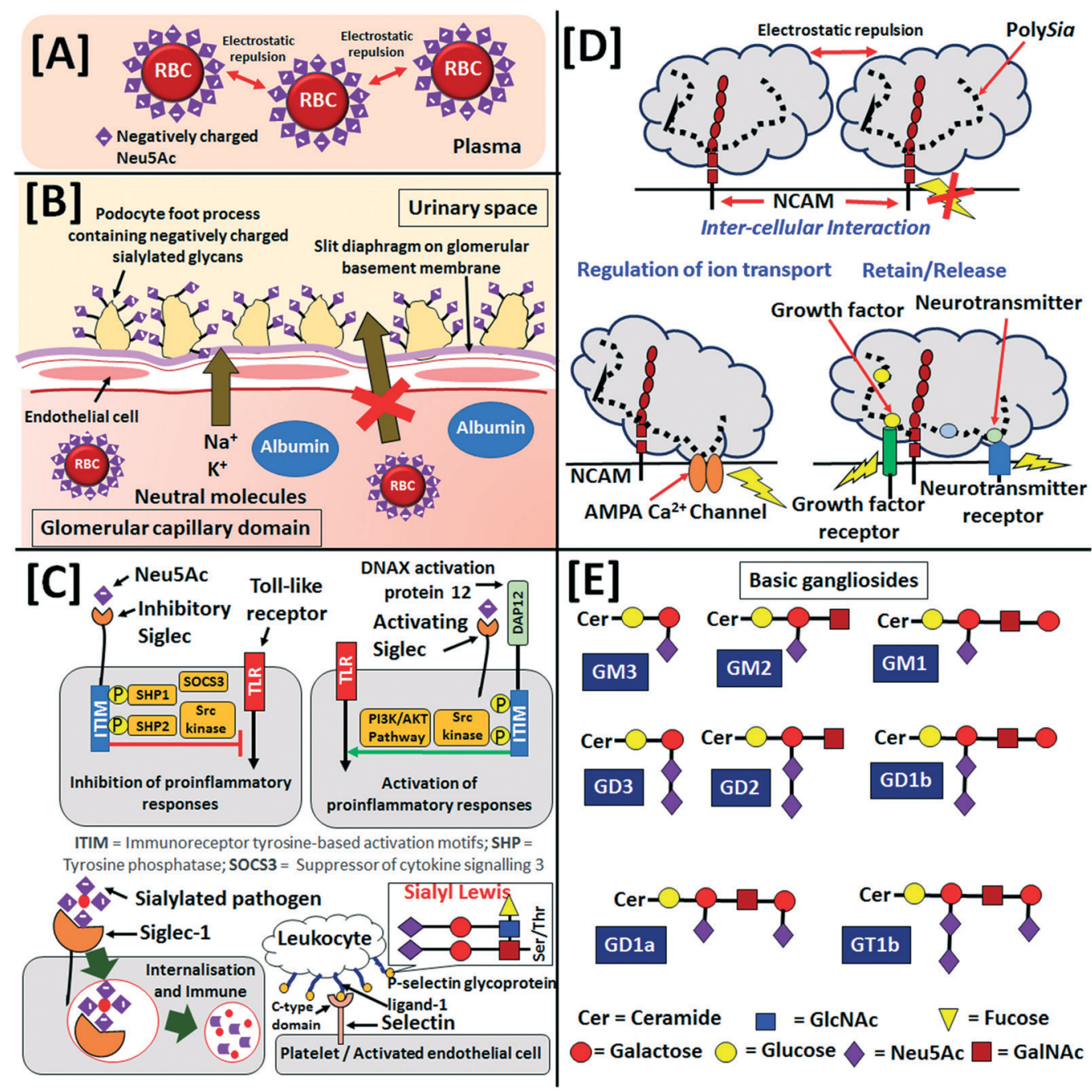

Fig. 2 Negative charge of Neu5Ac in [A] dispersion of RBC in blood and [B] glomerular filtration in kidney. [C] The inhibitory (top left) and activating (top right) siglec actions in immune system, internalisation and immune response of Siglec-1 (bottom left), interaction of C-type domain of selectin with sialyl Lewis of P-selectin glycoprotein ligand-1 of leukocyte (bottom right). [D] Intercellular repulsive interaction of polySia-NCAM, activation of ion channels and growth factor receptors through attractive interactions. [E] Sequence of saccharides in some of the basic gangliosides (the relative scale of objects of the schemes are not in actual dimensions). 
E-selectins are constitutively expressed on endothelial cells in the bone marrow and skin, but exposure to inflammatory cytokines is required for their expression in other organs. P-selectins are found in activated platelets. Sołkiewicz et al. recently reported that the specific reactivity of $\alpha 2,3-\mathrm{Neu} 5 \mathrm{Ac}$ recognising selectin Maackia amurensis agglutinin with sialylated serum immunoglobulin $\mathrm{G}$ as well as quantitative evaluation of sialylation and agalactosylation factor could be useful to diagnose inflammatory endometriosis disease. ${ }^{56}$

2.1.2 PolySia in central nervous system. PolySia in humans is mainly ( $\sim 90 \%)$ linked to the neural cell adhesion molecule (NCAM) (also known as CD56) protein in the brain (studied in rat), ${ }^{57}$ human cerebrospinal fluid, ${ }^{58} \alpha$-subunit of type 4 sodium channel protein, ${ }^{59}$ Sia transfer proteins viz. ST8- $\alpha \mathrm{N}-$ acetyl-neuraminide- $\alpha 2,8$-sialyltransferase-2 and -4 (i.e. ST8SiaII and ST8SiaIV (EC: 2.4.99)). ${ }^{60}$ PolySia is also expressed in a large variety of cells and proteins, such as human bone marrow-derived mesenchymal stromal cells, ${ }^{61}$ lymphoid cells viz. natural killer cell, ${ }^{62}$ activated CD4+ T-cells, ${ }^{63}$ synaptic cell adhesion molecule-1 mostly found in the subset of NG2 cells, ${ }^{64}$ CD36 in human milk, ${ }^{65}$ and neuropilin-2 on dendritic cells. ${ }^{66}$ Although, human cells have in total six ST8Sia, polySia is synthesised in the human cell's Golgi body by only ST8SiaII and ST8SiaIV followed by conjugation with NCAM $^{67-69}$ and regulation by intercellular $\mathrm{Ca}(\mathrm{II})$ catalytic synaptic transmissions. ${ }^{70}$ The oligoSia and polySia are metabolised by the enzyme endo- $\alpha$-sialidase (EC: 3.2 .1 .129$),{ }^{71}$ but it has recently been revealed through an in vitro study that although human neuraminidase enzymes NEU3 and NEU4 can degrade oligoSia at $\mathrm{pH}<7$, no human neuraminidase enzyme can hydrolyse polySia. ${ }^{72}$

NCAM participates in cytoplasmic signalling, intercellular and extracellular matrix interactions in the central nervous system. The long negatively charged hydrated polysia on NCAM are responsible for $\sim 20-30 \mathrm{~nm}$ intercellular space (Fig. 2[D]). However, polySia on NCAM attract neuro- and biologically active molecules viz. brain-derived neurotrophic factor, pro-brain-derived neurotrophic factor, neurotrophic factors-3, fibroblast growth factor-2, norepinephrine, dopamine, epinephrine, histone $\mathrm{H} 1$, chemokine ligand 21, etc. (Fig. 2[D]). ${ }^{73}$ It also shows attractive interaction to $\mathrm{Ca}^{2+}$ permeable AMPA channel (Fig. 2[D]). PolySia helps in the migration of neuronal progenitor cells from the subventricular zone of lateral ventricle and rostral migratory stream to the olfactory bulb in the embryonic nervous system. The polySia on the progenitors in the subventricular zone influences the timing of the differentiation process into interneurons in the olfactory bulb. ${ }^{74}$ During the embryonic and neonatal stages, polySia expressed on the growing axons helps to avoid interference of ectopic synapses projected towards specific targets; then, its under-expression on the developing axons and oligodendrocyte precursors starts at the onset of myelination. Furthermore, during the critical neonatal stage polySia provides insulation and controls synaptogenesis helping maturation of the central nervous system of the infant. However, the expression of polySia in the central nervous system is gradually decreased from the embryonic stage to mature infant ( $\sim 10$ years age) and mostly located at very low concentration in adults up to 80 years old in subventricular zone and granule cell layer of the hippocampus to maintain neurogenesis and neural plasticity. Furthermore, trace amounts of polySia present in the adult thalamus (paratenial, periventricular and anteroventral anterodorsal nuclei), hypothalamus (supraoptic and suprachiasmatic nuclei), habenular nuclei, entorhinalhippocampal complex, lateral geniculate nucleus, dorsal spinal laminae and mesencephalic central grey control the physiological plasticity. PolySia is also expressed on some sensory neurons in the spinal cord, optic nerve, tectum (axons of ganglion cells) and piriform cortex. The reintroduction of external polysia in adults has shown natural neural tissue repair. ${ }^{75-77}$ Weisgerber et al. reported $15.0 \pm 1.5 \mu \mathrm{g} \mathrm{mL}{ }^{-1}$ polyNeu5Ac in the cerebrospinal fluid of new-born and premature infants and its concentration decreased to $0.2 \pm 0.02 \mu \mathrm{g} \mathrm{mL}^{-1}$ in children $\geq 1$ year old. ${ }^{58}$ Simon et al. have recently reported the expression of polySia in human semen owing to the post-translational modification of NCAM and $\alpha 2,8$-polysialyltransferases ST8SiaII. $^{78}$ The expression of polySia to CD36 ratio in human breast milk is initially increased from $0.572 \pm 0.225$ during 7 days of colostrum to $3.424 \pm 0.938$ at 1 month and then again decreased to $1.491 \pm 0.044$ and $1.018 \pm 0.478$ after 3 and 6 months, respectively, from birth. ${ }^{65}$

Owing to the above-mentioned physiological roles of the polySia to humans, it is usually recognised as a harmless molecule by the human immune system. This phenomenon is often exploited by some bacteria such as Escherichia coli, Listeria monocytogenes, Neisseria meningitidis, Haemophilus influenzae b, Streptococcus agalactiae and Streptococcus pneumoniae having their own polySia glycocalyx causing invasive meningococcal diseases viz. meningitis, fulminant septicaemia, etc. ${ }^{79}$ However, Siglec-11 preferentially binds to polySia and inhibits inflammatory neurotoxicity of phagocytosis. ${ }^{80}$ The expression of polySia on several cancer cells is highly invasive and proliferative, being recognised as onco-developmental antigens. Thus, polySia is sometimes considered a potential biomarker to diagnose lung carcinoma, neuroblastoma, glioblastoma and pituitary tumours. Cancer therapy sometimes utilises antibodies and inhibitors specific to polySia-NCAM. ${ }^{81}$ Furthermore, the abnormal expression and impairment of polySia are associated with mental disorders viz. schizophrenia, bipolar disorder, autism spectrum disorder. ${ }^{82}$ Relapsing-remitting multiple sclerosis is caused by the inflammatory attacks on myelin and nerve fibers. The high activity of immunoglobulin $\mathrm{G}$ towards exogenous Neu5Gc and Neu5Ac showed some potential use in immunotherapy of relapsing-remitting multiple sclerosis. ${ }^{83}$

2.1.3 Gangliosides in human brain development and cancer biomarking. Gangliosides comprise a family of complex glycosphingolipids featuring a hydrophobic ceramide moiety bound to a glycan with at least one unit of 
Neu5Ac. The ceramide consists of a sphingoid base covalently linked to a fatty acid by an amide bond. The gangliosides are amphiphilic in nature due to the coexistence of hydrophobic ceramide moiety linked on the cell membrane and negatively charged hydrophilic Sia in the glycan chain exposed to the extracellular environment. The gangliosides are synthesised at the Golgi apparatus and trans-Golgi network through sequential activities of sialyltransferases and glycosyltransferases enzymes, which are regulated by intracellular sphingolipid traffic. The luminal surface of transport vehicles transfers the synthesised gangliosides to the external leaflet of the plasma membranes, where gangliosides in trans conformation directly bind membrane proteins such as lectins through either carbohydrate-amino acid or carbohydrate-carbohydrate interactions. Siglecs preferentially bind to the higher sialylated gangliosides, but galectins can bind monosialylated gangliosides. The endocytosis process directs the gangliosides to the surface of intra-lysosomal luminal vesicles, where they are eventually degraded. $^{84}$

In 1978, Svennerholm et al. reported the concentration of gangliosides in different human organs. ${ }^{85,86}$ The highest concentration (i.e., $3500-3000 \mathrm{nmol} \mathrm{g}^{-1}$ of tissue weight) of Neu5Ac was reported for the human brain's cerebral cortex followed by the cells in the cerebral white matter (1250-1000 nmol g ${ }^{-1}$ of tissue weight). The spleen (300-200 nmol g-1 of tissue weight), placenta (200-100 $\mathrm{nmol} \mathrm{g}^{-1}$ of tissue weight) and retina (150-100 $\mathrm{nmol} \mathrm{g}^{-1}$ of tissue weight) share almost similar concentration of gangliosides. Other organs viz. liver (100-50 $\mathrm{nmol} \mathrm{g}^{-1}$ of tissue weight), thyroid (100-60 $\mathrm{nmol} \mathrm{g}^{-1}$ of tissue weight), peripheral nerve (80-35 $\mathrm{nmol} \mathrm{g}^{-1}$ of tissue weight), skeletal muscle and muscular layer of small intestine (80-50 $\mathrm{nmol} \mathrm{g}^{-1}$ of tissue weight), kidney (60-30 $\mathrm{nmol} \mathrm{g}^{-1}$ of tissue weight), skin (30-35 nmol g ${ }^{-1}$ of tissue weight), fat tissue (10-15 $\mathrm{nmol} \mathrm{g}^{-1}$ of tissue weight) and mucosa (5-8 nmol $\mathrm{g}^{-1}$ of tissue weight) also showed moderate concentration of gangliosides. In the nomenclature of gangliosides, ' $\mathrm{G}$ ' refers to the ganglio series of glycosphingolipids, while ' $M$ ', 'D', 'T' and 'Q' define 'mono', 'di', 'tri' and 'tetra' Neu5Ac units, respectively. The migration order of gangliosides in thin-layer chromatography is designated by the number $1,2,3$, etc., whereas ' $a$ ', ' $b$ ' and 'c' refer to 'one', 'two' and 'three' units of Neu5Ac, respectively, linked to the innermost galactose unit of the glycan chain. ${ }^{87}$ Fig. 2[E] shows the arrangement of saccharides in some of the basic gangliosides. Ganglioside distribution and composition in human brain can vary greatly depending on age. The simple gangliosides viz. GM3, GD3 and 9OAc-GD3 are predominant in human embryonic brains, but as age increases, comparatively complex gangliosides viz. GM1, GD1a, GD1b and GT1b are upregulated with concomitant down-regulation of embryonic gangliosides. ${ }^{88,89}$ Ando et al. were able to determine the composition of adult white- and grey-matter of human brain by densitometry. They found the ganglioside bound Neu5Ac concentration in the human greyand white-matter as 875 and $275 \mu \mathrm{g} \mathrm{g}^{-1}$ of the wet tissue, respectively. They also reported that GD1a (21.7\%), GD1b $(18.2 \%)$, GT1b (16.3\%) and GM1 (14.9\%) are the major components of the grey matter, while GM1 $(21.6 \%)$, GD1b (16.9\%), GT1b (11.1\%) and GD1a (8.8\%) are major components of white matter. The other gangliosides such as GM2, GM3, GM4, GD2, GD3, GT1a, GQ1b and GD1a-GalNAc are also found in both the grey- and white- matter of the human brain. ${ }^{90}$ Sarbu et al. recently utilised electrosprayionization-ion-mobility-mass-spectrometry to study the ganglioside profile of purified normal foetal frontal lobe in the $37^{\text {th }}$ gestation week. They identified a total number of 143 ganglioside species having different glycan structures and ceramide constitutions including 47,37 and 25 structures of GT, GD and GM, respectively. They also reported the existence of a minimum $12 \mathrm{GQ}$ structures and glycans having Neu5Ac up to 8 units (which was earlier believed to be a maximum 5 units). ${ }^{91}$ The same research group later identified more than 140 ganglioside species in the adult human hippocampus by using an ion-mobility-mass-spectrometry hyphenated with the collision-induced-dissociation fragmentation method. ${ }^{92}$ They also compared the frontal and the occipital lobes of the brains of the 20 and 82 year-old males by nano-electron-sprayionisation orbitrap-mass-spectrometry hyphenated with collision-induced-dissociation fragmentation method and reported that the content of sialylated, fucosylated and acetylated gangliosides in the overall human brain could decrease with age. Interestingly, the gangliosides are overexpressed in the frontal lobe compared to the occipital lobe in young ages; while the opposite becomes true in old ages. ${ }^{93}$ Through ion-mobility-mass-spectrometry they have recently identified 113 gangliosides including GD2 and GD3 in the human cerebrospinal fluid and confirmed that some of the brain gangliosides could be passed to the cerebrospinal fluid due to immediate proximity to brain. ${ }^{94}$

The gangliosides are expressed along with phospholipids, cholesterol and glycosphingolipids on the plasma membrane's lipid rafts and participate in signal transduction (inhibition, activation, promotion, etc.) in cancer cells. This over-/under- expression of gangliosides is often used to diagnose several cancers and other diseases. ${ }^{95}$ The malignant brain tumour known as glioblastoma multiforme can be diagnosed from the overexpression of both GD3 and GT1 gangliosides. ${ }^{96}$ The high incidence of GD3 and GM3 gangliosides is a signature of human melanoma, a skin cancer. ${ }^{97}$ GM1 activates tropomyosin receptor kinase-A and promotes differentiation of the neuroblastoma cells by formation of receptor-GM1 complex on the cell surface. ${ }^{98}$ The GM1's expression in the skin increases with aging and senescence. It induces human aortic endothelial cells' insulin resistance. ${ }^{99}$ The exogeneous GM1 showed a neuroprotective effect for neurodegeneration, neuronal injury; as well as a beneficial role to patients having Huntington, Alzheimer, Parkinson diseases, epilepsy, stroke and multiple sclerosis. ${ }^{100}$ Furthermore, GM1 binds with the platelet-derived growth factor receptors, inhibits the signal to the glycolipid-enriched microdomain and suppresses the cell growth signal. ${ }^{101}$ On 
the contrary, platelet-derived growth factor B induces GD3 to enhance platelet-derived growth factor signal and promotes the cell proliferation and invasion in the gliomas in the glial cells of brain or spine. ${ }^{102}$ GD3 blocks the activation of nuclear factor kappa-light-chain-enhancer of activated B cells in the human hepatoblastoma HepG2 cell-line after ionizing radiation or daunorubicin therapy. Hence, GD3 pre-treatment promotes apoptotic cell death during radiation or chemo therapy in patients having hepatocellular carcinoma. ${ }^{103}$ Furthermore, GD3 activates CD95 induced apoptosis of lymphoid and myeloid tumour cells for leukaemia. ${ }^{104}$ On the other hand, the overexpression of GD3 on the malignant melanoma and human osteosarcomas cells activates p130Cas and promotes focal adhesion kinase and paxillin pathway. ${ }^{105-107}$ GD3 helps in the signalling of epidermal growth factor receptor and its activated form in the breast cancer stem cells and cell line. ${ }^{108}$ GM3 showed inhibition in the epidermal growth factor signalling pathway for the human neuroblastoma cell line NBL-W (for neural and brain cancer); ${ }^{109}$ human epidermoid carcinoma A431 cell (for skin cancer); ${ }^{110}$ PC-3 and LNCaP cell (for prostate cancer); ${ }^{111}$ YTS1, T24, 5637, and KK47 cell (for human bladder cancer); ${ }^{112}$ HSC-2 and SAS cell (for squamous carcinoma). ${ }^{113}$ GM3 inhibits PI-3K/AKT/MDM2 signalling as well as Wnt/ $\beta$-catenin signalling pathways, ${ }^{114,115}$ but promotes oxidative stressmediated mitochondrial pathway in HCT116 cell for human colorectal cancer. ${ }^{116}$ GM2 has potential in the diagnosis and therapy of pancreatic ductal adenocarcinoma as it is overexpressed in MIA-PaCa- 2 cell line and promotes TFG- $\beta 1$ signalling for invasion. ${ }^{117} \mathrm{GD} 2$ is expressed on the stem-like cells of triple-negative breast cancer ${ }^{118}$ and it is involved in the proliferation of MDA-MB-231 cells by promoting signalling of c-Met receptor. ${ }^{119}$ The GD3 and GD2 are overexpressed on glioma cell line U-251MG and promote the signalling of ERK1/2 and AKT pathway. ${ }^{120}$ GD2, GD1b, and GT1b are generally expressed on the small cell lung cancer cells $^{121}$ and GD2 promotes the activation of focal adhesion kinase pathway for integrin-mediated signal transduction. ${ }^{122}$ GD1a targets c-Met receptor and suppresses the metastasis of hepatocellular carcinoma in human hepatoma HepG2 cell by inhibiting the signalling of hepatocyte growth factor. ${ }^{123}$ Both exogenous and endogenous GD1b regulate breast cancer apoptosis as evidenced in the MCF-7 human breast cancer cells. ${ }^{124}$ The treatment with GT1b induces an early apoptosis in A549 lung cancer cells by modulating both caveolin-1 and p53 to inhibit fibronectin-a5b1-integrin-ERK signalling. ${ }^{125}$

2.1.4 Pregnancy, lactation and infant cognition. Many articles have indirectly indicated the benefits of Sia in the human cognitive processes including knowing, remembering, thinking, problem-solving and judgement, however no direct evidence of transferring Sia from the mother's placenta to the human foetus is reported to date. Rajan et al. reported that the total Sia concentration in human plasma increased from $1830 \pm 40 \mu \mathrm{M}$ for women $(n=60)$ during the menstrual cycle to $2580 \pm 50 \mu \mathrm{M}$ for pregnant women $(n=28)$ during $3^{\text {rd }}$ trimester (i.e., 26-40 weeks) and further increased to $3460 \pm$
$160 \mu \mathrm{M}$ in the post-partum period (i.e., 1-14 days postpartum). Similarly, the urine Sia concentration increased from $2350 \pm 80 \mu \mathrm{M}$ for women $(n=56)$ during the menstrual cycle to $5400 \pm 330 \mu \mathrm{M}$ for pregnant women $(n=27)$ during the $3^{\text {rd }}$ trimester but did not further increase in the postpartum period. However, no statistical correlation was observed in the neuraminidase and sialyltransferase activities during the pregnancy period compared to non-pregnant women. ${ }^{126}$ Alvi et al. reported an elevation of Sia concentration in serum from $1.63 \pm 0.3 \mathrm{mM}$ at the onset (i.e., $5-8$ weeks of pregnancy) to $2.06 \pm 0.49 \mathrm{mM}$ in the last stage (i.e., $37^{\text {th }}$ week) of pregnancy. ${ }^{127}$ The concentration of Sia in the saliva of women increased from $57.3 \pm 10.5 \mathrm{mg} \mathrm{\textrm {L } ^ { - 1 }}$ (control) to $149.6 \pm 62.5 \mathrm{mg} \mathrm{L}^{-1}$ at the $21^{\text {st }}$ week of gestation but decreased again to $129.3 \pm 16.5 \mathrm{mg} \mathrm{L}^{-1}$ at the $40^{\text {th }}$ week of gestation. ${ }^{128}$ The progress of pregnancy is also reflected in the Sia concentration on RBC membranes, where it increased to $96.30 \pm 34.20 \mathrm{mg} \mathrm{g}^{-1}$ of protein during 28-32 weeks of pregnancy $(n=25)$ compared to $42.33 \pm 15.85 \mathrm{mg} \mathrm{g}^{-1}$ of protein found in non-pregnant women $(n=10) .{ }^{129}$ The lectin dotting analysis of sialylation of amniotic fluid glycoconjugates by Sambucus nigra agglutinin (which is specific to $\alpha 2,6$-glycosidic link) revealed that $\alpha 2,6$-sialylated glycoconjugates in the amniotic fluid increased from $965 \pm$ 299 pixels at second trimester to $1806 \pm 292$ pixels in the perinatal period and further increased to $2099 \pm 225$ pixels in post-date pregnancy. ${ }^{130}$ Furthermore, Zhu et al. studied the concentration of Sia in the serum and breast milk of 133 pregnant women and infant cognitive development of their children over a year. It was reported that the concentration of Sia in the serum increased from $2.10 \pm 0.92 \mathrm{mM}$ in $10^{\text {th }}$ weeks to $2.59 \pm 0.95 \mathrm{mM}$ in the $16^{\text {th }}$ week and $2.95 \pm 0.98$ $\mathrm{mM}$ in the $38^{\text {th }}$ week of pregnancy, while Sia in the breast milk decreased from $5.15 \pm 0.18 \mathrm{mM}$ after 3 days to $1.99 \pm$ $0.08 \mathrm{mM}$ after 42 days and $0.53 \pm 0.04 \mathrm{mM}$ after 90 days of delivery. They evaluated the mental development index and psychomotor development index of infants at $90^{\text {th }}$ day from the date of delivery and found that a high concentration of Sia in the serum during the second trimester (i.e., $16^{\text {th }}$ week) of pregnancy promoted both early mental and psychomotor developments of the infants, whereas the high concentration of Sia in the serum in the third trimester (i.e., $38^{\text {th }}$ week) of pregnancy and in the breast milk in the first month postdelivery promoted the early mental development of infants. $^{131}$ Martín-Sosa et al. ${ }^{132}$ and Wang et al. ${ }^{133}$ also reported similar trends of decreasing concentration of total Sia in human breast milk from the colostrum to mature stage.

2.1.5 Sia in milk oligosaccharides. It is experimentally proven that the constituents of human breast milk are associated with higher cognitive levels of infants. ${ }^{134,135}$ Human and bovine milk contain $55-70$ and $40-50 \mathrm{~g} \mathrm{~L}^{-1}$ of lactose (i.e., digestible carbohydrate), respectively, but they have vastly different profiles for the neutral and acidic oligosaccharides. The major neutral human milk oligosaccharides (HMOs) are lacto- $N$-tetraose $\left(0.5-1.5 \mathrm{~g} \mathrm{~L}^{-1}\right)$, 
lacto- $N$-fucopentaose I $\left(1.2-1.7 \mathrm{~g} \mathrm{~L} \mathrm{~L}^{-1}\right)$, II $\left(0.3-1.0 \mathrm{~g} \mathrm{~L}^{-1}\right)$, III (0.01-0.2 $\left.\mathrm{g} \mathrm{L} \mathrm{L}^{-1}\right)$ and lacto- $N$-difucohexaose $\left(0.1-0.2 \mathrm{~g} \mathrm{~L}^{-1}\right)$. Although, lacto- $N$-tetraose was found in bovine milk in trace amounts, lacto- $N$-fucopentaose I, II, III and lacto- $N$ difucohexaose could not even be detected in bovine milk. Among the acidic milk oligosaccharides, $\operatorname{Neu} 5 \operatorname{Ac}\left(\alpha 2,6^{-}\right)$ lactose (i.e., 6'-sialyllactose) and $\operatorname{Neu} 5 \operatorname{Ac}(\alpha 2,3-)$ lactose (i.e., 3'sialyllactose) are found in the range of concentration $0.3-0.5$ and $0.1-0.3 \mathrm{~g} \mathrm{~L}^{-1}$, respectively in human milk, whereas only $6^{\prime}$-sialyllactose is found in bovine milk in lower concentration (0.03-0.06 $\mathrm{g} \mathrm{L}^{-1}$ ) compared to human milk. Neu5Ac2-lacto- $N$ tetraose, Neu5Ac-lacto- $N$-tetraose-a and -c are other acidic oligosaccharides found in human milk in moderate concentrations $\left(0.2-0.6, \quad 0.03-0.2\right.$ and $0.1-0.6 \mathrm{~g} \quad \mathrm{~L}^{-1}$, respectively), but found in trace levels in bovine milk. ${ }^{136}$ It is also reported that most $(\sim 70-83 \%)$ of the Sia in human milk exists in the form of sialylated HMOs, while a small fraction $(\sim 2-3 \%)$ of Sia exists in the casein-bound or free forms. The remaining $\sim 11-25 \%$ of Sia is generally bound to glycoproteins. ${ }^{132,133}$ Martin-Sosa et al. reported $\sim 7.7-14.5 \%$ $O$-acetylated Neu5Ac in the human milk, but could not find traces of Neu5Gc. ${ }^{132}$ The total concentration of Sia in commercial infant formulas usually lies in the range 0.05$0.63 \mathrm{mM}$, which is about $25 \%$ less than human breast milk. Furthermore, in contrast to human milk, a major fraction $(\sim 70 \%)$ of Sia in infant formulas is bound to proteins and about $0.9 \%$ of Sia remains in the free form whereas the oligosaccharide-bound Sia is significantly low $(\sim 27 \%) .{ }^{133}$ HMOs play a significant role in the nourishment of healthpromoting gastrointestinal tract bacteria, pathogen proliferation, brain and neural developments, etc. ${ }^{137}$ About 247 different HMOs having about 162 different chemical structures have been identified in human milk, ${ }^{138}$ however both concentration and profile of HMOs in human milk are highly dependent on the genetics, environment and behaviour. $^{139}$ This may be attributed to the systematic evolution of the natural immune system in the population in any particular location. ${ }^{140}$ The HMOs help in the development and growth of the infants' guts. A breast-fed infant of $<6$ month age can consume $\sim 56 \mathrm{~g}$ of lactose and $4-$ $12 \mathrm{~g}$ non-digestible oligosaccharides from an average consumption of $800 \mathrm{~mL}$ human milk per day. ${ }^{141}$

\subsection{Involvement of Sia in human bacterial and viral infections}

Bacteria and viruses often evolve to utilise and exploit Sia for evading the human's natural immune system. Hence, Sia is responsible for many bacterial and viral infections and eventually a greater number of viruses exploit Sia compared to bacterial infections.

2.2.1 Exploitation of Sia by bacteria to infect humans. Three main groups of bacteria have been identified to exploit Sia or polySia to cause human infections.

The first group would include bacteria which can de novo biosynthesise polySia or sialylated capsular polysaccharides, lipopolysaccharides, lipooligosaccharides and peptidoglycans by themselves on their own cell surface to mask the host's immune surveillance. Escherichia coli bacterial phage receptor displays an endogenous polySia network similar to polySia structures of brain microglia. ${ }^{142}$ This molecular mimicry helps $E$. coli in the cell-internalisation process as well as conferring protection from the innate immune network by engaging inhibitory Siglec-11. On the other hand, uropathogenic E. coli non-specifically binds to Sia on the urinary bladder epithelium. ${ }^{143}$ However, the interaction of $E$. coli with the activating Siglec-16 enhances proinflammatory cytokine expression. Thus, fortunately the impaired dynamics of Siglecs-11 and -16 leads to the elimination of this pathogen from the human body. ${ }^{144}$ Han et al. recently used $\mathrm{N}$-acetyl-9-azido-9-deoxy-neuraminic acid label in flow cytometry, metagenomic and whole-genome sequencing to identify a new strain of $E$. coli in complex human faecal microbiome. ${ }^{145}$ Neisseria meningitidis bacteria, which cause meningitis disease, also can synthesise $\alpha 2,8$-(serogroup B) and $O$-acetylated or non-acetylated $\alpha 2,9-($ serogroup C) polySia on the lipooligosaccharide cell surface. ${ }^{146}$ Hence, it inhibits the activation of an alternative pathway of the immune system. ${ }^{147}$ However, the preferential binding of $N$. meningitidis with Siglecs-1 and -5 leads to its efficient phagocytosis. ${ }^{148}$ Campylobacter jejuni bacteria can synthesise $\alpha 2,3^{-}$and $\alpha 2,8-\mathrm{Neu} 5 \mathrm{Ac}$ themselves on their own lipooligosaccharide cell structures and thus they can easily mimic the human peripheral nerve gangliosides, causing autoimmune neuropathy known as Guillain-Barré syndrome. ${ }^{149}$ The sialylated lipooligosaccharide of $C$. jejuni enhances dendritic cell activation and promotes B-cell responses by producing IFN- $\beta$ and TNF- $\alpha$ cytokines. ${ }^{150}$ Furthermore, $\alpha 2,3-$ and $\alpha 2,8-$ sialylated lipooligosaccharides interact with Siglecs-1 and -7 , respectively, on the dendritic cells and polarize naïve T-cells differently to T-helper-2 and -1 cells, respectively. ${ }^{151}$ Staphylococcus agalactiae bacteria, also known as group B Streptococcus, can produce $\alpha 2,3-\mathrm{Neu} 5 \mathrm{Ac}$ linked capsular polysaccharide themselves, to mimic the human glycocalyx and can cause meningitis in human infant and sepsis. Group B Streptococcus blocks the antimicrobial factor derived from the platelets and engages the inhibitory receptor Siglec-9 to block platelet activation. ${ }^{152}$ However, genetically or biochemically mediated $O$-acetylation of $\alpha 2,3-$ Neu5Ac capsular polysaccharide of group B Streptococcus minimises the virulence and neutrophil suppression. ${ }^{153}$

A second group of bacteria cannot synthesise Sia by themselves but can exploit host cell's Sia as a source of carbon for their own catabolism, colonization and biofilm formation. Haemophilus influenzae bacteria use dietary Neu5Gc as well as Neu5Ac from the host cell to sialylate outer membrane glycolipids and lipooligosaccharide and form biofilms. ${ }^{154}$ Streptococcus pneumonia bacteria, acquire the terminal Sia of human nasopharynx sialoglycans as a carbon source for airway colonisation. ${ }^{155}$ Pseudomonas aeruginosa bacteria which cause chronic infections of lungs, absorb Sia on their own surface from the sialylated glycoproteins 
present in human body fluids and engage the inhibitory Siglec-9 to attenuate the inflammatory responses of neutrophils. ${ }^{156,157}$ Neisseria gonorrhoeae bacteria cause the gonococcal infection known as gonorrhea. The bacterial sialyltransferase transfers Neu5Ac from host cell's CMPNeu5Ac to gonococcal lipooligosaccharide and downregulates the alternative complement pathway of innate immune surveillance. However, the use of either a fusion protein (consisting of complement inhibition factor $\mathrm{H}$ and fragment crystallizable region of immunoglobulin G) or un-protective analogue of Neu5Ac to interact with the bacterial lipooligosaccharide can be utilised for the immunotherapy of gonorrhoea. ${ }^{158}$ Haemophilus ducreyi bacteria, responsible for the chancroid disease, and Pasteurella multocida pathogen, causing soft-tissue infection, also utilise the host's sialylated glycans to evade human immune surveillance. ${ }^{159,160}$

The third group of bacteria use their own Sia or host cell's Sia as either receptor or ligand to mediate infection. The erythrocyte binding antigen 175 of Plasmodium falciparum pathogen (responsible for malaria) preferentially binds to Neu5Ac available on the RBC membrane. ${ }^{161}$ GM1 ganglioside is a known receptor of cholera toxin. The Vibrio cholerae neuraminidase enzyme released from Vibrio cholerae bacteria cleaves Sia from higher order gangliosides to unmask GM1 on the host cell surface. ${ }^{162}$ On the other hand, the cluster of genes in the vibrio pathogenicity island 2 of the Vibrio cholerae strain indicates that it can utilise the released Sia as the sole source of carbon and nitrogen for their own catabolism reactions. ${ }^{163}$ The Sia-binding adhesin of Helicobacter pylori bacteria targets the gangliosides of the host cell surface, stimulating neutrophils to produce reactive oxygen species, which often damage the gastric epithelium. ${ }^{164}$ On the other hand, Sia-binding adhesin of Streptococcus gordonii binds with Veillonella atypica; this process is necessary for intergeneric coaggregation, which causes dental biofilm. ${ }^{165}$

2.2.2 Viral exploitation of Sia in human infection. Sia directly and indirectly participates in the recognition, attachment and internalization of many enveloped and capsid viruses. The envelope glycoprotein-120 (gp120) of human immunodeficiency virus (popular as HIV) has partially sialylated complex oligosaccharides. ${ }^{166}$ The gp120 of human immunodeficiency virus envelop thus interacts with Siglecs-1 and -7 of monocyte-derived macrophages and CD4 ${ }^{+}$T-cells lymphoid organs. ${ }^{167,168}$ The sialylated $O$-glycans of enveloped glycoprotein $\mathrm{B}$ of herpes simplex virus have different binding avidity to inhibitory-pairedimmunoglobulin-like-type-2 receptor in $\alpha$ - and $\beta$-forms expressed on the immune cells. Those sialylated glycans modulate the host immune response and facilitate viral entry to host cells. ${ }^{169,170}$ Among the mosquito borne viruses, the sialylated glycoprotein -1 and -2 of the Ebola virus are usually recognised by Siglec- 1 of the host cells, ${ }^{171-173}$ whereas the envelop protein $\mathrm{E}$ of the Zika virus preferentially binds to $\alpha 2,3$-sialylated glycoproteins of host cells. ${ }^{174}$ The $\alpha 2,3-$ sialylated glycoprotein was found in the saliva of mosquito
Aedes aegypti and its complex with dengue virus was identified, ${ }^{175}$ but its relation to transmission to the host cell is yet not available in the literature. The human picornaviruses viz. coxsackievirus A24 and enteroviruses 68, preferentially bind to the unbranched $\alpha 2,6-\mathrm{Neu} 5$ Ac-glycans of the host cell, whereas enteroviruses 70 has preferential affinity to the unbranched $\alpha 2,3$-Neu5Ac-glycans. ${ }^{176,177}$ On the other hand, the human Lassa fever virus upon endocytosis engages the endogenous terminal $\alpha 2,3$-Neu5Ac-glycans on the lysosomal-associated membrane protein for further propagation of the infection. ${ }^{178}$ The rabies virus can efficiently target the gangliosides of central nervous system. ${ }^{179}$

The human influenza virus A, B, C have two surface glycoproteins viz. hemagglutinin and neuraminidase, which interact with the host cells. The globular domain of hemagglutinin trimer in the influenza $A$ and $B$ viruses preferentially binds with $\alpha 2,6^{-}$(in human) and $\alpha 2,3^{-}$(in avian) sialylated glycans, but influenza $\mathrm{C}$ virus binds to $9 O A c-$ Neu5Ac. On the other hand, the neuraminidase cleaves the post-infection glycoside bonds and releases the progeny in the cytosol. ${ }^{180}$ The human upper respiratory epithelial cells in the nasal mucosa, paranasal sinuses, pharynx, bronchi, etc., are highly susceptible to the influenza infection owing to higher availability of cell surface $\alpha 2,6-\mathrm{Neu} 5 \mathrm{Ac}$ glycoconjugates in the human upper airway. ${ }^{181}$ Human saliva and serum contain a minimum of 116 and 144 glycan binding proteins, which can block the terminal $\alpha 2,6-\mathrm{Neu} 5 \mathrm{Ac}$ glycoconjugates in competition to the hemagglutinin protein of influenza virus, thus helping to inhibit influenza infection. ${ }^{182,183}$ However, the expression of $\alpha 2,3$-Neu5Ac in the salivary glycoprotein MUC5B and immunoglobulin-A of pregnant women decreased drastically, resulting in less screening of avian influenza virus specially in the third trimester. ${ }^{184}$ Antiviral agents such as zanamivir, oseltamivir, peramivir, laninamivir are known commercially available neuraminidase inhibitor molecules, while tert-butyl hydroquinone, arbidol and their derivatives could restrict the hemagglutinin attachment to the sialylated glycoconjugates of host cells. ${ }^{185}$ Human mumps virus and parainfluenza virus use viral hemagglutinin-neuraminidase proteins to target unbranched $\alpha 2,3$-Neu5Ac glycoconjugates, in contrast to the $\alpha 2,6-\mathrm{Neu} 5 \mathrm{Ac}$ glycoconjugates preferred by the influenza virus. ${ }^{186-188}$ The hemagglutinin protein of adeno-associated virus serotype-1, $-4,-5$ and -6 recognises both $\alpha 2,3-\mathrm{Neu} 5 \mathrm{Ac}$ and $\alpha 2,6-\mathrm{Neu} 5 \mathrm{Ac}$ on $N$-linked glycoproteins. ${ }^{189}$

The VP1 of the human capsid protein viruses viz. BK polyomavirus and Merkel cell polyomavirus preferentially bind to $\alpha 2,3-N e u 5 A c$ glycoconjugates of urogenital tissues, astrocytes, oligodendrocytes, lymphocytes, renal cells, etc. ${ }^{190,191}$ whereas human JC polyomavirus prefers $\alpha 2,6$ Neu5Ac glycoconjugates of the glial cells. ${ }^{192}$ The $\sigma 1$ protein of reovirus binds GM2 (for type 1 serotype) and $\alpha 2,3 / 6 / 8$ Neu5Ac glycans (for type 3 serotype). ${ }^{193,194}$ The polypeptide VP8* of the spike protein VP4 of rotavirus interacts with subterminal Neu5Ac residue of the gangliosides GD1a and 
[A] General pictorial configuration of the Spike Protein of CoV
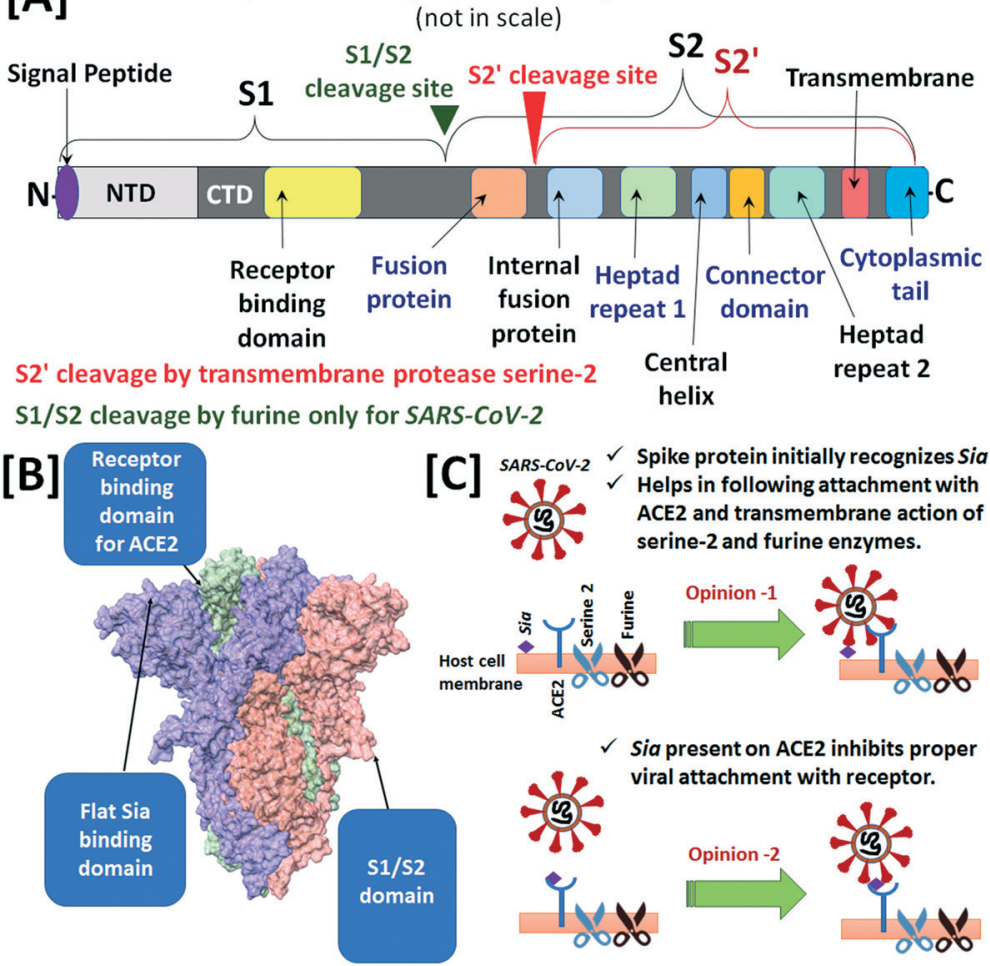

Fig. 3 [A] A pictorial configuration of the main constituents of the spike protein of SARS-CoV-2 indicating the cleavage sites viz. S1/S2 and S2'. [B] The model of unique feature of the spike protein of SARS-CoV-2 (main figure used with permission from ref. 206) Copyright 2020 John Wiley and Sons. [C] The contradictory opinions about the role of Sia in the attachment to human cells (figures are not to scale).

GM1 for key binding of the virus to host cells. ${ }^{195}$ The human adenovirus 37, causing severe epidemic keratoconjunctivitis, uses $\alpha 2,3$-Neu5Ac-glycans on GD1a ganglioside for the host cell binding and infectivity. ${ }^{196,197}$ On the other hand, the short fibre knob of human adenovirus 52 causing human gastroenteritis, preferentially recognizes polySia sequence for causing infection. ${ }^{198}$

The glycocalyx of human cells is important in the mechanism of infection of the human corona viruses (CoVs) viz. CoV-229E, CoV-NL63, OC43-CoV, HKU1-CoV, severe acute respiratory syndrome coronavirus (SARS-CoV), middle east respiratory syndrome coronavirus (MERS-CoV) and novel corona virus (SARS-CoV-2). ${ }^{199}$ Upon attachment of CoV, the transmembrane protease serine-2 of the host cell splits the spike protein $\mathrm{S}$ of $\mathrm{CoV}$ at site $\mathrm{S} 2$ ' (in between fusion protein and internal fusion protein of S2) into two subunits viz. S1 and S2, responsible for recognition and membrane fusion, respectively (Fig. 3[A]). The N-terminal domain (NTD) of the $\mathrm{S} 1$ unit i.e., $\mathrm{S}^{\mathrm{A}}$ identifies the sialylated glycans on the cell surface and facilitates the initial binding of $\mathrm{CoV}$ to the host cell, while the C-terminal domain (CTD) of $\mathrm{S} 1$ i.e., $\mathrm{S}^{\mathrm{B}}$ binds to the specific host receptors to assist fusion and cell internalization. ${ }^{200}$ Among the human CoVs, the CoV-229E and CoV-NL63 do not require Sia for host cell adhesion, rather they directly interact with aminopeptidase $N$ receptor and angiotensin-converting enzyme 2 (ACE2), respectively. ${ }^{201,202}$ The CTD of SARS-CoV binds to ACE2 cell receptor for recognition and host cell entry. On the other hand, OC43-CoV and HKU1-CoV viruses, causing common cold, pneumonia and bronchiolitis, have homodimeric hemagglutinin-esterase in $\mathrm{S}^{\mathrm{A}}$ and that recognises 9OAcNeu5Ac glycans as host cell receptors. ${ }^{203}$ The $\mathrm{S1}^{\mathrm{A}}$ of MERS$\mathrm{CoV}$ preferentially interacts with $\alpha 2,3$-Neu5Ac glycans compared to $\alpha 2,6-\mathrm{Neu} 5 \mathrm{Ac}$ glycans, while $\mathrm{S}^{\mathrm{B}}$ is involved in adherence to the specific cell surface entry receptor dipeptidyl peptidase $4 .{ }^{204}$

The novel corona virus SARS-CoV-2 which is responsible for the COVID 19 disease, is now considered most infectious among the group of human CoVs. The spike protein of SARS$\mathrm{CoV}-2$ has another cleavage motif at the boundary of S1-S2 subunits for furin-like enzymes of the host cell in addition to the transmembrane protease serine-2 unit, which is less expressed in the human lungs (Fig. 3[A]). The specific aminoacid sequence of the furin-like cleavage site is not present in other types of human CoVs. Hence, more efficient cleavage of the spike protein sub-units by both transmembrane protease serine- 2 and furin of the host cell may be one of the possible reasons for higher pathogenicity of SARS-CoV-2 compared to SARS-CoV and MERS-CoV. ${ }^{205}$ On the other hand, the presence of a flat and non-sunken sialic acid-binding unit at NTD of S1 subunit of the spike protein has theoretically been proposed in a recent article (Fig. $3[\mathrm{~B}]$ ). ${ }^{206}$ The recent in silico (performed through molecular docking simulations and electron density mapping) and computational studies, in line 
with the cryogenic microscopic evidence, have suggested the involvement of a flat Sia binding domain in the NTD of the spike protein in the establishment of initial contact with the sialylated glycoconjugates and GM1 of the host epithelium. This initial interaction is proposed to provide higher affinity binding between the spike protein and ACE2 receptor (opinion 1 in Fig. $3[\mathrm{C}]$ ). ${ }^{42,207,208}$ Furthermore, the in silico computational representation of the molecular isoelectronic density surface in terms of $2 \mathrm{D}$ Zernike polynomials also suggested the interaction of spike protein of SARS-CoV-2 with Sia receptors of the cells in the upper airways. ${ }^{209}$ Recently, a computational study in synchronization with massspectrometric and surface plasmon resonance (SPR) experiments on the interaction between Neu5Ac and SARSCoV-2 spike protein reported that both up and down states of receptor-bonding-domain (known as RBD) of the spike protein moderately bind with Neu5Ac. ${ }^{210}$ Furthermore, an exploration in the Human Protein Atlas repository revealed high expression of Neu5Ac biosynthesis enzymes viz. glucosamine (UDP- $N$-acetyl)-2-epimerase/ $N$ acetylmannosamine kinase, Neu5Ac-9-phosphate synthase and Neu5Ac-9-phosphate phosphatase in the salivary glands and hence, proposed about a possible role of Neu5Ac in SARSCoV-2 infection. ${ }^{211}$ On the other hand, the participation of other co-receptors viz. CD147, ${ }^{212}$ heparan sulfate, ${ }^{213}$ etc. is also proposed for the initial recognition of the virus by the host cell. Moreover, complex sialylated $\mathrm{N}$ - and $\mathrm{O}$-glycans have recently been evident on human ACE2 ${ }^{214}$ but those glycans have shown indication of resistance in the viral recognition by the host cells. ${ }^{215}$ Furthermore, the studies of SARS-CoV-2 infection on human epithelial lung cells and ex vivo human lung tissues revealed that heparan sulfate is an important coreceptor of this virus, while the sialylated glycans present on ACE2 can prevent protein spike and ACE2 interaction, which is most needed for viral attachment to the host cell (opinion 2 in Fig. $3[\mathrm{C}]) .{ }^{216}$ A study of the binding of soluble form of SARS-CoV-2 spike protein (in which entire external domain was stabilised by six proline residues and secondary antibody StrepMAB Classic, anti-twin-Strep-tag MoAb) to a sialoglycan microarray presenting 139 glycans representative of common terminal structures on vertebrate glycans showed the preferential affinity order as $\alpha 2,3$-Neu5Ac $>4 O A c-N e u 5 A c>$ $\alpha 2,6-N e u 5 A c \sim 9 O A c-N e u 5 A c \sim 9 N A c-N e u 5 A c>\alpha 2,3-N e u 5 G c$ $\sim \alpha 2,6-N e u 5 G c$. This multivalent Sia-affinity of the spike protein may be responsible for the formation of small and long-lived aerosol particle production from human upper airways. ${ }^{217}$ Recently published work by Nguyen et al. (during the proof-reading period of this review and included here for completion), revealed that the receptor-binding domain of the spike protein of SARS-CoV-2 has good binding affinity towards the gangliosides (GM1 and GM2), acidic (sialylated) HMOs and $\mathrm{ABH}$ blood group antigens (particularly $\mathrm{A}$ and $\mathrm{H}$ types $2,3,4) .{ }^{218}$ The authors used catch-and-release ESI-MS and hydrophilic-interaction-ultra HPLC to scan the affinity of both receptor-binding domain and S protein of SARS-CoV-2 over 132 mammalian and 7 non-mammalian glycans. The work provides an insight into aspects of COVID 19 disease 1) glycolipids of the host cell, especially gangliosides GM1 and GM2 in competition with cell surface heparan sulfate, bind to a common site of receptor-binding domain and S protein of SARS-CoV-2 and facilitate viral entry by the action of ACE2. The human brain and central nervous system share a higher fraction of gangliosides compared to other human organs (see Section 2.1.2), and this work aids understanding of the spread of SARS-CoV-2 infection to the central nervous system. $\left.{ }^{219} 2\right)$ Human milk has the lowest fraction $(\sim 12-14 \%)$ of acidic (sialylated) HMOs which can bind to the receptorbinding domain and the S protein of SARS-CoV-2. In this study, none of the 72 neonates breastfed for 14 days by COVID 19 positive mothers tested COVID 19 positive. ${ }^{220}$ 3) Antigen A of human blood cells predominantly stimulates (compared to other antigens $\mathrm{B}$ and $\mathrm{AB}$ ) the formation of sialoside clusters in target cells through cis-carbohydratecarbohydrate interactions. Therefore, humans having blood group A are more susceptible to SARS-CoV-2 infection. ${ }^{221}$ Furthermore, Nguyen et al. showed that decreasing cell surface Sia by either sialyltransferase inhibition, genetic knockout of biosynthesis of Sia or neuraminidase treatment decreased the SARS-CoV- 2 infectivity by $30-40 \%$ and this information is now very useful for the development of COVID 19 therapy. ${ }^{218}$ However, several questions on Sia-SARS-CoV-2 interactions including the influence on the human immune response and change of viral affinity with new variants of SARS-CoV-2 are yet to be explored. ${ }^{222}$ Overall, the role of Sia for SARS-CoV-2 infection is still an open question. ${ }^{44}$

The infection of SARS-CoV, MERS-CoV and SARS-CoV-2 to human organs leads to the release of high levels of proinflammatory cytokines and chemokines, which is known as a "cytokine storm". It is proposed that the cross reactivity of Sia with the host immune lectins might be responsible for this cytokine storm. ${ }^{43}$ Gas and water phase quantum mechanical calculations revealed that the monoprotonated form of anti-malarial drugs chloroquine and hydroxychloroquine, having anti-inflammatory properties, can form stable complexes with Neu5Ac. This may interfere with the ACE2 receptor and spike protein interaction and subsequently inhibit SARS-CoV-2 infection. ${ }^{223}$ Thus, in the uncertain therapeutic trials against COVID-19, these two drugs are being administrated to COVID-19 patients to fight against SARS-CoV-2 infection. ${ }^{24-226}$ However, more clinical studies are recommended for the prolonged use of chloroquine and hydroxychloroquine solely or in combination with other drugs for COVID-19 treatment. ${ }^{227}$ Another drug viz. remdesivir, which showed reliable clinical performance for MERS-CoV and SARS-CoV in the past pandemics, is also being used for clinical treatment of COVID-19. ${ }^{228,229}$ Interestingly, owing to the preferential affinity of Neu5Ac towards the spike protein glycoprotein of SARS-CoV-2 compared to SARS-CoV, a paper-based lateral flow point-of-care diagnostic sensor is prepared with Neu5Ac modified poly( $N$-hydroxyethyl acrylamide) coated gold nanoparticles to detect SARS-CoV-2 spike protein down to 5 
Table 1 Concentration of Sia in human body fluids and organs at occurrence of some diseases, cancers and addictions

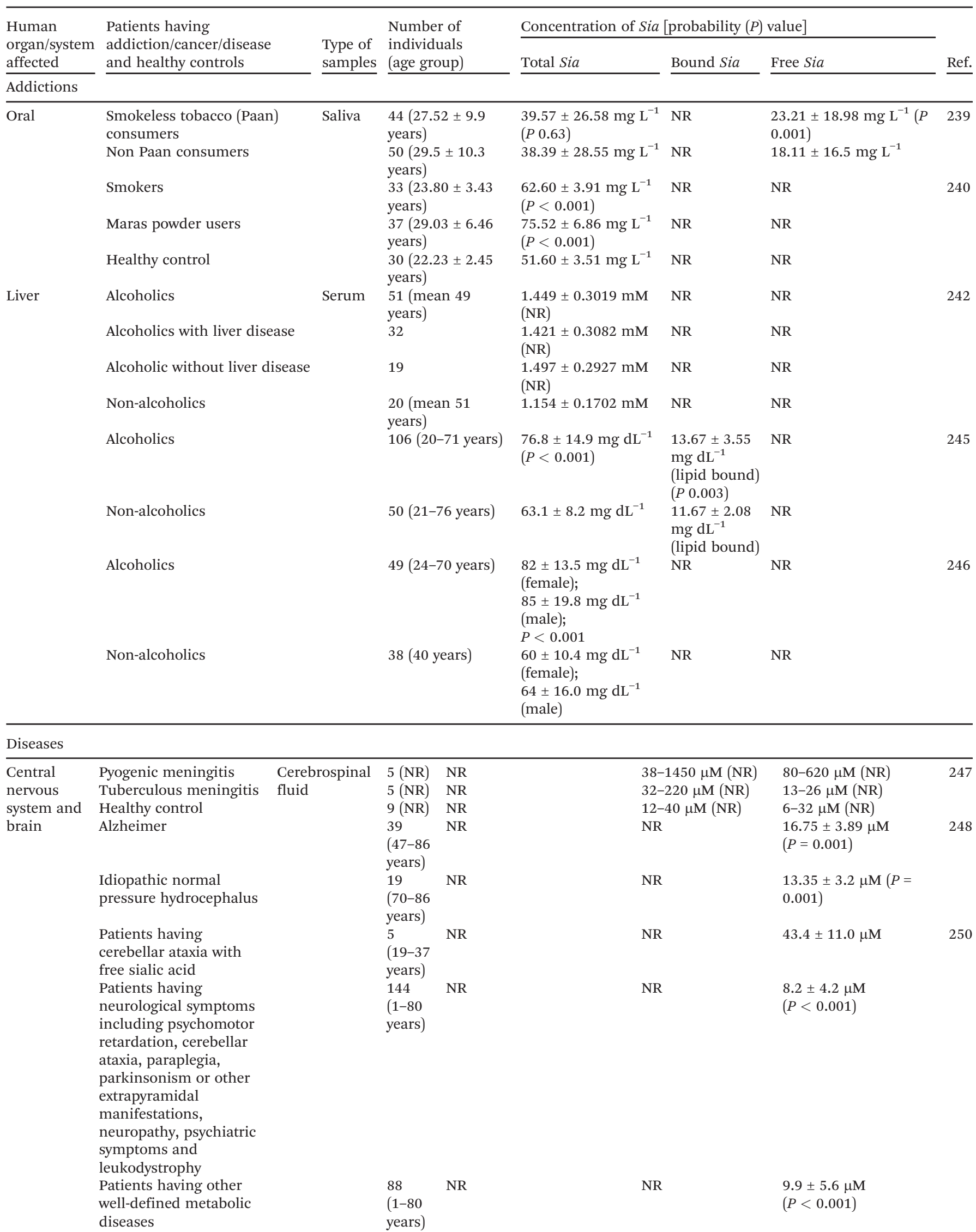


Table 1 (continued)

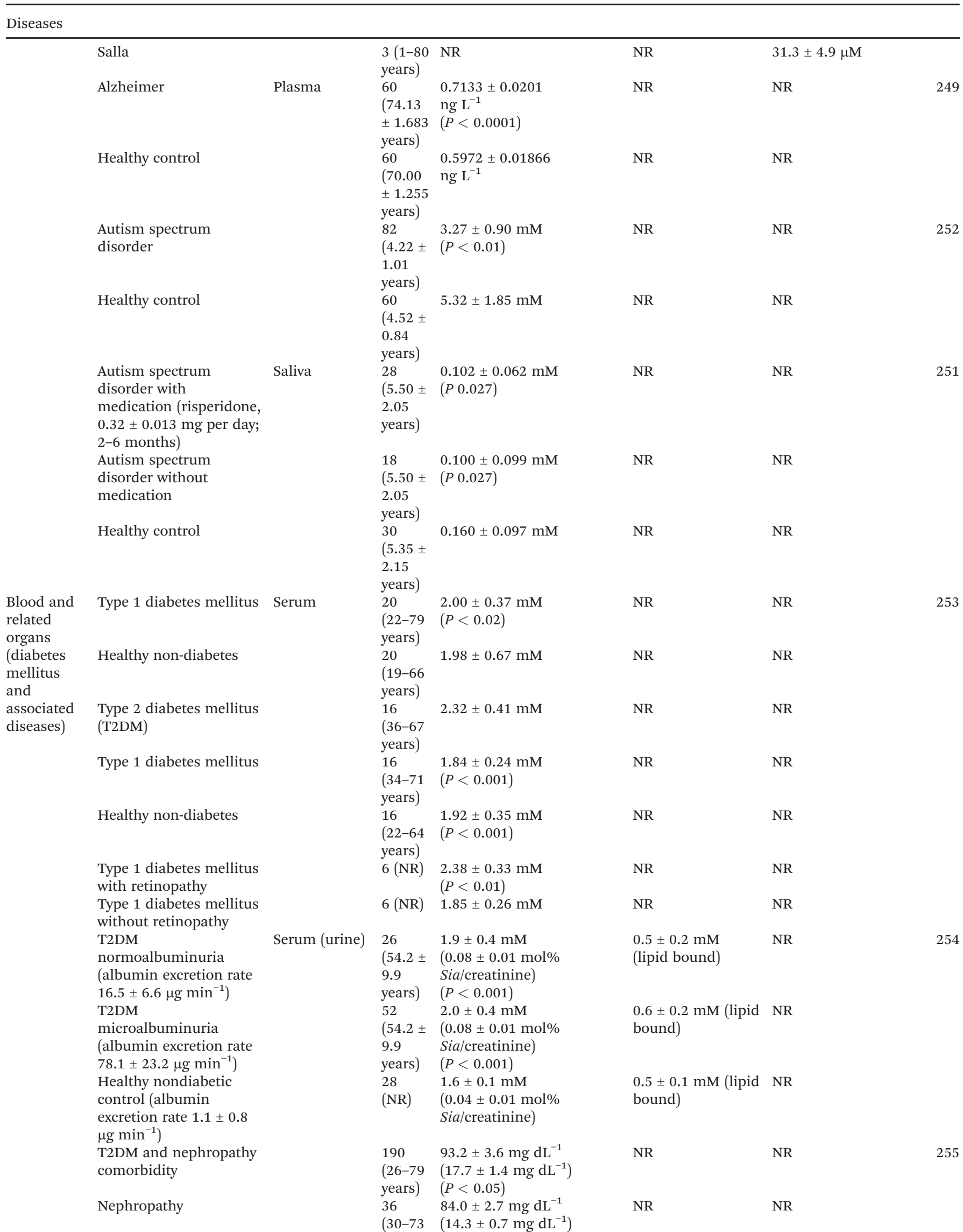


Table 1 (continued)

\begin{tabular}{|c|c|c|c|c|c|c|c|}
\hline \multicolumn{8}{|c|}{ Diseases } \\
\hline & \multirow{2}{*}{\multicolumn{2}{|c|}{$\mathrm{T} 2 \mathrm{DM}$}} & \multirow{2}{*}{$\begin{array}{l}\text { years }) \\
30 \\
(38-70 \\
\text { years })\end{array}$} & \multicolumn{4}{|l|}{$(P<0.05)$} \\
\hline & & & & $\begin{array}{l}82.6 \pm 1.3 \mathrm{mg} \mathrm{dL}^{-1} \\
\left(12.5 \pm 0.9 \mathrm{mg} \mathrm{dL}^{-1}\right) \\
(P<0.05)\end{array}$ & NR & NR & \\
\hline & Healthy control without & & 240 & $59.1 \pm 3.6 \mathrm{mg} \mathrm{dL}^{-1}$ & NR & NR & \\
\hline & T2DM and nephropathy & & $\begin{array}{l}(20-79 \\
\text { years })\end{array}$ & $\left(9.2 \pm 1.0 \mathrm{mg} \mathrm{dL}^{-1}\right)$ & & & \\
\hline & $\mathrm{T} 2 \mathrm{DM}$ & $\begin{array}{l}\text { Plasma (RBC } \\
\text { membrane) }\end{array}$ & $\begin{array}{l}146 \\
(22-80 \\
\text { years })\end{array}$ & $\begin{array}{l}175.00 \pm 68.89 \mu \mathrm{M} \\
(4.20 \pm 2.14 \mathrm{mmol} \\
\text { per mg protein }) \\
(P<0.05)\end{array}$ & NR & NR & 256 \\
\hline & $\begin{array}{l}\text { T2DM and nephropathy } \\
\text { comorbidity }\end{array}$ & & & $\begin{array}{l}174.13 \pm 23.20 \mu \mathrm{M} \\
(4.00 \pm 2.51 \mathrm{mmol} \text { per } \\
\text { mg protein }) \\
(P<0.05)\end{array}$ & NR & NR & \\
\hline & $\begin{array}{l}\text { T2DM and hypertension } \\
\text { comorbidity }\end{array}$ & & & $\begin{array}{l}176.00 \pm 54.82 \mu \mathrm{M} \\
(4.14 \pm 2.00 \mathrm{mmol} \text { per } \\
\text { mg protein }) \\
(P<0.05)\end{array}$ & NR & NR & \\
\hline & $\begin{array}{l}\text { T2DM and } \\
\text { hyperlipidemia } \\
\text { comorbidity }\end{array}$ & & & $\begin{array}{l}160.80 \pm 48.61 \mu \mathrm{M} \\
(3.93 \pm 2.10 \mathrm{mmol} \text { per } \\
\text { mg protein }) \\
(P<0.05)\end{array}$ & NR & NR & \\
\hline & Healthy control & & $\begin{array}{l}15 \\
(22-80 \\
\text { years })\end{array}$ & $\begin{array}{l}149.9 \pm 47.30 \mu \mathrm{M} \\
(5.84 \pm 1.43 \mathrm{mmol} \text { per } \\
\text { mg protein) }\end{array}$ & NR & NR & \\
\hline & $\begin{array}{l}\text { Gestational diabetes } \\
\text { mellitus }\end{array}$ & $\begin{array}{l}\text { RBC } \\
\text { membrane }\end{array}$ & $\begin{array}{l}16(29 \\
\pm 6 \\
\text { years })\end{array}$ & $\begin{array}{l}81.29 \pm 41.80 \mathrm{mg} \text { per } \\
\text { g protein }(P<0.001)\end{array}$ & NR & NR & 129 \\
\hline & $\begin{array}{l}\text { Healthy pregnant } \\
\text { women }\end{array}$ & & $\begin{array}{l}25(28 \\
\pm 5 \\
\text { years })\end{array}$ & $\begin{array}{l}96.30 \pm 34.20 \mathrm{mg} \text { per } \\
\text { g protein }(P<0.001)\end{array}$ & NR & NR & \\
\hline & $\begin{array}{l}\text { Healthy nonpregnant } \\
\text { women }\end{array}$ & & $\begin{array}{l}10(30 \\
\pm 4 \\
\text { years })\end{array}$ & $\begin{array}{l}42.33 \pm 15.85 \mathrm{mg} \text { per } \\
\text { g protein }\end{array}$ & NR & NR & \\
\hline & $\begin{array}{l}\text { High in } 50 \mathrm{~g} \text { glucose } \\
\text { challenge test }(1 \mathrm{~h} ; \\
\left.\text { glucose }>140 \mathrm{mg} \mathrm{dL}{ }^{-1}\right) \\
\text { and } 100 \mathrm{~g} \text { oral glucose } \\
\text { tolerance test }(3 \mathrm{~h} ; \\
\left.\text { glucose }>176 \mathrm{mg} \mathrm{dL}^{-1}\right)\end{array}$ & Serum & $\begin{array}{l}8 \\
(20-38 \\
\text { years })\end{array}$ & $\begin{array}{l}3.05(2.67-3.49) \mathrm{mM} \\
(P<0.001)\end{array}$ & NR & NR & 258 \\
\hline & $\begin{array}{l}\text { High in } 50 \mathrm{~g} \text { glucose } \\
\text { challenge test }(1 \mathrm{~h} ; \\
\left.\text { glucose }>140 \mathrm{mg} \mathrm{dL}^{-1}\right) ; \\
\text { but low in } 100 \mathrm{~g} \text { oral } \\
\text { glucose tolerance test }(3 \\
\mathrm{h} ; \text { glucose } \leq 176 \mathrm{mg} \\
\left.\mathrm{dL}^{-1}\right)\end{array}$ & & $\begin{array}{l}36 \\
(19-38 \\
\text { years })\end{array}$ & $\begin{array}{l}3.22(2.34-5.04) \mathrm{mM} \\
(P<0.001)\end{array}$ & NR & NR & \\
\hline & $\begin{array}{l}\text { Normal in } 50 \mathrm{~g} \text { glucose } \\
\text { challenge test }(1 \mathrm{~h} ; \\
\left.\text { glucose } \leq 140 \mathrm{mg} \mathrm{dL})^{-1}\right)\end{array}$ & & $\begin{array}{l}61 \\
(18-38 \\
\text { years })\end{array}$ & $2.66(1.2-4.59) \mathrm{mM}$ & NR & NR & \\
\hline & Behcet's syndrome & & $\begin{array}{l}16 \\
(\mathrm{NR})\end{array}$ & $\begin{array}{l}95.6 \pm 15.3(76-129) \\
\mathrm{mg} \mathrm{dL}^{-1}(P<0.01)\end{array}$ & $\begin{array}{l}29.8 \pm 7.4 \\
(17.2-45.6) \mathrm{mg} \mathrm{dL}^{-1} \\
(P>0.05)\end{array}$ & NR & 259 \\
\hline & Uveitis disease & & $\begin{array}{l}12 \\
(\mathrm{NR})\end{array}$ & $\begin{array}{l}75.8 \pm 8.1(64-91.8) \\
\mathrm{mg} \mathrm{dL}-1(P<0.01)\end{array}$ & $\begin{array}{l}26.6 \pm 3.0 \\
(21.4-32.4) \mathrm{mg} \mathrm{dL}^{-1} \\
(P>0.05)\end{array}$ & NR & \\
\hline & Healthy control & & $\begin{array}{l}22 \\
(\mathrm{NR})\end{array}$ & $\begin{array}{l}59.5 \pm 7.5 \\
(47-75.5) \\
\mathrm{mg} \mathrm{dL}\end{array}$ & $\begin{array}{l}19.2 \pm 3.2 \\
(15-24.5) \mathrm{mg} \mathrm{dL}^{-1}\end{array}$ & NR & \\
\hline Gum & Periodontitis & Saliva & $5(\mathrm{NR})$ & NR & NR & $\begin{array}{l}0.0040 \% \\
\text { (whole saliva) } \\
0.0019 \% \\
\text { (parotis saliva) }\end{array}$ & 260 \\
\hline & Rheumatoid arthritis & & $5(\mathrm{NR})$ & NR & NR & $\begin{array}{l}0.0053 \% \\
\text { (whole saliva) } \\
0.0035 \%\end{array}$ & \\
\hline
\end{tabular}


Table 1 (continued)

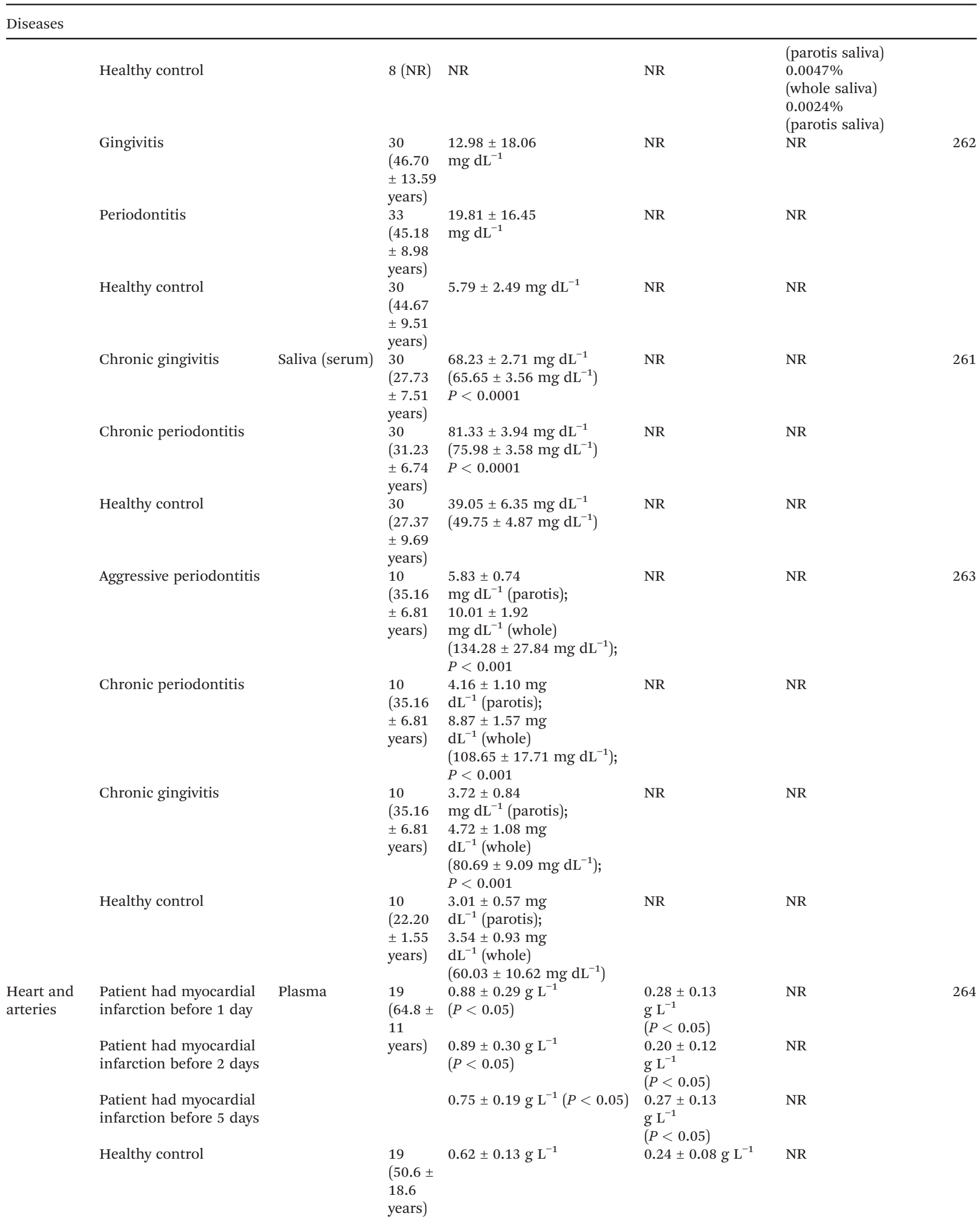


Table 1 (continued)

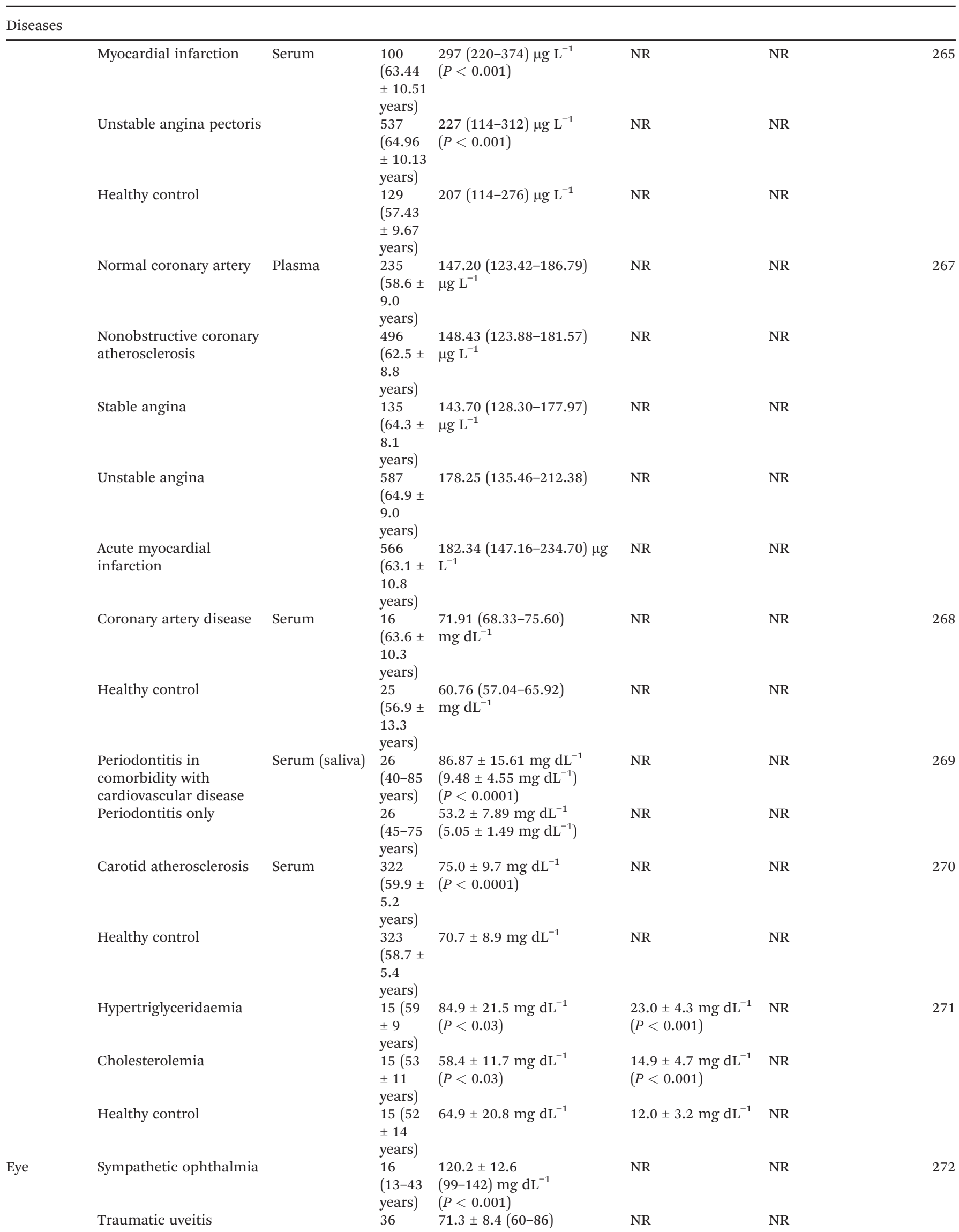


Table 1 (continued)

\begin{tabular}{|c|c|c|c|c|c|c|c|}
\hline \multicolumn{8}{|l|}{ Diseases } \\
\hline & & & $\begin{array}{l}(12-46 \\
\text { years })\end{array}$ & $\begin{array}{l}\mathrm{mg} \mathrm{dL}^{-1} \\
(P>0.1)\end{array}$ & & & \\
\hline & Healthy control & & $\begin{array}{l}40 \\
(16-40 \\
\text { years })\end{array}$ & $\begin{array}{l}67.8 \pm 7.9(56-83) \\
\mathrm{mg} \mathrm{dL}^{-1}\end{array}$ & NR & NR & \\
\hline \multirow[t]{3}{*}{ Thyroid } & $\begin{array}{l}\text { Sub-clinical } \\
\text { hypothyroidism }\end{array}$ & & $\begin{array}{l}35 \\
(34.4 \pm \\
10.3 \\
\text { years })\end{array}$ & $\begin{array}{l}37.1 \pm 15.5 \mathrm{mg} \mathrm{L}^{-1} \\
(P 0.775)\end{array}$ & NR & NR & 273 \\
\hline & Overt hypothyroidism & & $\begin{array}{l}25(33 \\
\pm 9.3 \\
\text { years })\end{array}$ & $\begin{array}{l}58.2 \pm 18.9 \mathrm{mg} \mathrm{L}^{-1} \\
(P<0.001)\end{array}$ & NR & NR & \\
\hline & Healthy control & & $\begin{array}{l}30 \\
(32.5 \pm \\
7.5 \\
\text { years })\end{array}$ & $38.1 \pm 12.0 \mathrm{mg} \mathrm{L}^{-1}$ & NR & NR & \\
\hline \multirow[t]{3}{*}{ Bowl } & Active ulcerations & & $\begin{array}{l}6(24.3 \\
\pm 3.8 \\
\text { years })\end{array}$ & $\begin{array}{l}69.7 \pm 9.4 \mathrm{mg} \mathrm{dL}^{-1} \\
(P<0.01)\end{array}$ & NR & NR & 274 \\
\hline & $\begin{array}{l}\text { No active ulcerations } \\
\text { (post-surgery) }\end{array}$ & & $\begin{array}{l}6(35.5 \\
\pm 12.8 \\
\text { years })\end{array}$ & $\begin{array}{l}54.7 \pm 5.5 \mathrm{mg} \mathrm{dL}^{-1} \\
(P<0.01)\end{array}$ & NR & NR & \\
\hline & Healthy control & & $\begin{array}{l}6(32.3 \\
\pm 4.7 \\
\text { years })\end{array}$ & $50.3 \pm 4.4 \mathrm{mg} \mathrm{dL}^{-1}$ & NR & NR & \\
\hline \multirow[t]{10}{*}{ Liver } & Hepatitis B & & $\begin{array}{l}50 \\
(19-71 \\
\text { years })\end{array}$ & $\begin{array}{l}1.32(0.06-1.84) \mathrm{mM} \\
(P 0.047)\end{array}$ & NR & NR & 275 \\
\hline & Hepatitis C & & $\begin{array}{l}40 \\
(19-67 \\
\text { years })\end{array}$ & $\begin{array}{l}1.67(1.18-2.96) \mathrm{mM} \\
(P 0.025)\end{array}$ & NR & NR & \\
\hline & Healthy control & & $\begin{array}{l}30 \\
(21-54 \\
\text { years })\end{array}$ & $1.43(0.96-2.16 \mathrm{mM})$ & NR & NR & \\
\hline & Malignant jaundice & & $\begin{array}{l}55 \\
(35-87 \\
\text { years })\end{array}$ & $\begin{array}{l}7.95 \mathrm{mg} \mathrm{L}^{-1} \text { (median); } \\
\text { Sia/protein } 1.20\end{array}$ & NR & NR & 276 \\
\hline & Jaundice & & $\begin{array}{l}30 \\
(35-87 \\
\text { years })\end{array}$ & $\begin{array}{l}6.86 \mathrm{mg} \mathrm{L}^{-1}(\text { median}) \\
\text { Sia/protein } 1.03(P<0.001)\end{array}$ & NR & NR & \\
\hline & Healthy control & & $\begin{array}{l}24 \\
(24-56 \\
\text { years })\end{array}$ & $\begin{array}{l}5.97 \mathrm{mg} \mathrm{L}^{-1} \text { (median); } \\
\text { Sia/protein } 0.79\left(\begin{array}{l}\text { P } 0.041)\end{array}\right.\end{array}$ & NR & NR & \\
\hline & $\begin{array}{l}\text { Alcoholic patients } \\
\text { having cirrhosis }\end{array}$ & & $\begin{array}{l}31 \\
(27-52 \\
\text { years })\end{array}$ & $\begin{array}{l}5.81(3.89-10.06) \mathrm{mg} \mathrm{L}^{-1} \\
(P<0.001)\end{array}$ & NR & $\begin{array}{l}0.55(0.34-0.94) \mathrm{mg} \mathrm{L}^{-1} \\
(P 0.017)\end{array}$ & 277 \\
\hline & $\begin{array}{l}\text { Non-alcoholic patients } \\
\text { having cirrhosis }\end{array}$ & & $\begin{array}{l}24 \\
(27-52 \\
\text { years })\end{array}$ & $\begin{array}{l}5.43(3.79-7.88) \mathrm{mg} \mathrm{L}^{-1} \\
(P<0.001)\end{array}$ & NR & $\begin{array}{l}0.49(0.34-0.82) \mathrm{mg} \mathrm{L}^{-1} \\
(P 0.035)\end{array}$ & \\
\hline & $\begin{array}{l}\text { Patients having chronic } \\
\text { viral hepatitis } \mathrm{C}\end{array}$ & & $\begin{array}{l}24 \\
(27-52 \\
\text { years })\end{array}$ & $\begin{array}{l}5.76(4.42-8.11) \mathrm{mg} \mathrm{L}^{-1} \\
(P<0.001)\end{array}$ & NR & $\begin{array}{l}0.48(0.34-0.63) \mathrm{mg} \mathrm{L}^{-1} \\
(P 0.016)\end{array}$ & \\
\hline & Healthy control & & $\begin{array}{l}49 \\
(21-79 \\
\text { years })\end{array}$ & $6.22(5.4-8.0) \mathrm{mg} \mathrm{L}^{-1}$ & NR & $0.49(0.36-0.61) \mathrm{mg} \mathrm{L}^{-1}$ & \\
\hline \multirow[t]{4}{*}{ Kidney } & $\begin{array}{l}\text { Chronic } \\
\text { glomerulonephritis }\end{array}$ & Serum (urine) & $\begin{array}{l}35 \\
(25-60 \\
\text { years })\end{array}$ & $\begin{array}{l}82.3 \pm 6.5 \mathrm{mg} \mathrm{dL}^{-1} \\
\left(0.150 \pm 0.03 \mathrm{mg} \mathrm{mL} \mathrm{mL}^{-1}\right) \\
(P<0.001)\end{array}$ & $\begin{array}{l}19.7 \pm 0.9 \mathrm{mg} \mathrm{dL}^{-1} \\
\text { lipid bound (NR) } \\
(P<0.001)\end{array}$ & NR & 278 \\
\hline & Chronic renal failure & & $\begin{array}{l}27 \\
(19-54 \\
\text { years })\end{array}$ & $\begin{array}{l}70.7 \pm 5.5 \mathrm{mg} \mathrm{dL} \mathrm{dL}^{-1} \\
\text { (pre-dialysis) }\end{array}$ & $\begin{array}{l}17.7 \pm 0.8 \mathrm{mg} \mathrm{dL}^{-1} \\
\text { lipid bound } \\
\text { (pre-dialysis) }\end{array}$ & NR & \\
\hline & & & & $\begin{array}{l}71.2 \pm 6.8 \mathrm{mg} \mathrm{dL}{ }^{-1} \\
\text { (post-dialysis) } \\
\left(0.147 \pm 0.04 \mathrm{mg} \mathrm{mL}^{-1}\right) \\
(P<0.001)\end{array}$ & $\begin{array}{l}20.6 \pm 1.1 \mathrm{mg} \mathrm{dL} \mathrm{d}^{-1} \\
\text { lipid bound } \\
\text { (post-dialysis) (NR) } \\
(P<0.001)\end{array}$ & & \\
\hline & Healthy control & & $\begin{array}{l}60 \\
(16-64\end{array}$ & $\begin{array}{l}59.8 \pm 7.9 \mathrm{mg} \mathrm{dL}^{-1} \\
\left(0.098 \pm 0.04 \mathrm{mg} \mathrm{mL}^{-1}\right)\end{array}$ & $\begin{array}{l}15.9 \pm 0.8 \mathrm{mg} \mathrm{dL}^{-1} \\
\text { lipid bound }\end{array}$ & NR & \\
\hline
\end{tabular}


Table 1 (continued)

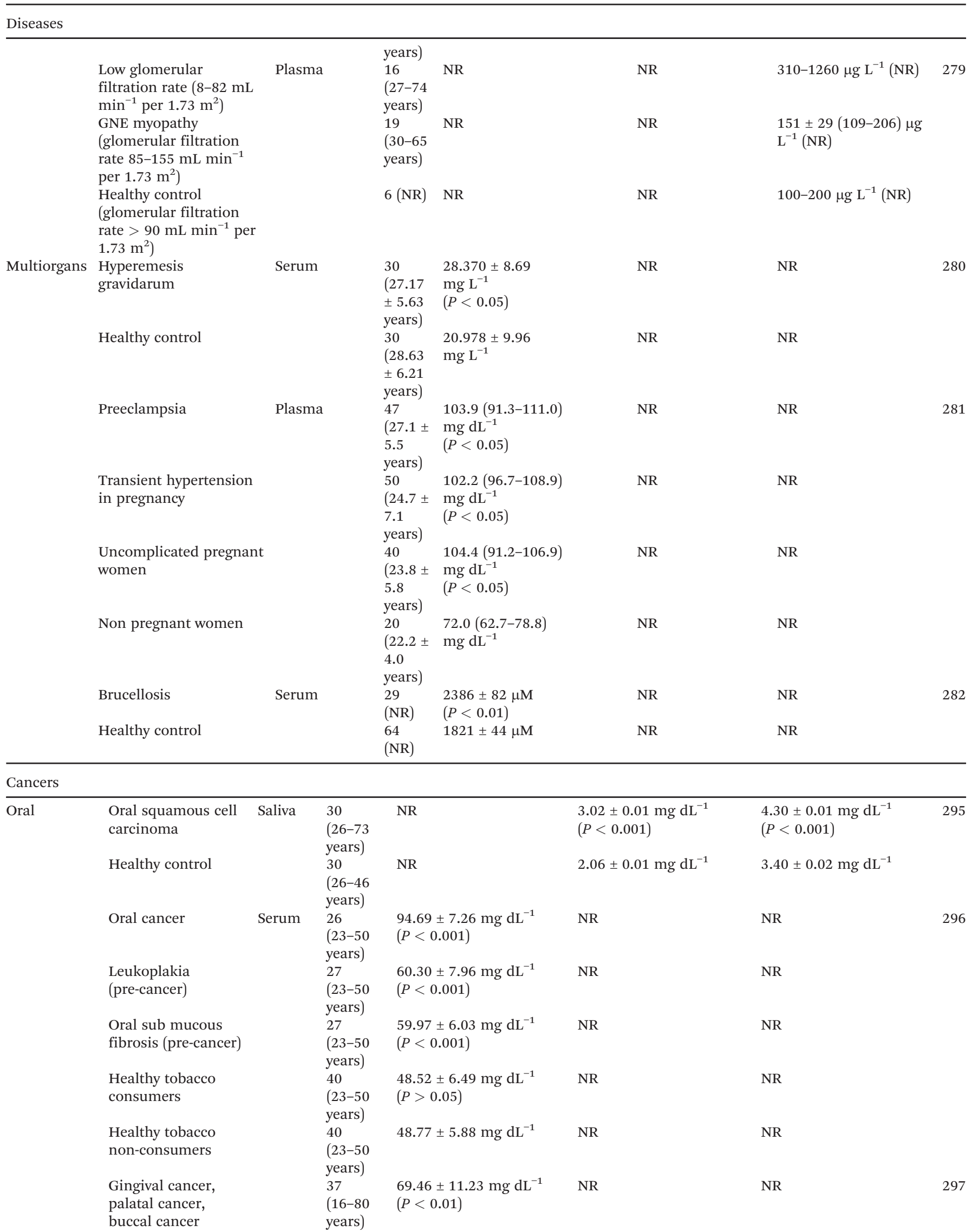


Table 1 (continued)

\begin{tabular}{|c|c|c|c|c|c|c|c|}
\hline \multicolumn{8}{|l|}{ Cancers } \\
\hline & $\begin{array}{l}\text { Salivary gland } \\
\text { tumours }\end{array}$ & & $\begin{array}{l}23 \\
(16-80 \\
\text { years })\end{array}$ & $\begin{array}{l}70.58 \pm 12.07 \mathrm{mg} \mathrm{dL}^{-1} \\
(P<0.01)\end{array}$ & NR & NR & \\
\hline & Lip and skin cancer & & $\begin{array}{l}22 \\
(16-80 \\
\text { years })\end{array}$ & $\begin{array}{l}59.24 \pm 12.10 \mathrm{mg} \mathrm{dL}^{-1} \\
(P<0.01)\end{array}$ & NR & NR & \\
\hline & $\begin{array}{l}\text { Tongue and floor } \\
\text { cancer }\end{array}$ & & $\begin{array}{l}20 \\
(16-80 \\
\text { years })\end{array}$ & $\begin{array}{l}75.01 \pm 12.00 \mathrm{mg} \mathrm{dL}-1 \\
(P<0.01)\end{array}$ & NR & NR & \\
\hline & $\begin{array}{l}\text { Malignant fibrous } \\
\text { histiocytoma }\end{array}$ & & $\begin{array}{l}4(16-80 \\
\text { years })\end{array}$ & $\begin{array}{l}85.63 \pm 5.45 \mathrm{mg} \mathrm{dL}^{-1} \\
(P<0.01)\end{array}$ & NR & NR & \\
\hline & Sarcoma & & $\begin{array}{l}3(16-80 \\
\text { years })\end{array}$ & $\begin{array}{l}64.06 \pm 5.01 \mathrm{mg} \mathrm{dL}^{-1} \\
(P<0.01)\end{array}$ & NR & NR & \\
\hline & Mandibular cancer & & $1(\mathrm{NR})$ & $\begin{array}{l}69.72 \mathrm{mg} \mathrm{dL}^{-1} \\
(P<0.01)\end{array}$ & NR & NR & \\
\hline & $\begin{array}{l}\text { Benign tumours in } \\
\text { oral and } \\
\text { maxillofacial region }\end{array}$ & & $\begin{array}{l}60 \\
(23-54 \\
\text { years })\end{array}$ & $\begin{array}{l}58.28 \pm 8.34 \mathrm{mg} \mathrm{dL}^{-1} \\
(P>0.05)\end{array}$ & NR & NR & \\
\hline & Healthy control & & $\begin{array}{l}80 \\
(22-44 \\
\text { years })\end{array}$ & $55.02 \pm 7.2 \mathrm{mg} \mathrm{dL}^{-1}$ & NR & NR & \\
\hline \multirow[t]{3}{*}{ Bile duct } & Cholangiocarcinoma & & $\begin{array}{l}89(55 \pm \\
10 \text { years })\end{array}$ & $\begin{array}{l}2.75 \pm 0.67 \mathrm{mM} \\
(P<0.001)\end{array}$ & NR & NR & 298 \\
\hline & $\begin{array}{l}\text { Benign } \\
\text { hepatobiliary } \\
\text { diseases }\end{array}$ & & $\begin{array}{l}38(55 \pm \\
14 \text { years })\end{array}$ & $\begin{array}{l}2.33 \pm 0.69 \mathrm{mM} \\
(P<0.002)\end{array}$ & NR & NR & \\
\hline & Healthy control & & $\begin{array}{l}43(44 \pm \\
14 \text { years })\end{array}$ & $1.89 \pm 0.46 \mathrm{mM}$ & NR & NR & \\
\hline \multirow[t]{2}{*}{ Colon/rectum } & Colorectal cancer & & $\begin{array}{l}123 \\
(34-88 \\
\text { years })\end{array}$ & $\begin{array}{l}3.27 \pm 1.12 \mathrm{mM} \\
49.01 \pm 16.52 \mu \mathrm{mol} \\
\mathrm{g}^{-1} \text { of total protein } \\
(P<0.001)\end{array}$ & $\begin{array}{l}3.24 \pm 1.11 \mathrm{mM} \\
48.59 \pm 16.43 \mu \mathrm{mol} \\
\mathrm{g}^{-1} \text { of total protein } \\
(P<0.001)\end{array}$ & $0.03 \pm 0.01 \mathrm{mM}$ & 299 \\
\hline & Healthy control & & $\begin{array}{l}72 \\
(34-88 \\
\text { years })\end{array}$ & $\begin{array}{l}2.14 \pm 0.41 \mathrm{mM} \\
23.90 \pm 4.81 \mu \mathrm{mol} \\
\mathrm{g}^{-1} \text { of total protein }\end{array}$ & $\begin{array}{l}2.12 \pm 0.41 \mathrm{mM} \\
23.59 \pm 4.78 \mu \mathrm{mol} \\
\mathrm{g}^{-1} \text { of total protein }\end{array}$ & $0.03 \pm 0.01 \mathrm{mM}$ & \\
\hline \multirow[t]{6}{*}{ Ovary } & $\begin{array}{l}\text { Endometrial } \\
\text { neoplasia }\end{array}$ & & $\begin{array}{l}45 \\
(37-81 \\
\text { years })\end{array}$ & $\begin{array}{l}2.38 \pm 0.72 \mathrm{mM} \\
27.91 \pm 8.00 \mu \mathrm{mol} \\
\mathrm{g}^{-1} \text { of protein } \\
(P<0.001)\end{array}$ & NR & NR & 300 \\
\hline & Other neoplasia & & $\begin{array}{l}7(37-81 \\
\text { years) }\end{array}$ & $\begin{array}{l}2.53 \pm 1.29 \mathrm{mM} \\
28.45 \pm 11.80 \mu \mathrm{mol} \\
\mathrm{g}^{-1} \text { of protein } \\
(P 0.0086)\end{array}$ & NR & NR & \\
\hline & Healthy women & & $\begin{array}{l}20 \\
(20-36 \\
\text { years })\end{array}$ & $\begin{array}{l}1.52 \pm 0.25 \mathrm{mM} \\
19.28 \pm 2.24 \mu \mathrm{mol} \\
\mathrm{g}^{-1} \text { of protein }\end{array}$ & NR & NR & \\
\hline & Ascites cells & Tissue & $\begin{array}{l}6 \\
\text { (adults), } \\
7 \text { (cords) }\end{array}$ & $\begin{array}{l}1.46 \mu \mathrm{g} \mathrm{g}^{-1}(\mathrm{KDN}) \\
91.2 \mu \mathrm{g} \mathrm{g}^{-1} \\
(\mathrm{Neu} 5 \mathrm{Ac})(\mathrm{NR})\end{array}$ & $\begin{array}{l}0.16 \mu \mathrm{g} \mathrm{g}^{-1}(\mathrm{KDN}) \\
82 \mu \mathrm{g} \mathrm{g}^{-1}(\mathrm{Neu} 5 \mathrm{Ac})(\mathrm{NR})\end{array}$ & $\begin{array}{l}1.3 \mu \mathrm{g} \mathrm{g}^{-1}(\mathrm{KDN}) \\
9.2 \mu \mathrm{g} \mathrm{g}^{-1} \text { (Neu5Ac) } \\
(\mathrm{NR})\end{array}$ & 301 \\
\hline & Tumour ovary & & & $\begin{array}{l}0.87 \mu \mathrm{g} \mathrm{g}^{-1}(\mathrm{KDN}) \\
244 \mu \mathrm{g} \mathrm{g}^{-1}(\text { Neu5Ac) }\end{array}$ & $\begin{array}{l}0.10 \mu \mathrm{g} \mathrm{g}^{-1}(\mathrm{KDN}) ; 230 \mu \mathrm{g} \\
\mathrm{g}^{-1}(\mathrm{Neu} 5 \mathrm{Ac})\end{array}$ & $\begin{array}{l}0.77 \mu \mathrm{g} \mathrm{g}^{-1}(\mathrm{KDN}) \\
14 \mu \mathrm{g} \mathrm{g}^{-1}(\mathrm{Neu} 5 \mathrm{Ac})\end{array}$ & \\
\hline & $\begin{array}{l}\text { Healthy ovarian } \\
\text { tissue }\end{array}$ & & & $\begin{array}{l}0.56 \mu \mathrm{g} \mathrm{g}^{-1}(\mathrm{KDN}) \\
170 \mu \mathrm{g} \mathrm{g}^{-1}(\mathrm{Neu} 5 \mathrm{Ac})\end{array}$ & $\begin{array}{l}0.11 \mu \mathrm{g} \mathrm{g}^{-1}(\mathrm{KDN}) \\
135 \mu \mathrm{g} \mathrm{g}^{-1}(\mathrm{Neu} 5 \mathrm{Ac})\end{array}$ & $\begin{array}{l}0.45 \mu \mathrm{g} \mathrm{g}^{-1}(\mathrm{KDN}) \\
35 \mu \mathrm{g} \mathrm{g}^{-1}(\mathrm{Neu} 5 \mathrm{Ac})\end{array}$ & \\
\hline \multirow[t]{2}{*}{ Throat } & Tumour & & $\begin{array}{l}49 \\
(\text { mean } \\
62.2)\end{array}$ & $\begin{array}{l}1.8 \pm 0.2 \mu \mathrm{g} \mathrm{g}^{-1}(\mathrm{KDN}) \\
85.2 \pm 7.6 \mu \mathrm{g} \mathrm{g}^{-1} \\
(\text { Neu5Ac);0.03 } 0.01 \mu \mathrm{g} \\
\mathrm{g}^{-1}(\text { Neu5Gc) }(P<0.01)\end{array}$ & $\begin{array}{l}0.1 \pm 0.01 \mu \mathrm{g} \mathrm{g}^{-1}(\mathrm{KDN}) \\
79.7 \pm 7.5 \mu \mathrm{g} \mathrm{g}^{-1} \\
(\text { Neu5Ac); } 0.02 \pm 0.01 \mu \mathrm{g} \\
\mathrm{g}^{-1}(\text { Neu5Gc) }(P<0.01)\end{array}$ & $\begin{array}{l}1.7 \pm 0.2 \mu \mathrm{g} \mathrm{g}^{-1}(\mathrm{KDN}) \\
5.5 \pm 0.7 \mu \mathrm{g} \mathrm{g}^{-1}(\mathrm{Neu} 5 \mathrm{Ac}) \\
0.01 \pm 0.003 \mu \mathrm{g} \mathrm{g}^{-1} \\
\text { (Neu5Gc) }(P<0.01)\end{array}$ & 302 \\
\hline & $\begin{array}{l}\text { Regional lymph } \\
\text { nodes }\end{array}$ & & $\begin{array}{l}10 \\
(\text { mean } \\
62.2)\end{array}$ & $\begin{array}{l}1.2 \pm 0.2 \mu \mathrm{g} \mathrm{g}^{-1}(\mathrm{KDN}) \\
70.8 \pm 7.9 \mu \mathrm{g} \mathrm{g}^{-1} \\
(\text { Neu5Ac); } 0.015 \pm 0.005 \\
\mu \mathrm{g} \mathrm{g}^{-1}(\text { Neu } 5 \mathrm{Gc})\end{array}$ & $\begin{array}{l}0.1 \pm 0.01 \mu \mathrm{g} \mathrm{g}^{-1}(\mathrm{KDN}) \\
67.2 \pm 7.8 \mu \mathrm{g} \mathrm{g}^{-1} \\
(\text { Neu5Ac);0.01 } \\
\mathrm{g}^{-1}(\text { Neu5Gc) }\end{array}$ & $\begin{array}{l}1.1 \pm 0.2 \mu \mathrm{g} \mathrm{g}^{-1}(\mathrm{KDN}) \\
3.6 \pm 0.5 \mu \mathrm{g} \mathrm{g}^{-1}(\mathrm{Neu} 5 \mathrm{Ac}) \\
0.005 \pm 0.003 \mu \mathrm{g} \mathrm{g}^{-1} \\
\text { (Neu5Gc) }\end{array}$ & \\
\hline \multirow[t]{2}{*}{ Lung } & $\begin{array}{l}\text { Advanced level of } \\
\text { lung cancer }\end{array}$ & Serum & $3(\mathrm{NR})$ & $4839 \pm 443 \mu \mathrm{M}$ & $\mathrm{NR}$ & NR & 282 \\
\hline & Healthy control & & $64(\mathrm{NR})$ & $1821 \pm 44 \mu \mathrm{M}$ & NR & NR & \\
\hline Breast & $\begin{array}{l}\text { Breast cancer with } \\
\text { secondary growth }\end{array}$ & & 36 (NR) & $\begin{array}{l}1773 \pm 58 \mu \mathrm{M} \\
\text { (not differentiable) }\end{array}$ & NR & NR & \\
\hline
\end{tabular}


Table 1 (continued)

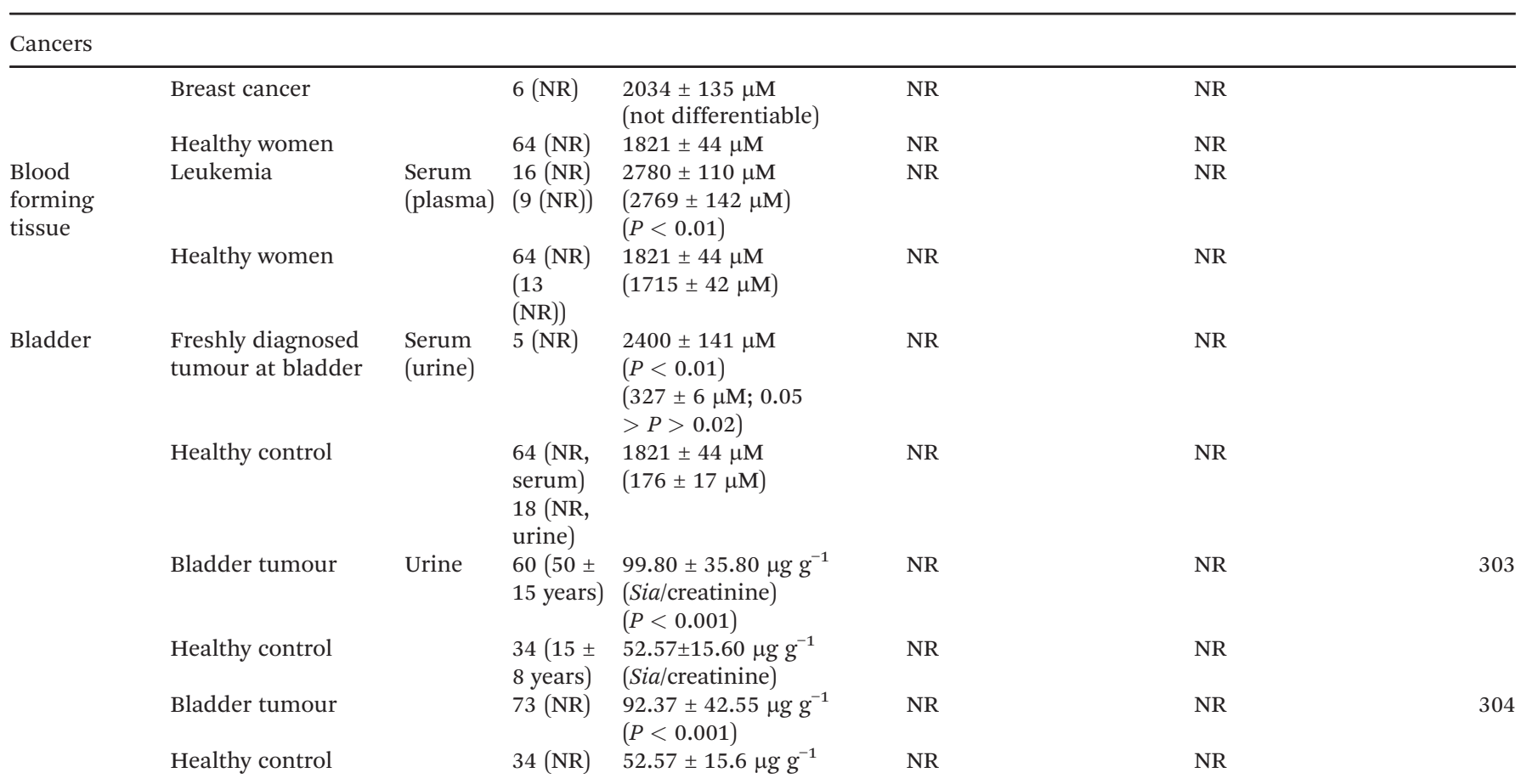

NR: not reported.

mg $\mathrm{L}^{-1}$ concentration within $30 \mathrm{~min}$ through a biolayer interferometry analysis. ${ }^{230}$

\subsection{Sia as potential biomarker for human diseases}

2.3.1 Metabolic diseases of Sia. The metabolic diseases of Sia are generally rare in humans. The impaired transport of free Neu5Ac across the lysosomal membrane causes an autosomal recessive lysosomal storage disorder known as Salla disease, which is diagnosed from the high concentration of free Neu5Ac in urine and tissues of the patients compared to the healthy control. The mean concentrations of total and free Sia were evident as 163.3 and $90.0 \mathrm{mg} \mathrm{g}^{-1}$ of creatinine, respectively, in the urine of the Salla patients ( $n=13 ; 16-61$ years old) compared to 52.1 and $5.5 \mathrm{mg} \mathrm{g}^{-1}$ of creatinine, respectively, in the urine of healthy control $\left(n=24 ; 25-40\right.$ years old).$^{231}$ Similarly, the impaired transport of free Neu5Ac and gluconic acid across the lysosomal membrane causes infantile sialic acid storage disease to infants. It was reported that even in the normal activities of the lysosomal enzymes, the concentration of free Neu5Ac in the pathogenic fibroblast of a male infant having infantile sialic acid storage disease was elevated to $3.5 \pm 0.7$ $\mu \mathrm{mol} \mathrm{g}^{-1}$ of fresh weight compared to $0.2 \pm 0.04 \mu \mathrm{mol} \mathrm{g}{ }^{-1}$ of fresh weight found in the healthy control fibroblast. ${ }^{232,233}$ Sialuria is another metabolic disease of Sia, when the feedback mechanism for biosynthesis of Sia by the rate-limiting enzyme UDP- $N$-acetylglucosamine-2-epimerase is inhibited, the Sia gets stored in the cytoplasm resulting into elevated urinary excretion in the concentration range 5.8-7.2 $\mathrm{g} \mathrm{Neu5Ac}$ per day and $\sim 40$ times higher concentration of free Neu5Ac in the skin fibroblasts. ${ }^{234}$ The sialidosis disease is a result of a deficiency of $\alpha$-neuraminidase enzyme and it leads to an accumulation of sialylated oligosaccharides and glycoproteins in human tissues and urine. ${ }^{235}$ The lysosomal protective protein cathepsin-A is essential for the activity of $\alpha$-neuraminidase enzyme and it delays the proteolysis of $\beta$-galactosidase. The defect in the lysosomal protective protein cathepsin-A enzyme complex results into the galactosialidosis disease. ${ }^{236}$ The reduced activity of the enzymes $\mathrm{N}$-acetylmannosamine kinase and UDP- $N$ acetylglucosamine-2-epimerase leads to impaired biosynthesis of Neu5Ac causing congo-red-positive and rimmed vacuoles depositions in the fibres of the muscles. This is known as hereditary inclusion body myopathy. ${ }^{237}$ The blocking of endogenous synthesis of NeuNAc because of a rare genetic disorder stops the production of Neu5Ac in cells. Hence, the concentration of ManNAc increases in urine and plasma resulting in Neu5Ac synthase deficiency disorder. A recent clinical study on oral administration (@150 mg $\mathrm{kg}^{-1}$ day $^{-1}$ ) of exogenous free Neu5Ac to six Neu5Acsynthase-deficiency disorder patients $(4$ adults and 2 children) for 3 days has showed no decrease in the ManNAc concentration in urine, although an increase in the concentration of Neu5Ac was evident in urine. It was attributed to the fact of rapid excretion of Neu5Ac in urine following a rapid adsorption of the same in human body. $^{238}$

2.3.2 The potential of Sia as a biomarker of addiction, disease and cancer. Given the critical roles Sia plays in many 
biological processes, as described in section 2.1, Sia and their bioconjugates have received much attention as biomarkers for several diseases. The concentration of Sia in human body fluids and organs alters due to occurrence of some diseases, cancers and addiction to tobacco, alcohols, maras and paan. Related case studies are outlined in Table 1 and discussed below. In order to avoid any statistical propagation of errors, we have listed the units and figures as reported by the original authors.

2.3.2.1. Sia as biomarker of harmful addictions. The tobacco specific nitrosamines are metabolites of nicotine formed during the growth, curing, aging and processing of tobaccos. Smoking of burned tobaccos and chewing of smokeless tobaccos viz. paan (tobaccos and other ingredients wrapped with betel quid) and Maras powder (extracted from Nicotiana rustica Linn tobacco) increase chronic inflammation and concentration of reactive oxygen species in human body. The free Sia concentration in the saliva of addicted paan consumers (@1.41 \pm 0.65 pack per day for $4.23 \pm 3.42$ years) was found higher $\left(23.21 \pm 18.98 \mathrm{mg} \mathrm{L}^{-1} ; P<0.001\right)$ compared to non-consumer controls $\left(18.11 \pm 16.5 \mathrm{mg} \mathrm{L}^{-1}\right)$, but the total Sia concentration in saliva did not statistically differ upon consumption of paan. ${ }^{239}$ On the other hand, the saliva of young group of regular Maras powder consumers (@ 20 g per day) showed presence of higher $\left(75.52 \pm 6.86 \mathrm{mg} \mathrm{L}^{-1} ; P<\right.$ 0.001) concentration of total Sia compared to that of young group of regular tobacco smokers (@ 20 cigarettes per day) $\left(62.60 \pm 3.91 \mathrm{mg} \mathrm{L}^{-1} ; P<0.001\right)$ and unaddicted controls $\left(51.60 \pm 3.51 \mathrm{mg} \mathrm{L}^{-1}\right){ }^{240}$

The activity of sialidase increases in the presence of ethanol and its metabolites such as acetaldehydes, reactive oxygen species and fatty-acid ethyl esters, whereas the activity of sialyltransferases in the Golgi body decreases. Hence, the concentration of total Sia in human serum is generally elevated for chronic alcoholics ( $1000 \mathrm{~g}$ ethanol per week) due to desialylation of apolipoprotein $\mathrm{J}$, cholesteryl ester transfer protein and transferrin. ${ }^{241}$ The concentration of total Sia in serum of 51 chronic alcoholics was found specifically higher $(1.449 \pm 0.3019 \mathrm{mM})$ compared that of 20 nonalcoholics (1.154 $\pm 0.1702 \mathrm{mM})$. However, those with or without liver disease could not be statistically differentiated from the measured concentration of total Sia in serum. ${ }^{242}$ Apolipoprotein $\mathrm{J}$ is highly sialylated $(\sim 26-28$ Sia per molecule) glycoprotein found in human plasma and serum and long-term alcohol intake inhibits the hepatic glycolization process of apolipoprotein J. About 28 moles of Sia per mole of apolipoprotein J (known as Sia index) was found in the blood of non-alcoholic healthy human $(n=20)$, while the Sia index decreased to 12-14 moles of Sia per mole of apolipoprotein $\mathrm{J}$ in the plasma of alcoholics $(n=15)$ consuming alcohol @85-90 g per day $(P<0.001)^{243}$ and interestingly Sia index started partially recovering slowly after stopping alcohol consumption. ${ }^{24}$ Although, the concentration of total Sia was found to be distinctly elevated in heavy alcoholics, a noticeable difference was observed in the concentration of lipid bound Sia, which was not much influenced by the status of the liver cells. ${ }^{245}$ The Sia index or elevated total Sia concentration in the serum of both male and female alcoholics can be used for biomarking alcohol abuse as an alternative or a supplement to the existing laboratory biomarkers viz. carbohydrate-deficient transferrin, $\gamma$-glutamyltransferase, mean corpuscular volume, aspartate aminotransferase and alanine aminotransferase. Sia is highly specific (95.5\%) and sensitive $(57.7 \%)$ as an alcohol abuse biomarker for female alcoholics, where its sensitivity is slightly inferior to $\gamma$-glutamyltransferase, comparable to carbohydrate-deficient transferrin and superior to other alcohol biomarkers. However, Sia (81.3\%) and $\gamma$-glutamyltransferase $(87.5 \%)$ have low specificity to identify male alcoholics compared to carbohydrate-deficient transferrin $(100 \%) .^{246}$

2.3.2.2. Sia as biomarker of disease. The concentration of total Neu5Ac in the cerebrospinal fluid significantly increased to 38-1450 $\mu \mathrm{M}$ for pyogenic meningitis and 32-220 $\mu \mathrm{M}$ for tuberculous meningitis compared to $12-40 \mu \mathrm{M}$ for healthy controls. The high concentration of free Neu5Ac in the range $80-620 \mu \mathrm{M}$ is much distinctive for pyogenic meningitis patients compared to healthy control $(6-32 \mu \mathrm{M})$, which entirely covers the range of free Neu5Ac concentrations found in tuberculous meningitis patients (13$26 \mu \mathrm{M}){ }^{247}$ The dementia disease viz. Alzheimer is difficult to be diagnosed from the neurodegenerative disease viz. idiopathic normal pressure hydrocephalus. The elevated concentrations of free Neu5Ac and glycerate simultaneously with demoted concentration of serine and 2-hydroxybutyrate in the cerebrospinal fluid could easily discriminate Alzheimer disease from idiopathic normal pressure hydrocephalus disease. The concentrations of free Neu5Ac in the cerebrospinal fluid of Alzheimer and idiopathic normal pressure hydrocephalus patients were found to be $16.75 \pm$ 3.89 and $13.35 \pm 3.2 \mu \mathrm{M}$, respectively. ${ }^{248}$ Sia has antioxidant properties and thus defends oxidative stress in brain cells. The concentration of total Sia in the plasma of Alzheimer patients were found to be higher $\left(0.7133 \pm 0.0201 \mathrm{ng} \mathrm{L}^{-1}\right)$ compared to that of healthy control $(0.5972 \pm 0.01866 \mathrm{ng}$ $\mathrm{L}^{-1}$ ). The total Sia concentrations in the plasma of 38 female and 22 male Alzheimer patients were found to be $0.6814 \pm$ 0.14022 and $0.6755 \pm 0.1985 \mathrm{ng} \mathrm{L}{ }^{-1}$, respectively. ${ }^{249}$ A rare Sia syndrome known as cerebellar ataxia is difficult to be diagnosed with free Sia as its patients usually have similar free Sia concentration in urine, plasma and peripheral nerves compared to healthy controls. However, the free Sia concentration in the cerebrospinal fluid of cerebellar ataxia patients were found to be much higher $(43.4 \pm 11.0 \mu \mathrm{M})$ compared to other patients having well-defined neurological symptoms $(8.2 \pm 4.2 \mu \mathrm{M})$ and other diseases $(9.9 \pm 5.6 \mu \mathrm{M})$ including Salla disease $(31.3 \pm 4.9 \mu \mathrm{M}) .{ }^{250}$ In-cell polymerization of Sia forms polySia glycans, which are associated with NCAM and control the molecular interactions during neural development, synaptic plasticity, etc. Thus, the concentration of Sia in the saliva of children having autism spectrum disorder is significantly less $(0.100 \pm 0.099 \mathrm{mM})$ 
compared to healthy children $(0.160 \pm 0.097 \mathrm{mM})$. The medication of risperidone (a) $0.32 \pm 0.013 \mathrm{mg}$ per day to a group of children for 2-6 months slightly increased the Sia concentration in saliva to $0.102 \pm 0.062 \mathrm{mM}^{251}$ Similar trends are also observed in the concentration of Sia in the plasma of children having autism spectrum disorder compared to the healthy control. ${ }^{252}$

Crook et al. reported that the total Sia concentration in the serum of 20 type- 1 diabetic mellitus patients (having 10.6 $\pm 4.5 \mathrm{mM}$ plasma glucose concentration and taking daily insulin dose of $54.6 \pm 21.2$ unit) was $2.00 \pm 0.37 \mathrm{mM}$, which was not statistically significant $(P<0.02)$ compared to that of 20 non-diabetic healthy humans $(1.98 \pm 0.67 \mathrm{mM})$. The comorbidity of retinopathy to type-1 diabetes mellitus further increased the total Sia concentration in serum to $2.38 \pm 0.33$ $\mathrm{mM}(P<0.01)$. The total serum Sia concentration of 16 agegender matched type-1 diabetic mellitus patients, type-2 diabetic mellitus (T2DM) patients and non-diabetic patients were found to be $1.92 \pm 0.35 \mathrm{mM}(P<0.001), 2.32 \pm 0.41 \mathrm{mM}$ and $1.85 \pm 0.26 \mathrm{mM}(P<0.001)$, respectively. ${ }^{253}$ Nephropathy is a disease which interrupts the usual activity of kidney due to the damage of its cell membrane. The neuraminidase activity increases in the blood of nephropathic patients compared to the healthy individual and it further increases with the comorbidity of T2DM. Diabetic normoalbuminuria and diabetic microalbuminuria are two pre-stages of diabetic nephropathy and those are identified by the daily urinary albumin excretion rate $\leq 30$ and $31-299 \mathrm{mg}$, respectively. Although total Sia concentration in both serum and urine of T2DM patients having either normoalbuminuria or microalbuminuria distinguishably increased compared to the non-diabetic healthy controls, while no correlation in the concentration of lipid bound Sia concentration in serum was observed. ${ }^{254}$ Furthermore, the higher neuraminidase activity in both serum and urine increased independently due to T2DM and nephropathy diseases compared to healthy controls and therefore, the comorbidity of these two diseases further increased the neuraminidase activity in serum and urine. Hence, the total concentration of Sia in serum and urine of T2DM-nephropathic patients, nephropathic patients, T2DM patients and healthy control follow the same decreasing order. ${ }^{255}$

The lipid membrane of RBC becomes damaged due to the oxidative stress in the blood of T2DM patients. Therefore, the lipid peroxidation of RBC increases the concentration of Sia in plasma but decreases that on RBC. This effect becomes more pronounced in T2DM patients having nephropathy. Therefore, simultaneous monitoring of lipid peroxidation of RBC and Sia level on RBC could be able to predict the appearance of nephropathy in T2DM patients. ${ }^{256}$ A large cohort study including 40 years of follow-up on 6718 T2DM patients (3445 men and 3273 women) in the age-group of $47.2 \pm 13.0$ years showed that the median of Sia concentration in blood is $680 \mathrm{mg} \mathrm{L}^{-1}$ for both men and women. After adjusting the covariates such as age, body mass index, systolic blood pressure, cholesterol, aspartate aminotransferase and alanine aminotransferase activities and socioeconomic status, it was found that the elevated Sia concentration in the blood of T2DM patients was statistically correlated to a higher chance of incidence responsible for diabetes-related hospitalizations and the risk-factor $(P<$ 0.0001 ) was more to women compared to men. ${ }^{257}$ The gestational diabetes mellitus disease is associated with higher whole blood viscosity and reduced erythrocyte deformability in the $26^{\text {th }}$ week of pregnancy. Gestational diabetic mellitus patients have blood glucose concentration more than $140 \mathrm{mg} \mathrm{dL}{ }^{-1}$ in the ' $1 \mathrm{~h}-50 \mathrm{~g}$ glucose tolerance test' and having the same exceeding $176 \mathrm{mg} \mathrm{dL}^{-1}$ in the next ' 3 h-100 g oral glucose tolerance test'. The amount of Sia in RBC protein increases during the development of the pregnancy, but due to the irregularities in the microcirculation of the blood in gestational diabetic mellitus patients, there exists an imbalance in the amount of Sia in the RBC. ${ }^{129,258}$ The blood vessel inflammation happened due to Behcet's syndrome and thus because of that the total Sia concentration in serum increased to $95.6 \pm 15.3 \mathrm{mg} \mathrm{\textrm {dL } ^ { - 1 }}$ compared to that of patients having uveitis disease $(75.8 \pm$ $\left.8.1 \mathrm{mg} \mathrm{dL}{ }^{-1}\right)$ and healthy humans (59.5 $\left.\pm 7.5 \mathrm{mg} \mathrm{dL}^{-1}\right)$. However, the resolution in the lipid bound Sia concentration for diagnosis of Behcet's syndrome and uveitis disease was very poor. ${ }^{259}$

Periodontal disease happens due to the attack of oral bacteria at the gum tissue around the teeth. The recoverable early stage of periodontal disease is known as gingivitis, whereas the destructive acute stage of this disease is known as periodontitis. Zipkin et al. reported that the free Sia concentration in the parotid and whole saliva of young patients having periodontal disease decreased to $0.0019 \%$ and $0.0040 \%$, respectively, compared to those of healthy control $(0.0024 \%$ and $0.0047 \%$, respectively) owing to its utilization in the bacterial plaque formation. However, the opposite phenomenon was observed for patients having autoimmune rheumatoid arthritis $(0.0035 \%$ and $0.0053 \%$, respectively). ${ }^{260}$ The inflammatory periodontal disease increases the oxidative stress in human body and to defend that oxidative stress, the total Sia concentration in human saliva and serum increases owing to higher sialidase activity. Therefore, the total Sia concentration in both saliva and serum progressively increases from gingivitis to periodontitis diseases compared to healthy controls. ${ }^{261-263}$

The concentration of Sia in plasma increases during and immediately after the event of myocardial infraction. Hence, the total plasma Sia concentration, but not the lipid bound Sia, was statistically correlated to the event of the myocardial infraction compared to the healthy control. The total plasma Sia concentration increased continuously after 1, 2 and 5 day(s) to $0.88 \pm 0.29 \mathrm{~g} \mathrm{~L}^{-1}(P<0.05), 0.89 \pm 0.30 \mathrm{~g} \mathrm{~L}^{-1}(P<$ $0.05)$ and $0.75 \pm 0.19 \mathrm{~g} \mathrm{~L}^{-1}(P<0.05)$ compared to that in the plasma of healthy humans $\left(0.62 \pm 0.13 \quad \mathrm{~g}^{-1}\right)$ not encountered the event of myocardial infraction. However, no difference and correlation were observed in the concentration of total serum Sia between patients and survivors. ${ }^{264}$ 
Recently, it was observed that Neu5Ac concentration in serum has similar diagnostic efficacy compared to the common biomarkers viz. creatine kinase-MB and troponin I for acute coronary syndrome. Patients having myocardial infarction have higher concentration (median $297 \mu \mathrm{g} \mathrm{L}{ }^{-1}$ ) of Neu5Ac in the serum compared to the that of patients having unstable angina pectoris (median $227 \mu \mathrm{g} \mathrm{L}^{-1}$ ) and healthy control (median $207 \mu \mathrm{g} \quad \mathrm{L}^{-1}$ ), however it cannot statistically differentiate between the ST-elevation and non-ST-elevation myocardial infarction. The cut-off value of Neu5Ac in serum was reposted as $330.5 \mu \mathrm{g} \mathrm{L^{-1 }}$ (optimal) and $351.5 \mu \mathrm{g} \mathrm{\textrm {L } ^ { - 1 }}$ (high-risk) acute coronary syndrome. ${ }^{265} \mathrm{~A}$ cohort study on 18429 men and 19414 women of age $59.5 \pm 6.5$ years along with 40 years of follow-up revealed that the elevated blood Sia concentration ( $>$ median $700 \mathrm{mg} \mathrm{L}^{-1}$ ) and pulse pressure (>median $70 \mathrm{~mm} \mathrm{Hg}$ ) could both independently predict the risk of cardiovascular incident for patients of cardiovascular diseases $(P<0.0001){ }^{266}$ It has recently been reported that Neu5Ac fits well in the cavity of the protein RhoA and Cdc42 in human plasma and activates Rho/Rho-associated coiledcoil containing protein kinase (both 1 and 2), c-Jun $\mathrm{N}$-terminal kinase and extracellular signal-regulated kinase signalling pathways in cardiomyocytes, but it does not fit with Rac1 protein and thus it does not follow p38 signalling pathway. Hence, the elevated concentration of Neu5Ac in the serum of patients having normal coronary artery, nonobstructive coronary atherosclerosis, stable angina found in the range 143.70-147.20 $\mu \mathrm{g} \mathrm{L}^{-1}$ and it increased to 178.25 $\mu \mathrm{g} \mathrm{L}^{-1}\left(P=9.3 \times 10^{-3}\right)$ in patients having unstable angina and $182.34 \mu \mathrm{g} \mathrm{L} \mathrm{L}^{-1}\left(P=1.7 \times 10^{-4}\right)$ in patients having acute myocardial infarction. ${ }^{267}$ The coronary artery disease also caused desialylation of low-density lipoprotein and increased the total Sia concentration in serum of the patients (mean 71.91 (68.33-75.60) $\left.\mathrm{mg} \mathrm{dL}^{-1} ; P<0.001\right)$ compared to the healthy control $\left(60.76 \quad(57.04-65.92) \quad \mathrm{mg} \quad \mathrm{dL}^{-1}\right){ }^{268}$ Furthermore, total Sia concentration in the serum and saliva of periodontitis patients increased in the comorbidity of cardiovascular diseases. ${ }^{269}$ The total Sia concentration in the serum can also statistically identify $(P<0.0001)$ the induction of carotid atherosclerosis in humans caused by plaque deposition in the brain arteries. ${ }^{270}$ Crook et al. studied the total and lipid bound serum Sia concentrations in the patients having lipoprotein patterns of Fredrickson phenotypes IIa (cholesterolemic) and IIb (hypertriglyceridaemic). The total Sia concentration of healthy controls was found to be higher compared to the cholesterolemic patients, but lower compared to the hypertriglyceridaemic patients. However, the lipid bound Sia concentration was highest in hypertriglyceridaemic patients $\left(23.0 \pm 4.3 \mathrm{mg} \mathrm{dL}^{-1}\right)$ compared to cholesterolemic patients $\left(14.9 \pm 4.7 \mathrm{mg} \mathrm{dL}{ }^{-1}\right)$ and healthy controls $(12.0 \pm 3.2 \mathrm{mg}$ $\left.\mathrm{dL}^{-1}\right) .{ }^{271}$

A perforating injury to the eyes after surgical or accidental trauma causes a bilateral granulomatous uveitis known as sympathetic ophthalmitis. The concentration of total Sia in the serum of sympathetic ophthalmia patients was significantly higher $(120.2 \pm 12.6 \mathrm{mg} / 100 \mathrm{~mL} ; P<0.001)$ compared to that of the healthy control $(67.8 \pm 7.9 \mathrm{mg} / 100$ $\mathrm{mL})$. However, the symptoms of traumatic uveitis $(71.3 \pm 8.4$ $\mathrm{mg} / 100 \mathrm{~mL} ; P>0.1$ ) in humans could not be statistically diagnosed compared to healthy controls. $^{272}$ The concentration of Sia in the serum of patients having overt hypothyroidism $\left(58.2 \pm 18.9 \quad \mathrm{mg}^{-1}\right)$ was statistically distinctively elevated compared to that observed in the patients having sub-clinical hypothyroidism $(37.1 \pm 15.5 \mathrm{mg}$ $\left.\mathrm{L}^{-1}\right)$ and healthy individual $\left(38.1 \pm 12.0 \mathrm{mg} \mathrm{L}^{-1}\right)$ might be due to the influence of atherogenesis. ${ }^{273}$ The inflammation due to the formation of ulcerations in the digestive tract happens in Crohn's disease. The total Sia concentration in the serum of patients having active ulcerations was significantly increased to $69.7 \pm 9.4 \mathrm{mg} \mathrm{dL}-1$ compared to that of the healthy humans $\left(50.3 \pm 4.4 \mathrm{mg} \mathrm{dL}{ }^{-1}\right)$. The successful surgery of the ulcerations could decrease it to $54.7 \pm 5.5 \mathrm{mg} \mathrm{dL}{ }^{-1}$, which was close to the normal levels. ${ }^{274}$

Sialylation of glycoproteins and glycolipids happens in the liver and thus chronic liver disease viz. hepatitis B and C alters the total Sia concentration in the serum. The median of Sia concentration in serum decreases to $1.32 \mathrm{mM}$ in hepatitis B patients from $1.43 \mathrm{mM}$ in healthy human due to reduced sialyltransferase activity by hepatitis B viral infection. In contrast, the median of Sia concentration in serum increases to $1.67 \mathrm{mM}$ in hepatitis $\mathrm{C}$ patients due to elevated sialyltransferase activity by hepatitis $\mathrm{C}$ viral infection, but it cannot provide any indication about the progress of either hepatitis B or C. ${ }^{275}$ The total Sia concentration in serum of patients having jaundice with malignant tumours of ampulla of Vater, pancreas, liver, cholecystitis and bile ducts was found $7.95 \mathrm{mg} \mathrm{L}^{-1}$ (median) with the Sia to total protein ratio 1.20 compared to those of healthy individual $\left(5.97 \mathrm{mg} \mathrm{L}^{-1}\right.$ (median); 0.79; $P<0.001)$. The total Sia concentration (6.86 $\mathrm{mg} \mathrm{L}^{-1}$ ) and Sia to total protein ratio (1.03) are statistically different $(P=0.041)$ for patience having non-malignant jaundice viz. choledocholithiasis, cholecystolithiasis, calculous or non-calculous chronic cholecystitis, exacerbation of chronic cholangitis, stricture of the common bile duct. ${ }^{276}$ The free Sia concentration in serum was reported as a potential biomarker for chronic liver diseases viz. alcoholic cirrhosis, although it could not statistically differentiate nonalcoholic patients having cirrhosis and other liver diseases viz. hepatitis $\mathrm{C}$, etc. ${ }^{277}$

The concentration of pyruvate increases in chronic renal failure and chronic glomerulonephritis. Thus, the biosynthesis of Neu5Ac becomes predominant in renal disease. The total Sia concentrations in serum and urine of patients having chronic renal failure and glomerulonephritis are statistically differentiable compared to the healthy control, however the concentration of lipid bound Sia does not meet this trend. ${ }^{278}$ The kidney can filter free Sia, which cannot be reabsorbed there. The concentration of free Sia in the plasma of patients having GNE myopathy (glomerular filtration rate $85-155 \mathrm{~mL} \min ^{-1}$ per $1.73 \mathrm{~m}^{2}$ ) was not differentiable compared to healthy controls, but the 
concentration of free Sia in plasma of patients having very low glomerular filtration rate increased drastically to 310$1260 \mu \mathrm{g} \mathrm{L}{ }^{-1}$ due to the glomerular dysfunction. ${ }^{279}$

Pregnant women sometimes suffer from hyperemesis gravidarum disease during the $22^{\text {nd }}$ week of pregnancy and it can be predicted and diagnosed from the elevation of the concentration of total Sia in the serum of pregnant patients having hyperemesis gravidarum $\left(28.370 \pm 8.69 \mathrm{mg} \mathrm{\textrm {L } ^ { - 1 }}\right)$ compared to that in the healthy control group $(20.978 \pm 9.96$ $\mathrm{mg} \mathrm{L}^{-1}$ ) with statistical significance $P<0.05{ }^{280}$ Pregnancy syndrome preeclampsia is another pregnancy related disease resulting to high blood pressure, damage of liver and kidney extending even to neonatal and maternal morbidity and mortality. Owing to high inflammation in preeclampsia patients, Sia was thought to be a potential biomarker for this disease. However, studies showed that plasma concentration of Sia could not be considered as suitable biomarker compared to neopterin for diagnosing preeclampsia during pregnancy. ${ }^{281}$

The bacterial infection brucellosis caused by the consumption of raw and unpasteurized dairy products increased the total serum Sia concentration to $2386 \pm 82 \mu \mathrm{M}$ compared to the healthy controls $(1821 \pm 44 \mu \mathrm{M}){ }^{282}$ Oxidative stress in the cell produces reactive oxygen species including hydrogen peroxide, which can be arrested by Neu5Ac and polysia to form a decarboxylation product 4-(acetylamino)-2,4dideoxy-D-glycero-D-galacto-octonic acid (ADOA) at neutral $\mathrm{pH}$ $\sim 7.5 .^{283}$

It is also observed that long exposure $(21.00 \pm 11.75$ years $)$ of pesticides to non-alcoholic and non-smoker field workers increased the total Sia concentration in serum to $44.854 \pm$ $36.48 \mathrm{mg} \mathrm{L}^{-1}$ compared to the healthy control (581.95 \pm $134.36 \mathrm{mg} \mathrm{L}^{-1}$ ) due to induction of several diseases originated from the pesticides. ${ }^{284}$ Similarly, workers exposed to cadmium in nonferrous smelter for about 8 years had lower Sia in RBC membrane $\left(22.6 \pm 1.8 \mathrm{mg} \mathrm{g}^{-1}\right.$ of protein; $\left.P<0.01\right)$ compared to the healthy controls $\left(25.8 \pm 3.0 \mathrm{mg} \mathrm{g}^{-1}\right.$ of protein), however they had elevated concentration of total Sia in plasma $\left(761.8 \pm 83.5 \mathrm{mg} \mathrm{L}^{-1} ; P<0.01\right)$ and urine $(276.7 \pm$ $132.3 \mu \mathrm{g} \mathrm{g}^{-1}$ of creatinine; $\left.P<0.05\right)$ compared to the control group $\left(640.4 \pm 70.7 \mathrm{mg} \mathrm{L}^{-1} ; 174.5 \pm 70.9 \mu \mathrm{g} \mathrm{g} \mathrm{g}^{-1}\right.$ of creatinine). ${ }^{285}$ Synovial fibroblasts are stromal cells present in synovium joint and they maintain the lubrication and cartilage integrity of the joints. Local inflammation stimulates tumour necrosis factor, which inhibits the activity of glycosyltransferase ST6Gal1 and diminished $\alpha 2,6$ sialylation on synovial fibroblasts leading to rheumatoid arthritis. $^{286}$

The Neu5Gc is not synthesised in the human body, but it is eventually released in human cells mainly through diets of dairy products and animal meats. Interestingly, the human natural immune system does not identify it as fatal "xeno (foreign)-antigen", but automatically produces anti-Neu5Gc antibody even during the first year of human life. ${ }^{287}$ The concentration of anti-Neu5Gc antibody in the blood of healthy human ( $n=120 ; 20-80$ years $)$ is reported as $2.7 \pm 0.3$ ng $\mu \mathrm{L}^{-1}{ }^{288}$ However, excessive consumption of Neu5Gc rich diets (lamb, pork and beef meats, goat and sheep milks) ${ }^{289-292}$ increases the interaction of anti-Neu5Gc antibody with xeno Neu5Gc antigen and thus eventually may promote inflammations leading to cancers. ${ }^{28,293,294}$

2.3.2.3. Sia as cancer biomarkers. The oral squamous cell carcinoma is an oral cancer that happens due to excessive smoking of tobacco and drinking alcohol. Sanjay et al. reported that the concentrations of both lipid bound and free Sia in the saliva of 30 oral squamous cell carcinoma patients were higher $\left(3.02 \pm 0.01\right.$ and $4.30 \pm 0.01 \mathrm{mg} \mathrm{dL}{ }^{-1}$, respectively) compared to 30 healthy humans $(2.06 \pm 0.01$ and $3.40 \pm 0.02 \mathrm{mg} \mathrm{dL}^{-1}$, respectively). ${ }^{295}$ Other oral cancers, pre-cancers and tumours can be diagnosed from the total serum Sia concentrations. Bose et al. did not find any statistically significant difference in total Sia serum concentration between healthy tobacco consumers (48.52 \pm $\left.6.49 \mathrm{mg} \mathrm{dL}^{-1}\right)$ and non-consumers $\left(48.77 \pm 5.88 \mathrm{mg} \mathrm{dL}^{-1}\right)$. However, the total serum Sia concentration increased to $60.30 \pm 7.96$ and $59.97 \pm 6.03 \mathrm{mg} \mathrm{dL} \mathrm{dL}^{-1}$ for pre-cancers leukoplakia and oral sub mucous fibrosis, respectively. It further increased to $94.69 \pm 7.26 \mathrm{mg} \mathrm{dL}^{-1}$ for patients having oral cancers. ${ }^{296}$ The total serum Sia concentration also increased in patients having malignant fibrous histiocytoma $\left(85.63 \pm 5.45 \mathrm{mg} \mathrm{dL}^{-1}\right)$, tongue and floor cancer $(75.01 \pm$ $\left.12.00 \mathrm{mg} \mathrm{dL}^{-1}\right)$, salivary gland tumours $(70.58 \pm 12.07 \mathrm{mg}$ $\mathrm{dL}^{-1}$ ), mandibular cancer $\left(69.72 \mathrm{mg} \mathrm{dL} \mathrm{L}^{-1}\right)$, gingival, palatal and buccal cancer $\left(69.46 \pm 11.23 \mathrm{mg} \mathrm{dL}^{-1}\right)$, sarcoma (64.06 \pm $\left.5.01 \mathrm{mg} \mathrm{dL}^{-1}\right)$, lip and skin cancer $\left(59.24 \pm 12.10 \mathrm{mg} \mathrm{dL}^{-1}\right)$ and benign tumours in oral and maxillofacial region (58.28 \pm $\left.8.34 \mathrm{mg} \mathrm{dL}^{-1}\right)$ compared to healthy controls $(55.02 \pm 7.2 \mathrm{mg}$ $\left.\mathrm{dL}^{-1}\right) \cdot{ }^{298}$

The serum concentration of total Sia increased to $2.75 \pm$ $0.67 \mathrm{mM}(P<0.001)$ in the case of cholangiocarcinoma patients compared to the healthy controls $(1.89 \pm 0.46 \mathrm{mM})$ and further it remained statistically different $(2.33 \pm 0.69$ $\mathrm{mM} ; P<0.002$ ) from the serum concentration of Sia for patients having benign hepatobiliary diseases viz. liver abscesses, liver cirrhosis, cholecystitis, cholangitis, bile duct stricture and stones, pancreatic stones, gallstones, intrahepatic stones, etc. ${ }^{298}$ The concentration of bound as well as total Sia in the serum of patients having colorectal cancer affecting the colon and rectum significantly increased compared to the healthy control. Therefore, the total Sia concentration in serum and Sia to total protein ratio can be used to diagnose the induction of colorectal cancer and Dukes' stage. ${ }^{299}$

The monoclonal premalignant endometrial glandular lesion, which is known as endometrial intraepithelial neoplasia, is a pre-stage of endometrial adenocarcinoma. The patients having intraepithelial neoplasia had higher $(2.38 \pm$ $0.72 \mathrm{mM}$ and $27.91 \pm 8.00 \mu \mathrm{mol} \mathrm{g}^{-1}$ of serum protein) total Sia concentration in serum compared to healthy women ( 1.52 $\pm 0.25 \mathrm{mM}$ and $19.28 \pm 2.24 \mu \mathrm{mol} \mathrm{g}^{-1}$ of protein). However, it could not statistically discriminate endometrial intraepithelial neoplasia from other neoplasia. ${ }^{300}$ Inoue et al. 
Glycosyl donor

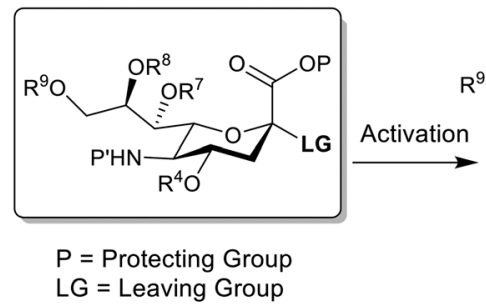

Fig. 4 Schematic representation of a generic sialylation reaction. first reported by using HPLC-FLD that the ratio of free KDN to free Neu5Ac increased to $6.3 \%$ in the ovarian cancerous RBC compared to $1.5 \%$ in RBC of healthy human ovarian tissue and it further increased to $16 \%$ in the RBC of ascites cells. A positive correlation of the ratio of KDN/Neu5Ac (both in free form) was observed in different types and stages of ovarian cancers. This ratio was found as $18 \%$ in a young woman having ovarian mature cystic teratoma, while it was found as $5.3 \%$ in the ovarian cyst of a patient having mucinous adenocarcinoma. The ratio significantly changed in the ascites cell having mucinous adenocarcinoma from $0.55 \%$ at incidence to $33 \%$ in stage IIIa. Further, it was proposed that free KDN in the RBC of ovarian cancer patients might act as oncofetal antigen and thus it overexpressed (1.6 $\mu \mathrm{g}$ free KDN per mL RBC; $0.7 \mu \mathrm{g}$ free Neu5Ac per mL RBC) in the foetal cord RBC of neonates compared to the maternal RBC of mothers having malignant ovarian cancer $(0.9 \mu \mathrm{g}$ free KDN per mL RBC; $0.4 \mu \mathrm{g}$ free Neu5Ac per mL RBC).$^{301}$ Wang et al., in 2015, by LC-MS/MS found that the overexpression of KDN in human cells was not limited to only ovarian cancer, rather it was also overexpressed in the human body for many types of cancers. They further identified the presence of Neu5Gc in cancer cells. They reported a higher amount of free KDN in throat tumours compared to lymph nodes and furthermore, the overexpression of free KDN in throat cancers even occurred in the absence of lymphatic metastasis. The amount of total KDN also varied upon the tumour sites in the order of hypopharynx $\left(2.4 \pm 0.8 \mu \mathrm{g} \mathrm{g}^{-1}\right)>$ glottis $\left(1.9 \pm 0.3 \mu \mathrm{g} \mathrm{g}^{-1}\right)>$ supraglottic region $(1.7 \pm 0.3 \mu \mathrm{g}$ $\left.\mathrm{g}^{-1}\right)>$ sub-glottic region $\left(0.8 \pm 0.11 \mu \mathrm{g} \mathrm{g}^{-1}\right) \cdot{ }^{302}$ However, the mechanism of synthesis of KDN in the cancerous cells is still unconvinced to date.

The total serum Sia concentration of 3 patients having active level of lung cancer was found to be sufficiently high $(4839 \pm 443 \mu \mathrm{M})$ compared to that of healthy controls (1821 \pm $44 \mu \mathrm{M})$. Thus, total serum Sia can be considered as a potential biomarker for lung cancer, but not for breast cancer as the total serum Sia concentration of 3 patients having breast cancer and 36 patients having secondary growth were found to be $2034 \pm 135$ and $1773 \pm 58 \mu \mathrm{M}$, respectively. ${ }^{282}$ On the other hand, the total Sia concentrations in both serum and plasma of leukemia patients $(2780 \pm 110$ and $2769 \pm 142$ $\mu \mathrm{M}$, respectively) were found to be sufficiently higher compared to healthy humans $(1821 \pm 44$ and $1715 \pm 42 \mu \mathrm{M}$, respectively). ${ }^{282}$ The ratio of total Sia to creatinine concentration in the urine was a good marker for bladder tumours as this ratio significantly increased to $99.80 \pm 35.80$ $\mu \mathrm{g} \mathrm{\textrm {g } ^ { - 1 }}$ (ref. 303) and $92.37 \pm 42.55 \mu \mathrm{g} \mathrm{g}^{-1}$ (ref. 304) for the tumour patients compared to the healthy human (52.57 \pm $\left.15.60 \mu \mathrm{g} \mathrm{g}^{-1} ; P<0.001\right)$ and interestingly with the progress of the treatment/therapy this ratio decreased and became closer to the control value indicating the disappearance of the tumour from the bladder. ${ }^{303,304}$ Further, a recent study on human glial cell line (1321N1) revealed that Sia assisted in the upregulation of interleukine-4,10 gene expressions resulting into metastasis of glioblastoma (an aggressive brain cancer), but in contrast lipopolysaccharide retarded the same. $^{305}$

\section{Commercial production of Sia}

\subsection{Extraction of Sia from natural resources}

The EBN is one of the largest commercial resources of free Neu5Ac. Owing to high content i.e., $\sim 2-5 \% \mathrm{w} / \mathrm{w}$ of extractable Neu5Ac in boiling water, stew of EBN is very popular in eastern countries. In 1977, Martin et al. developed a facile method to extract $6.5 \mathrm{~g}$ of Neu5Ac from $300 \mathrm{~g}$ of EBN simply by refluxing the pulverized EBN in boiling water for $5 \mathrm{~h}$ followed by partial-freeze drying pre-concentration and subsequently ultra-filtration through Diaflo XM-50 and Diaflo UM-10 filters. The filtrate was again passed through Dowex 1 $\times 4$ ion-exchange column for further purification and crude Neu5Ac was obtained by lyophilization of the purified filtrate. The crude Neu5Ac was then dissolved in water, passed through Dowex $1 \times 4$ and lyophilized to achieve pure Neu5Ac. ${ }^{306}$ In 2018, Wong et al. reported that $48 \mathrm{~h}$ of digestion of EBN in a simulated gastric fluid at pH 2 and 37 ${ }^{\circ} \mathrm{C}$ could completely release free Neu5Ac digestible by humans. ${ }^{307}$ Nowadays EBN has been used in foods, cosmetics and pharmaceuticals as one of the ingredients. It is being commercially produced and exported worldwide from Thailand, Indonesia, Malaysia and China generating a good revenue. However, commercially produced EBN in swiftlet farms generally contains nitrite, minerals, heavy metals, fungi, mites and bacteria contaminants originating from the farm, packing materials and adulterants such as egg white, 
swim bladder, porcine skin, white fungus. Thus direct consumption of commercial EBN has associated risk. ${ }^{308-311}$

$\kappa$-Caseinoglycomacropeptide (cGMP) is a C-terminal sialylated phosphorylated glycopeptide having 64 amino acid residues and it is another recognised natural source of Sia. ${ }^{312}$ Chymosin enzyme releases cGMP during cheese making and then cGMP is isolated from the caseinate hydrolysate. The regular cGMP contains $\sim 81 \%$ (w/w) protein and 42-52 $\mathrm{mg}$ Sia per $g$ of protein, however pre-treatment of bovines with exogenic Sia may enrich the Sia concentration in cGMP to 190-230 mg Sia per g of protein and reduce the protein content to $50-60 \%(\mathrm{w} / \mathrm{w})$ in cGMP. Hence, mixing of normal or enriched cGMP in infant formula is a means to bring the bovine based infant formula closer to human breast milk. ${ }^{313}$

Sialex, ${ }^{314}$ which is a Sia concentrate production of Ecological Formulas, ${ }^{315}$ is commercial dietary supplement available in the market and it is derived from mucin extract. The commercially available Lacprodan ${ }^{\circledR}$ CGMP-10/20 consisting of $\geq 95 \%$ cGMP, $>81 \%$ protein concentrate and a very low level of phenylalanine is a good source of protein for people suffering from phenylketonuria. ${ }^{316}$

\subsection{Chemical, chemoenzymatic and whole cell biocatalytic synthesis of Neu5Ac}

Danishefsky et al. reported the stereoselective method for chemical synthesis of Neu5Ac starting from lactic ester by using furan surrogate and boron trifluoride etherate catalyst. However, the yield of Neu5Ac was not encouraging for large scale production. ${ }^{317}$ The chemical synthesis of Sia glycoconjugates remains a challenging task despite impressive developments in this field which have allowed for very precise control of the stereochemical outcome in Sia's glycosylation reactions with $\alpha$-anomers typically being the targets with biological relevance (Fig. 4). ${ }^{318}$ This often requires the multi-step synthesis of complex Neu5Ac and other Sia glycosyl donors. ${ }^{319,320}$ Some of these difficulties are related to the unusual structure of the 9-carbon backbone of Sia, the hindered tertiary anomeric centre, the presence of an electron-withdrawing carboxyl group directly linked to the anomeric carbon and the lack of neighbouring participating group in $\mathrm{Sia}^{321}$

For these reasons, chemoenzymatic strategies have been found to be efficient approaches for the preparation of Sia and their derivatives. ${ }^{322-324}$ Neu5Ac can be produced in large scale in a two-step enzymatic process, where GlcNAc is initially converted to ManNAc by $\mathrm{N}$-acetylglucosamine-2epimerase (EC 5.1.3.8) under alkaline condition and then ManNAc produces Neu5Ac in the presence of excess pyruvate and sialic acid aldolase. Here, the aqueous alkaline solution (i.e., $\mathrm{pH}>11$ ) of GlcNAc mixed with a catalytic amount of epimerase (cloned and developed from porcine kidney ${ }^{325}$ ) is kept at $25-35{ }^{\circ} \mathrm{C}$ for $12-20 \mathrm{~h}$ to reach the equilibrium ratio 4:1 of GlcNAc:ManNAc followed by neutralisation with acetic acid. The neutralised mixture is diluted with 6 times volume of isopropanol at $20-25{ }^{\circ} \mathrm{C}$ for precipitating out GlcNAc and enriching supernatant with ManNAc. This step is usually repeated several times to reach the ratio $1: 4$ (for large scale) or $1: 10$ (for lab scale) of GlcNAc:ManNAc. The ManNAc enriched mixture is incubated at pH $7-8,20-30{ }^{\circ} \mathrm{C}$ for $48 \mathrm{~h}$ with sodium pyruvate in the presence of aldolase cloned from TG1[pMexAld] and TG1[pPLAld] strains of $E$. coli. Here, the ratio of ManNAc: pyruvate should be maintained as $1: 2.5$ to get $\sim 95 \%$ conversion of ManNAc to Neu5Ac, which is separated from the equilibrium mixture by ion-exchange chromatography. ${ }^{326}$ The isolation and purification of Neu5Ac from the equilibrium mixture is indeed a difficult step and thus a membrane reactor containing two embedded enzymes could be an economic way to produce large quantities of Neu5Ac, but it often encounters low production yield. ${ }^{327}$

Table 2 The recommended level of Neu5Ac. $2 \mathrm{H}_{2} \mathrm{O}$ as an ingredient in commercial food products as per regulation EU/2017/2375 dated on 15/12/2017 (ref. 41)

\begin{tabular}{|c|c|}
\hline Category of Food where & Recommended level of Neu5Ac· $2 \mathrm{H}_{2} \mathrm{O}$ \\
\hline Infant and follow-on formulae & $50 \mathrm{mg} \mathrm{L}^{-1}$ of reconstituted formula \\
\hline $\begin{array}{l}\text { Baby foods for infants; processed cereal-based foods; foods for } \\
\text { young children }\end{array}$ & $50 \mathrm{mg} \mathrm{kg}^{-1}$ of solid food \\
\hline Special medical purpose food for infants and young children & $\begin{array}{l}\text { Should be considered case to case; but in any case, not exceeding the } \\
\text { specified level for the category mentioned in this table }\end{array}$ \\
\hline Dietary intakes for weight control & $200 \mathrm{mg} \mathrm{L}^{-1}$ (for liquid); $1.7 \mathrm{~g} \mathrm{~kg}^{-1}$ (for solid) \\
\hline Foods suitable for people having intolerance to gluten & $1.25 \mathrm{~g} \mathrm{~kg}^{-1}$ \\
\hline $\begin{array}{l}\text { Unflavoured pasteurised and sterilised milk; flavoured drinks; fruit } \\
\text { juices and nectars; vegetable juices and nectars }\end{array}$ & $50 \mathrm{mg} \mathrm{L}^{-1}$ \\
\hline Table-top sweeteners & $8.3 \mathrm{~g} \mathrm{~kg}^{-1}$ \\
\hline Coffee, tea, herbal and fruit infusions; chicory and its extracts & $200 \mathrm{mg} \mathrm{kg}^{-1}$ \\
\hline Cereal bars & $500 \mathrm{mg} \mathrm{kg}^{-1}$ \\
\hline $\begin{array}{l}\text { Unflavoured and flavoured fermented milk-based products } \\
\text { including heat treated products after fermentation }\end{array}$ & $50 \mathrm{mg} \mathrm{L}^{-1}$ (for liquid); $400 \mathrm{mg} \mathrm{kg}^{-1}$ (for solid) \\
\hline Dairy analogues including beverage whiteners & $50 \mathrm{mg} \mathrm{L}^{-1}$ (for liquid); $250 \mathrm{mg} \mathrm{kg}^{-1}$ (for solid) \\
\hline Food supplements in any form for infants ( $\leq 1$ year old) & $55 \mathrm{mg}$ per day \\
\hline Food supplements in any form for young children (1-2 year(s) old) & $130 \mathrm{mg}$ per day \\
\hline Food supplements in any form for children (3-10 years old) & $250 \mathrm{mg}$ per day \\
\hline Food supplements in any form for general population $(>10$ years & $300 \mathrm{mg}$ per day \\
\hline
\end{tabular}


Furthermore, the use of $\operatorname{rhRnBp}$, which is a recombinant human renin binding protein, in the reaction mixture enhances the activity of both enzymes. ${ }^{328}$ The epimerase, which is cloned and developed from porcine kidney, has limited solubility in the aqueous solution. This issue is recently overcome by the strain BT0453 cloned and isolated from Bacteroides thetaiotaomicron, which is a human gut symbiont. ${ }^{329}$ Bloemendal et al. prepared a continuous flow reactor by immobilising aldolase on immobead-150P to increase the process efficiency and conversion factor (up to $82 \%)$ of Neu5Ac. ${ }^{330}$

The company Glycom A/S, ${ }^{331}$ Denmark, which was acquired by the Royal DSM $^{332}$ in 2020, developed (in 2013) a two-step chemical and chemicoenzymatic method to prepare Neu5Ac $\cdot 2 \mathrm{H}_{2} \mathrm{O}$ by avoiding the epimerization reaction. In the first step, $N$-substituted-D-mannosamine was prepared from a chemical reaction of D-fructose with 3-4 equivalent excess of benzylamine via Heyns-rearrangement reaction followed by hydrogenation on palladium black catalyst. Then ManNAc was prepared by acetylation of $N$-substituted-D-mannosamine. The second step of this method was the usual chemicoenzymatic aldolase reaction between purified ManNAc and sodium pyruvate. The product Neu5Ac $\cdot 2 \mathrm{H}_{2} \mathrm{O}$ was washed, purified and crystallized several times with acetic acid and acetone. ${ }^{333}$

Whole cell biocatalysis is another prospective means to prepare Neu5Ac on a large scale. This concept was developed with an objective to avoid the tedious extraction of aldolase and epimerase enzymes as well as excessive use of exogeneous pyruvate. Whole cell biocatalysis directly uses a culture medium having an engineered strain of microorganism, which is unable to decompose Neu5Ac compared to natural strain but capable of in situ production of both enzymes necessary for the synthesis of Neu5Ac from a precursor (such as GlcNAc) and a carbon source (such as glucose or fructose or glycerol) in the culture medium. The engineered strain E. coli NAN8-71/pLT4 (ref. 334) and E. coli
SA-05/pDTrc-AB/pCDF-pck-ppsA ${ }^{335}$ could successfully produce 35 and $18.17 \pm 0.27 \mathrm{~g} \mathrm{~L}^{-1} \mathrm{Neu} 5 \mathrm{Ac}$, respectively, by whole cell biocatalysis.

\section{Timeline of regulatory affairs relevant to Sia in food and nutritional products}

Neu5Ac is the most abundant Sia in healthy humans and it is biosynthesised endogenously de novo in cytosol through an anabolic physiological process. It participates directly and indirectly in many physiological processes especially in the growth and development of neonatal and infants as discussed in Section 2. Either compromised biosynthesis or heavy loss of Neu5Ac at any stage of life can induce harmful effects to humans especially in their early stages of life. In this direction, a strong hypothesis exists to compensate the deficiency of Neu5Ac by an external dietary input, where the dietary Sia could be adsorbed in the human body by an action of neuraminidase in the small intestine and colon. ${ }^{336,337}$ The European Parliament and Council of European Union issued regulation EC/258/97 in January, 1997 on novel foods and food ingredients. ${ }^{338}$ Although, the presence of Neu5Ac in human breast milk and bovine milk derived infant formula was evident by several research groups, the Scientific Committee on Food of the Health and Consumer Protection Directorate-General, European Commission, in May 2003, did not find adequate scientific data to consider Neu5Ac as an essential component for infant and follow-on formula. ${ }^{339}$ Thus, Neu5Ac was not included in the global standard for infant formula composition recommended by the international expert group coordinated by the European Society for Paediatric Gastroenterology, Hepatology and Nutrition in 2005. ${ }^{340}$ In December 2006, the European Parliament and Council of European Union issued another regulation EC/1924/2006 on the nutrition and health

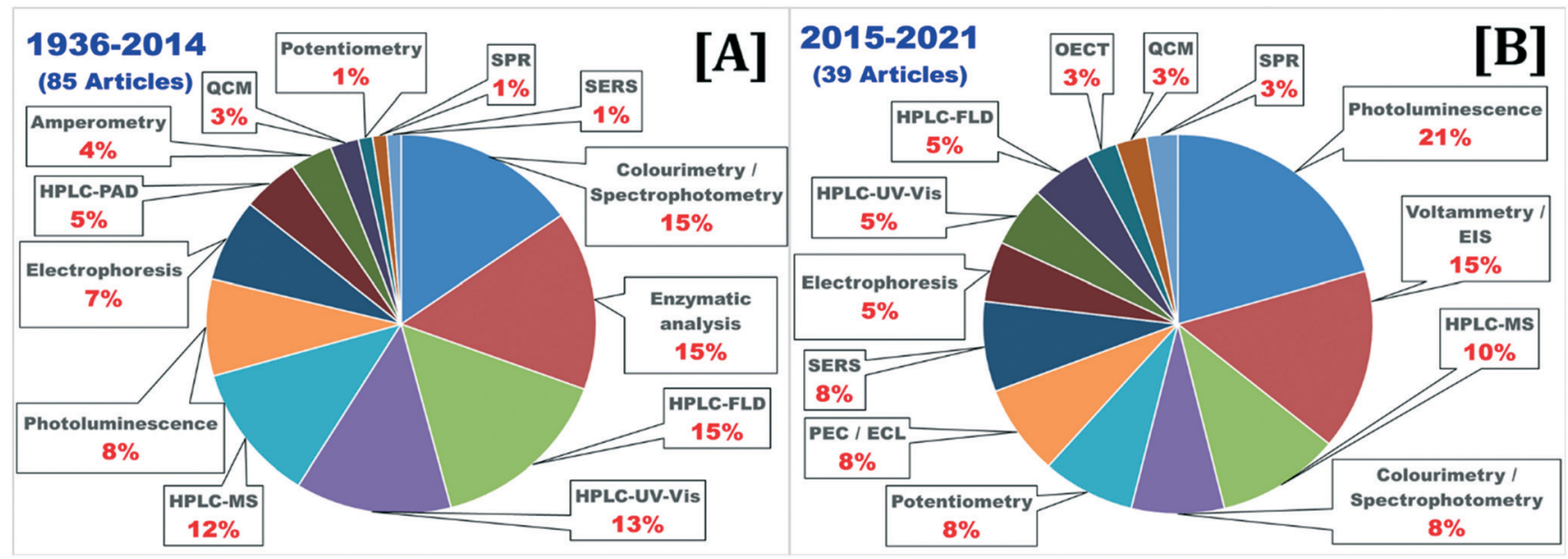

Fig. 5 Statistical analysis of different analytical methods for assay of Sia in biological and commercial food samples reported during [A] 1936-2014 and [B] 2015-2021 (September). 
claims on foods. Article 13 of this regulation deals with inclusion of compounds adding nutritional value to growth, development and other functions of the body, psychological benefits, slimming effects, etc. ${ }^{341}$ Following this, the European Commission requested the European Food Safety Authority (EFSA) panel on dietetic products, nutrition and allergies to provide an opinion addressing scientific substantiation of claims for including Sia in food products under Article 13 of the regulation EC/1924/2006 owing to its positive role in learning and memory developments (Question No. EFSA-Q-2008-2330 dated on 02/07/2009). The panel evaluated the contemporary relevant information provided by the Member States, but did not find any conclusive evidence of benefits by the dietary intake of Sia in relation to learning and memory. ${ }^{342}$ Hence, scientific opinion in 2014 on the essential composition of infant and follow-on formula was that although Sia was recognised as a source of energy and macronutrients originating from milk, it was not recommended for deliberate addition for uncertainty probability of sub-chronic dietary toxicity effects. ${ }^{141}$

Later in 2014, the sub-chronic dietary toxicity effect of Neu5Ac. $2 \mathrm{H}_{2} \mathrm{O}$ as prepared by Glycom A/S (briefly mentioned in Section 4.2) was tested on both male and female SpragueDawley rats for 13 weeks. No observed adverse effect level for the oral toxicity of Neu5Ac· $2 \mathrm{H}_{2} \mathrm{O}$ was determined as 974 (for male rats) and 1246 (for female rats) $\mathrm{mg} \mathrm{kg}$ (body weight) ${ }^{-1}$ day $^{-1}$. It was also found safe to use up to $2 \%$ level (i.e., 1895 $\mathrm{mg} \mathrm{kg}\left(\right.$ body weight ${ }^{-1}$ day $^{-1}$ ) of maternal dietary intake. Furthermore, this compound was assessed as non-mutagenic and non-genotoxic through the bacterial-reverse-mutation and in vitro mammalian cell micronucleus tests with samples taken from a 23 year old adult male. ${ }^{343}$ It was experimentally proven in 2014 that the supplement of Sia in the form of either free Sia, gangliosides, 3'-sialyllactose, cGMP or their combination during at least one stage of preconception, pregnancy and lactation could improve the health and development of the foetus and/or child. ${ }^{344}$

The progress of research on the health benefits of Sia, results on the lack of mutagenic, genotoxic and sub-chronic toxicity effect of Sia up to $2 \%$ dietary level and industrially viable production of Sia could set the scene for its industrial application. Hence, on September 24, 2015, Glycom A/S applied for the pre-market "Generally Recognized as Safe Exemption" approval for Neu5Ac- $2 \mathrm{H}_{2} \mathrm{O}$ (off-white crystalline powder; purity $\geq 97 \%$, stable for 36 months without any special package), which was structurally identical to the human milk's free Neu5Ac, to the office of Food Additive Safety in the Food and Drug Administration. ${ }^{345}$ The Food Safety Authority of Ireland made an initial assessment on that application in March 2016 and they did not identify any

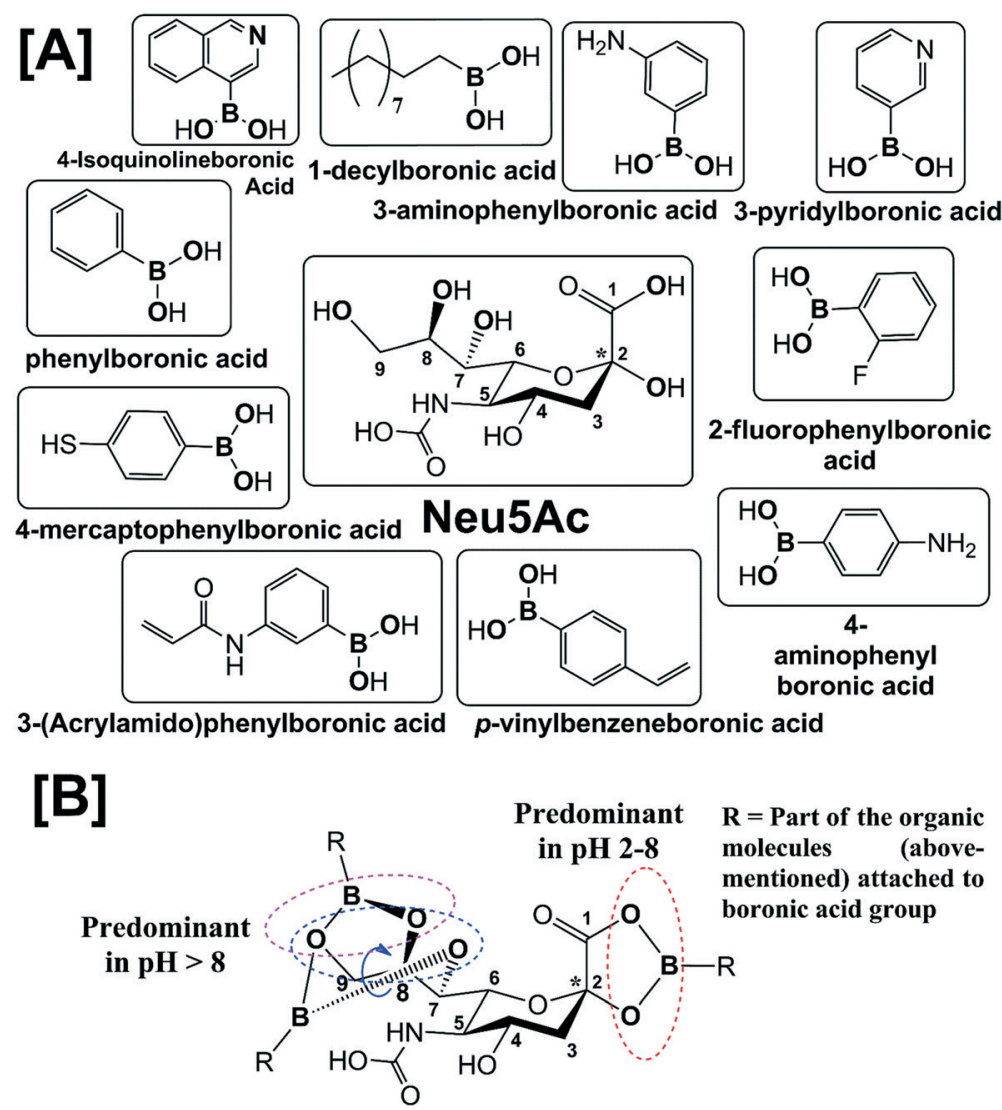

Fig. 6 [A] Types of boronic acid molecules used in different assays of Neu5Ac as discussed in Section 5. [B] Change of binding sites of boronic acid functional group at Neu5Ac in different $\mathrm{pH}$ ranges. 
safety concern in using of Neu5Ac. $2 \mathrm{H}_{2} \mathrm{O}$ in food products. ${ }^{346}$ Hence, Dossier 187 was issued in April 2016 by the advisory Committee for Novel Foods and Processes on the initial assessment. ${ }^{347}$ The EFSA Panel on dietetic products, nutrition and allergies (NDA) in June 2017 published a scientific opinion on the safety of synthetic Neu5Ac $\cdot 2 \mathrm{H}_{2} \mathrm{O}$ as a novel food pursuant to EC regulation 258/97. They found it a safe additive for foods and food supplements at proposed levels suitable for general population above 10 years of age. ${ }^{348}$ Following that opinion, the European Commission published a decision EU/2017/2375 on December 15, 2017 authorising use of Neu5Ac $\cdot 2 \mathrm{H}_{2} \mathrm{O}$ in the market as a food ingredient at recommended levels (Table 2) under regulation EC/258/97. ${ }^{41}$

As mentioned in Section 2.2.1, Sia-binding adhesin of Helicobacter pylori bacteria often targets cell surface gangliosides causing gastric adenocarcinoma. Hence, food ingredients/supplements having anti-adhesive agents have good commercial importance in terms of prevention and therapy of $H$. pylori related diseases. Although, bovine milk and chicken egg white are promising dietary sources of antiadhesive agents against $H$. pylori, commercial preventive and therapeutic supplements having lactoferrin, fat globule membrane fractions and 3'-sialyllactose sodium salt have high prospect in the food industry. ${ }^{349-351}$ In April 2019, Phipps et al. reported the toxicological safety studies of $3^{\prime}$ sialyllactose sodium salt ${ }^{352}$ and 6'-sialyllactose sodium salt, ${ }^{353}$ which were manufactured by Glycom A/S through microbial fermentation process with a genetically engineered strain E. coli K-12-DH1-MDO. They performed in vitro genotoxicity studies in addition to a 90 day-oral (gavage) toxicity study initiating test doses from $7^{\text {th }}$ day from birth of neonatal rats, which can equivalently represent the development of the reproductive system and central nervous system of new-born human infants. New-born infants consume $\sim 600 \mathrm{~mL}$ human milk per day and thus they can consume up to $<360 \mathrm{mg}$ per day of 3 '-sialyllactose and $\sim 72-$ $324 \mathrm{mg}$ per day of $6^{\prime}$-sialyllactose only from human milk. Therefore, it was proposed to be safer to include $0.2 \mathrm{~g} \mathrm{~L}^{-1}$ of $3^{\prime}$-sialyllactose ${ }^{352}$ and $0.4 \mathrm{~g} \quad \mathrm{~L}^{-1}$ of $6^{\prime}$-sialyllactose in reconstituted products. ${ }^{353}$ On August 21, 2019, Glycom A/S again applied for the pre-market "Generally Recognized as Safe Exemption" approval for 3'-sialyllactose sodium salt (GRAS Notice No. 880) (554 $^{3}$ and 6 -sialyllactose sodium salt (GRAS Notice No. 881) (155 $^{35}$ to office of Food Additive Safety in the Food and Drug Administration. The European Food Safety Authority has recently reviewed both the applications and concluded these materials as safe according to the novel food pursuant regulation EU/2015/2283 for using as food supplements, consumption of which should be avoided on the same day of consuming human and bovine milks, fermented milk-based products, curd cheese, etc. so as not to exceed daily intake limits of $3^{\prime}$-sialyllactose and 6'sialyllactose from other natural sources. ${ }^{356,357}$ As per the latest update available on DSM's website, GlyCare ${ }^{\mathrm{TM}}$ 3SL (ref. 358) and GlyCare ${ }^{\mathrm{TM}}$ 6SL (ref. 359) will be commercially available soon in the market.
Herrmann et al. recently reported a COGNIS study (a neurocognitive and immunological study of a new formula for healthy infants) on 220 healthy infants by feeding breast milk $(n=50)$, standard infant formula $(n=75)$ and nutrient enriched infant formula $(n=75)$ for 18 initial months since their birth. The enriched infant formula had a different composition of arachidonic acid (10.2-15.8 $\mathrm{mg} \mathrm{dL}^{-1}$ ), docosahexaenoic acid (10.2-11.2 $\mathrm{mg} \mathrm{dL}^{-1}$ ); gangliosides (9 $\mathrm{mg} \mathrm{\textrm {L } ^ { - 1 }}$ ); nucleotides (2.92-2.94 $\mathrm{mg} \mathrm{dL}^{-1}$ ) and sialic acid (105 $\mathrm{mg} \mathrm{\textrm {L } ^ { - 1 }}$ ) compared to the standard infant formula. This study revealed that the risk of respiratory tract and gastrointestinal infections was reduced by $30.2 \%$ and $32.5 \%$, respectively, in the infants consumed enriched formula compared to the infants consumed standard formula. The enriched infant formula showed almost similar benefits compared to human breast milk. ${ }^{360}$ Ma et al. have recently published an article stating that oral administration of Neu5Ac @ 0.1-0.3 mg per day to mice for 3 weeks increased the liver weight, gut villus volume, number of goblet cell; decreased activity of aspartate aminotransferase and changed the microbial composition and activity in gastrointestinal tract of mice. ${ }^{361}$ However, the effect of oral administration of Sia in human gastrointestinal tract is yet unreported.

\section{Analytical approaches to the assay of Sia in biological and commercial food samples}

The sections above demonstrate the commercial and biological relevance of Sia in relation to the immune system, the central nervous system, pregnancy and lactation, their role in bacterial and viral infections in addition to disease biomarkers. This clearly conveys the medical and commercial importance of accurate determination of Sia in human plasma, serum, urine, brain-fluid; commercial dairy products, infant formula; plants tissues and animal organs. It can be seen from Fig. 5[A] that a majority of assays of Sia up to 2014 was based on colourimetry-spectrophotometry (15\%), enzymatic analysis (15\%), high-performance liquid chromatography (HPLC) coupled with fluorescence detection (FLD) (15\%), UV-visible detection (UV-vis) (13\%) and massspectrometry (MS) (12\%). Assays with photoluminescence $(8 \%)$ and electrophoresis (7\%) were moderately studied and HPLC coupled with pulse amperometric detection (PAD), amperometry (4\%), quartz crystal microbalance (QCM) (3\%), potentiometry (1\%), SPR (1\%) and surface enhanced Raman spectroscopy (SERS) (1\%) were introduced in late 90s and early 2000s. In the last 7 years (i.e., 2015-2021), a significant thrust is evident in the development of photoluminescence (21\%) and electrochemical assay of Sia including voltammetry and electrochemical impedance spectroscopy (EIS) (15\%), potentiometry (8\%), photoelectrochemistry (PEC) and electrochemiluminescence (ECL) (8\%) and organic electrochemical transistor (OECT) (3\%) (Fig. 5[B]). The development of colourimetry-spectrophotometry (8\%), HPLC- 
UV-vis (5\%), HPLC-FLD (5\%) is significantly decreased, whereas shares of HPLC-MS (10\%), electrophoresis (5\%) and QCM (3\%) remain almost similar. A slight increase in interest of SPR (3\%) and SERS (8\%) assay methods has been observed in the last 7 years. Citing key observations of 124 landmark publications, this section will briefly discuss the evolution of different assays for Sia accounting for the limitations of preceding methods.

\subsection{Exploitation of preferential interaction between Sia and boronic acid for Sia's assay}

The boronic acid functional group, present in compounds known as "boronlectins", chemically mimics the action of lectins for high affinity towards the diol of saccharides such as glucose at high $\mathrm{pH}^{362}$ It is important to mention that many analytical methods exploited the preferential interactions of boronic acid functional group with Sia compared to other sugar molecules. Fig. 6[A] shows the molecules viz. 4-isoquinolineboronic acid, phenylboronic acid, 3-aminophenylboronic acid, 4-aminophenylboronic acid, 4-mercaptophenylboronic acid, $p$-vinylbenzeneboronic acid, 2-fluorophenylboronic acid, 1-decylboronic acid, 3-pyridylboronic acid, 3-(acrylamido)phenylboronic acid, etc. as mentioned in this review. The insights into specific interaction between Neu5Ac and phenylboronic acids (PBAs) are briefly discussed here. Otsuka et al. studied the complexes of free Neu5Ac and 3-(propionamido)phenylboronic acid in the $\mathrm{pH}$ range $4-10$ by ${ }^{1} \mathrm{H},{ }^{11} \mathrm{~B},{ }^{13} \mathrm{C}$ and ${ }^{15} \mathrm{~N}$ nuclear magnetic resonance (NMR) spectroscopies. The binding constant (at physiological $\mathrm{pH}$ i.e., 7.4) of 3-(propionamido)phenylboronic acid complex with free
Neu5Ac $\left(37.6 \pm 3.1 \mathrm{M}^{-1}\right)$ was found to be exceptionally high compared to that of galactose $\left(15.0 \pm 2.2 \mathrm{M}^{-1}\right)$, mannose (8.5 $\left.\pm 0.9 \mathrm{M}^{-1}\right)$ and glucose $\left(5.1 \pm 1.2 \mathrm{M}^{-1}\right)$. They proposed that Neu5Ac possessed favourable intramolecular hydrogen bonding interaction between the glycerol moiety (involving $-\mathrm{OH}$ groups of $\mathrm{C}-7, \mathrm{C}-8$ and $\mathrm{C}-9$ ) and amide group at $\mathrm{C}-5$ (Fig. 6[A]). The $-\mathrm{B}(\mathrm{OH})_{2}$ functional group of the compound was proposed to interact with the glycerol side chain $(\mathrm{C}-7, \mathrm{C}-$ 8) of Neu5Ac. ${ }^{363}$ Later, Djanashvili et al., performed ${ }^{11} \mathrm{~B},{ }^{13} \mathrm{C}$ and ${ }^{17} \mathrm{O}$ NMR spectroscopy of phenylboronic acid $\left(\mathrm{p} K_{\mathrm{a}} 10.05\right.$ \pm 0.03 ) complexes of glycolic acid, erythronic acid, threonic acid, Neu5Ac and $2 \alpha$-methyl derivative of Neu5Ac in the $\mathrm{pH}$ range 2-12 and found that the stability constant of phenylboronic acid complex (at $25^{\circ} \mathrm{C}$ and $\mathrm{pH}$ 7.4) of Neu5Ac $\left(11.6 \pm 1.9 \mathrm{M}^{-1}\right)$ is higher compared to that of glycolic acid $\left(1.6 \pm 0.2 \mathrm{M}^{-1}\right)$, erythronic acid $\left(4.4 \pm 0.5 \mathrm{M}^{-1}\right)$ and threonic acid $\left(11.4 \pm 1.5 \mathrm{M}^{-1}\right)$. They proposed, in contradiction to Otsuka et al.'s report, ${ }^{363}$ that phenylboronic acid interaction should be formed with the $\alpha$-hydroxycarboxylate unit (i.e., $\mathrm{C}-1$ and $\mathrm{C}-2)$ of Neu5Ac in the $\mathrm{pH}$ range 2-8 and with the glycerol tail (i.e., $\mathrm{C}-7 / \mathrm{C}-8$ and $\mathrm{C}-9$ ) of the side chain at $\mathrm{pH}>$ 8 , but the involvement of C-7, C-8 glycerol tail was unfavourable due to the erythro configuration (Fig. 6[B]). ${ }^{364}$ Since then, the actual mechanism of boronic acid and Neu5Ac complexation was unresolved for a long period. Meanwhile it was also reported that this complexation might not occur for bound Neu5Ac in physiological conditions. Recently, Nishitani et al. performed ${ }^{11} \mathrm{~B},{ }^{13} \mathrm{C} \quad \mathrm{NMR}$ spectroscopy and density functional theory simulations of phenylboronic acid complex with both $\alpha$ - and $\beta$-pyranoid structures of Neu5Ac and concluded that phenylboronic acid could bind with $\alpha$-hydroxycarboxylate unit (i.e., $\mathrm{C}-1$ and $\mathrm{C}-2$ )

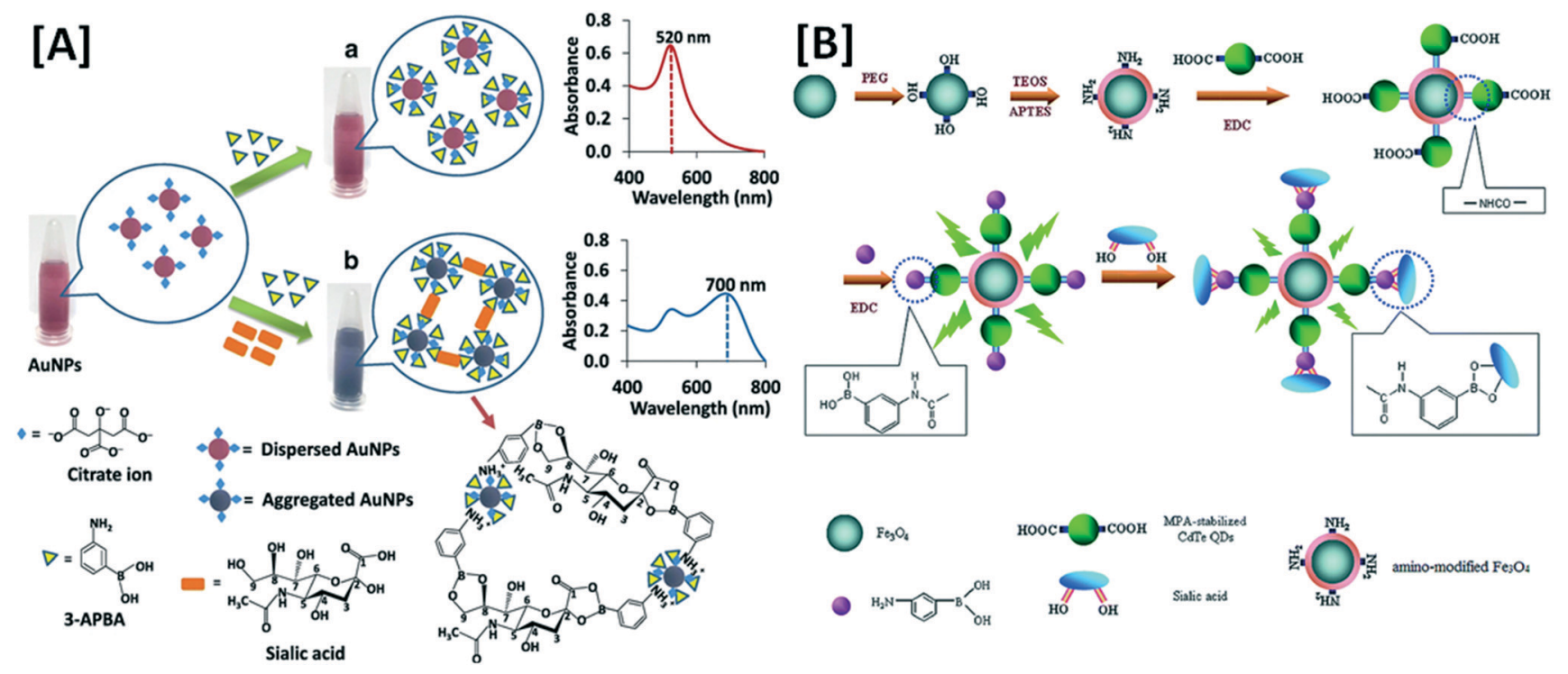

Fig. 7 [A] Ratio-metric spectrophotometric assay of Neu5Ac by using relative absorbances at 520 and $700 \mathrm{~nm}$ of the aqueous dispersion of citrate capped-gold nanoparticles (AuNPs) modified with 3-aminophenylboronic acid (3-APBA) before and after incubation with Sia (figures reproduced with permission from ref. 379) Copyright 2018 Springer Nature. [B] Fluorometric assay of Neu5Ac by covalently linking both $3-\mathrm{APBA}_{\text {and }} \mathrm{Fe} \mathrm{O}_{4}$ nanoparticles with CdTe fluorophores through 1-ethyl-3-(3-dimethylaminopropyl)carbodiimide (EDC) (figures reproduced with permission from ref. 388) Copyright 2016 The Royal Society of Chemistry. 
of $\beta$-pyranoid Neu5Ac, but could not interact with $\alpha$-pyranoid Neu5Ac, which predominantly exists in membrane bound glycans. Furthermore, the C-2 position is also not available for the phenylboronic acid complexation due to blockage by glycoside bond. Therefore, phenylboronic acid or similar compounds although preferentially bind free Sia, they often fail to selectively recognize Sia at termini cell-surface glycans. $^{365}$ The 4-isoquinolineboronic acid has recently showed highest binding affinity to Neu5Ac (formation constant $5390 \pm 190 \mathrm{M}^{-1}$ ) compared to common neutral saccharides (glucose, fructose, sorbitol, etc.), catechol, ribose5 -P, lactic acid and gluconic acid in aqueous phosphate buffer ( $\mathrm{pH} 3$ ) due to the formation of a ternary quaternary heterocyclic nitrogen containing 4-isoquinolineboronic acidNeu5Ac-phosphate complex unlike vicinal diol complexes. Thus, at neutral $\mathrm{pH}$, the affinity of 4-isoquinolineboronic acid to catechol, sorbitol, fructose became higher compared to Neu5Ac (formation constant $83 \pm 23 \mathrm{M}^{-1}$ ) and glucose (formation constant $8.9 \pm 1.4 \mathrm{M}^{-1}$ ). ${ }^{366}$

\subsection{Colourimetry-spectrophotometry}

Colourimetry and spectrophotometry were the dominant classical assays of Sia in early days. Blix, being one of the discoverers of Sia, used direct Ehrlich reagent (i.e., $5 \% \mathrm{w} / \mathrm{v}$ $p$-dimethylaminobenzaldehyde in $1: 1 \mathrm{v} / \mathrm{v}$ ethanol $(95 \% \mathrm{v} / \mathrm{v})$ and concentrated $\mathrm{HCl}$ ) to identify and quantify total Sia from a purple coloured product having absorbance maxima $\left(\lambda_{\max }\right)$ at $565 \mathrm{~nm} .{ }^{6}$ To avoid possible interference from pyrrole derivatives and alkali-treated mucopolysaccharides in direct Ehrlich assay, Klenk et al., the other pioneer of Sia, used modified Bial's method (i.e., orcinol, $\mathrm{FeCl}_{3}$, concentrated $\mathrm{HCl}, 100{ }^{\circ} \mathrm{C}$ ) producing a red-violet product having $\lambda_{\max }$ at $572 \mathrm{~nm}$; but this colourimetric assay of Sia could not avoid the interference of pentose, fructose, sorbose, 2-furaldehyde, uronic acids, keto-hexoses. ${ }^{4}$ The modified Dische's assay with $0.5 \%$ diphenylamine solution in glacial acetic acid containing $5 \% \mathrm{H}_{2} \mathrm{SO}_{4}$ was also used to quantify total Sia from a pink coloured supernatant having $\lambda_{\max }$ at $530 \mathrm{~nm}$, but it also suffered the interference from tryptophan and indole-3-acetic acid. $^{367,368}$ Svennerholm proposed resorcinol in $\mathrm{HCl}$ with catalytic amount of $\mathrm{CuSO}_{4}$ for colourimetric assay of total Sia at $\lambda_{\text {max }} 580 \mathrm{~nm}$, but encountered interferences from pentose, keto-hexoses and 2-deoxyhexose. ${ }^{369}$ Furthermore, the low molar absorption coefficients $(\varepsilon)$ in the range 5300-6900 $\mathrm{M}^{-1}$ $\mathrm{cm}^{-1}$ (for Neu5Ac) of those chromophores resulted into poor sensitivity of these colorimetric assays. The $\mathrm{HIO}_{4}$-resorcinol assay followed by extraction of the chromophore (having $\lambda_{\max }$ at $630 \mathrm{~nm}$ ) in tertiary-butanol significantly improved the sensitivity of colourimetric assay owing to higher value of $\varepsilon$ (27900 $\mathrm{M}^{-1} \mathrm{~cm}^{-1}$ for Nue5Ac). ${ }^{370}$ Furthermore, $10-60 \mu \mathrm{g}$ of total Sia was determined by spectrophotometry at $\lambda_{\max } 307$ $\mathrm{nm}$ in $0.01 \% o$-phenanthroline solution in $0.1 \mathrm{M} \mathrm{NaCl}(\mathrm{pH}$ 6.0). ${ }^{371}$ To separately quantify free, bound and total Sia, Spyridaki et al. used different $\mathrm{HIO}_{4}$ treatments (i.e. at $0{ }^{\circ} \mathrm{C}$ for $10 / 30 \mathrm{~min}$ for free/total Sia; at $37^{\circ} \mathrm{C}$ for $35 \mathrm{~min}$ for bound
Sia) before the acidic resorcinol treatment followed by extraction of the chromophore (having $\lambda_{\max }$ at $625 \mathrm{~nm}$ ) with tertiary-butanol. The linear dynamic range (LDR) and a limit of detection (LOD) for Neu5Ac were also improved to 20-200 $\mu \mathrm{M}$ and $1 \mu \mathrm{M}$, respectively, due to an increase of $\varepsilon$ to 35435 $\mathrm{M}^{-1} \mathrm{~cm}^{-1}$. 372

Warren and Aminoff independently made a breakthrough in the spectrophotometric assay of Sia in 1959. Warren incubated Sia for $30 \mathrm{~min}$ at $37{ }^{\circ} \mathrm{C}$ with $0.2 \mathrm{M} \mathrm{HIO}_{4}$ in $9 \mathrm{M}$ $\mathrm{H}_{3} \mathrm{PO}_{4}$ to produce aldehyde, which after removal of excess $\mathrm{HIO}_{4}$ by $10 \% \mathrm{NaAsO}_{2}$ in $0.5 \mathrm{M} \mathrm{Na}_{2} \mathrm{SO}_{4}+0.1 \mathrm{~N} \mathrm{H}_{2} \mathrm{SO}_{4}$, reacted with $0.6 \%$ thiobarbituric acid in $0.5 \mathrm{M} \mathrm{Na}_{2} \mathrm{SO}_{4}$ while heating at $100{ }^{\circ} \mathrm{C}$ for $15 \mathrm{~min}$. The chromophore extracted with cyclohexanone showed a red colour with $\lambda_{\max }$ at $549 \mathrm{~nm}(\varepsilon=$ $61000 \mathrm{M}^{-1} \mathrm{~cm}^{-1}$ for Nue5Ac; $50000 \mathrm{M}^{-1} \mathrm{~cm}^{-1}$ for Neu5Gc). ${ }^{373}$ Aminoff slightly modified this method by incubating Sia for $30 \mathrm{~min}$ at $37{ }^{\circ} \mathrm{C}$ with $0.025 \mathrm{M} \mathrm{HIO}_{4}$ in $0.125 \mathrm{~N} \mathrm{H}_{2} \mathrm{SO}_{4}$ at $\mathrm{pH}$ 1.2 to produce aldehyde, which after removal of excess $\mathrm{HIO}_{4}$ by $2 \% \mathrm{NaAsO}_{2}$ in $0.5 \mathrm{~N} \mathrm{HCl}$, reacted with $0.1 \mathrm{M}$ thiobarbituric acid in water (at pH 9.0) while heating at $100{ }^{\circ} \mathrm{C}$ for $15 \mathrm{~min}$. The red colour chromophore extracted with 1-butanol containing $5 \%(\mathrm{v} / \mathrm{v})$ of $12 \mathrm{~N} \mathrm{HCl}$ had $\lambda_{\max }$ at $549 \mathrm{~nm}$ and $\varepsilon$ 70000 and $51000 \mathrm{M}^{-1} \mathrm{~cm}^{-1}$ for Nue5Ac and Neu5Gc, respectively. ${ }^{374}$ These two methods were well adopted for several years by different research groups to determine Sia in biological samples owing to high sensitivity of assay by virtue of high $\varepsilon$ values. However, both methods were limited to only free Sia and suffered interference from 2-keto-3-deoxygluconic acid and hexoses. Furthermore, these methods failed to produce reliable values in the concentration range $0.1-1.0 \mu \mathrm{g}$ of Sia. The LDR of colourimetric assay of Sia was brought down to $225 \mathrm{ng}-3.09 \mu \mathrm{g}$ by modifying the thiobarbituric acid treatment followed by extraction steps of Aminoff. There, the aldehyde was allowed to react with $0.1 \mathrm{M}$ thiobarbituric acid (at pH 9.0) in a boiling water bath for $10 \mathrm{~min}$ followed by cooling in an ice bath for $2 \mathrm{~min}$. Then the reaction mixture was incubated in water bath at $37{ }^{\circ} \mathrm{C}$ for $2 \mathrm{~min}$ and the chromophore was extracted with 1-butanol containing 5.7\% $(\mathrm{v} / \mathrm{v})$ of $10.5 \mathrm{~N} \mathrm{HCl}^{375}$

Massamiri et al. developed a 3-methyl-2-benzothiazolone hydrazone based method avoiding acid hydrolysis pretreatment step. In this method, biological samples were shaken in 0.05-2.00 $\mathrm{mM} \mathrm{NaIO}$ in phosphate buffer saline (PBS) at $\mathrm{pH} 7.4$ in the dark for $15 \mathrm{~min}$ at $4{ }^{\circ} \mathrm{C}$. Then formaldehyde in equivalent amount to bound Sia was released in the solution. The supernatant was successively treated with $10 \%(\mathrm{w} / \mathrm{v}) \mathrm{ZnSO}_{4}$ in $1 \mathrm{~N} \mathrm{NaOH}$ for $5 \mathrm{~min}$ and 0.01 M 3-methyl-2-benzothiazolone hydrazone in phosphate buffer for $20 \mathrm{~min}$ at room temperature. Then $5 \%(\mathrm{w} / \mathrm{v}) \mathrm{FeCl}_{3}$ was added into the reaction mixture, vigorously shaken and left for $15 \mathrm{~min}$ before the absorbance was read at $625 \mathrm{~nm}$. However, this assay was not specific for Sia as 2-deoxyribose and hexoses interfered with the measurement and there was a chance of over-estimation of Sia due to the presence of endogenous formaldehyde. ${ }^{376}$ Later, in another spectrophotometric assay, Sia was reacted with $2 \%(\mathrm{w} / \mathrm{v})$ 
ninhydrin in a solution of DMSO-lithium acetate buffer (at pH 5.2) and glacial acetic acid on a boiling water bath for 10 min followed by cooling in ice-bath for $2 \mathrm{~min}$. Its chromophore showed $\lambda_{\max }$ at $470 \mathrm{~nm}\left(\varepsilon=66400 \mathrm{M}^{-1} \mathrm{~cm}^{-1}\right.$ for Nue5Ac). In this method the interference from L-tryptophan (having $\lambda_{\max }$ at $385 \mathrm{~nm}$ ), L-cystine (having $\lambda_{\max }$ at $485 \mathrm{~nm}$ ), L-proline (having $\lambda_{\max }$ at $510 \mathrm{~nm}$ ) and L-cysteine (having $\lambda_{\max }$ at $560 \mathrm{~nm}$ ) could be eliminated by using a small column of cation-exchange resin before the spectrometric assay. ${ }^{377}$ This method, with a little modification, has recently been used for the spectrophotometry-based flow batch analysis of Sia in the whole, semi-skimmed and skimmed milks. The mixture of Sia in sample/standard, $0.1 \mathrm{M} \mathrm{HCl}$ and $0.16 \mathrm{M}$ ninhydrin of equal volume was pumped into the batch flow chamber and mixed for $5 \mathrm{~min}$ at $75^{\circ} \mathrm{C}, \mathrm{pH} 1.6$ and the absorbance of the product was recorded at $470 \mathrm{~nm}$. The LDR and LOD of the method were reported as $1.0-10.0 \mathrm{mg} \mathrm{L}^{-1}$ and $0.239 \mathrm{mg} \mathrm{L}^{-1}$, respectively, for Nue5Ac with no significant interference from L-cystine, L-cystein, L-tryptophan and ammonia. ${ }^{378}$

No significant progress, except two recent works reported by Jayeoye et al., was observed in the development of spectrophotometric assays for the determination of Sia in present times. Aqueous suspension of gold nanoparticles (AuNPs) of average diameter $13 \mathrm{~nm}$ was prepared by citric acid reduction method and 3-aminophenylboronic acid was electrostatically assembled on the surface of AuNPs in $1 \mathrm{mM}$ phosphate buffer solution at $\mathrm{pH}$ 5.6. The dispersion of boronic acid modified AuNPs was of red wine colour having $\lambda_{\max }$ at $520 \mathrm{~nm}\left(\varepsilon=2.7 \times 10^{8} \mathrm{M}^{-1} \mathrm{~cm}^{-1}\right)$, which after incubation with $\mathrm{Sia}$ for $5 \mathrm{~min}$ at room temperature changed to blue with appearance of a new absorbance peak at $700 \mathrm{~nm}$ due to aggregation of AuNPs linked through Sia (Fig. 7[A]). Hence, the ratio of absorbances at $700 \mathrm{~nm}$ to $520 \mathrm{~nm}$ was used for spectrophotometric assay of Sia in the LDR $0.15-1.0$ $\mathrm{mM}$ and LOD $0.06 \mathrm{mM}$ without significant interference from glucose, fructose, galactose, mannose and disaccharide sucrose. This assay was successfully tested with known concentration of spiked Sia in the simulated human saliva. ${ }^{379}$ Later, the LOD of this assay was further improved to $35 \mu \mathrm{M}$ with two LDRs $80-250$ and $300-700 \mu \mathrm{M}$ by modifying the surface of AuNPs with dithiobis(succinimidylpropionate) through a ligand exchange mechanism at room temperature without changing the basic UV-vis absorbance profile of AuNPs having $\lambda_{\max }$ at $520 \mathrm{~nm}$. Again no significant interference was observed from glucose, mannose, lactose, fructose, sucrose, maltose and galactose in this assay, which was successfully tested with Sia spiked in the commercial human serum extracted from human male $\mathrm{AB}$ plasma. ${ }^{380}$

Here, we summarize the perspective of colourimetric and spectrophotometric assay of Sia. For this purpose, we have compared the LDR and LOD mentioned in either $\mathrm{M}$ or $\mathrm{g} \mathrm{L}^{-1}$ units in the above-mentioned publications considering $309.273 \mathrm{~g} \mathrm{~mol}^{-1}$ molar mass of Neu5Ac for interconversion of units, if required. The AuNPs-boronic acid based spectrophotometric method, although recently developed, could not produce lower LOD compared to classical dye- based colourimetric assay, but it minimized the interferences of other saccharides in the quantification of Neu5Ac. The lowest LOD reported for AuNPs-boronic acid based spectrophotometric assay was $35 \mu \mathrm{M}$ having two separate LDRs of $80-250$ and $300-700 \mu \mathrm{M} .^{380}$ On the other hand, acidic ninhydrin dye based flow-batched spectrophotometric assay could provide lowest LOD of $0.77 \mu \mathrm{M}$ (converted from $0.239 \mathrm{mg} \mathrm{L}^{-1}$ ) with narrow LDR of 3.23-32.3 $\mu \mathrm{M}$ (converted from 1.0-10.0 $\mathrm{mg} \mathrm{L}^{-1}$ ) without interference from L-cystine, L-cystein, L-tryptophan and ammonia. ${ }^{378}$ Therefore, enough scope exists to develop new ultrasensitive spectrophotometric assay of Sia in real biological and food samples.

\subsection{Photoluminescence}

Photoluminescence assay showed higher sensitivity compared to spectrophotometric or colorimetric assay of Sia. ${ }^{381,382}$ In the reaction of both bound and free Sia with $5 \mathrm{mM}$ 3,5diaminobenzoic acid in $0.125 \mathrm{~N} \mathrm{HCl}$ at $100{ }^{\circ} \mathrm{C}$ for $16 \mathrm{~h}$, a green fluorescent product having excitation and photoluminescence maxima at 405 and $510 \mathrm{~nm}$, respectively, was produced. While this fluorometric assay produced a good LDR of $0.15-2.0 \mu \mathrm{mol}$ of Sia per $50 \mu \mathrm{L}$ of 3,5-diaminobenzoic acid, it could not overcome strong interference of hexoses. Furthermore, dihydrochloride salt of 3,5-diaminobenzoic acid was commercially unavailable and thus had to be prepared from the commercially available precursors. ${ }^{381}$ Hammond followed the Aminoff's thiobarbituric acid process, but instead of measuring absorbance at $549 \mathrm{~nm}$, the 1-butanol extract was excited at 550 $\mathrm{nm}$. It emitted a fluorescence light having intensity peak at 565 $\mathrm{nm}$ suitable for fluorometric assay of Neu5Ac with LDR 10-250 ng (i.e., 32-800 pmol), but suffered interference of 2-deoxyribose. ${ }^{382}$ In contemporary times, another fluorometric assay was reported for the reaction of free Sia with pyridoxamine dihydrochloride, zinc acetate and pyridine in methanol at $70{ }^{\circ} \mathrm{C}$ for $45 \mathrm{~min}$. The excitation of the fluorophore with $395 \mathrm{~nm}$ light resulted to a photoluminescence having intensity peak at $470 \mathrm{~nm}$. This assay was suitable for the LDR 0.1-10.0 $\mu \mathrm{g}$ of free Nue5Ac, but $\alpha$-ketoacids interfered in the measurement. ${ }^{383}$ On the other hand, mild oxidation of free Sia by $1 \mathrm{mM} \mathrm{NaIO}_{4}$ in PBS (pH 7.2) at $4{ }^{\circ} \mathrm{C}$ for $15 \mathrm{~min}$ in the dark could quantitatively produce formaldehyde, which after removal of excess periodate by $2 \% \mathrm{NaAsO}_{2}$ in $0.5 \mathrm{~N} \mathrm{HCl}$, was allowed to incubate at $60{ }^{\circ} \mathrm{C}$ for $10 \mathrm{~min}$ with a mixture of acetylacetone, ammonium acetate, glacial acetic acid and distilled water. Free Nue5Ac was assayed from the fluorescence intensity of a lightyellow fluorophore (having excitation and luminescence maxima at 410 and $510 \mathrm{~nm}$, respectively) with the LDR of $2-10 \mu \mathrm{g}$ and a LOD of $0.1 \mu \mathrm{g}(0.3 \mathrm{nmol})$. o-Acetylated (at either C-8 or C-9 position) Sia could not be oxidized by $\mathrm{NaIO}_{4}$, thus $o$-deacetylation by $0.1 \mathrm{M} \mathrm{NaOH}$ should be a pre-treatment step for this assay, which suffered interference from endogenous pyruvate. ${ }^{384}$ In 2008, Matsuno et al. reported a comparatively less hazardous fluorometric assay for both free and bound Sia by oxidising with $10 \mathrm{mM} \mathrm{NaIO}{ }_{4}$ at $0{ }^{\circ} \mathrm{C}$ for $45 \mathrm{~min}$ to quantitatively produce formaldehyde followed by removal of 
excess periodate by reaction with $50 \mathrm{mM} \mathrm{Na} \mathrm{S}_{2} \mathrm{O}_{3}$ solution. The fluorophore, having excitation and luminescence maxima at 388 and $471 \mathrm{~nm}$, respectively, was produced from the reaction of formaldehyde with $4 \mathrm{M}$ ammonium acetate (at $\mathrm{pH}$ 7.5) and ethanolic solution of $0.1 \mathrm{M}$ acetoacetanilide for $10 \mathrm{~min}$ at room temperature. The LDR and LOD of this fluorometric assay of Nue5Ac were reported as $0.3-27 \mathrm{nmol}$ and $4 \mathrm{pmol}$, respectively. However, this photoluminescence assay suffered a strong interference from the glucose derived sorbitol, which could eventually produce two equivalents of formaldehydes. ${ }^{385}$ Alves et al. reported a solid-phase fluorometric assay of Nue5Ac with LDR and LOD $0.4-2000.0$ and $0.4 \mathrm{mg} \mathrm{L}^{-1}$, respectively, by incubating Nue5Ac with Eu(III)-coordinated silica modified by sodium thenoyltrifluoroacetonate in ethanol (carbonate buffer $\mathrm{pH}$ 6) for $3 \mathrm{~min}$ and measuring the fluorescence intensity at $615 \mathrm{~nm}$ for a photoexcitation at $345 \mathrm{~nm}^{386}$

Several photoluminescence assays based on phenylboronic acid linked established fluorophores viz. CdTe, fluorescein isothiocyanate, etc. exploited the preferential affinity of phenylboronic acid to Nue5Ac. Wang et al. covalently conjugated CdTe (excitation and fluorescence maxima at 330 and $502 \mathrm{~nm}$, respectively) with Sambucus nigra bark lectin, which specifically recognised Sia and increased the fluorescence intensity. The LDR and LOD of this assay were

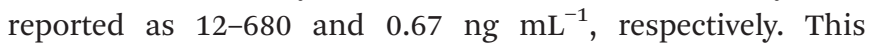
method was successfully implemented to quantify Sia in different egg products viz. whole egg, yolk and egg white powders, egg noodles, cake and steamed bun. ${ }^{387}$ Wang et al., on the one hand, prepared amine-functionalized magnetic $\mathrm{Fe}_{3} \mathrm{O}_{4}$ nanoparticles $\left(\mathrm{NH}_{2}-\mathrm{Fe}_{3} \mathrm{O}_{4}\right)$ by modifying polyethylene glycol 400 coated $\mathrm{Fe}_{3} \mathrm{O}_{4}$ nanoparticles with 3-aminopropyl triethoxysilane and tetraethylorthosilicate. On the other hand, they prepared fluorescent 3-mercaptopropionic acid capped CdTe quantum dots from a solution of $\mathrm{Cd}(\mathrm{II})$, NaHTe and 3-mercaptopropionic acid. Then they covalently linked 3-mercaptopropionic acid capped CdTe quantum dots on modified $\mathrm{Fe}_{3} \mathrm{O}_{4}$ nanoparticles to prepare the fluorescence probe for assay of Sia (Fig. 7[B]). The probe was incubated with Nue5Ac in $5 \mathrm{mM}$ PBS $(\mathrm{pH} 7.4)$ at $37{ }^{\circ} \mathrm{C}$ for $3 \mathrm{~h}$ and magnetically separated from the reaction mixture, washed and dispersed again in $5 \mathrm{mM}$ PBS (pH 7.4) for measuring the fluorescence intensity at $\sim 550 \mathrm{~nm}$. The fluorescence intensity of the probe was linearly quenched with the concentration of Nue5Ac resulting LDR and LOD 0.05-1.5 mg $\mathrm{mL}^{-1}$ and $16 \mu \mathrm{g} \mathrm{mL} \mathrm{m}^{-1}$ without any significant interference from $\mathrm{Na}^{+}, \mathrm{K}^{+}, \mathrm{Mg}^{2+}, \mathrm{Ca}^{2+}, \mathrm{Zn}^{2+}, \mathrm{Cu}^{2+}, \mathrm{Hg}^{2+}, \mathrm{Pb}^{2+}, \mathrm{Mn}^{2+}, \mathrm{Fe}^{3+}$, dopamine, glucose, galactose, mannose and fructose. Hence, this assay of Nue5Ac was validated with commercial infant formula. ${ }^{388}$ A comparatively simpler strategy was proposed by Hao et al., where aminophenylboronic acid was covalently linked to fluorescein isothiocyanate producing the fluorescence probe having excitation and luminescence intensity peak at 493 and $515 \mathrm{~nm}$, respectively, in Tris-HCl ( $\mathrm{pH}$ 7.40). The fluorescence intensity was completely quenched in the presence of $90 \mathrm{mg}$ reduced graphene oxide dispersion due to the Förster resonance energy transfer from fluorescence probe stacks to reduced graphene oxide. The fluorescence intensity was regained, and simultaneously reduced graphene oxide was precipitated out upon incubation of this dispersion with Nue5Ac at room temperature for $2-3 \mathrm{~h}$ owing to the higher affinity of aminophenylboronic acid modified fluorescein isothiocyanate to Nue5Ac than reduced graphene oxide. The LDR and LOD of this assay for Neu5Ac were reported as 0.55.0 and $0.044 \mathrm{mM}$, respectively. ${ }^{389}$

$\mathrm{Xu}$ et al. hydrothermally synthesised boronic-acid-functionalized carbon dots of average diameter $3.5 \mathrm{~nm}$ having luminescence maxima at $390 \mathrm{~nm}$ by heating the aqueous solution of 3-pyridylboronic acid at $160{ }^{\circ} \mathrm{C}$ for $8 \mathrm{~h}$ and used it for fluorometric assay of Nue5Ac by incubating at room temperature for 4 min with Neu5Ac in $10 \mathrm{mM}$ PBS $(\mathrm{pH}=5.5)$ from the decrease of fluorescence intensity linearly to concentration of Nue5Ac in the LDR 0.08-4.0 mM. This method could detect Nue5Ac down to 54 $\mu \mathrm{M}$ without any interference from glucose, mannose and galactose. Hence, this fluorometric assay was validated to quantify Nue5Ac in real human serum samples. ${ }^{390}$ Wang et al. have recently reported a similar methodology by using dispersion of fluorescent B-, $\mathrm{N}$-doped carbon dots of diameter 2-7 $\mathrm{nm}$ having excitation and luminescent maxima at 560 and $645 \mathrm{~nm}$ (quantum yield 8.56\% with respect to rhodamin $6 \mathrm{G}$ ), respectively, in $10 \mathrm{mM}$ glycine buffer (pH 5.5). B-, N-doped carbon dots were prepared from a mixture of 10:1 (w/w) o-phenylenediamine:3-aminophenylboronic acid (w:w 10:1) by hydrothermal synthesis at $160{ }^{\circ} \mathrm{C}$ for $6 \mathrm{~h}$. The fluorescence intensity of the dispersion at $645 \mathrm{~nm}$ increased upon incubation with Nue5Ac at $37{ }^{\circ} \mathrm{C}$ for $30 \mathrm{~min}$ because of the favourable complex formation between Sia and boronic acid groups present on the surface of B-, N-doped carbon dots. The LDR and LOD of Neu5Ac assay were reported as $0.02-1.0 \mathrm{mM}$ and 9.24 $\mu \mathrm{M}$, respectively, without any significant interference from urea, isoleucine, proline, galactose, maltose, $\mathrm{Na}^{+}, \mathrm{K}^{+}, \mathrm{Ca}^{2+}, \mathrm{NH}_{4}{ }^{+}$, $\mathrm{SCN}^{-}$and $\mathrm{Cl}^{-}$. Thus, the assay was validated for quantifying spiked known amount of Nue5Ac in simulated human saliva samples. ${ }^{391}$

Wang et al. have recently developed an indicatordisplacement photoluminescence assay for Sia by preparing fluorescein sodium dye anchored covalent organic framework, TpPa-1, as fluorescent indicator having excitation and luminescence maxima at 437 and $514 \mathrm{~nm}$, respectively. A hydrogel mould of the fluorescent indicator was prepared with sodium alginate and was immersed in $\mathrm{Cr}\left(\mathrm{NO}_{3}\right)_{3}$ solution for $2 \mathrm{~h}$ and then washed thoroughly. The luminescence of the fluorescent indicator was significantly quenched by $\mathrm{Cr}^{3+}$ by virtue of strong indicator-receptor interaction. The fluorescence intensity of the indicator hydrogel was partially regained in the presence of Sia in neutral water due to partial displacement of $\mathrm{Cr}^{3+}$ from the hydrogel matrix to the solution by the electrostatic attraction to negatively charged Sia present in the solution. The LDR and LOD of this fluorometric assay were reported as 10 $\mathrm{nM}-10 \mathrm{mM}$ (in logarithmic scale) and $7.08 \mathrm{nM}$, respectively, with no significant interference from $\mathrm{CaCl}_{2}, \mathrm{MgCl}_{2}, \mathrm{KCl}, \mathrm{NaCl}$, $\mathrm{NaHCO}_{3}$, glucose, L-proline and urea. An on-off-on sequential action of this method was validated for quantifying Sia in real human serum samples. ${ }^{392} \mathrm{Yu}$ et al. have recently reported the use of photoluminescent UiO-66- $\mathrm{NH}_{2} @ \mathrm{~B}(\mathrm{OH})_{2}$ (having excitation and luminescence maxima at 320 and $\sim 470 \mathrm{~nm}$, respectively) to determine Neu5Ac in the LDR 0.05-2.5 $\mathrm{mM}$ with 
a LOD of $0.025 \mathrm{mM}$ owing to the preferential interaction of the diol of Neu5Ac with the boronic acid functional group at $\mathrm{pH}$ 7.4. ${ }^{393}$ A molecular logic-gate has also been successfully designed by incorporating 4-carboxyphenylboronic acid in $\mathrm{Eu}(\text { atpt })_{1.5}($ phen $)\left(\mathrm{H}_{2} \mathrm{O}\right)_{n}$ metal-organic-framework to detect Sia from the fluorescence intensity ratio at $\lambda_{470} / \lambda_{614} \mathrm{~nm} .{ }^{394}$ Wang et al. prepared a fluorescent polydiacetylene based liposome type structure by UV-light assisted polymerization with three monomers viz. 10,12-pentacosadiynoic acidphenylboronic acid (as Sia recognising unit), 10,12-pentacosadiynoic acid-1,8-naphthalimide (as fluorescent unit with excitation and luminescence maxima at 420 and $535 \mathrm{~nm}$, respectively) and 10,12-pentacosadiynoic acid-ethyl acrylate with molar ratio $4.5: 1.0: 4.5$ in methylene chloride containing $10 \%$ methyl alcohol (v/v). The prepared liposome suffered from self-quenching fluorescence due to transfer of energy from 1,8-naphthalimide unit to polydiacetylene backbone. The pendent side chain configuration was disturbed in the presence of Sia-boronic acid complex and the original fluorescence of 1,8-naphthalimide was restored. This assay reported LDR up to $0.4 \mathrm{mM}$ with a LOD of $14 \mu \mathrm{M}$ with little spectral deformation in the presence of glucose, galactose and mannose. ${ }^{395}$ Yue et al. used 6-carboxyfluorescein (excitation and emission maxima at 494 and $520 \mathrm{~nm}$, respectively) tagged aptamer (5'-6carboxyfluorescein-TAGGGAATTCGTCGACGGAT-3) to quantify Neu5Ac in LDR 20-1000 nM with tolerable interference of Neu5Gc, KDN, glucose, sucrose and maltose. The aptamer tagged fluorophore lost photoluminescence after adsorbing on the dispersed graphene oxide in solution, but Neu5Ac brought the aptamers back into the solution due their preferential affinity resulting into the development of the photoluminescence of 6-carboxyfluorescein. ${ }^{396}$

Binding of different family members of Sia to lactosespecific lectin-peanut agglutinin slightly varies with respect to the core composition of binding domain Asp-Pro-Ala-Asp peptides. A panel consisting of 6 types of dipeptide combinations labelled with fluorescein (excitation and emission maxima at 470 and $514 \mathrm{~nm}$, respectively) could discriminate Neu5Ac, Neu5Gc, KDN, $N$-acetylneuraminic acid methyl ester, $\mathrm{N}$-acetyl-2,3-didehydro-2-deoxyneuraminic acid, 2,4,7,8,9-penta-OAc- $N$-acetylneuraminic acid methyl ester. ${ }^{397}$ Furthermore, the fluorescence intensity of pyrene-conjugatedhistidine (excitation and emission maxima at 330 and 385/ $410 \mathrm{~nm}$, respectively) decreased in the presence of Neu5Ac and 2,3'-sialyllactose due to hindrance in gelation, which usually occurred in the presence of other monosaccharides and sialic acid analogues. The fluorometric dynamics of gelformation of pyrene-conjugated-histidine can be used to recognise Neu5Ac in complex matrix. ${ }^{398}$ Neu5Ac significantly enhanced the fluorescence intensity (at $658.8 \mathrm{~nm}$ ) of phenylboronic acid functionalised squarylium cyanine dyes having shorter alkyl chain due to formation of J-aggregate (Nue5Ac: dye as $2: 1$ ) complex through multipoint interaction of dye with Neu5Ac compared to other monosaccharides. On the other hand, no such enhancement was observed by Neu5Ac for similar dyes having longer alkyl chain due to formation of $\mathrm{H}$-aggregate (Nue5Ac: dye as 1:1) complex similar to other monosaccharides. This method is useful to discriminate Neu5Ac in biological samples. ${ }^{399}$

Here, we summarize the perspective of photoluminescence assay of Sia. For this purpose, we have compared the LDR and LOD mentioned in either $\mathrm{M}$ or $\mathrm{g} \mathrm{L}^{-1}$ units in the abovementioned publications considering $309.273 \mathrm{~g} \mathrm{~mol}^{-1}$ molar mass of Neu5Ac for interconversion of units, if required. Most of the photoluminescence assays of Sia reported LDR within $\sim 20-5000 \mu \mathrm{M}$ with LOD $\sim 10-60 \mu \mathrm{M} .^{388-391,393}$ The solid-phase fluorometric assay could provide a wide LDR 1.3$6500 \mu \mathrm{M}$ with a LOD of $1.3 \mu \mathrm{M} .^{386}$ The ultra-sensitive $\mathrm{Cr}(\mathrm{III})$ displacement fluorometric assay with fluorescein sodium dye anchored TpPa-1 could provide a wide LDR of $10 \mathrm{nM}-10 \mathrm{mM}$ (although in logarithmic scale) with sufficiently low LOD (7.08 $\mathrm{nM}$ ) without interference from L-proline and urea. ${ }^{392}$ However, the fluorescent CdTe quantum dots modified with Sambucus nigra bark lectin could provide lowest LOD (2.1

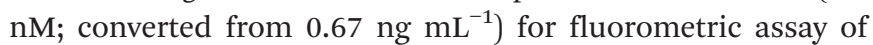
Sia with a moderately wide LDR $3.88 \mathrm{nM}-2.2 \mu \mathrm{M}$ (converted from 12-680 $\mathrm{ng} \mathrm{mL}{ }^{-1}$ ) in linear scale without interference in commercial egg products. ${ }^{387}$ Therefore, the research towards the development of ultrasensitive photoluminescence assay of Sia in real biological and food samples is open to further investigations.

\subsection{Enzymatic analysis}

The enzymatic reactions of Sia can produce secondary assayable chemicals viz. $\mathrm{H}_{2} \mathrm{O}_{2}$, reduced nicotinamide adenine dinucleotide $(\mathrm{NADH})$, etc. Exo- $\alpha$-sialidase can release Sia from the terminal residue of sialylated glycoproteins, glycolipids and oligosaccharides having $\alpha 2,3-, \alpha 2,6-$ and $\alpha-2,8$-glycosidic bonds (reaction 1). However, 4O-acetylated Sia is irresponsive to this enzyme. ${ }^{400}$ Sialic acid aldolase can reversibly convert Neu5Ac to ManNAc and pyruvate during incubation at $37^{\circ} \mathrm{C}$ and $\mathrm{pH} 7.1$ for $15 \mathrm{~min}$ (reaction 2). At equilibrium, the molar ratio of Neu5Ac:ManNAc: pyruvate attained 1:9:9 with an equilibrium constant $0.064 \pm 0.020 \mathrm{M}$ at $37^{\circ} \mathrm{C} .{ }^{401,402}$ The optimum $\mathrm{pH}$ and Michaelis constant of the reaction were reported as 7.1-7.3 and $3.3 \times 10^{-3} \mathrm{M}$, respectively. Neu5Ac almost completely cleaved at concentrations $<1 \mathrm{mM}$, but a significant amount of un-reacted Neu5Ac remained in the solution at equilibrium at higher concentrations. The enzymatic cleavage reaction could be stopped by increasing the temperature of the incubated solution to $100{ }^{\circ} \mathrm{C}$ for $2 \mathrm{~min}^{403}$ This enzymatic reaction is also equally effective for Neu5Gc producing $N$-glycolyl-D-mannosamine and pyruvate under similar condition but is ineffective for $O$-acetylated Sia. Therefore, Neu5Ac could be quantitatively assayed indirectly through either of four different options by measuring either ManNAc or pyruvate. 


$$
\begin{aligned}
& \text { Neu5Ac } \stackrel{\text { Sialic acid aldolase (EC:4.1.3.3) }}{\Longleftrightarrow} \text { ManNAc + Pyruvate } \quad \text { (Reaction 2) } \\
& \text { Pyruvate }+\mathrm{NADH} \stackrel{\text { Lactate dehydrogenase (EC:1.1.1.27) }}{\Longleftrightarrow} \text { Lactate }+\mathrm{NAD}^{+} \\
& \text {(Reaction 3) } \\
& \text { Pyruvate }+\mathrm{PO}_{4}{ }^{3-}+2 \mathrm{H}^{+}+\mathrm{O}_{2} \stackrel{\text { Pyruvate oxidase (EC:1.2.3.3); Thiamine pyrophosphate,Flavin adenine dinucleotide }}{\Longleftrightarrow} \text { Acetylphosphate }+\mathrm{CO}_{2}+\mathrm{H}_{2} \mathrm{O}_{2} \\
& \mathrm{H}_{2} \mathrm{O}_{2}+\text { Substrate (in Reduced Form) } \stackrel{\text { Horseradish peroxidase (EC:1.2.3.3) }}{\Longleftrightarrow} \mathrm{H}_{2} \mathrm{O}+\text { Substrate (in Oxidised Form) } \\
& \text { (Reaction 4) } \\
& \text { (Reaction 5) } \\
& \mathrm{ManNAc}+\mathrm{NAD}^{+} \stackrel{N \text {-acetylmannosamine-1-dehydrogenase (EC:1.1.1.233) }}{\Longleftarrow} N \text {-acetyl-D-mannosaminolactone }+\mathrm{NADH}+\mathrm{H}^{+} \\
& \text {(Reaction 6) } \\
& \text { ManNAc } \stackrel{N \text {-acetylglucosamine-2-epimerase (EC:5.1.3.8) }}{\rightleftharpoons} N \text {-acetyl-D-glucosamine }
\end{aligned}
$$$$
\text { (Reaction 7) }
$$$$
N \text {-acetyl-D-glucosamine }+\mathrm{O}_{2} \stackrel{N \text {-acetylhexosamine oxidase (EC:1.1.3.29) }}{\Longleftrightarrow} N \text {-acetyl-D-glucosaminate }+\mathrm{H}_{2} \mathrm{O}_{2}
$$

Option 1. The first option is to measure pyruvate by spectrophotometry or fluorometry through the auxiliary enzymatic reaction of lactate dehydrogenase (EC: 1.1.1.27) and NADH (previously known as reduced diphosphopyridine nucleotide) substrate. Lactate dehydrogenase enzymatically reduces pyruvate to lactate and at the same time, the coreactant $\mathrm{NADH}$ is oxidised to $\mathrm{NAD}^{+}$(previously known as oxidised diphosphopyridine nucleotide) (reaction 3). Lactate dehydrogenase solution has UV-B absorbance with maxima at $285 \mathrm{~nm}$, while NADH has both UV-C and UV-A absorbances with maxima at 250 and $340 \mathrm{~nm}\left(\varepsilon_{340}=6.22 \times 10^{3} \mathrm{M}^{-1} \mathrm{~cm}^{-1}\right)$. Furthermore, NADH exhibits blue colour fluorescence with broad luminescence peak $\sim 440-460 \mathrm{~nm}$ upon exciting with a light source at $340 \mathrm{~nm} .{ }^{404}$ Although $\mathrm{NAD}^{+}$has intrinsic UV-C absorbance with $\lambda_{\max }$ at $250 \mathrm{~nm}$, it does not absorb light above $300 \mathrm{~nm}^{405}$ Therefore, the concentration of pyruvate produced after the aldolase reaction can be assayed from the difference of peak intensities of absorbance (measured at 340 $\mathrm{nm}$ ) or fluorescence (measured at $446 \mathrm{~nm}$ ) of NADH just before and after the reaction with Lactate dehydrogenase. However, the endogenous pyruvate and enzymatic impurity viz. NADH oxidase interfere in this assay. ${ }^{406,407}$

Option 2. Pyruvate oxidase (EC: 1.2.3.3) quantitatively produces $\mathrm{H}_{2} \mathrm{O}_{2}$ from pyruvate in the presence of dissolved oxygen, inorganic phosphate, thiamine pyrophosphate and flavin adenine dinucleotide (reaction 4). The produced $\mathrm{H}_{2} \mathrm{O}_{2}$ can be measured spectrophotometrically from the concentration of oxidised form of an auxiliary substrate by the action of horseradish peroxidase (EC: 1.2.3.3). The frequently used auxiliary substrate include 4-aminoantipyrine along with 4-chlorophenol (probing at $505 \mathrm{~nm}$ ), ${ }^{408} \mathrm{~N}$-ethyl- $N$ (3-sulfopropyl)-3,5-dimethoxyaniline (probing at $590 \mathrm{~nm}$ ), ${ }^{409}$ $N$-ethyl- $N$-2-hydroxyethyl-3-toluidine, ${ }^{410} \quad 10$-acetyl-3,7dihydroxyphenoxazine (probing at $570 \mathrm{~nm}$ ), etc. (reaction 5).

Option 3. The first two options suffered from the interference of endogenous pyruvate and that could be eliminated by an
Option 4. $\mathrm{H}_{2} \mathrm{O}_{2}$ could be quantitatively produced by the successive enzymatic reactions of ManNAc with $\mathrm{N}$-acetylglucosamine-2-epimerase and $\mathrm{N}$-acetylhexosamine oxidase (EC: 1.1.3.29) in the presence of dissolved oxygen (reaction 7 and 8). ${ }^{409}$ Furthermore, ManNAc can also be measured down to $10 \mu \mathrm{g}$ by modified Elson and Morgan method (spectrophotometrically by using Ehrlich's reagent). ${ }^{412}$

The enzymatic assays of Sia are very specific and selective, but the high cost of purified enzymes and their stability in diverse sample conditions sometimes limit applications. Readers should be aware of the fact that except one publication, ${ }^{411}$ none of the above-mentioned enzymatic assay provided information about the LDR and LOD for Sia.

\subsection{Chromatography}

5.5.1 Chromatography with UV-vis detector (UV-vis). The research and development on the chromatographic assay of Sia started relatively later than colourimetric, spectrophotometric and enzymatic methods mentioned above. Svennerholm showed that Sia could be separated from complex biological matrix by an anion exchange resin, Dowex $2 \times 8$ in acetate form followed by assayed using spectrophotometric resorcinol method. ${ }^{413}$ Extending this concept, Krantz et al. reported in 1975 about the use of an automated anion exchange (by using Rexyn-201( $\left.\mathrm{Cl}^{-}\right)$resin in acetate form) chromatography coupled with Aminoff's spectrophotometric detection methodology for the quantification of Neu5Ac. The chromatographic peak area was found to be linear for 1.5-12.0 nmole of Neu5Ac. However, the retention time of Neu5Ac and Neu5Gc was found to be similar (i.e., $20 \mathrm{~min}$ ). ${ }^{414}$ On the other hand, Neu5Ac was silylated with $\mathrm{N}, \mathrm{O}$-bis(trimethylsilyl)trifluoroacetamide and quantified down to $8 \mathrm{ng}$ by gas-liquid chromatography using $2 \%(\mathrm{w} / \mathrm{w})$ OV-17 column, flame 
ionization detector and trans-stilbene as an internal standard. ${ }^{415,416}$ In contemporary times, Sia was identified by high-resolution mass-spectrometry after converting carboxyl and hydroxyl groups of Sia to methyl ester and tri-methyl-silyl derivatives, respectively. ${ }^{417}$ Silver et al. developed an isocratic HPLC method for quantification of Neu5Ac in the LDR 0.32-

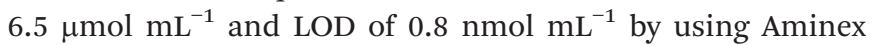
HPX-87 cation-exchange resin, UV detector (fixed at $206 \mathrm{~nm}$ ) and Neu5Gc as an internal standard. The peak height ratio of Neu5Ac (at retention time $7.8 \mathrm{~min}$ ) to Neu5Gc (at retention time $11.36 \mathrm{~min}$ ) was used in this HPLC-UV-vis assay. ${ }^{418}$ Shukla et al. compared the performance of cation-exchange resin (DC-6A) and anion-exchange resin (DA-X8-11) for the quantification of Neu5Ac, Neu5Gc and their $O$-acetylated derivatives. They found that the retention time (20.2 and 20.6 min for Neu5Ac and Neu5Gc, respectively), LOD (1 $\mu \mathrm{g}$ i.e., 3 nmol) and sensitivity of cation-exchanger with $0.4 \mathrm{M}$ sodium citrate buffer ( $\mathrm{pH}$ 6.0) were better compared to those (22.0 and $28.6 \mathrm{~min}$ for Neu5Ac and Neu5Gc, respectively; LOD $3 \mu \mathrm{g}$ i.e., $10 \mathrm{nmol}$ ) of anion-exchanger with $0.8 \mathrm{M}$ borate including $0.3 \mathrm{M}$ sodium acetate buffer ( $\mathrm{pH}$ 8.55). However, the resolution of Sia in the cation-exchanger was inferior compared to the anion-exchanger. ${ }^{419}$ They further modified the HPLC method to effectively separate and quantify $\mathrm{N}, \mathrm{O}$ acetylated derivatives of Sia including cytidine-5'monophospho-Neu5Ac, sialyloligosaccharides, neutral sugars and $\mathrm{N}$-acylmannosamines within $16 \mathrm{~min}$. Here the authors used Aminex A-28 anion-exchange resin, $0.75 \mathrm{mM} \mathrm{Na} \mathrm{SO}_{4}$ solution as mobile phase and UV detectors set at 195 and 215 $\mathrm{nm}$. The LOD of Sia by this HPLC-UV-vis assay was reported as $6 \mathrm{ng}$ (i.e., 20 pmol). ${ }^{420}$ Karamanos et al. used per-Obenzoylation (by using 10\% (w/v) benzoic anhydride and 5\% $(\mathrm{w} / \mathrm{v}) \mathrm{p}$-dimethylaminopyridine in pyridine) of Neu5Ac and Neu5Gc and eluted the mixture through reversed-phase HPLC (C18 column) by $67 \%$ (v/v) aqueous acetonitrile and measured Neu5Ac down to 30 pmol (i.e., $10 \mathrm{ng}$ ) by UV detector set at $231 \mathrm{~nm} .{ }^{421}$ Unland et al. performed Folch partition just before and after the benzoylation of hydrolysed Neu5Ac and Neu5Gc to separate and individually quantify both Neu5Ac and Neu5Gc down to $20 \mathrm{ng}$ through HPLC equipped with UV detector set at $230 \mathrm{~nm} .{ }^{422}$ Although HPLC provided better separation efficiency among the family members of Sia as well as from the other saccharides compared to other classical assays, the use of UV detector restricted the selective assay of Sia in complex biological matrix. Therefore, an effort was made to elute the chromophore produced from the reaction of Neu5Ac with Aminoff's reagent through HPLC column by $n$-butanol $5 \%(\mathrm{v} /$ v) in $12 \mathrm{~N} \mathrm{HCl}$ and setting the visible detector at $549 \mathrm{~nm}$ to assay Neu5Ac in picomole ranges. ${ }^{423}$ Recently, Ye et al. studied hydrophilic chromatography along with HPLC equipped with UV detector (at $205 \mathrm{~nm}$ ) to determine Sia in the LDR and LOD 5-100 and $0.2 \mu \mathrm{g} \mathrm{mL}{ }^{-1}$, respectively. The hydrophilic chromatographic column improved the retention behaviour of Sia on the HPLC column. ${ }^{29}$ Levonis et al. used a reversed-phase HPLC-UV-vis assay for separately quantifying
Neu5Ac and Neu5Gc in the LDR $0.05-0.40$ and $0.025-0.200$ $\mathrm{mM}$, respectively, in unprocessed bovine milk. They reported the LOD $5.5 \mu \mathrm{M}$ for Neu5Ac and $0.4 \mu \mathrm{M}$ for Neu5Gc. ${ }^{424}$ The interference of other organic compounds in the UV-vis detection compromise the specificity and sensitivity of HPLCUV-vis assay. Hence, most of the HPLC assays of Sia are based on the hyphenation of reversed-phase HPLC with either fluorescence detection (FLD), pulsed-amperometry detection (PAD) or mass-spectrometry detection (MS).

5.5.2 Chromatography with fluorescence detection (FLD). In HPLC-FLD assay, the Sia (post-hydrolysing samples) were tagged with the fluorophore molecules viz. 4'-hydrazino-2stilbazole (excitation and luminescence maxima at 415 and $550 \mathrm{~nm}$, respectively), ${ }^{425}$ malononitrile (excitation and luminescence maxima at 360 and $430 \mathrm{~nm}$, respectively), ${ }^{426,427}$ $o$-phenyldiamine dihydrochloride (excitation and luminescence maxima at 232 and $420 \mathrm{~nm}$, respectively), ${ }^{428}$ 1,2-diamino-4,5-methyleneoxybenzene (DMB, excitation and luminescence maxima at 369 and $453 \mathrm{~nm}),{ }^{429-433} 4-(N, N$ dimethylaminosulfonyl)-7-piperazino-2,1,3-benzoxadiazole (excitation and luminescence maxima at 450 and $560 \mathrm{~nm}$, respectively), ${ }^{434,435} \quad o$-phenylenediamine (excitation and luminescence maxima at 337 and $417 \mathrm{~nm}$, respectively), ${ }^{436}$ 4,5-dimethylbenzene-1,2-diamine (excitation and luminescence maxima at 379 and $432 \mathrm{~nm}$, respectively), ${ }^{437}$ etc. before passing through HPLC column followed by detection at the respective emission wavelength upon exposing the specific excitation light. The stilbazole method was free from the interference of $\alpha$-keto acids other than Sia with respect to specific retention time but suffered interference from pyruvate and two suspicious peaks just adjacent to the peak of Neu5Ac. Furthermore, 4'-hydrazino-2stilbazole derivative of Sia was found to be unstable in light and stable for maximum $2 \mathrm{~h}$ in the dark. ${ }^{425} \mathrm{~A}$ malononitrile method showed LDR 3-60 nmol and a LOD of $400 \mathrm{pmol}$ for both Neu5Ac and Neu5Gc and little interference from other carbohydrates, amino acids, amines, aldehydes, $\alpha$-keto acids and carboxylic acids. However, a few amino sugars, deoxy sugars and catecholamines could also form similar derivatives and interfered in the measurements. ${ }^{427}$ Later this method was also used for the determination of Neu5Ac with LDR 30-1000 $\mathrm{ng} \mathrm{mL}^{-1}$ and a LOD of $2 \mathrm{ng} \mathrm{mL}^{-1}$ in human serum. ${ }^{426}$ The LDR of $o$-phenyldiamine method was reported as 2-450 pmol of Neu5Ac, but accurate quantification of Sia by this method was required at least 5-6 blank runs due to the high self-fluorescence of the anthanilic acid. ${ }^{428}$ Hara et al. tagged Neu5Ac and Neu5Gc with DMB prior to HPLC pass and found $40 \mathrm{fmol}$ (i.e., $12 \mathrm{pg}$ ) LOD (S/N 2) for both Sia for $10 \mu \mathrm{L}$ sample volume. ${ }^{429}$ Further, with minor modification they could reach LOD 25 fmol (i.e., $7.7 \mathrm{pg}$ ) of Neu5Ac and $23 \mathrm{fmol}$ (i.e., $7.5 \mathrm{pg}$ ) of Neu5Gc (S/N 2) for the same volume of sample. ${ }^{430}$ They also extended this method for determination of $O$-acetylated Neu5Ac with LDR 57-192 fmol for $10 \mu \mathrm{L}$ sample volume. ${ }^{431}$ Stanton et al. hydrolysed the human pituitary gonadotropins viz. follitropin and lutropin in $0.1 \mathrm{M}$ trifluoroacetic acid at $80{ }^{\circ} \mathrm{C}$ for $1 \mathrm{~h}$ to 
release Neu5Ac, which was tagged with DMB followed by HPLC analysis with Neu5Gc as an internal standard and reported LDR of 3.5-28 pmol. ${ }^{432}$ Martín et al. used this DMB based HPLC-FLD assay for the quantification of Neu5Ac in commercial infant formula with the LDR 25-250 ng and a LOD of $3.71 \mathrm{ng}$ of Neu5Ac. ${ }^{433}$ However, DMB is highly light sensitive and an expensive reagent. It is only stable at room temperature for a couple of hours and must be stored below $-20{ }^{\circ} \mathrm{C}$ in dark in inert gas chamber for making it stable for at least $24 \mathrm{~h}$. Therefore, Orozco-Solano et al. developed a semi-automated methodology consisting of ultrasoundassisted hydrolysis, solid-phase extraction (for preconcentration and clean-up) and DMB derivatisation followed by insertion of sample to $\mu$-liquid-chromatography column equipped with fluorescence detector. The ultrasound shortened the time of DMB derivatisation to $20 \mathrm{~min}$ compared to $180 \mathrm{~min}$ required in conventional heating method and furthermore, separation and quantification of Sia were completed within $20 \mathrm{~min}$. The authors reported LDR 0.1-100 ng $\mathrm{mL}^{-1}$ (for Neu5Ac) and 0.5-500 ng mL $\mathrm{mL}^{-1}$ (for Neu5Gc). The LOD of Neu5Ac was found in the range 0.1-0.8 pg (i.e., $0.1-0.8 \mathrm{ng} \mathrm{mL}^{-1}$ ) in different samples. ${ }^{438}$ Ota et al. used 4-(N,N-dimethylaminosulfonyl)-7-piperazino-2,1,3benzoxadiazole fluorophore for simultaneous assay of Neu5Ac and its oxidised product ADOA by hydrophilic-interactionHPLC-FLD with LDR 576 fmol-2.0 nmol (for Neu5Ac) and 556 fmol-2.0 nmol (for ADOA). The LOD of this assay was reported as $173 \mathrm{fmol}$ (for Neu5Ac) and $167 \mathrm{fmol}$ (for ADOA) and they demonstrated first the presence of ADOA in human saliva. ${ }^{435}$ Recently, Kawasaki et al. slightly improved the LDR to $221 \mathrm{fmol}-1.5 \mathrm{nmol}$ (for Neu5Ac) and $44 \mathrm{fmol}-1.5 \mathrm{nmol}$ (for ADOA) as well as LOD to $67 \mathrm{fmol}$ (for Neu5Ac) and $13 \mathrm{fmol}$ (for ADOA). ${ }^{434}$ The derivatization of Neu5Ac with fluorescent molecule viz. O-phenylenediamine, followed by HPLC equipped with diode array detector was also used to determine Neu5Ac in the fat globule membrane of yak milk with LDR 50-500 $\mu \mathrm{g} \mathrm{mL}{ }^{-1}$ and LOD $10 \mu \mathrm{g} \mathrm{mL}{ }^{-1}$. ${ }^{436}$ The HPLC-FLD assay with 4,5-dimethylbenzene-1,2-diamine as tagged fluorophore was used to determine both free and total Neu5Ac and Neu5Gc in foetal bovine serum and glycoprotein fetuin. The authors reported the LOD of the assay as $6.00 \mathrm{pg}$ (for Neu5Ac) and $8.80 \mathrm{pg}$ (for Neu5Gc). ${ }^{437} \mathrm{UiO}-66-\mathrm{NH}_{2}$, which is a zirconium metal organic framework conjugated with 2-aminoterephthalic acid was used to tag Sia for reversed phase HPLC-FLD assay of Neu5Ac and Neu5Gc in the LDR 10-1000 pmol $\mathrm{L}^{-1}$ with LODs of 0.11 and $0.16 \mathrm{pmol}$, respectively. $^{439}$

5.5.3 Chromatography with pulsed-amperometric detection (PAD). Manzi et al. first reported a new separation process for Sia at neutral pH by using carbopac PA1 anionexchange column of pellicular resin followed by post-column addition of $0.3 \mathrm{M} \mathrm{NaOH}$ for PAD with potentiostatic pulse sequence of $0.05 \mathrm{~V}$ for $2 \mathrm{~s}$ followed by $0.6 \mathrm{~V}$ for $2 \mathrm{~s}$ and $-0.8 \mathrm{~V}$ for $5 \mathrm{~s}$ for a total duration of $1 \mathrm{~min}$ with measurable current in the range $100-300 \mathrm{nA} .{ }^{440}$ Although the potential for PAD is not very critical, the potential of the first pulse, which could oxidise the analyte of interest should be kept within 0.0-0.05 $\mathrm{V}$ for better $\mathrm{S} / \mathrm{N}$. The frequently used durations for the first, second and third potentiostatic pulses were $0.2,0.2$ and 0.4 $\mathrm{s}$, respectively. The objectives of the second and third pulses were oxidative cleaning and reductive reactivation of the electrode, respectively. ${ }^{441}$ Rohrer et al. performed a highperformance anion-exchange chromatography for simultaneously measuring Neu5Ac and Neu5Gc by using KDN as an internal standard. They reported LDR 10500 pmol and a LOD of 2 pmol for both Neu5Ac and Neu5Gc. However, they found that the accuracy of measurement was compromised with the age of the gold electrode, because over the time of experiment the upper layer of gold electrode was dissolved into the solution during the oxidative cleaning step. This recession of the detector electrode down to its original position increased the thickness of the thin-layer channel and decreased the velocity of fluid flow over the electrode leading to the compromised electrode response. ${ }^{442}$ Rocklin et al. addressed this issue and designed a new quadruplepotential waveform consisting of the potentiostatic pulse sequence of $0.1 \mathrm{~V}$ for $0.2 \mathrm{~s}$ for oxidative measurement followed by $-2.0 \mathrm{~V}$ for $0.01 \mathrm{~s}$ for reductive cleaning, $0.6 \mathrm{~V}$ for $0.01 \mathrm{~s}$ for activation through oxide growth and $-0.1 \mathrm{~V}$ for 0.05 s for generation of catalytic sites by oxide reduction. ${ }^{443}$

5.5.4 Chromatography with mass-spectrometry detection (MS). Shaw et al. first used HPLC-MS assay to determine Neu5Ac and Neu5Gc by using reversed phase HPLC column coupled with positive-ion mode electron-spray-ionization (ESI) source and $N$-acetylneuraminic acid methyl ester as an internal standard. The areas of the chromatographic peaks at retention time $5.88 \mathrm{~min}(\mathrm{~m} / \mathrm{z} 324)$ for the internal standard, $7.23 \mathrm{~min}(\mathrm{~m} / \mathrm{z} 326)$ for Neu5Gc and $8.00 \mathrm{~min}(\mathrm{~m} / \mathrm{z} \mathrm{310})$ for Neu5Ac were used to plot the individual calibration curves in the LDR $5-100 \mu \mathrm{g} \mathrm{mL}^{-1}$ with LOD of $0.5 \mathrm{ng}$ for Neu5Ac and $1.0 \mathrm{ng}$ for Neu5Gc. ${ }^{444}$ van der Ham et al. extended this technique to quantify free and total-Neu5Ac in human urine by using reversed phase HPLC coupled with negative mode ESI source, quadrupole MS/MS detector and $1,2,3-{ }^{13} \mathrm{C}_{3}$ Neu5Ac as an internal standard in isotope dilution method. Here, the negatively charged Neu5Ac (at $m / z$ 308.2) and internal standard (at $m / z$ 311.2) having same retention time (i.e., $2.6 \mathrm{~min}$ ), were fragmented by collision induced dissociation to daughter products $(\mathrm{m} / \mathrm{z} 87.0$ for Neu5Ac and 90.0 for $1,2,3-{ }^{13} \mathrm{C}_{3}$ Neu5Ac), whose relative intensities were used to measure the concentration of conjugated Neu5Ac in urine from the difference between concentrations of total and free Neu5Ac. The LDR of this assay was extended up to $7800 \mu \mathrm{mol} \mathrm{L}{ }^{-1}$ for both forms of Neu5Ac, whereas the LOD of total and free Neu5Ac was 1.7 and $0.3 \mu \mathrm{M}$, respectively. ${ }^{445}$ Allevi et al. modified the reversed phase column with 1-decylboronic acid, used both $1,2,3{ }^{13} \mathrm{C}_{3}$ Neu5Ac and 1,2,3${ }^{13} \mathrm{C}_{3}$ Neu5Gc for isotope dilution and replaced quadrupole MS/MS by quadrupole ion-trap MS/MS detector. This modification resolved the chromatographic peaks of Neu5Ac (at retention time $8.81 \mathrm{~min}$ ) and Neu5Gc (at retention time $7.21 \mathrm{~min}$ ) and showed LDR of $0.1-80 \mathrm{mg} \mathrm{L}^{-1}$ for both $\mathrm{Sia}^{446}$ 
A similar HPLC-MS assay was developed by Hammad et al. by using an aminopropyl-bonded silica phase column and negative-ion multiple-reaction-monitoring mode mass spectrometer for the simultaneous determination of Neu5Ac (LDR 0.1-3.0 ng $\mu \mathrm{L}^{-1}$; LOD $5 \mathrm{pg}$ ) and Neu5Gc (LDR 0.01-0.3 ng $\mu \mathrm{L}^{-1}$; LOD $1 \mathrm{pg}$ ) along with other monosaccharides derived from glycoprotein and blood serum. ${ }^{447}$ The reversed phase HPLC coupled with negative-ion mode ESI source and triple quad MS/MS detector successfully quantified Neu5Ac in edible bird nest. ${ }^{26}$ Shi et al. used isotope dilution hydrophilic interaction chromatography coupled with positive-ion mode ESI source and selective reaction monitor tandem MS/MS detector for assay of Neu5Ac and $N$-acetylmannosamine in human plasma with LDR 25.0-10 $000 \mathrm{ng} \mathrm{mL}^{-1}$ for Neu5Ac. ${ }^{448}$ The ultra-HPLC coupled with positive-ion mode ESI source and selective reaction monitor tandem quadrupole MS/MS detector were also used to determine Neu5Ac in the milk-based commercial infant formulas with $\mathrm{LDR} \quad 0.05-5.0 \mu \mathrm{g} \mathrm{mg} \mathrm{m}^{-1} .449$ However, the formation of $\mathrm{Na}^{+} / \mathrm{K}^{+} / \mathrm{NH}_{4}{ }^{+}$adduct with the $\mathrm{COO}^{-}$functional group of Sia sometimes limits the direct HPLC-MS assay.

Fernando et al. protected the carboxyl group of Neu5Ac with fluorophore 1,2-diamine-4,5-dimethoxyl benzene dihydrochloride (excitation and luminescence maxima at 369 and $453 \mathrm{~nm}$, respectively) and carried out the HPLC-MS assay coupled with scanning fluorescence detector, positive ion mode ESI source and quadrupole mass spectrometer with an internal standard $\alpha$-keto glutaric acid. The LOD of this assay was calculated as $7 \mathrm{pg}$ from the MS peak of fluorophore derivative of Neu5Ac at $m / z 442 .{ }^{450}$ Xia et al. extracted glycoprotein from the root of a Tibetan plant Potentilla anserina L. and released Neu5Ac and Neu5Gc from that glycoprotein by acid hydrolysis. They used 3-methyl-1-(naphthalen-2-yl)-1 $H$-pyrazol-5(4H)-one in ammonia solution to make pre-derivatives of the Sia and eluted the fluorophore derivatives of Sia through reversed phase HPLC coupled with UV detector (at $254 \mathrm{~nm}$ ) for measurement and both positive- and negative-ion mode ESI sources, ion-trap mass spectrometer for identification. They could produce LDR 0.25$10.0 \mu \mathrm{M}$ for both Neu5Ac and Neu5Gc with LOD 1.09 pmol (for Neu5Ac) and 1.06 pmol (for Neu5Gc). ${ }^{31}$ Hayama et al. prederivatised Neu5Ac and Neu5Gc with heptadecafluoroundecylamine in the presence of 4-(4,6dimethoxy-1,3,5-triazin-2-yl)-4-methylmorpholinium chloride and used fluorous-phase fluophase reversed-phase HPLC column coupled with positive mode ESI source and Qtrap tandem mass spectrometer to assay Neu5Ac and Neu5Gc in the LDR 1-100 $\mu \mathrm{M}$ (for Neu5Ac) and 0.05-10 $\mu \mathrm{M}$ (for Neu5Gc). ${ }^{451}$ The pre-derivatization with $\mathrm{HCl}-n$-butanol and reversed phase isotope dilution mass-spectrometry in positive-mode ESI source and tandem mass-spectrometer showed LDR and LOD 2-1000 and $0.42 \mu \mathrm{M}$, respectively, for Neu5Ac. ${ }^{452}$ Wang et al. followed a similar strategy i.e., isotope dilution of Neu5Ac with $1,2,3-{ }^{13} \mathrm{C}_{3}$ Neu5Ac, inclusion of ketodeoxynonulosonic acid as an internal standard followed by pre-derivatisation with 3,4-diaminotoluene and eluting through ultra-HPLC coupled with positive ion mode ESI source and multiple reaction monitoring with Qtrap MS/MS detector. They used the $\mathrm{m} / \mathrm{z}$ transition $396 \rightarrow 253$ at retention time $3.6 \mathrm{~min}$ for the assay of Neu5Ac with LDR 20.0-2.00 $\times 10^{4}$ $\mathrm{ng} \mathrm{mL}^{-1} \cdot{ }^{453}$ Priego-Capote et al. used derivatives of Neu5Ac and Neu5Gc with DMB and pre-concentrated by a solid-phase extractor (hysphere polymeric polydi-vinylbenzene resin) online coupled with reversed phase chromatography having both positive- and negative-ion mode ESI source and multiple reaction monitoring with QqQ MS/MS detector. They reported LDR $0.2-500 \mathrm{ng} \mathrm{mL}^{-1}$ for both the target analytes in urine and

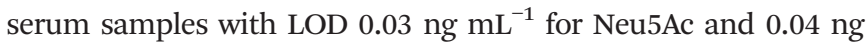
$\mathrm{mL}^{-1}$ for Neu5Gc. ${ }^{454}$ Yesilyurt et al. used DMB derivative of Neu5Ac for HPLC-MS assay in the egg jelly coat of the sea urchin Paracentrotus lividus by using capillary liquid chromatography coupled with positive ion mode ESI source and ultra-ion trap tandem MS/MS detector. ${ }^{455}$

In the present day, the HPLC-FLD and HPLC-MS/MS (with or without fluorescence tagging) methods are the most reliable techniques for ultra-sensitive assays of Sia in the clinical and commercial food samples. The DMB based HPLC-FLD assay could produce a moderately wide LDR of $0.32-320 \mathrm{nM}$ with a LOD of $0.32 \mathrm{nM}$ of Neu5Ac. ${ }^{438}$ On the other hand, a DMB derivative of Neu5Ac preconcentrated by hysphere polymeric polydi-vinylbenzene resin online coupled with HPLC-ESI-MS/MS analyser resulted to wider LDR of 0.65 nm-1.6 $\mu \mathrm{M}$ of Neu5Ac with the lowest reported LOD of 97 pM. $^{454}$

\subsection{Capillary electrophoresis}

Chen et al. used sialic acid aldolase for the enzymatic reaction of Neu5Ac to produce ManNAc, which was derivatised with the anionic fluorescent dye 8-aminopyrene1,3,6-trisulfonic acid (having excitation and luminescence maxima at 425 and $503 \mathrm{~nm}$, respectively) for the quantification of Neu5Ac by capillary electrophoretic separation followed by laser-induced fluorescence detection in the LDR 0.1-10 nmol. ${ }^{456}$ On the other hand, Neu5Ac was directly derivatised with 2-aminoacridone (having excitation and photoluminescence maxima at 429 and $529 \mathrm{~nm}$, respectively), but monitored at $260 \mathrm{~nm}$ after capillary electrophoresis. The LDR and LOD of this assay were reported as $10-120$ and $1 \mu \mathrm{M}$ of Neu5Ac, respectively. ${ }^{457}$ Dong et al. used only high-performance capillary electrophoresis (HPCE) coupled with UV detection at $195 \mathrm{~nm}$ for assay of Neu5Ac without any pre- or post-derivatisation. The reported the LDR and LOD for Neu5Ac as $0.064-6.40 \mathrm{mM}$ and $9.6 \mu \mathrm{M}$, respectively. ${ }^{458}$ Strousopoulou et al. derivatised Neu5Ac to per-O-benzoylated Neu5Ac by benzoic anhydride and quantified it with capillary zone electrophoresis coupled with diode-array detector fixed at $231 \mathrm{~nm}$. They reported the LDR and LOD of Neu5Ac as 5-5000 $\mu \mathrm{g} \mathrm{mL} \mathrm{L}^{-1}$ and $2 \mu \mathrm{M}$, respectively. ${ }^{459}$ Taga et al. developed a capillary electrophoresis assay featured with in-capillary sialidase digestion for the determination of Neu5Ac in sialoglycans and sialoglycoproteins. They introduced the samples into a running $50 \mathrm{mM}$ acetate buffer ( $\mathrm{pH}$ 5.0) containing exo- $\alpha$ - 
sialidase (of concentration $250 \mathrm{mU} \mathrm{mL}^{-1}$ ) from the cathodic end of the capillary and then applied $5 \mathrm{kV}$ for $20 \mathrm{~min}$ followed by $20 \mathrm{kV}$ for $5 \mathrm{~min}$ between two ends of the capillary. The authors achieved good linear response in the concentration range $0.025-10.0 \mathrm{mg} \mathrm{mL}^{-1}$ with a UV detector fixed at $200 \mathrm{~nm} .^{460}$

Ortner et al. developed an assay method for the simultaneous determination of Neu5Ac and Neu5Gc by capillary zone electrophoresis coupled with negative-ion mode ESI source and ion-trap MS detector. They reported LDR and LOD 10-100 and $2 \mu \mathrm{g} \mathrm{mL}^{-1}$, respectively, for both Sia released from the glycoproteins after acid hydrolysis. ${ }^{461}$ Zheng et al. oxidised Neu5Ac to $\beta$-formyl pyruvic acid by $\mathrm{HIO}_{4}-\mathrm{H}_{2} \mathrm{SO}_{4}$ treatment and then derivatised with electroactive 2-thiobarbituric acid. This derivatised Neu5Ac was assayed by sample-stacking capillary electrophoresis coupled with amperometric detection on a carbon disc electrode kept at $0.950 \mathrm{~V}$ vs. saturated calomel electrode. They reported the LDR and LOD as 2-200 and $0.5 \mu \mathrm{g}$ $\mathrm{mL}^{-1}$, respectively, with distinguishable signal of excess 2-thiobarbituric acid, 2-deoxy-D-ribose, fucose, glucose, formaldehyde, acetaldehyde and propaldehyde. ${ }^{462}$ Wang et al. developed a capillary electrophoresis method in conjugation with capacitively coupled contactless conductivity detection based on synergistic electrophoretic stacking technique of field- amplified sample injection and moving chemical reaction boundary. This method was found to be suitable for the assay of both Neu5Ac and Neu5Gc in the commercial milk and milk powder samples with LDR 0.02-2.0 $\mu \mathrm{g} \mathrm{mL}^{-1}$ (in milk) and 0.01$2.0 \mu \mathrm{g} \mathrm{g}^{-1}$ (in milk powder). The LOD of Neu5Ac and Neu5Gc in real samples was reported as $2.2 \mathrm{ng} \mathrm{mL}^{-1}$ (in milk); $1.7 \mathrm{ng} \mathrm{mL} \mathrm{m}^{-1}$ (in milk powder) and $2.0 \mathrm{ng} \mathrm{mL}^{-1}$ (in both milk and milk powder), respectively. ${ }^{463}$

In summarising electrophoretic analytical approaches to Sia quantitation, it could be conferred that although this method is not as ultra-sensitive as chromatographic assays, it is simpler to operate to quantify Sia in commercial food samples at moderately trace-levels. The pre-derivatization of Neu5Ac with fluorophores viz. 2-aminoacridone and benzoic anhydride followed by capillary electrophoresis could result in LDR of 10-120 and 16-16000 $\mu \mathrm{M}$, respectively, with LOD of 1 and $2 \mu \mathrm{M}$, respectively. ${ }^{457,459}$ The lowest possible LDR (65-6500 nM; converted from 0.02-2.0 $\mu \mathrm{g} \mathrm{mL}^{-1}$ ) and LOD (5.5 $\mathrm{nM}$; converted from $1.7 \mathrm{ng} \mathrm{mL}^{-1}$ ) for capillary electrophoretic assay of Sia was achieved by coupling with capacitively coupled contactless conductivity detection technique. ${ }^{463}$ Hence, there is scope for scientific research and development for ultra-sensitive electrophoretic assays of Sia in clinical samples and food products.

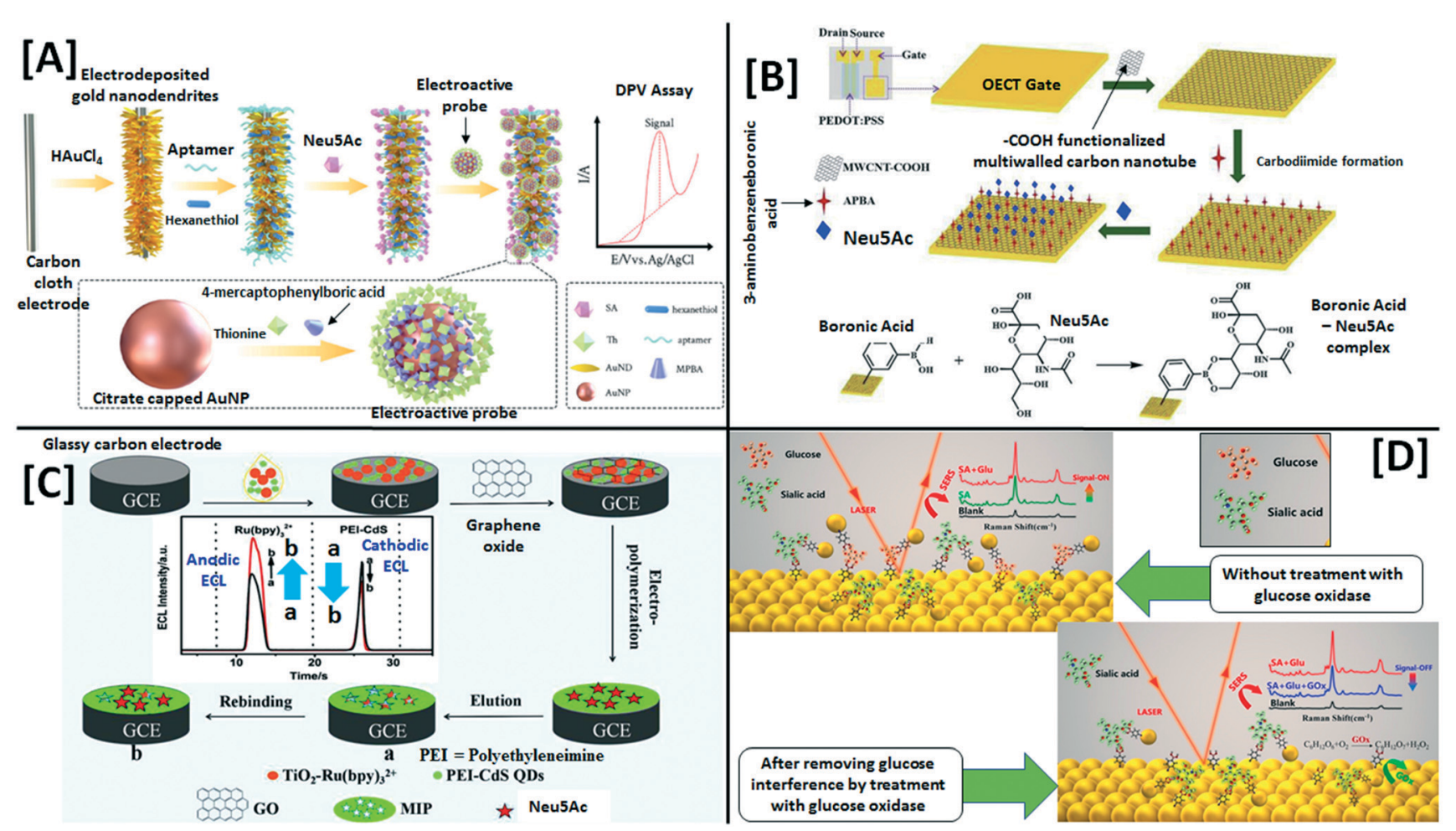

Fig. 8 [A] DPV assay of Neu5Ac by using aptamer coated gold nanodendrites electrochemical platform and thionine-4-marcaptophenylboronic acid electroactive probe (figures reproduced with permission from ref. 472) Copyright 2020 John Wiley and Sons. [B] Interaction of Neu5Ac with 3-aminobenzeneboronic acid covalently linked to carboxylic acid functionalized multiwalled carbon nanotubes placed on the gate of OECT (figures reproduced with permission from ref. 476) Copyright 2020 Elsevier. [C] Ratiometric MIP based ECL assay of Neu5Ac on glassy carbon electrode modified with $\mathrm{TiO}_{2}-\mathrm{Ru}(\mathrm{bpy})_{3}{ }^{2+}$ nanoparticles, polyethyleneimine (PEI) capped CdS quantum dots and graphene oxide (figures reproduced with permission from ref. 479) Copyright 2020 Elsevier. [D] SERS assay of Neu5Ac in the presence of glucose by using glucose oxidase pretreatment (figures reproduced with permission from ref. 488) Copyright 2020 American Chemical Society. 


\subsection{Electrochemistry and electroluminescence}

5.7.1 Amperometry. Amperometry was first used as only a detection technique of HPLC-PAD in 1998, but its first-step towards direct electrochemical assay of Sia happened 10 years later, when Marzouk et al., developed a prototype amperometric biosensor for Sia by utilising the concept of enzymatic reactions of Sia as discussed in the Section 5.4. They co-immobilized $4 \%(\mathrm{w} / \mathrm{v})$ sialic acid aldolase and $6 \%(\mathrm{w} / \mathrm{v})$ pyruvate oxidase by $0.9 \%(\mathrm{w} / \mathrm{v})$ glutaraldehyde in the presence of $9 \%(\mathrm{w} / \mathrm{v})$ bovine serum albumin in phosphate buffer $(\mathrm{pH}$ 6.3). They optimised aldolase/oxidase as 1.5; glutaraldehyde/ (aldolase + oxidase + albumin) as 0.05 and (aldolase + oxidase)/ albumin as 1.1 for best sensitivity of Sia and $15 \mu \mathrm{L}$ of this mixture in phosphate buffer $(\mathrm{pH}$ 6.3) was drop-dried over 25 $\mathrm{mm}$ diameter microporous polyester membrane. On the other hand, 1,3-diaminobenzene was electropolymerized as a thin layer on a platinum working electrode using a potentiodynamic method for protecting the platinum surface and the dryenzyme contained polyester membrane was fixed at the top of the modified platinum electrode by using a Teflon cap. This polyester membrane helped to reduce the interference, contain and protect the enzymes and increase the reproducibility of the sensor. The amperometry was recorded at $0.6 \mathrm{~V}$ vs. $\mathrm{Ag} / \mathrm{AgCl}$ reference electrode in $\mathrm{PBS}\left(\mathrm{pH} 6.3\right.$ and $37^{\circ} \mathrm{C}$ ) containing 0.5 $\mathrm{mM}$ thiamine pyrophosphate cofactor and Neu5Ac. The response was linear up to $200 \mu \mathrm{M}$ with a LOD of $10 \mu \mathrm{M}$ for Neu5Ac. ${ }^{464}$ Later, they extended this methodology by constructing an amperometric flow-through cell detector as an attachment of immobilized enzyme reactors to achieve better LDR and LOD as $10 \mu \mathrm{M}-5 \mathrm{mM}$ and $2 \mu \mathrm{M}$, respectively, for Neu5Ac. ${ }^{465}$ Fatoni et al. developed a porous conducting network of chitosan-grafted polyaniline cryogel for amperometric assay of Sia. They initially prepared polyaniline (a conducting polymer) from aniline in $0.1 \mathrm{M} \mathrm{HCl}$ by ammonium peroxodisulphate oxidation and dispersed it along with ferrocene (a redox mediator), bovine serum albumin and $5.0 \%$ glutaraldehyde (a cross-linker) in chitosan. Then that mixture was drop-casted on a multi-walled carbon nanotube modified gold electrode (to enhance the current) and immediately stored at $-20{ }^{\circ} \mathrm{C}$ overnight for cryogelation followed by thawing at $4{ }^{\circ} \mathrm{C}$ for $1 \mathrm{~h}$. Using this procedure, the authors prepared a porous cryogenic conducting polymer network on the working electrode that could host $2: 1$ sialic acid aldolase: pyruvate oxidase along with $5.0 \%$ glutaraldehyde in $0.1 \mathrm{M}$ phosphate buffer ( $\mathrm{pH}$ 7.0). Instead of probing $\mathrm{H}_{2} \mathrm{O}_{2}$, they probed the amperometric current of ferrocene redox reaction at $0.2 \mathrm{~V} v s$. $\mathrm{Ag} / \mathrm{AgCl}$ in $0.05 \mathrm{M}$ phosphate buffer $(\mathrm{pH} 8)$. The pyruvate oxidase converted pyruvate to acetylphosphate, $\mathrm{H}_{2} \mathrm{O}_{2}$ and $\mathrm{CO}_{2}$ (see section 5.4) and itself was regenerated by ferrocinium/ferrocene redox reaction. The amperometric assay was suitable to determine Neu5Ac in the LDR 0.025-15.0 mM with a LOD of $18 \mu \mathrm{M}$ without any significant interference of ascorbic acid, uric acid and pyruvic acid. This assay was successfully validated to quantify Sia in blood plasma samples. ${ }^{466}$
5.7.2 Potentiometry. A potentiometric assay of Sia was first reported by Zhou et al. They electrochemically reduced graphene oxide on glassy carbon electrode onto which 3-aminophenylboronic acid was electropolymerised to prepare a modified electrode capable of forming a stable complex with Neu5Ac interacting through the boronic acid functional group of 3-aminophenylboronic acid in 0.1 M PBS (pH 4.75). The open-circuit potential of the cell as a function of time changed in the presence of Neu5Ac compared to that in the absence of Neu5Ac. The change in the open-circuit potential of the modified electrode as a function of the concentration of Neu5Ac was found to be linear in the LDR 2 $\mu \mathrm{M}-1.38 \mathrm{mM}$ with a LOD of $0.8 \mu \mathrm{M}$. They successfully quantified the concentration of Sia in the human blood serum by this potentiometric assay. ${ }^{467}$ The same research group prepared a molecularly imprinted polymer (MIP) based electrode with 3-aminophenylboronic acid electropolymerised on the hydrophilic carbon cloth in the presence of NaF (a polymerization catalyst) and Neu5Ac complex of 3-aminophenylboronic acid as the template. The potentiometric assay was carried out in $0.1 \mathrm{M}$ PBS ( $\mathrm{pH} 4.8$ ) with an equilibration time of $100 \mathrm{~s}$. The change in the electrode potential of the MIP modified electrode was found to be linear over $40-440 \mu \mathrm{M}$ of Neu5Ac with a LOD of $0.5 \mu \mathrm{M}$. The authors successfully employed this potentiometric assay for measuring Neu5Ac levels in infant formulas. ${ }^{468}$ Huang et al. prepared a similar MIP, but on carboxylated multiwalled carbon nanotube casted glassy carbon electrode. They developed this potentiometric assay for the quantification of Neu5Ac in human serum samples with LDR $80 \mu \mathrm{M}-8.2 \mathrm{mM}$ and a LOD of $60 \mu \mathrm{M}$ in the physiological $\mathrm{pH}^{469}$ Shishkanova et al. showed that chemically bound 3-aminophenylboronic acid (through carbodiimide protocol) on electropolymerised 3-aminobenzoic acid could also be employed for the potentiometric assay of Neu5Ac with a sensitivity of $-38 \pm 6$ $\mathrm{mV}$ and a LOD of $21 \mu \mathrm{M} .{ }^{470}$

5.7.3 Voltammetry and electrochemical impedance spectroscopy (EIS). Sun et al. reported the differential pulse voltammetry (DPV) study for the determination of Neu5Ac on a paper-based electrode in the different parts of pea seedlings. They placed a piece of carbon tape on a conductive indium-tin-oxide coated glass plated and modified with multiwalled carbon nanotubes. The effective detection area (i.e., $4 \mathrm{~mm}$ diameter) of the modified electrode was treated under oxygen plasma for $1 \mathrm{~min}$. Then small samples (taken from different zones of pea seedling) were acquired with a sample punch and were directly placed on the effective electrode area one at a time. The sample was covered by a piece of filter-paper soaked with phosphate buffer $(\mathrm{pH}$ 7.5) and a clasp with platinum and $\mathrm{Ag} / \mathrm{AgCl}$ wires was placed on it to act as counter and reference electrodes, respectively. This voltammetric assay resulted to a LDR of $1-100 \mu \mathrm{M}$ of Neu5Ac. ${ }^{30}$ Liu et al. reported a non-enzymatic indicator displacement voltammetry assay of Neu5Ac in human blood and urine samples pre-treated using ion-exchange column. Aqueous dispersion of meso-tetra(4-carboxyphenyl)-porphine 
and graphene oxide $(1: 2 \mathrm{w} / \mathrm{w})$ was drop-casted on the glassy carbon electrode and dopamine was covalently linked on it by the carbodiimide route. Then 2 -fluorophenylboronic acid was allowed to be adsorbed on the electrode surface owing to the interaction of the boronic acid functional group with the catecholamine dopamine. A DPV scan of the dopamine modified electrode in $0.1 \mathrm{M}$ PBS ( $\mathrm{pH}$ 7.0) showed an anodic peak at $0.25 \mathrm{~V}$ corresponding to oxidation of dopamine. After modification with 2-fluorophenylboronic acid, the anodic current at $0.25 \mathrm{~V}$ decreased and a new peak appeared at $0.6 \mathrm{~V}$ corresponding to the oxidation of an ester boronic aciddopamine complex. In the presence of Neu5Ac in the electrolyte solution, the anodic peak at $0.6 \mathrm{~V}$ disappeared and the anodic current at $0.25 \mathrm{~V}$ increased due to the preferential bonding of 2-fluorophenylboronic acid with Neu5Ac in the solution compared to the diol unit of dopamine present on the electrode surface. The DPV peak current at $0.25 \mathrm{~V}$ proportionally increased with the concentration of Neu5Ac in the range $0.1-7.5 \mathrm{mM}$ with a LOD of $28.5 \mu \mathrm{M}$. This voltammetric assay suffered significant interference from ascorbic acid, glucose and uric acid and thus samples were required to be pre-treated with an ion-exchange column. ${ }^{471}$ Lv et al. reported an aptamer based voltammetric sensor for the determination of Sia in hospital acquired human blood samples (Fig. 8[A]). Carbon cloth electrode was electrochemically modified with gold nanodendrites and incubated in the solution of aptamer sequence (i.e., TCCCT ACGgC GCTAA CCGAT AgGTG TAGCG TGgGg CACAT GTTCG CGCCA CCGTG CTACA AC) of Sia for $12 \mathrm{~h}$ at room temperature. The non-specific binding sites of this aptasensor base were blocked by 1-hexanethiol. On the other hand, an electroactive probe was prepared by 4-mercaptophenylboric acid and thionine modified and citrate-capped AuNPs. Then the aptasensor base was incubated in the aqueous solution of Neu5Ac in $0.1 \mathrm{M}$ phosphate buffer $(\mathrm{pH} 4.5)$ for $3 \mathrm{~h}$ at room temperature followed by incubation with the electroactive probe in the same buffer for $5 \mathrm{~h}$. Finally, Neu5Ac was assayed indirectly from the equivalent cathodic peak of thionine by DPV through potential scan from $0.4 \mathrm{~V}$ to $-0.4 \mathrm{~V}$ in $0.1 \mathrm{M}$ phosphate buffer ( $\mathrm{pH} 4.5$ ) in the LDR $0.1-440 \mu \mathrm{M}$ with a LOD of $0.08 \mu \mathrm{M} .{ }^{472}$ Hai et al. synthesised pyridylboronic acid to specifically bind Sia in lower $\mathrm{pH}$ (5-6) and used it along with the poly-3,4-ethylenedioxythiophene to determine Neu5Ac in the LDR 0.1-3.0 $\mathrm{mM}$ with a LOD $0.1 \mathrm{mM}$ by using ferri-/ferrocyanide as a redox probe for the DPV assay. ${ }^{473}$ Ding et al. reported an electrochemical impedance spectroscopy (EIS) based stimuli-responsive polymer electrode hyphenated with in vivo microdialysis for electrochemical assay of Neu5Ac for Alzheimer disease in live rat brain microdialysates. They electrochemically deposited gold nanoflowers on a screenprinted carbon electrode and prepared a copolymer consisting of $\mathrm{N}$-isopropylacrylamide, acryloyl-3amidophenylboronic acid, acryloyl-3,5-bis(trifluoromethyl)phenylthiourea and $S$-benzyl dithiobenzoate with the mole ratio of $170: 15: 15: 2$ through a reversible addition- fragmentation chain transfer polymerization mechanism. Here, $S$-benzyl dithiobenzoate anchored the copolymer on the gold nanoflowers, the amide group of poly- $(N-$ isopropylacrylamide) made hydrogen bonds with the $\mathrm{N}-\mathrm{H}$ functionality of acryloyl-3,5-bis(trifluoromethyl)phenylthiourea and $\mathrm{O}-\mathrm{H}$ functionality of acryloyl-3amidophenylboronic acid provided a gated-channel polymeric network to the approach of the redox-probe (i.e., $\left[\mathrm{Fe}(\mathrm{CN})_{6}\right]^{3-1}$ ${ }^{4-}$ ) towards the working electrode surface. In the presence of Neu5Ac in the assay electrolyte, the hydrogen bond between poly-( $N$-isopropylacrylamide) and acryloyl-3amidophenylboronic acid became weaker due to the higher affinity of Neu5Ac towards the boronic acid functional group and the polymeric network became more open towards the passage of the redox-probe to/from electrode surface. The authors used $0.1 \mathrm{M}$ artificial cerebrospinal fluid buffer solution containing $\left[\mathrm{Fe}(\mathrm{CN})_{6}\right]^{3-/ 4-}$ redox probe and EIS assay was carried out at $0.14 \mathrm{~V}$ with a sine potential perturbation of $5 \mathrm{mV}$ amplitude and frequency range $0.01-10^{5} \mathrm{~Hz}$. The charge-transfer-resistance linearly decreased with the concentration of Neu5Ac in the range $1 \mathrm{pM}-10 \mu \mathrm{M}$ with a LOD of $0.4 \mathrm{pM}$ without any significant interference from glucose, mannose, galactose, fucose, xylose, fructose, $\mathrm{K}^{+}, \mathrm{Na}^{+}$, $\mathrm{Ag}^{+}, \mathrm{Ca}^{2+}, \mathrm{Mg}^{2+}, \mathrm{Zn}^{2+}, \mathrm{Cu}^{2+}, \mathrm{Co}^{2+}, \mathrm{Fe}^{2+}, \mathrm{Mn}^{2+}, \mathrm{Ni}^{2+}, \mathrm{Cd}^{2+}, \mathrm{Fe}^{3+}$, $\mathrm{Al}^{3+}$, amino acids (Glu, Gly, Phe, Met, Val, Cys, His, Iso, Lys, Leu, Tyr), ascorbic acid, uric acid, dopamine, lactate, 3,4dihydroxyphenylacetic acid and 5-hydroxytryptamine. ${ }^{474}$ Broncová et al. electropolymerized 3,4-diaminobenzoic acid on a platinum electrode and covalently anchored 3-aminophenylboronic acid by a two-step carbodiimide modification. Authors performed EIS assay in the frequency range $0.1 \mathrm{~Hz}-100 \mathrm{kHz}$ at $0 \mathrm{~V}$ with an amplitude of $10 \mathrm{mV}$ in $0.04 \mathrm{M}$ Britton-Robinson buffer ( $\mathrm{pH}$ 7.0) and found that the difference between polarization and solution resistances linearly varied with the concentration (in logarithmic scale) of Neu5Ac in range $25 \mu \mathrm{M}-0.998 \mathrm{mM}^{475}$

5.7.4 Organic electrochemical transistor (OECT). Chen et al. have recently reported the assay of Sia in human serum by an OECT. It was fabricated by coating Cr (of 10 $\mathrm{nm}$ thick) and $\mathrm{Au}$ (of $100 \mathrm{~nm}$ thick) layers on a glass plate followed by photolithographic patterning (Fig. 8[B]). Then poly-(3,4-ethylenedioxythiophene) doped with poly-(styrene sulfonate) along with 5\% glycerin and 5\% dimethyl sulfoxide $(\mathrm{V} / \mathrm{V})$ were spin-coated on that platform to form a conducting channel between drain and source. On the other hand, carboxylic acid functionalized multiwalled carbon nanotubes were drop-casted on the gate followed by covalent immobilization of 3-aminobenzeneboronic acid via carbodiimide formation. Then Neu5Ac in $0.01 \mathrm{M}$ PBS ( $\mathrm{pH}$ 7.4) was incubated on the OCET for $10 \mathrm{~min}$ at roomtemperature and the drain-source current was recorded for $300 \mathrm{~s}$ at $0.9 \mathrm{~V}$ gate voltage and $50 \mathrm{mV}$ drain voltage compared to source, which was effectively grounded. The current response was found to be linear in the 0.1-7.0 $\mathrm{mM}$ concentration range of Neu5Ac without any significant interference from glucose, mannose, lactose, fructose, 
sucrose, maltose, galactose, ribose, dopamine, ascorbic acid and uric acid. The authors successfully used this assay to quantify Neu5Ac in the serum samples collected from the lung cancer patients and healthy people. ${ }^{476}$

5.7.5 Photoelectrochemical and electrochemiluminescence (ECL). Wang et al. have recently developed a photoelectrochemical assay of Sia. They prepared a composite polymer from poly-[(9,9-di- $n$-octyfluorenyl-2,7-diyl)alt-(benzo[2,1,3]thiadia-zol-4,8-diyl)], poly-(styrene-co-maleic anhydride) and photosensitizer tetraphenylporphyrin mixed in the weight ratio $20: 4: 1$. Then the composite polymer was mixed with equal amount of rutile $\mathrm{TiO}_{2}$ and a monoclonal antibody was anchored to $\mathrm{TiO}_{2}$-composite polymer mixture. On the other hand, a glassy carbon electrode was modified with fullerene to increase the electrochemical current response and successively that was modified with AuNPs to chemically anchor 4-mercaptophenylboronic acid for the recognition of Sia. Then, Neu5Ac was incubated on the modified electrode surface for $40 \mathrm{~min}$ at room temperature in 0.1 M PBS (pH 7.4) and the Neu5Ac modified electrode was allowed to react with the monoclonal antibody anchored $\mathrm{TiO}_{2}$-composite polymer mixture by incubation for another $40 \mathrm{~min}$ at room temperature. The photocurrent (recorded in the potential range $0.5-0.6 \mathrm{~V} v s$. $\mathrm{Ag} / \mathrm{Ag} \mathrm{Cl}$ reference electrode) and the temperature (recorded upon laser irradiation at 808 $\mathrm{nm}, 1.0 \mathrm{w} \mathrm{cm}{ }^{-2}$ ) of the system linearly increased with concentration (in logarithmic scale) of Neu5Ac in the range $3.5 \times 10^{-5}-35.0 \mathrm{ng} \mathrm{mL}^{-1}$ with a LOD of $1.2 \times 10^{-5} \mathrm{ng} \mathrm{mL}^{-1}$. The authors successfully employed this photoelectrochemical assay to measure Neu5Ac in blood samples collected from human volunteers. ${ }^{477}$

Fang et al. have recently developed a self-enhanced and renewable biosensor for ultra-sensitive detection of Sia in human serum though ECL assay. For this purpose, the ECL bio-probe was prepared by mixing $\mathrm{Ru}(\mathrm{bpy})_{3}{ }^{2+}$ with $\mathrm{TiO}_{2}$ mesocrystals for $6 \mathrm{~h}$ followed by addition of 4-mercaptobenzoic acid and bismuth nano-belts. The monoclonal antibody was anchored to this surface via a carbodiimide route. On the other hand, fullerene followed by $\mathrm{TiO}_{2}$ mesocrystals were drop-casted on a glassy carbon electrode and 4-mercaptophenylboronic acid was also added on this surface. Furthermore, the nonspecific sites available on the modified electrode were blocked by adding $1 \%$ bovine serum albumin. For the ECL assay, the modified electrode was incubated with the solution of Neu5Ac in 0.1 M PBS (pH 8.0) for $40 \mathrm{~min}$ at room temperature and further incubated for another $40 \mathrm{~min}$ after adding the ECL bio-probe. The ECL response of Neu5Ac recorded in the potential range $0.8-1.5 \mathrm{~V}$ in $0.1 \mathrm{M}$ PBS ( $\mathrm{pH}$ 8.0) was found to be linear with concentration (in logarithmic scale) of Neu5Ac in the range $3.5 \times 10^{-5}-350 \mathrm{ng} \mathrm{mL}^{-1}$ with a LOD of $1.17 \times 10^{-5} \mathrm{ng} \mathrm{mL}^{-1}$. Interestingly, the modified electrode could be regenerated by simply immersing into 0.1 M PBS ( $\mathrm{pH}$ 6.0) when Neu5Ac conjugated with the ECL bio-probe detached from the modified electrode surface, which can be re-used for the next assay with fresh bio-probe. ${ }^{478}$
A ratiometric MIP based ECL sensor was developed by Cao et al. in 2020 for sensitive and selective detection of Neu5Ac in the commercially available synthetic human serum and EBN (Fig. 8[C]). Initially, $\mathrm{TiO}_{2}-\mathrm{Ru}(\mathrm{bpy})_{3}{ }^{2+}$ nanoparticles and polyethyleneimine capped CdS quantum dots (w:w $1: 4)$ were drop-casted on a glassy carbon electrode and covered with a few layers of graphene oxide to enhance the overall conductivity of the modified electrode suitable for electrochemical applications. The MIP was potentiodynamically electropolymerized on the modified electrode in a solution of $0.3 \mathrm{mM}$ 3-aminophenylboronic acid and $0.2 \mathrm{mM}$ Neu5Ac (acted as template) in $0.1 \mathrm{M}$ PBS (pH 4.5). After removal of the template, the modified electrode was incubated in a solution of Neu5Ac (to be assayed) in 0.1 M PBS ( $\mathrm{pH}$ 4.5) for $180 \mathrm{~s}$ followed by washing and drying. The ECL assay was carried out in $0.1 \mathrm{M}$ PBS ( $\mathrm{pH} 7.5)$ solution containing $50 \mathrm{mM} \mathrm{H}_{2} \mathrm{O}_{2}$ by cyclic voltammetry in the range $-1.6 \mathrm{~V}$ to $1.2 \mathrm{~V}$ at a scan rate of $200 \mathrm{mV} \mathrm{s}^{-1}$. In this assay, Neu5Ac and $\mathrm{H}_{2} \mathrm{O}_{2}$ both acted as co-reactants for the anodic ECL of $\mathrm{TiO}_{2}-\mathrm{Ru}(\mathrm{bpy})_{3}{ }^{2+}$; whereas only $\mathrm{H}_{2} \mathrm{O}_{2}$ acted as reactant for cathodic ECL of PEI-CdS quantum dots. Thus, in the presence of Neu5Ac, the intensity of the anodic ECL increased due to the availability of both co-reactants, but the intensity of the cathodic ECL of PEI-CdS quantum dots decreased due to the blockage of the available passage of $\mathrm{H}_{2} \mathrm{O}_{2}$ through imprinted cavities by Neu5Ac occupancy in the $\mathrm{MIP}^{479}$

In the perspective of electrochemical assays as discussed in the above sub-sections, it should be mentioned that current electrochemical assays of Sia are competing well with expensive and time-consuming chromatographic and electrophoretic assays. The amperometric and potentiometric assays could provide a good LDR within about $20 \mu \mathrm{M}-15 \mathrm{mM}$ range for Neu5Ac. ${ }^{464,466-469}$ The aptamer based DPV assay could detect Sia at ultra-trace levels down to $80 \mathrm{nM}$ in clinical samples $^{472}$ and the EIS assay was able to bring the LOD further down to $0.4 \mathrm{pM}$ with a LDR of $1 \mathrm{pM}-10 \mu \mathrm{M} .{ }^{474}$ There are few reports published on the OECT, photoelectrochemical and ECL based electrochemical assays, although the ECL assay showed interesting results for quantifying Neu5Ac in the wide LDR $0.11 \mathrm{pM}-1.13 \mu \mathrm{M}$ (converted from $3.5 \times 10^{-5}$

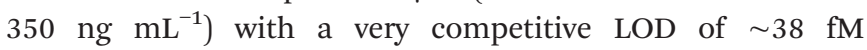
(converted from $1.17 \times 10^{-5} \mathrm{ng} \mathrm{mL}^{-1}$ ) to HPLC-MS/SM assays. ${ }^{478}$ Therefore, this branch of electrochemical assay of Sia can inspire further research.

\subsection{Quartz crystal microbalance (QCM)}

In the year 2000, Kugimiya et al. coated two different types of MIPs on $9 \mathrm{MHz}$ AT-cut platinum QCMs for assay of Sia in methanol (or water) in pyridine $(99: 1 \mathrm{v} / \mathrm{v})$. The first type of MIP was prepared with $p$-vinylbenzeneboronic acid as a chemical receptor of Sia, whereas the second type of MIP was prepared with $p$-vinylbenzeneboronic acid and $N, N, N$ trimethylaminoethyl methacrylate, which could provide additional attractive electrostatic force to the carboxylate 
Table 3 Summary of LDR, LOD and nature of tested samples of the analytical methods (as discussed in Section 5.2-5.10) validated to quality Sia in either biological or commercial samples

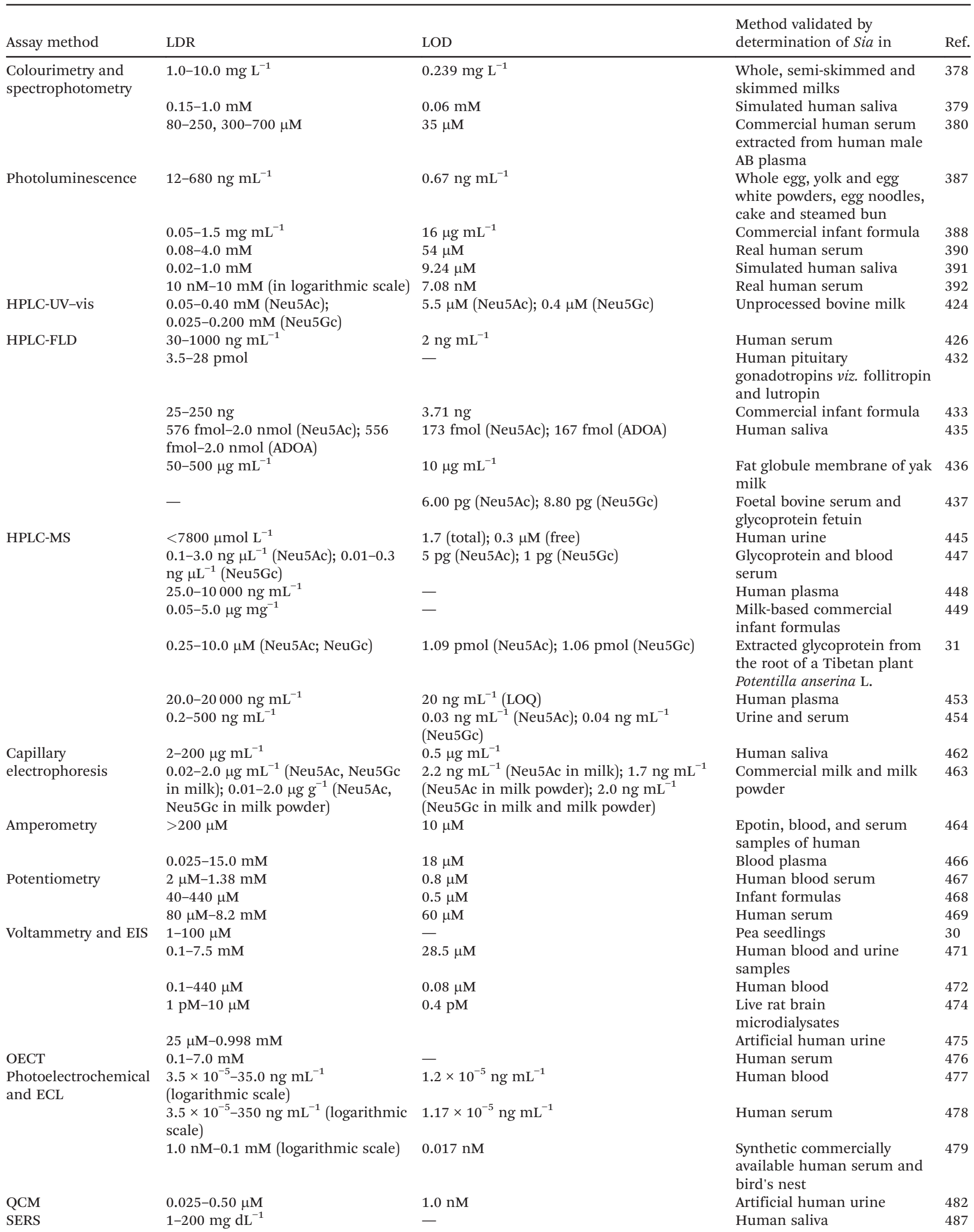


Table 3 (continued)

\begin{tabular}{llll}
\hline Assay method & LDR & LOD & $\begin{array}{l}\text { Method validated by } \\
\text { determination of Sia in }\end{array}$ \\
\hline $0.25-1.5 \mu \mathrm{M}$ & $0.25 \mu \mathrm{M}$ & Human blood plasma \\
\hline
\end{tabular}

functional group of Sia. The $p$-vinylbenzeneboronic acid ester of Sia was used as a template molecule during formation of both MIPs. The resonance oscillation frequency of both the modified QCMs linearly varied with the concentration of Sia in the range 20-250 nmol. ${ }^{480}$ Twelve years later, Duan et al. used a gold QCM and modified it with a monolayer of 4-mercaptophenylboronic acid for a direct assay of Sia solely relying on the special affinity of boronic acid to Sia. The LDR and LOD of this QCM assay reported as 0.50-5.0 and 0.15 $\mathrm{mM}$, respectively. ${ }^{481}$ In 2018, Qiu et al. modified gold QCM with allylmercaptane to introduce an allyl group on the QCM surface and then prepared a MIP on it by using Sia (as template molecule), 4-aminophenylboronic acid (as functional monomer), $N, N$-methylene-bis(acrylamide) (as cross-linker) and ammonium persulfate (as polymerisation initiator). This assay provided the best LDR and LOD of 0.025-0.50 $\mathrm{MM}$ and $1.0 \mathrm{nM}$, respectively, for Sia in $50 \mathrm{mM}$ phosphate buffer ( $\mathrm{pH}$ 7.7) among all QCM assays of Sia. ${ }^{482}$ Hence, the research on the QCM assay of Sia can be considered as rare, being less reported compared to other assays.

\subsection{Surface plasmon resonance (SPR)}

In 2001, Kugimiya et al. prepared $p$-vinylbenzeneboronic acid ester of Neu5Ac by azeotropic distillation in dry pyridine and used the ester as a template molecule for a thin MIP layer prepared on a gold-coated SPR chip. The MIP was prepared by co-polymerizing $N, N, N$ trimethylaminoethyl methacrylate, 2-hydroxyethyl methacrylate, ethyleneglycol dimethacrylate and 2,2'azobis(dimethylvaleronitrile) in DMF. In the assay, the sample was passed along with $20 \mathrm{mM}$ Tris-HCl buffer $(\mathrm{pH}$ 8.0) carrier solution over the SPR chip and the SPR resonance angle was monitored at $660 \mathrm{~nm}$. The authors observed no change in the SPR resonance angle for free Neu5Ac compared to the control, but the SPR resonance angle linearly changed for sialylated gangliosides in the concentration range $0.1-1.0 \mathrm{mg} \mathrm{mL}^{-1} \cdot{ }^{483}$ After a long gap until 2018, Li et al. developed a new SPR assay of Sia owing to the synchronous amplification of the opto-electric response of localised SPR during linear sweep of electrochemical potential. They sputter coated $\mathrm{SiO}_{2}$ layer of $100 \mathrm{~nm}$ thickness on the nanocone array of (poly)ethyleneterephthalate substrate fabricated by laser interference lithography followed by reaction ion etching. Then, AuNPs of diameter $\sim 40 \mathrm{~nm}$ were deposited on it by electron-beam evaporation technique. They also electrodeposited silver nanoparticles (AgNPs) of diameter $\sim 30-50 \mathrm{~nm}$ on it by using a potentiodynamic method to enhance the conductivity of the platform and hence sensitivity of the nanochip, while modifying the surface of AuNPs with mercaptophenyl boronic acid for selective adsorption of Neu5Ac. The localised SPR was recorded in the wavelength range 400-650 $\mathrm{nm}$ in $0.01 \mathrm{M} \mathrm{PBS}(\mathrm{pH} 7.4$ ) during the sweep of electrode potential in the range $0.0-0.3 \mathrm{~V} v s$. $\mathrm{Ag} / \mathrm{AgCl}$ at a scan rate of $0.05 \mathrm{~V} \mathrm{~s}^{-1}$. The applied electrochemical potential increased the sensitivity of localised SPR. The refractive index of the SPR-chip and water interface increased in the presence of Neu5Ac because of the preferential binding of Sia by the boronic acids and the SPR peak intensity decreased while shifting to higher wavelengths. At the same time, the adsorbed Sia on the SPR-chip hindered the movement of the redox-probe (the name was not specified in the manuscript) towards the electrode decreasing voltammetric peak current in the presence of Sia in the test solution. Hence, using localised SPR signal recorded during the potential sweep authors could quantify Neu5Ac in the LDR $0.05-5.00 \mathrm{mM}$ with a LOD of $17 \mu \mathrm{M} .{ }^{484}$ However, it can be easily understood now that SPR based analysis of Sia is another neglected branch of science along with QCM assay.

\subsection{Surface-enhanced Raman spectroscopy (SERS)}

In 2014, Vinogradova et al. first reported the possibility of SERS assay of Sia by using citrate capped AgNPs. Density functional calculation suggested that the negatively charged Neu5Ac could be chemisorbed on the surface of AgNPs via competitive adsorption of the carboxylate functional groups. The Raman peak of Neu5Ac at $1391 \mathrm{~cm}^{-1}$ enhanced significantly after the adsorption on citrate capped AgNPs upon excitation with $785 \mathrm{~nm}$ light. ${ }^{485}$ In order to understand the mechanism of adsorption of Neu5Ac on citrate capped AgNPs, Hernández-Arteaga et al. extended the experimental and DFT studies on Neu5Ac adsorbed on citrated capped AgNPs in comparison to propanethiol capped AgNPs. It was revealed that citrates could form aggregate structures on AgNPs leaving enough vacant sites available for the adsorption of Neu5Ac on silver by competitive surface adsorption of carboxylate functional groups, whereas propanethiol could uniformly coat AgNPs and hence did not allow adsorption of Nue5Ac on the silver surface. ${ }^{486}$ They further extended this study for the diagnosis of breast cancer through the SERS assay of Neu5Ac in human plasma. They used a special logarithmic equation with the average intensities of the SERS peaks at $1391 \mathrm{~cm}^{-1}$ (corresponding to stretching of $-\mathrm{COOH}$ ), $1237 \mathrm{~cm}^{-1}$ (corresponding to $\mathrm{C}-\mathrm{N}$ 
[A]

(a)

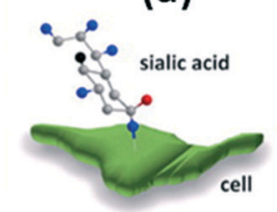

(b)

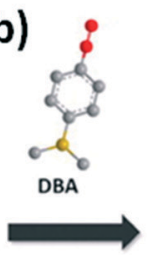

cell

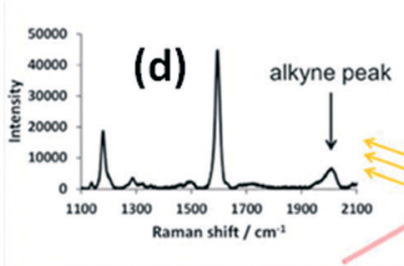

(c)

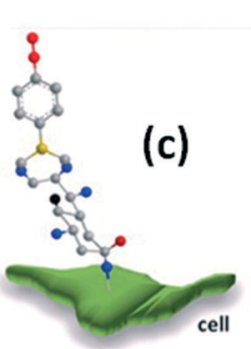

(e)

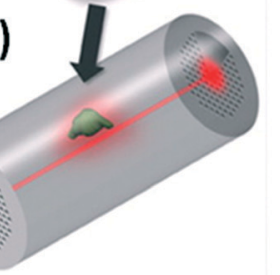

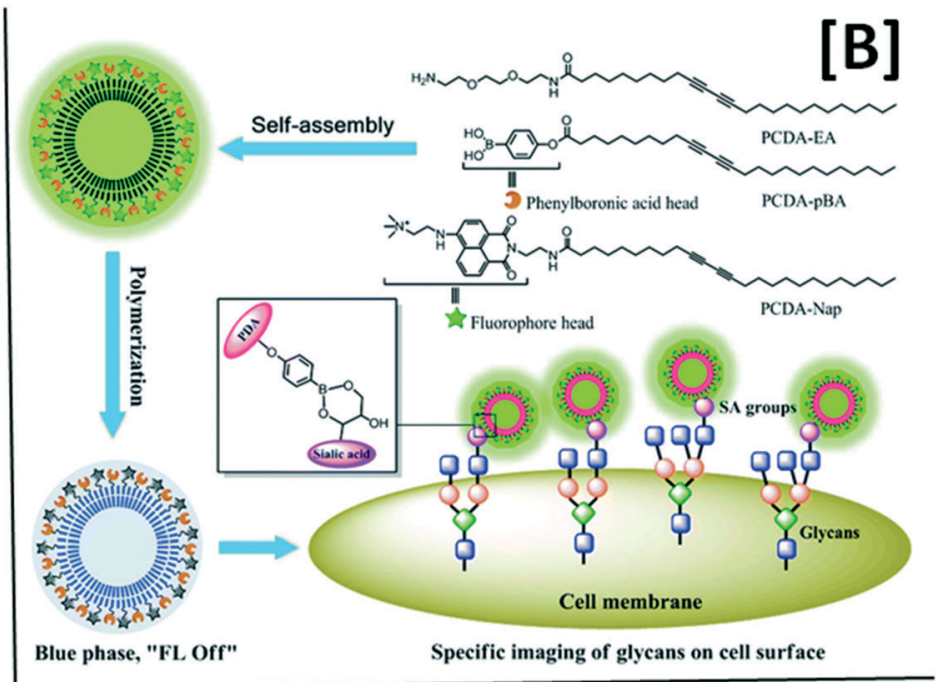

Blue phase, "FL Off"
Specific imaging of glycans on cell surface

(i) [C]

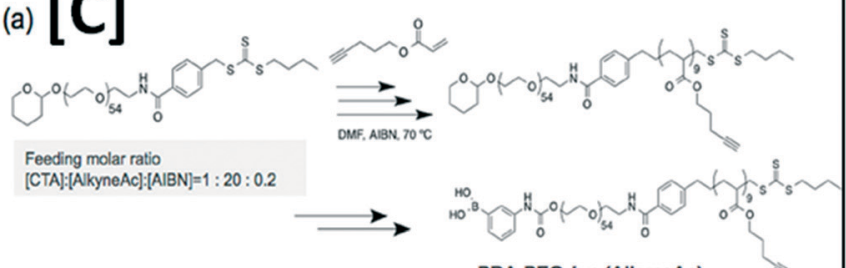

(b)

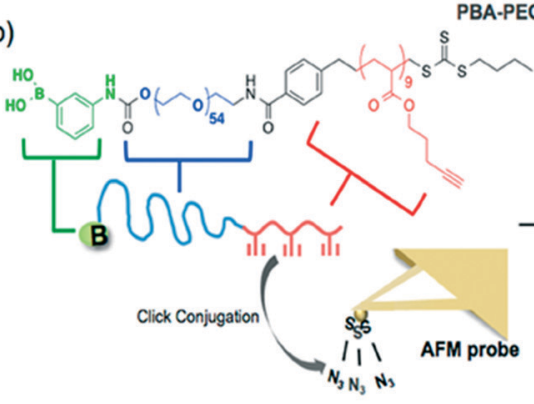

PBA-PEG-b-p (AlkyneAc)

(c)
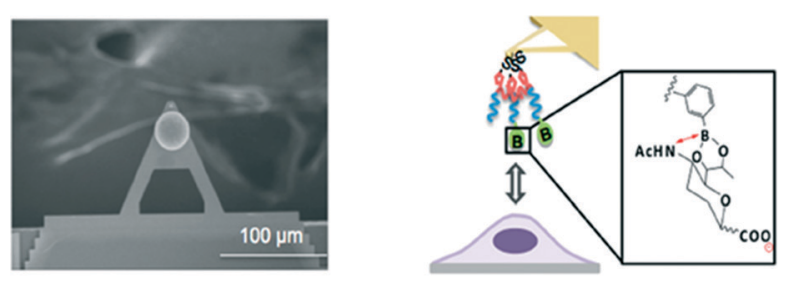

[D]

(a)

(b)
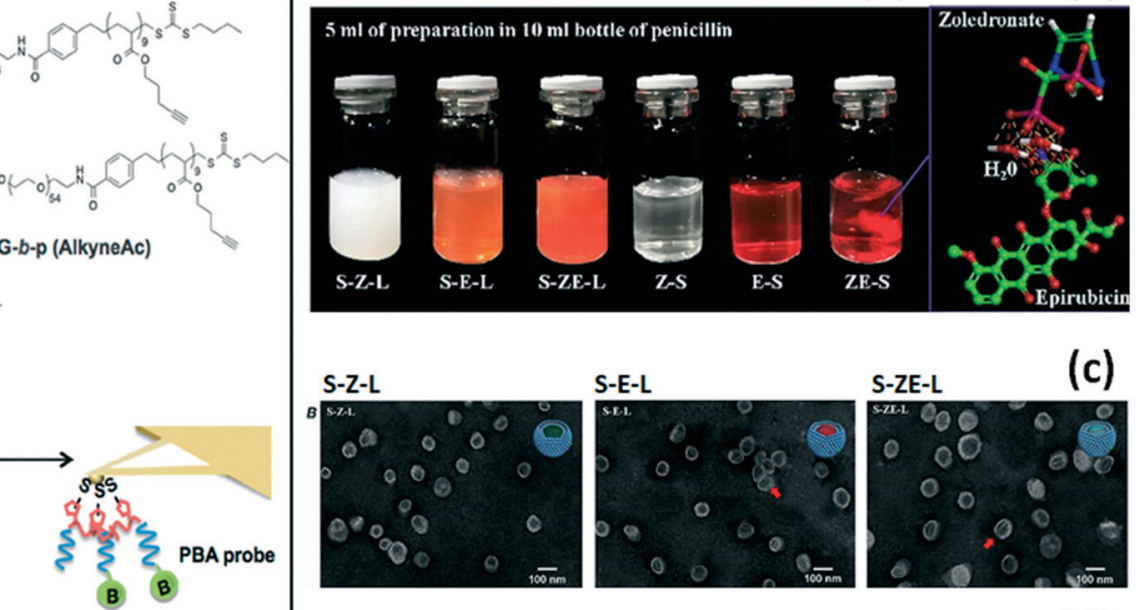

S-ZE-L

(c)
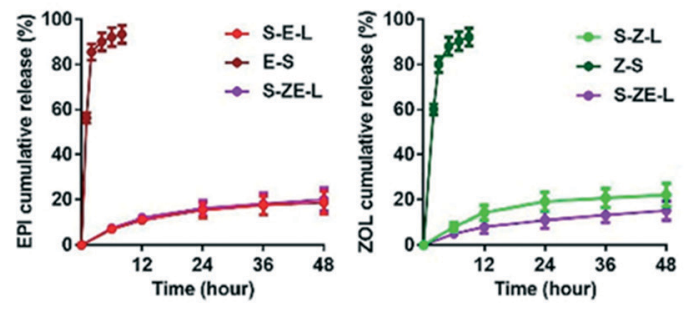

(d)

Fig. 9 [A] Illustration of highly sensitive SERS method for detection and quantification method of Sia on single cell using photonic-crystal fiber with gold nanoparticles: (a) chemical structure of Sia on cell surface; (b) chemical structure of 4-(dihydroxyborophenyl) acetylene (DBA); (c) DBA-bonded Sia on the membrane of a cell at the C-8,9 diol of Sia; (d) Raman spectrum detected from DBA tagged cell in a solid core photonic crystal fiber, the $2000 \mathrm{~cm}^{-1}$ peak corresponded to alkyne group from DBA; (e) schematic of solid core photonic crystal fiber as a SERS platform for detection of Sia on a single cell (figures reproduced with permission from ref. 517) Copyright 2015 Elsevier. [B] UV-light assisted self-assembly of 10,12-pentacosadiynoic acid-phenylboronic acid (PCDA-pBA as Sia recognising unit), 10,12-pentacosadiynoic acid-1,8-naphthalimide (PCDA-Nap as fluorescent unit with excitation and luminescence maxima at 420 and $535 \mathrm{~nm}$, respectively) and 10,12-pentacosadiynoic acid-ethyl acrylate (PCDA-EA) to form a composite polydiacetylene (PDA) based liposome and the schematic illustration of the as-prepared PDA liposomes for specific cell-glycan imaging (figures reproduced with permission from ref. 395) Copyright 2018 Royal Society of Chemistry. [C] Preparation of a phenylboronic acid (PBA) end functionalised poly-(ethylene glycol) (PEG) onto a cantilever of atomic force microscope (AFM) for dynamic Sia specific imaging on human breast cancer cell surfaces with sub-micrometer scale resolution: (a) synthetic scheme for PBA end-functionalized polymer; (b) installation of the polymer to an AFM cantilever by click chemistry. (c) Scanning electron microscopy image of the prepared PBA-modified AFM cantilever and schematic representation of its interaction with Sia on cell surface (figures reproduced with permission from ref. 530) Copyright 2020 American Chemical Society. [D] (a) The appearance of liposome (L) composed of hydrogenated soy phosphatidylcholine, cholesterol and Sia-octadecylamine in solution of epirubicin (S-E-L), zoledronate (S-Z-L), mixture of epirubicin and zoledronate $(S-Z E-L)$ in comparison to solution of epirubicin (E-S), zoledronate (Z-S), mixture of epirubicin and zoledronate (ZE-S); (b) stable complex of epirubicin and zoledronate with water molecules, (c) transmission electron micrographs of the liposomes S-Z-L, S-E-L and S-ZE-L (scale bar: $100 \mathrm{~nm}$, the red arrows mark the low-solubility aggregates); (d) in vitro drug release from S-E-L, S-Z-L and S-ZE-L liposomes in comparison to E-S and Z-S ( $n=3$ ) (figures reproduced with permission from ref. 531) Copyright 2021 Elsevier. 
mode of amide III) and $1002 \mathrm{~cm}^{-1}$ (corresponding to breathing of pyranose ring) in the concentration range 1-200 mg dL ${ }^{-1}$ of Neu5Ac. ${ }^{487}$

Recently, Teng et al. reported an enzyme assisted SERS assay of Neu5Ac in the human blood serum (Fig. 8[D]). They drop-casted citrate capped AuNPs on an indium-tin-oxide coated glass plate and submerged that into $0.1 \mathrm{mM}$ 4-mercaptophenylboronic acid solution in dilute ethanol $(\mathrm{pH}$ 9.18) for $24 \mathrm{~h}$ at room temperature to make a sensing platform. Then, Neu5Ac and glucose were incubated on the sensing platform for $2 \mathrm{~h}$ followed by incubation with $0.1 \mathrm{mM}$ 4-mercaptophenylboronic acid solution in dilute ethanol $(\mathrm{pH}$ 9.18) for another $24 \mathrm{~h}$ at room temperature. Then, that sensing platform was thoroughly washed and again immersed into the colloidal dispersion of citrate capped AuNPs for $18 \mathrm{~h}$ at room temperature to form a sandwich structure with AuNPs. To eliminate the interference of glucose, the same procedure was followed but after incubation of the test solution of Sia containing glucose with glucose oxidase at $37{ }^{\circ} \mathrm{C}$ for $2 \mathrm{~h}$. The SERS signal intensities of Neu5Ac both with and without glucose interference were independently recorded using a confocal Raman instrument set with $785 \mathrm{~nm}$ laser line and subtracted to calculate the concentration of Neu5Ac. The LDR and LOD of this SERS assay were reported as $0.25-1.5$ and $0.25 \mu \mathrm{M}$, respectively. ${ }^{488}$ The SERS detection of Sia, although promising for clinical applications, is understudied to date compared to other assays for detection and quantification of Sia.

Table 3 represents a summary of LDR, LOD and nature of tested samples of the analytical methods (as discussed in Section 5.2-5.10) validated to quality Sia in either biological or commercial samples.

\subsection{Commercially available Sia assay kits}

The commercially available assay kits of Sia are mostly limited to either colourimetric-spectrophotometric, fluorometric or HPLC-FLD methods. The colorimetric assay kit E-BC-K068 $8^{489}$ and MBS2540448 ${ }^{490}$ \& MBS2563693 ${ }^{491}$ are microplate-reader and spectrophotometer based reagents containing Sia standard (i.e., reagent 1) and a mixture of methyl resorcinol and an oxidant (i.e., reagent 2). The incubation of serum, plasma, saliva, urine, hydrothorax, tissue and cell samples containing Sia with reagent 2 produces a purplish red complex having $\lambda_{\max }$ at $560 \mathrm{~nm}$. The concentration of Sia in the sample can be determined within $60 \mathrm{~min}$ (total assay time) from the absorbance value of the sample with respect to standard in LDR 0.022-7.0 mM. The majority of colourimetric/fluorometric assay kits of Sia follow either of enzymatic or improved Warren method. The assay kits K566, ${ }^{492}$ EnzyChrom ESLA, ${ }^{493}$ LS-K187, ${ }^{494}$ PK-CA577K566, ${ }^{495}$ ab83375, ${ }^{496}$ ABIN411705, ${ }^{497}$ CAK1183, ${ }^{498}$ MBS8309610, ${ }^{499}$ MBS841610, ${ }^{500}$ S1013-31Q, ${ }^{501}$ \& A0535$01 \mathrm{~A},{ }^{502}$ Kit-1099 ${ }^{503}$ and Kit-2477 ${ }^{504}$ produce equivalent amount of $\mathrm{H}_{2} \mathrm{O}_{2}$ from free Sia by the successive enzymatic reactions of sialic acid aldolase and pyruvate oxidase (reactions 2 and 4 of Section 5.4). Either absorbance (at 570 $\mathrm{nm}$ ) or fluorescence (excitation and emission maxima at 535 and $587 \mathrm{~nm}$, respectively) of the oxidised product of the reaction between $\mathrm{H}_{2} \mathrm{O}_{2}$ and amplex red (also known as amplisyn red, 10-acetyl-3,7-dihydroxyphenoxazine and Oxi-Red probe) in the presence of horseradish peroxidase enzyme (reaction 5 of Section 5.4) is used for quantification of free Sia in LDR 0.1-10 nmol (0.02-1.0 $\mathrm{mM}$ (colourimetric) and 0.002-0.100 $\mathrm{mM}$ (fluorometric)) in 40-60 min (assay time). On the other hand, the assay kits KA1655, ${ }^{505}$ DSLA, ${ }^{506}$ S1013$31 \mathrm{P},{ }^{507}$ MAK314, ${ }^{508}$ Kit- $0783^{509}$ and BA0058 ${ }^{510}$ oxidise Sia by periodate to formylpyruvic acid, which produces a pinkcoloured product (having absorbance at $549 \mathrm{~nm}$ and excitation/emission maxima at 555/585 nm) from reaction with thiobarbituric acid. These kits can quantify free Sia in LDR 0.005-1.0 $\mathrm{mM}$ (colourimetric) and 0.0005-0.100 $\mathrm{mM}$ (fluorometric) in 40-60 min (assay time).

The commercially available Sia assay kit SIALICQ can determine both bound and free Sia through successive enzymatic reactions of exo- $\alpha$-sialidase, sialic acid aldolase and lactate dehydrogenase in the presence of NADH, whose absorbance is monitored at $340 \mathrm{~nm}$ (reactions 1-3 of Section 5.4). ${ }^{511}$

The Sia assay kits $4400^{512}$ and GKK- $407^{513}$ use (ultra) HPLC-FLD methods with a pre-DMB derivatization step for the determination of free and bound (by additional hydrolysis step) Sia down to fmols. The assay kits LT-KDMB$\mathrm{A}^{514}$ and GS24-SAP ${ }^{515}$ follow similar procedure and it provided Sia reference panels containing Neu5Ac, Neu5Gc, Neu5,7Ac 2 , Neu5,9Ac 2 , Neu5,Gc9Ac, Neu5,7,(8),9Ac Gc $_{3}$ along with quantitative standards of Neu5Ac and Neu5Gc.

\section{Indirect utilization of Sia in cytosensing, therapy and imaging of living cells}

As discussed in the previous section, the SERS based assay is underutilised to date with respect to quantification of Sia, however Song et al. have recently used this technique to capture images of Sia on living cells. They prepared a SERS probe of gold nanoflower modified with 5,50-dithio-bis(2nitrobenzoic acid) (as Raman reporter) and 3-mercaptophenylboronic acid (as Sia receptor). This modified nanoflower can bind to the cell surface Sia at physiological $\mathrm{pH}$ (i.e., 7.4) with the boronic acid group, which will also be available to make a sandwich detection system by anchoring another SERS probe made of polySia and 5,50dithio-bis(2-nitrobenzoic acid) modified poly(amidoamine) encapsulated AuNPs. This sandwich-based SERS technique was used to image the cell surface over-expression of Sia on the human breast adenocarcinoma (MCF-7) cells in comparison to normal immortalized human keratinocytes (HaCaT) cells. ${ }^{516}$ Gong et al. synthesised 4-(dihydroxyborophenyl) acetylene for dual role. It results in an interference-free Raman signal as well as binding to Sia 
on cell surface. Upon loading the mixture of AuNPs and test cells incubated with 4-(dihydroxyborophenyl) acetylene at the side panel of the photonic crystal fibre and propagating laser light through central core, they could measure the average Sia concentration even on a single-cell by utilising the Raman peak at $2000 \mathrm{~cm}^{-1}$ corresponding to acetylene unit (Fig. 9[A]). ${ }^{517}$ Similarly, He et al. modified AgNPs of average diameter $60 \mathrm{~nm}$, by both 4-mercaptophenylboronic acid (as Sia binding unit) and 4-mercaptobenzenitrile (as Raman reporter) to quantify the average cell surface Sia concentration from the interference-free SERS peak at 2232 $\mathrm{cm}^{-1}$ corresponding to cyanide unit. ${ }^{518}$ Liang et al. modified AgNPs of average diameter of $40 \mathrm{~nm}$ by 4-mercaptophenylboronic acid and used confocal SERS technique at 1074 and $1570 \mathrm{~cm}^{-1}$ for measuring and imaging the overexpression of Sia on HepG2, HeLa, BNL.CL2 cells to diagnose breast cancer. ${ }^{519}$ Shinde et al. prepared a $\mathrm{SiO}_{2}$ (as core of diameter $\sim 200 \mathrm{~nm}$ ) and fluorescent-MIP (as shell of thickness $\sim 10 \mathrm{~nm}$ ) based composite material for selective imaging of sialylated glycans on cell surfaces. They used nitrobenzoxadiazole (as fluorescence reporter having excitation and luminescence peaks at 411 and $509 \mathrm{~nm}$, respectively), ester of polyvinylphenylboronic acid and Neu5Ac (as template) and 2-aminoethyl-methacrylate hydrochloride (as additional hydrogen bonding agent) and 2-(-3-(4-nitrobenzo[c] [1,2,5]oxadiazo-7-yl)ureido)-

ethylmethacrylate (as additional carboxylate recognition site for Sia) in the MIP shell. This core-shell fluorescence probe was successfully used to image the sialylated glycans on surfaces of the prostate cancer cell lines DU145, PC3 and leukemic cell line Jurkat $\mathrm{T}$ cells. ${ }^{520}$ As discussed in section 5.3, the fluorescent polydiacetylene based liposome was prepared for the fluorescence-based assay of free Sia. $100 \mu \mathrm{M}$ of this fluorescence probe was also used for imaging sialylated glycans expressed on MCF-7 cells through confocal microscopy (Fig. 9[B]). ${ }^{522}$ Peng et al. prepared tetraphenylethene tagged peptidylboronic acids having aggregation-induced emission at $460 \mathrm{~nm}$ (maxima). The change in luminescent intensity was selective for Sia compared to other monosaccharides and this phenomenon was used to label and image cancer cells owing to higher Sia expressions on their cell surfaces. ${ }^{521}$ Recently, Geng et al. modified AgNPs of average diameter $\sim 50 \mathrm{~nm}$ with 4-mercaptophenylboronic acid to recognise Sia and used it in a non-linear optical imaging technique known as four-wavemixing to visualize Sia on A549, HeLa, HepG2 and MCF-7 cells. ${ }^{522}$ Almeida-Marrero et al. recently synthesised a photosensitizer by covalently linking dendritic zinc(II) phthalocyanine with 3 units of Neu5Ac for the photodynamic therapy through in situ generation of photoinduced singlet oxygen and other reactive species in the lysosome. The amphiphilic Neu5Ac modified photosensitizer formed nonphotoresponsive self-assembled nano-aggregates and enters into the cellular lysosome, where it could regain its photoresponse. ${ }^{523}$ Yang et al. modified a gold coated QCM with mercaptobutanedioic acid followed by concanavalin A lectin to specifically attach mannose of the cell surface of RBC. Then AuNPs modified with 4-aminobenzeneboronic acid were added on the modified QCM with RBC to measure the average number of Sia $2.1 \pm 0.2 \times 10^{8}$ on RBC of healthy person compared to $8.2 \pm 0.7 \times 10^{7}$ on $\mathrm{RBC}$ of a diabetic patient. ${ }^{524}$

Qian et al. demonstrated a multivalent recognition and signal amplification strategy for cancer cell cytosensing and dynamic evaluation of cell surface Sia using graphene oxide functionalised with 3-aminophenylboronic acid for cell capture and Sambucus nigra agglutinin and thionine conjugated to gold nanoparticles. The DPV based electrochemical method was used to monitor the changes in expression of Sia in response to addition of sialidase enzyme. $^{525}$ A similar approach combined 3-aminophenylboronic acid modified carbon nanospheres for Sia recognition with horseradish peroxidase decorated gold nanoparticles for signal amplification. The electrochemical cytosensor realised an identification system using Sambucus nigra agglutinin and 3-aminophenylboronic acid modified carbon nanospheres for cancer cell capture with measurement of the expression level of Sia on MCF-7 cells $v s$. control cell lines (LOD of 25 cells per mL). ${ }^{526}$ Zhang et al. electrochemically prepared poly-pyrrole on a gold electrode allowing physical inclusion of bovine serum albumin incorporated silver submicron particles into the polymer matrix. Then the electrode was modified with 3-aminophenylboronic acid through the cross-linking agent $p$-phenylene-diisothiocyanate. This modified electrode was used to diagnose renal cell carcinoma from the change of charge-transfer resistance of $\left[\mathrm{Fe}(\mathrm{CN})_{6}\right]^{3-/ 4-}$ electrochemical reaction with LDR and LOD 17-1.7 $\times 10^{6}$ and 6 Cell786-O per $\mathrm{mL}(\mathrm{S} / \mathrm{N}=3)$, respectively. ${ }^{527}$ Matsumoto et al. used 3-aminophenylboronic acid end-functionalised poly(ethylene glycol) modified gold electrode for potentiometric determination of a blood-circulating glycoprotein fetuin at $\mathrm{pH}$ 7.4. ${ }^{528}$

Landa et al. modified AuNPs of average diameter $20 \mathrm{~nm}$ with Neu5Ac to generate a negatively charged nanoprobe of zeta potential $-13.21 \pm 1.87 \mathrm{mV}$ and absorption maxima at $520 \mathrm{~nm}$ in neutral $\mathrm{pH}$. This nanoprobe was agglomerated in the presence of gram-positive bacteria viz. Staphylococcus aureus and methicillin resistant Staphylococcus aureus extending the absorption to longer wavelengths, but did not show any changes in the presence of Gram-negative bacteria viz. Pseudomonas aeruginosa. This method was effective to discriminate Gram-positive and Gram-negative bacteria at high concentration $\sim 10^{5} \mathrm{CFU} \mathrm{mL}^{-1}$ in tryptic soy broth medium and serum sample. ${ }^{529}$

Finally, a phenylboronic acid end functionalised poly(ethylene glycol) was decorated onto a cantilever of atomic force microscope for dynamic Sia specific imaging on human breast cancer cell surfaces with sub-micrometer scale resolution (Fig. 9[C]). A greater extent of probe-surface interaction was observed for the high Sia expressed MCF-7 as compared to health control cell lines, taking advantage 
of the reversible and $\mathrm{pH}$ dependant boronic acid-Sia binding chemistry. ${ }^{530}$ Sia receptors are usually overexpressed on the surface of tumour-associated macrophages. Sui et al. reported that sequential administration of Sia $\left(0.2 \mathrm{mg} \mathrm{mL} \mathrm{m}^{-1}\right)$ modified epirubicin (0.056 $\mathrm{mg} \mathrm{mg}^{-1}$ of lipid) liposome followed by (after $24 \mathrm{~h}$ ) Sia modified zoledronate $\left(0.08 \mathrm{mg} \mathrm{mg}^{-1}\right.$ of lipid) liposome (Fig. 9[D]) could kill the tumour-associated macrophages and restrict tumour growth in mice. ${ }^{531}$

The commercially available EZClick ${ }^{\mathrm{TM}}$ sialic acid (ManAz) modified glycoprotein assay kit K441 uses direct feeding of modified ManAc precursor into the cell for biosynthesis of Sia followed by its participation in $N$-glycosylation of cell surface protein, which can be mapped and quantified by using fluorescence-activated cell sorting method following the click reaction with an alkyne-containing dye. This assay is very useful to identify the altered sialylation of tumour-cell surfaces. ${ }^{532}$ Similarly, the GlyS Kit is used to screen the terminal Sia content of glycans in protein of interest even in the presence of host cell glycoproteins in crude samples by high throughput Octet system. ${ }^{533}$

\section{Future direction}

Sia is widely distributed in free, polymeric and conjugated forms in living creatures. However, the discovery and identification of new members of the Sia family is yet an open science. Furthermore, with the advancement of analytical methodologies to achieve ultra-trace LODs, exploration of Sia in different parts of plants has a great opportunity to either discover green resources of Sia or confirm the absence of Sia in plants, fruits and vegetables.

The involvement of Sia in important physiology including brain development and formation of central nervous system during foetal and neonatal stages has been studied mostly on animals viz. laboratory rats and pigs and correlated to human physiology. The participation of Sia in the human immune system has been studied, and has keen ongoing interest, especially given the inconclusive evidence of Sia's involvement in several bacterial and viral infections including SARS-CoV-2 causing COVID-19 disease. The over-/underexpression of Sia in human cells/tissues/fluids during physiological disorders and onset of cancers are now in high surveillance to promote Sia as one of the potential biomarkers for a number of human diseases.

The correlated case studies of Sia in human lactation and infant cognition produced sufficient evidence to receive regulatory approval for use of Neu5Ac. $2 \mathrm{H}_{2} \mathrm{O}, 3$ '-sialyllactose sodium salt and 6'-sialyllactose sodium salt in infant formula and commercial food products as nutrition additives. This has definitely boosted the demand of Sia in commercial domain, although the number of economic and large-scale production of Sia suitable for safe consumption by humans is very limited at present.

The emerging biological relevance of Sia in human health and clinical sciences along with its commercial role in

human health and nutrition has increased the importance of development of robust sensors and diagnostic methods for Sia in complex clinical and food matrices. There is a vast scope of research and development in this direction as presented in this review. In summary, it should be mentioned that knowledge of the biological role and participation of Sia in human physiology is expanding day-by-day. Hence, the extension of the analytical horizons of Sia beyond the current state of the art will underpin further explorations in the expansive Sia galaxy.

\section{Symbols and abbreviations}

\section{Symbols}

$\begin{array}{ll}\varepsilon & \text { Molar absorption coefficient } \\ \lambda_{\text {Max }} & \text { Absorbance maxima } \\ \mathrm{C} & \text { Carbon } \\ n & \text { Number of samples/persons/patients }\end{array}$

\section{Abbreviations}

ACE2

ADOA

AgNPs

AuNPs

cGMP

CMP

$\mathrm{CoV}$

CTD

DMB

DPV

EBN

ECL

EIS

ESI

HMOs

HPLC-FLD

HPLC-MS

HPLC-PAD

HPLC-UV-vis

KDN

LDR

LOD

ManNAc

MERS-CoV

MIP

$\mathrm{NADH}$

NCAM

ND

Neu5Ac
Angiotensin-converting enzyme 2

4-(Acetylamino)-2,4-dideoxy-D-glycero-Dgalacto-octonic acid

Silver nanoparticles

Gold nanoparticles

Caseinoglycomacropeptide

Cytidine-5'-monophosphate

Corona virus

C-Terminal domain

1,2-Diamino-4,5-methyleneoxybenzene

Differential pulse voltammetry

Edible bird's nest

Electrochemiluminescence

Electrochemical impedance spectroscopy

Electron spray ionization

Human milk oligosaccharides

High performance liquid chromatography coupled with fluorescence detection

High performance liquid chromatography coupled with mass-spectrometry detection

High performance liquid chromatography coupled with pulsed-amperometry detection High performance liquid chromatography coupled with UV-Vis detection

2-Keto-3-deoxy-D-glycero-D-galacto-nononic acid

Linear dynamic range

Limit of detection

$\mathrm{N}$-Acetyl-D-mannosamine

Middle east respiratory syndrome coronavirus

Molecularly imprinted polymer

Reduced nicotinamide adenine dinucleotide Neural cell adhesion molecule

Not detected

$N$-Acetyl-D-neuraminic acid 


$\begin{array}{ll}\text { Neu5Gc } & \text { N-Glycolyl-D-neuraminic acid } \\ \text { NMR } & \text { Nuclear magnetic resonance } \\ \text { NR } & \text { Not reported } \\ \text { NTD } & \text { N-terminal domain } \\ \text { OECT } & \text { Organic electrochemical transistors } \\ \text { PBS } & \text { Phosphate buffer saline } \\ \text { PEC } & \text { Photoelectrochemistry } \\ \text { polySia } & \text { Poly-sialic acid } \\ \text { QCM } & \text { Quartz crystal microbalance } \\ \text { RBC } & \text { Red blood cells } \\ \text { SAMPs } & \text { Self-associated molecular patterns } \\ \text { SARS-CoV } & \text { Severe acute respiratory syndrome } \\ & \text { coronavirus } \\ \text { SARS-CoV-2 } & \text { Severe acute respiratory syndrome } \\ & \text { coronavirus } 2 \text { (novel corona virus) } \\ \text { SERS } & \text { Surface-enhanced Raman spectroscopy } \\ \text { Sia } & \text { Sialic acid } \\ \text { Siglec } & \text { Sialic acid binding immunoglobulin like } \\ & \text { lectin } \\ \text { SPR } & \text { Surface plasmon resonance } \\ \text { ST8SiaII } & \text { ST8- } \alpha-N \text {-Acetyl-neuraminide- } \alpha-2,8- \\ & \text { sialyltransferase- } 2 \\ \text { ST8SiaIV } & \text { ST8- } \alpha-N \text {-Acetyl-neuraminide- } \alpha-2,8- \\ & \text { sialyltransferase-4 } \\ \text { T2DM } & \text { Type } 2 \text { diabetic mellitus } \\ & \text { Uridine diphosphate- } N \text {-acetylglucosamine }\end{array}$

\section{Funding source}

This project has received funding from the Enterprise Ireland and the European Union's Horizon 2020 Research and Innovation Programme under the Marie Skłodowska-Curie Career FIT PLUS grant agreement no. 847402 (Project No. MF20200140).

\section{Author contributions}

Dr. Saurav K. Guin has completed the literature survey and written the original draft. Dr. Eithne Dempsey and Dr. Trinidad Velasco-Torrijos reviewed and edited the manuscript. Dr. Dempsey and Dr. Guin are jointly involved in conceptualisation, funding acquisition and administration of this project.

\section{Conflicts of interest}

There are no conflicts to declare.

\section{Acknowledgements}

Dr. Guin wishes to acknowledge the Open-Access Publication Policy of Enterprise Ireland and the European Union's Horizon 2020 Research and Innovation Programme under the Marie Skłodowska-Curie Career FIT PLUS fellowship for dissemination of work to wider community. The authors acknowledge Dr. Fergal Lawless and Glanbia Ingredients Ireland. Dr. Guin wishes to thank Dr. P.K. Pujari, Director of
Radiochemistry and Isotope Group and Dr. S. Kannan, Head of Fuel Chemistry Division in Bhabha Atomic Research Centre for approving his visit (on leave) in Ireland.

\section{References}

1 R. Schauer and J. P. Kamerling, in Glycoproteins II, ed. J. Montreuil, J. F. G. Vliegenthart and H. Schachter, Elsevier Science Publishers B.V, Amsterdam, 1997, pp. 243-372.

2 T. Janas and T. Janas, Biochim. Biophys. Acta, Biomembr., 2011, 1808, 2923-2932.

3 E. Klenk, Biol. Chem., 1935, 235, 24-36.

4 E. Klenk, H. Langerbeins and E. Schumann, Biol. Chem., 1941, 270, 185-193.

5 E. Klenk, Biol. Chem., 1941, 268, 50-58.

6 F. G. Blix, Biol. Chem., 1936, 240, 43-54.

7 G. Blix, L. Svennerholm and I. Werner, Acta Chem. Scand., 1952, 6, 358-362.

8 T. Yamakawa and S. Suzuki, J. Biochem., 1951, 38, 199-212.

9 A. Gottschalk, Nature, 1951, 176, 845-847.

10 J. R. E. Hoover, G. A. Braun and P. György, Arch. Biochem. Biophys., 1953, 47, 216-217.

11 F. Zilliken, G. A. Braun and P. György, Arch. Biochem. Biophys., 1955, 54, 564-566.

12 K. Richard, R. Brossmer and M. von W. Schulz, Chem. Ber., 1954, 87, 123-127.

13 A. Gottschalk, Nature, 1955, 176, 881-882.

14 F. G. Blix, A. Gottschalk and E. Klenk, Nature, 1957, 179, 1088.

15 L. Warren and H. Felsenfeld, J. Biol. Chem., 1962, 237, 1421-1431.

16 M. E. Tanner, Bioorg. Chem., 2005, 33, 216-228.

17 L. Shaw and R. Schauer, Biol. Chem. Hoppe-Seyler, 1988, 369, 477-486.

18 T. Hayakawa, Y. Satta, P. Gagneux, A. Varki and N. Takahata, Proc. Natl. Acad. Sci. U. S. A., 2001, 98, 11399-11404.

19 P. S. K. Ng, R. Böhm, L. E. Hartley-Tassell, J. A. Steen, H. Wang, S. W. Lukowski, P. L. Hawthorne, A. E. O. Trezise, P. J. Coloe, S. M. Grimmond, T. Haselhorst, M. Von Itzstein, A. W. Paton, J. C. Paton and M. P. Jennings, Nat. Commun., 2014, 5, 5750.

20 S. A. Springer, S. L. Diaz and P. Gagneux, Immunogenetics, 2014, 66, 671-674.

21 M. Jahan, P. C. Thomson, P. C. Wynn and B. Wang, Food Chem., 2021, 343, 128439.

22 S. Inoue and K. Kitajima, Glycoconjugate J., 2006, 23, 277-290.

23 S. Ghosh, Sialic acid and biology of life: An introduction, Elsevier B.V., 2020/01/17, 2020.

24 M. Yang, S. H. Cheung, S. C. Li and H. Y. Cheung, Food Chem., 2014, 151, 271-278.

25 O. Mahaq, M. A. Mohd, M. Jaoi Edward, N. Mohd Hanafi, S. Abdul Aziz, H. Abu Hassim, M. H. Mohd Noor and H. Ahmad, Brain Behav., 2020, 10, e01817. 
26 G. K. Chan, K. Y. Zheng, K. Y. Zhu, T. T. Dong and K. W. Tsim, The Journal of Ethnobiology and Traditional Medicine, 2013, 120, 620-628.

27 R. Zeleny, D. Kolarich, R. Strasser and F. Altmann, Planta, 2006, 224, 222-227.

28 A. N. Samraj, O. M. T. Pearce, H. Läubli, A. N. Crittenden, A. K. Bergfeld, K. Band, C. J. Gregg, A. E. Bingman, P. Secrest, S. L. Diaz, N. M. Varki, A. Varki and S. A. Kornfeld, Proc. Natl. Acad. Sci. U. S. A., 2015, 112, 542-547.

29 L. Ye, L. Mu, G. Li and Y. Bao, J. Food Compos. Anal., 2020, 87, 103393.

30 L. J. Sun, Y. Xie, Y. F. Yan, H. Yang, H. Y. Gu and N. Bao, Sens. Actuators, B, 2017, 247, 336-342.

31 L. Xia, L. Liu, F. Qu, R. Kong, G. Li and J. You, Chromatographia, 2017, 80, 861-872.

32 R. Schauer and J. P. Kamerling, Exploration of the Sialic Acid World, Elsevier Inc., 1st edn, 2018, vol. 75.

33 H. Yang, L. Lu and X. Chen, Biotechnol. Adv., 2021, 46, 107678.

34 M. Huizing, M. E. Hackbarth, D. R. Adams, M. Wasserstein, M. C. Patterson, S. U. Walkley, W. A. Gahl, K. Dobrenis, J. Foglio, B. Gasnier, M. Hackbarth, M. Lek, M. C. V. Malicdan, L. E. Paavola, R. Reimer, R. Y. Wang and R. Zoncu, Neurosci. Lett., 2021, 755, 135896.

35 R. Heida, Y. C. Bhide, M. Gasbarri, Ö. Kocabiyik, F. Stellacci, A. L. W. Huckriede, W. L. J. Hinrichs and H. W. Frijlink, Drug Discovery Today, 2021, 26, 122-137.

36 P. Burzy, K. Mikołajczyk, M. Jodłowska and E. Ja, Biomolecules, 2021, 11, 831.

37 E. Gianchecchi, A. Arena and A. Fierabracci, Int. J. Mol. Sci., 2021, 22, 5774.

38 X. Zhou, G. Yang and F. Guan, Cell, 2020, 9, 273.

39 R. Lacomba, J. Salcedo, A. Alegría, M. Jesús Lagarda, R. Barberá and E. Matencio, J. Pharm. Biomed. Anal., 2010, 51, 346-357.

40 J. Cheeseman, G. Kuhnle, D. I. R. Spencer and H. M. I. Osborn, Bioorg. Med. Chem., 2021, 30, 115882.

41 V. Andriukaitis, Official Journal of the European Union, 2017, L 337, 63-67.

42 A. B. Engin, E. D. Engin and A. Engin, Environ. Toxicol. Pharmacol., 2020, 79, 103436.

43 P. Wielgat, K. Rogowski, K. Godlewska and H. Car, Cell, 2020, 9, 1963.

44 X.-L. Sun, Glycobiology, 2021, cwab032.

45 W. Zhao, T. L. L. Chen, B. M. Vertel and K. J. Colley, J. Biol. Chem., 2006, 281, 31106-31118.

46 F. Tokumasu, G. R. Ostera, C. Amaratunga and R. M. Fairhurst, Exp. Parasitol., 2012, 131, 245-251.

47 S. E. Quaggin, J. Clin. Invest., 2007, 117, 1480-1483.

48 A. Varki, Glycobiology, 2011, 21, 1121-1124.

49 X. Wang, N. Mitra, I. Secundino, K. Banda, P. Cruz, V. Padler-Karavani, A. Verhagen, C. Reid, M. Lari, E. Rizzi, C. Balsamo, G. Corti, G. De Bellis, L. Longo, W. Beggs, D. Caramelli, S. A. Tishkoff, T. Hayakawa, E. D. Green, J. C. Mullikin, V. Nizet, J. Bui and A. Varki, Proc. Natl. Acad. Sci. U. S. A., 2012, 109, 9935-9940.

50 P. R. Crocker, J. C. Paulson and A. Varki, Nat. Rev. Immunol., 2007, 7, 255-266.
51 H. Läubli and A. Varki, Cell. Mol. Life Sci., 2020, 77, 593-605.

52 S. Pillai, I. A. Netravali, A. Cariappa and H. Mattoo, Annu. Rev. Immunol., 2012, 30, 357-392.

53 B. S. Blaum, J. P. Hannan, A. P. Herbert, D. Kavanagh, D. Uhrín and T. Stehle, Nat. Chem. Biol., 2015, 11, 77-82.

54 C. Q. Schmidt, A. L. Hipgrave Ederveen, M. J. Harder, M. Wuhrer, T. Stehle and B. S. Blaum, Glycobiology, 2018, 28, 765-773.

55 B. A. H. Smith and C. R. Bertozzi, Nat. Rev. Drug Discovery, 2021, 20, 217-243.

56 K. Sołkiewicz, H. Krotkiewski, M. Jędryka and E. M. Kratz, Sci. Rep., 2021, 11, 5586.

57 J. Finne, J. Biol. Chem., 1982, 257, 11966-11970.

58 C. Weisgerber, M. Husmann, M. Frosch, C. Rheinheimer, T. W. Peuckert and I. Gorgen, J. Neurochem., 1990, 55, 2063-2071.

59 J. Ahrens, N. Foadi, A. Eberhardt, G. Haeseler, R. Dengler, A. Leffler, M. Mühlenhoff, R. Gerardy-Schahn and M. Leuwer, Pharmacology, 2011, 87, 311-317.

60 J. Nakayama, M. N. Fukuda, B. Fredette, B. Ranscht and M. Fukuda, Proc. Natl. Acad. Sci. U. S. A., 1995, 92, 7031-7035.

61 M. S. Skog, J. Nystedt, M. Korhonen, H. Anderson, T. A. Lehti and M. I. Pajunen, Stem Cell Res. Ther., 2016, 7, 113.

62 P. M. Drake, J. K. Nathan, C. M. Stock, P. V. Chang, M. O. Muench, D. Nakata, J. R. Reader, P. Gip, K. P. K. Golden, B. Weinhold, R. Gerardy-Schahn, F. A. Troy and C. R. Bertozzi, J. Immunol., 2008, 181, 6850-6858.

63 T. M. Villanueva-Cabello, L. D. Gutiérrez-Valenzuela, D. V. López-Guerrero, M. E. Cruz-Muñoz, H. M. Mora-Montes and I. Martínez-Duncker, Glycobiology, 2019, 29, 557-564.

64 S. Werneburg, F. F. R. Buettner, M. Mühlenhoff and H. Hildebrandt, Stem Cell Res., 2015, 14, 339-346.

65 U. Yabe, C. Sato, T. Matsuda and K. Kitajima, J. Biol. Chem., 2003, 278, 13875-13880.

66 S. Curreli, Z. Arany, R. Gerardy-schahn, D. Mann and N. M. Stamatos, J. Biol. Chem., 2007, 282, 30346-30356.

67 R. W. Nelson, P. A. Bates and U. Rutishauser, J. Biol. Chem., 1995, 270, 17171-17179.

68 S. S. Mendiratta, N. Sekulic, A. Lavie and K. J. Colley, J. Biol. Chem., 2005, 280, 32340-32348.

69 S. S. Mendiratta, N. Sekulic, F. G. Hernandez-Guzman, B. E. Close, A. Lavie and K. J. Colley, J. Biol. Chem., 2006, 281, 36052-36059.

70 J. L. Brusés and U. Rutishauser, J. Cell Biol., 1998, 140, 1177-1186.

71 P. C. Hallenbeck, E. R. Vimr, F. Yu, B. Basslero and A. Troyn, J. Biol. Chem., 1987, 262, 3553-3561.

72 C. D. Hunter and C. Cairo, ChemRxiv, 2021, DOI: 10.26434/ chemrxiv.14065025.v1.

73 A. Mori, M. Hane, Y. Niimi, K. Kitajima and C. Sato, Glycobiology, 2017, 27, 834-846.

74 F. Miragall, G. Kadmon, M. Husmann and M. Schachner, Dev. Biol., 1988, 129, 516-531.

75 L. Bonfanti, Prog. Neurobiol., 2006, 80, 129-164. 
76 U. Rutishauser, Nat. Rev. Neurosci., 2008, 9, 26-35.

77 C. Sato and K. Kitajima, Sialic Acids in Neurology, Elsevier Inc., 1st edn, 2019, vol. 76.

78 P. Simon, S. Bäumner, O. Busch, R. Röhrich, M. Kaese, P. Richterich, A. Wehrend, K. Müller, R. Gerardy-schahn, M. Mühlenhoff, H. Geyer, R. Geyer, R. Middendorff and S. P. Galuska, J. Biol. Chem., 2013, 288, 18825-18833.

79 R. D. Astronomo and D. R. Burton, Nat. Rev. Drug Discovery, 2010, 9, 308-324.

80 Y. Wang and H. Neumann, J. Neurosci., 2010, 30, 3482-3488.

81 J. Roth, C. Zuber, P. Komminoth, T. Sata, W. P. Li and P. U. Heitz, Histochem. Cell Biol., 1996, 106, 131-148.

82 C. Sato and K. Kitajima, Mol. Aspects Med., 2020, 100892, In press.

83 K. F. Boligan, J. Oechtering, C. W. Keller, B. Peschke, R. Rieben, N. Bovin, L. Kappos, R. D. Cummings, J. Kuhle, S. von Gunten and J. D. Lünemann, Neurol. Neuroimmunol. Neuroinflamm., 2020, 7, e676.

84 R. Sandhoff and K. Sandhoff, FEBS Lett., 2018, 592, 3835-3864.

85 L. Svennerholm, in Cholera and Related Diarrheas 43rd Nobel Symposium, Stockholm, 1978, pp. 80-87.

86 L. Svennerhom, Gangliosides and Synaptic Transmission, Springer, Boston, MA, 1980.

87 L. Svennerholm, Prog. Brain Res., 1994, 101, xi-xiv.

88 R. K. Yu, T. Ariga, M. Yanagisawa and G. Zeng, in Glycoscience, ed. B. O. Fraser-Reid, K. Tatsuta and J. Thiem, 2008, pp. 1671-1695.

89 R. K. Yu, Y. Nakatani and M. Yanagisawa, J. Lipid Res., 2009, 50, S440-S445.

90 S. Ando, N. C. Chang and R. K. Yu, Anal. Biochem., 1978, 89, 437-450.

91 M. Sarbu, A. C. Robu, R. M. Ghiulai, Ž. Vukelić, D. E. Clemmer and A. D. Zamfir, Anal. Chem., 2016, 88, 5166-5178.

92 M. Sarbu, Ž. Vukelić, D. E. Clemmer and A. D. Zamfir, Analyst, 2018, 143, 5234-5246.

93 M. Sarbu, L. Dehelean, C. V. A. Munteanu, Ž. Vukelić and A. D. Zamfir, Anal. Biochem., 2017, 521, 40-54.

94 M. Sarbu, S. Raab, L. Henderson, D. Fabris, Z. Vukelic, D. E. Clemmer and A. D. Zam, Biochimie, 2020, 170, 36-48.

95 N. Sasaki, M. Toyoda and T. Ishiwata, Int. J. Mol. Sci., 2021, 22, 5076.

96 M. Sarbu, L. Petrica, D. E. Clemmer, Ž. Vukelić and A. D. Zamfir, J. Am. Soc. Mass Spectrom., 2021, 32, 1249-1257.

97 M. Sarbu, D. E. Clemmer and A. D. Zamfir, Biochimie, 2020, 177, 226-237.

98 E. Chiricozzi, E. Di Biase, M. Maggioni, G. Lunghi, M. Fazzari, D. Y. Pomè, R. Casellato, N. Loberto, L. Mauri and S. Sonnino, J. Neurochem., 2019, 149, 231-241.

99 N. Sasaki, Y. Itakura and M. Toyoda, Int. J. Mol. Sci., 2019, 20, 1-12.

100 S. Sipione, J. Monyror, D. Galleguillos, N. Steinberg and V. Kadam, Front. Neurosci., 2020, 14, 572965.
101 T. Mitsuda, K. Furukawa, S. Fukumoto, H. Miyazaki, T. Urano and K. Furukawa, J. Biol. Chem., 2002, 277, 11239-11246.

102 Y. Ohkawa, H. Momota, A. Kato, N. Hashimoto, Y. Tsuda, N. Kotani, K. Honke, A. Suzumura, K. Furukawa, Y. Ohmi, A. Natsume, T. Wakabayashi and K. Furukawa, J. Biol. Chem., 2015, 290, 16043-16058.

103 R. París, A. Morales, O. Coll, A. Sánchez-Reyes, C. GarcíaRuiz and J. C. Fernández-Checa, J. Biol. Chem., 2002, 277, 49870-49876.

104 R. De Maria, L. Lenti, F. Malisan, B. Tomassini, A. Zeuner, M. R. Rippo and R. Testi, Science, 1997, 277, 1652-1655.

105 Y. Makino, K. Hamamura, Y. Takei, R. Hasan, Y. Ohkawa and G. Lauc, Biochim. Biophys. Acta, Gen. Subj., 2016, 1860, 1753-1763.

106 K. Furukawa, M. Kambe, M. Miyata, Y. Ohkawa, O. Tajima and K. Furukawa, Cancer Sci., 2014, 105, 52-63.

107 K. Hamamura, M. Tsuji, H. Hotta, Y. Ohkawa, M. Takahashi, H. Shibuya, H. Nakashima, Y. Yamauchi, N. Hashimoto, H. Hattori, M. Ueda, K. Furukawa and K. Furukawa, J. Biol. Chem., 2011, 286, 18526-18537.

108 Y. Liang, C. Wang, I. Wang, Y. Chen, L. Li, M. Ho, T. Chou, Y. Wang, S. Chiou, Y. Lin and J. Yu, Oncotarget, 2017, 8, 47454-47473.

109 B. L. Mirkin, S. H. Clark and C. Zhang, Cell Proliferation, 2002, 35, 105-115.

110 N. Kawashima, Y. Nishimiya, S. Takahata and K. I. Nakayama, J. Biol. Chem., 2016, 291, 21424-21433.

111 S. Kawamura, I. Sato, T. Wada, K. Yamaguchi, Y. Li, D. Li, X. Zhao, S. Ueno, H. Aoki, T. Tochigi, M. Kuwahara, T. Kitamura, K. Takahashi, S. Moriya and T. Miyagi, Cell Death Differ., 2012, 19, 170-179.

112 H. Wang, T. Isaji, M. Satoh, D. Li, Y. Arai and J. Gu, Urology, 2013, 81, 210.E11-210.E15.

113 K. Shiga, K. Takahashi, I. Sato, K. Kato, S. Saijo, S. Moriya, M. Hosono and T. Miyagi, Cancer Sci., 2015, 106, 1544-1553.

114 H. J. Choi, T. W. Chung, S. K. Kang, Y. C. Lee, J. H. Ko, J. G. Kim and C. H. Kim, Glycobiology, 2006, 16, 573-583.

115 K. Takahashi, M. Hosono, I. Sato, K. Hata, T. Wada, K. Yamaguchi, K. Nitta, H. Shima and T. Miyagi, Int. J. Cancer, 2015, 137, 1560-1573.

116 T. W. Chung, H. J. Choi, S. J. Kim, C. H. Kwak, K. H. Song, U. H. Jin, Y. C. Chang, H. W. Chang, Y. C. Lee, K. T. Ha and C. H. Kim, PLoS One, 2014, 9, e92786.

117 N. Sasaki, K. Hirabayashi, M. Michishita, K. Takahashi, F. Hasegawa, F. Gomi, Y. Itakura, N. Nakamura, M. Toyoda and T. Ishiwata, Sci. Rep., 2019, 9, 19369.

118 K. Nguyen, Y. Yan, B. Yuan, A. Dasgupta, J. Sun, H. Mu, K. A. Do, N. T. Ueno, M. Andreeff and V. Lokesh Battula, Mol. Cancer Ther., 2018, 17, 2689-2701.

119 A. Cazet, M. Bobowski, Y. Rombouts, J. Lefebvre, A. Steenackers, I. Popa, Y. Guérardel, X. Le Bourhis, D. Tulasne and P. Delannoy, Glycobiology, 2012, 22, 806-816.

120 T. Iwasawa, P. Zhang, Y. Ohkawa, H. Momota, T. Wakabayashi, Y. Ohmi, R. H. Bhuiyan, K. Furukawa and K. Furukawa, Int. J. Oncol., 2018, 52, 1255-1266. 
121 S. Yoshida, S. Fukumoto, H. Kawaguchi, S. Sato, R. Ueda and K. Furukawa, Cancer Res., 2001, 61, 4244-4252.

122 W. Aixinjueluo, K. Furukawa, Q. Zhang, K. Hamamura, N. Tokuda, S. Yoshida, R. Ueda and K. Furukawa, J. Biol. Chem., 2005, 280, 29828-29836.

123 S. Hyuga, N. Kawasaki, M. Hyuga, M. Ohta, R. Shibayama, T. Kawanishi, S. Yamagata, T. Yamagata and T. Hayakawa, Int. J. Cancer, 2001, 94, 328-334.

124 S. H. Ha, J. M. Lee, K. M. Kwon, C. H. Kwak, F. Abekura, J. Y. Park, S. H. Cho, K. Lee, Y. C. Chang, Y. C. Lee, H. J. Choi, T. W. Chung, K. T. Ha, H. W. Chang and C. H. Kim, Int. J. Mol. Sci., 2016, 17, 652.

125 J. H. Hwang, J. S. Sung, J. M. Kim, Y. H. Chung, J. S. Park, S. H. Lee and I. S. Jang, Am. J. Cancer Res., 2014, 4, 801-810.

126 R. Rajan, A. R. Sheth and S. S. Rao, Eur. J. Obstet. Gynecol. Reprod. Biol., 1983, 16, 37-46.

127 M. H. Alvi, N. A. Amer and I. Sumerin, Obstet. Gynecol., 1988, 72, 171-174.

128 E. Salvolini, R. Di Giorgio, A. Curatola, L. Mazzanti and G. Fratto, Br. J. Obstet. Gynaecol., 1998, 105, 656-660.

129 N. Moretti, R. A. Rabini, L. Nanetti, G. Grechi, M. C. Curzi, N. Cester, L. A. Tranquilli and L. Mazzanti, Metabolism, 2002, 51, 605-608.

130 M. Orczyk-Pawiłowicz, J. Floriański, J. Zalewski and I. Katnik-Prastowska, Glycoconjugate J., 2005, 22, 433-442.

131 Y. Zhu and M. Li, Int. J. Clin. Exp. Med., 2017, 10, 12322-12328.

132 S. Martín-Sosa, M. J. Martín, L. A. García-Pardo and P. Hueso, J. Pediatr. Gastroenterol. Nutr., 2004, 39, 499-503.

133 B. Wang, J. Brand-Miller, P. McVeagh and P. Petocz, Am. J. Clin. Nutr., 2001, 74, 510-515.

134 E. B. Isaacs, B. R. Fischl, B. T. Quinn, W. K. Chong, D. G. Gadian and A. Lucas, Pediatr. Res., 2010, 67, 357-362.

135 M. K. Kim and J.-W. Choi, Int. Breastfeed J., 2020, 15, 83.

136 S. Mills, R. P. Ross, C. Hill, G. F. Fitzgerald and C. Stanton, Int. Dairy J., 2011, 21, 377-401.

137 J. Lis-Kuberka and M. Orczyk-Pawiłowicz, Nutrients, 2019, 11, 306.

138 T. Urashima, J. Hirabayashi, S. Sato and A. Kobata, Trends Glycosci. Glycotechnol., 2018, 30, SE51-SE65.

139 M. K. McGuire, C. L. Meehan, M. A. McGuire, J. E. Williams, J. Foster, D. W. Sellen, E. W. Kamau-Mbuthia, E. W. Kamundia, S. Mbugua, S. E. Moore, A. M. Prentice, L. J. Kvist, G. E. Otoo, S. L. Brooker, W. J. Price, B. Shafii, C. Placek, K. A. Lackey, B. Robertson, S. Manzano, L. Ruíz, J. M. Rodríguez, R. G. Pareja and L. Bode, Am. J. Clin. Nutr., 2017, 105, 1086-1100.

140 D. S. Newburg, Am. J. Clin. Nutr., 2017, 105, 1027-1028.

141 EFSA NDA Panel (EFSA Panel on Dietetic Products Nutrition and Allergies), EFSA J., 2014, 12, 3760.

142 T. A. Lehti, M. I. Pajunen, M. S. Skog and J. Finne, Nat. Commun., 2017, 8, 1915.

143 S. Sakarya, G. T. Ertem, S. Oncu, I. Kocak, N. Erol and S. Oncu, FEMS Immunol. Med. Microbiol., 2003, 39, 45-50.

144 F. Schwarz, C. S. Landig, S. Siddiqui, I. Secundino, J. Olson, N. Varki, V. Nizet and A. Varki, EMBO J., 2017, 36, 751-760.
145 Z. Han, P. S. Thuy-Boun, W. Pfeiffer, V. F. Vartabedian, A. Torkamani, J. R. Teijaro and D. W. Wolan, Sci. Rep., 2021, 11, 4763.

146 T. D. Mubaiwa, E. A. Semchenko, L. E. Hartley-tassell, C. J. Day, M. P. Jennings and K. L. Seib, Pathog. Dis., 2017, 75, ftx063.

147 G. A. Jarvis and N. A. Vedros, Infect. Immun., 1987, 55, 174-180.

148 C. Jones, M. Virji and P. R. Crocker, Mol. Microbiol., 2003, 49, 1213-1225.

149 S. L. Xiang, M. Zhong, F. C. Cai, B. Deng and X. P. Zhang, J. Neuroimmunol., 2006, 174, 126-132.

150 R. Huizinga, W. Van Rijs, J. J. Bajramovic, M. L. Kuijf, J. D. Laman, J. N. Samsom and C. Jacobs, J. Immunol., 2013, 191, 5636-5645.

151 M. Bax, M. L. Kuijf, A. P. Heikema, W. van Rijs, S. C. M. Bruijns, J. J. García-Vallejo, P. R. Crocker, B. C. Jacobs, S. J. van Vliet and Y. van Kooyk, Infect. Immun., 2011, 79, 2681-2689.

152 S. Uchiyama, J. Sun, K. Fukahori, N. Ando, M. Wu, F. Schwarz and S. S. Siddiqui, Proc. Natl. Acad. Sci. U. S. A., 2019, 116, 7465-7470.

153 S. Weiman, S. Uchiyama, F.-Y. C. Lin, D. Chaffin, A. Varki, V. Nizet and A. L. Lewis, Biochem. J., 2013, 428, 163-168.

154 P. S. K. Ng, C. J. Day, J. M. Atack, L. E. Hartley-Tassell, L. E. Winter, T. Marshanski, V. Padler-Karavani, A. Varki, S. J. Barenkamp, M. A. Apicella and M. P. Jennings, MBio, 2019, 10, e00422-19.

155 K. Hentrich, J. Löfling, A. Pathak, V. Nizet, A. Varki and B. Henriques-Normark, Cell Host Microbe, 2016, 20, 307-317.

156 B. Khatua, A. Ghoshal, K. Bhattacharya, C. Mandal, B. Saha, P. R. Crocker and C. Mandal, FEBS Lett., 2010, 584, 555-561.

157 B. Khatua, K. Bhattacharya and C. Mandal, J. Leukocyte Biol., 2012, 91, 641-655.

158 S. Ram, J. Shaughnessy, R. B. De Oliveira, L. A. Lewis, S. Gulati and P. A. Rice, Pathog. Dis., 2017, 75, ftx049.

159 S. M. Spinola, W. Li, K. R. Fortney, D. M. Janowicz, B. Zwickl, B. P. Katz and R. S. Munson, Infect. Immun., 2012, 80, 679-687.

160 F. M. Tatum, L. B. Tabatabai and R. E. Briggs, Microb. Pathog., 2009, 46, 337-344.

161 A. Varki and P. Gagneux, Proc. Natl. Acad. Sci. U. S. A., 2009, 106, 14739-14740.

162 I. Moustafa, H. Connaris, M. Taylor, V. Zaitsev, J. C. Wilson, M. J. Kiefel, M. Von Itzstein and G. Taylor, J. Biol. Chem., 2004, 279, 40819-40826.

163 S. Almagro-Moreno and E. F. Boyd, Infect. Immun., 2009, 77, 3807-3816.

164 M. Unemo, M. Aspholm-Hurtig, D. Ilver, J. Bergström, T. Borén, D. Danielsson and S. Teneberg, J. Biol. Chem., 2005, 280, 15390-15397.

165 P. Zhou, J. Liu, X. Li, Y. Takahashi and F. Qi, PLoS One, 2015, 10, e0143898.

166 H. Geyer, C. Holschbach, G. Hunsmann and J. Schneider, J. Biol. Chem., 1988, 263, 11760-11767. 
167 Z. Zou, A. Chastain, S. Moir, J. Ford, K. Trandem, E. Martinelli, C. Cicala, P. Crocker, J. Arthos and P. D. Sun, PLoS One, 2011, 6, e24559.

168 S. Varchetta, P. Lusso, K. Hudspeth, J. Mikulak, D. Mele, S. Paolucci, R. Cimbro, M. Malnati, A. Riva, R. Maserati, M. U. Mondelli and D. Mavilio, Retrovirology, 2013, 10, 154.

169 J. Wang, Q. Fan, T. Satoh, J. Arii, L. L. Lanier, P. G. Spear, Y. Kawaguchi and H. Arase, J. Virol., 2009, 83, 13042-13045.

170 Q. Lu, G. Lu, J. Qi, H. Wang, Y. Xuan, Q. Wang, Y. Lia, Y. Zhang, C. Zheng, Z. Fana, J. Yan and G. F. Gao, Proc. Natl. Acad. Sci. U. S. A., 2014, 111, 8221-8226.

171 A. S. Kondratowicz, N. J. Lennemann, P. L. Sinn, R. A. Davey, C. L. Hunt, S. Moller-Tank, D. K. Meyerholz, P. Rennert, R. F. Mullins, M. Brindley, L. M. Sandersfeld, K. Quinn, M. Weller, P. B. McCray, J. Chiorini and W. Maury, Proc. Natl. Acad. Sci. U. S. A., 2011, 108, 8426-8431.

172 S. Yuan, L. Cao, H. Ling, M. Dang, Y. Sun, X. Zhang, Y. Chen, L. Zhang, D. Su, X. Wang and Z. Rao, Protein Cell, 2015, 6, 814-824.

173 D. Perez-Zsolt, I. Erkizia, M. Pino, M. García-Gallo, M. T. Martin, S. Benet, J. Chojnacki, M. T. Fernández-Figueras, D. Guerrero, V. Urrea, X. Muñiz-Trabudua, L. Kremer, J. Martinez-Picado and N. Izquierdo-Useros, Nat. Microbiol., 2019, 4, 1558-1570.

174 C. W. Tan, C. H. Huan Hor, S. Sen Kwek, H. K. Tee, I. C. Sam, E. L. K. Goh, E. E. Ooi, Y. F. Chan and L. F. Wang, Emerging Microbes Infect., 2019, 8, 426-437.

175 J. Cime-Castillo, P. Delannoy, G. Mendoza-Hernández, V. Monroy-Martínez, A. Harduin-Lepers, H. Lanz-Mendoza, F. D. L. C. Hernández-Hernández, E. Zenteno, C. CabelloGutiérrez and B. H. Ruiz-Ordaz, BioMed Res. Int., 2015, 504187.

176 G. Zocher, N. Mistry, M. Frank, I. Hähnlein-Schick, J. O. Ekström, N. Arnberg and T. Stehle, PLoS Pathog., 2014, 10, e1004401.

177 T. Imamura, M. Okamoto, S.-I. Nakakita, A. Suzuki, M. Saito, R. Tamaki, S. Lupisan, C. N. Roy, H. Hiramatsu, K.-E. Sugawara, K. Mizuta, Y. Matsuzaki, Y. Suzuki, H. Oshitani and S. Perlman, J. Virol., 2014, 88, 2374-2384.

178 L. T. Jae, M. Raaben, A. S. Herbert, A. I. Kuehne, A. S. Wirchnianski, T. K. Soh, S. H. Stubbs, H. Janssen, M. Damme, P. Saftig, S. P. Whelan, J. M. Dye and T. R. Brummelkamp, Science, 2014, 344, 1506-1510.

179 F. Superti, B. Hauttecoeur, M. J. Morelec, P. Goldoni, B. Bizzini and H. Tsiang, J. Gen. Virol., 1986, 67, 47-56.

180 G. Ayora-Talavera, J. Recept., Ligand Channel Res., 2018, 10, $1-11$.

181 K. Shinya, M. Ebina, S. Yamada, M. Ono, N. Kasai and Y. Kawaoka, Nature, 2006, 440, 435-436.

182 N. Limsuwat, O. Suptawiwat, C. Boonarkart, P. Puthavathana, W. Wiriyarat and P. Auewarakul, Arch. Virol., 2016, 161, 649-656.

183 Z. Chen, W. Chen, Q. Wang, Y. Qin, X. Wang, T. Ma, P. Zhang, X. Li, X. Wang, L. Ding and Z. Li, J. Mol. Struct., 2021, 1230, 129859.
184 L. Ding, X. Fu, W. Guo, Y. Cheng, X. Chen, K. Zhang, G. Zhu, F. Yang, H. Yu, Z. Chen, X. Wang, X. Wang, X. Wang and Z. Li, Int. J. Biol. Macromol., 2021, 184, 339-348.

185 T. Ginex and F. J. Luque, Expert Opin. Ther. Pat., 2021, 31, 53-66.

186 R. E. Forgione, C. Di Carluccio, M. Kubota, Y. Manabe, K. Fukase, A. Molinaro, T. Hashiguchi, R. Marchetti and A. Silipo, Sci. Rep., 2020, 10, 1589.

187 M. Amonsen, D. F. Smith, R. D. Cummings and G. M. Air, J. Virol., 2007, 81, 8341-8345.

188 I. V. Alymova, A. Portner, V. P. Mishin, J. A. McCullers, P. Freiden and G. L. Taylor, Glycobiology, 2012, 22, 174-180.

189 L.-Y. Huang, A. Patel, R. Ng, E. B. Miller, S. Halder, R. McKenna, A. Asokan and M. Agbandje-McKenna, J. Virol., 2016, 90, 5219-5230.

190 R. Burger-Calderon and J. Webster-Cyriaque, Cancers, 2015, 7, 1244-1270.

191 N. J. Bayer, D. Januliene, G. Zocher, T. Stehle, A. Moeller and B. S. Blaum, J. Virol., 2020, 94, e01664-19.

192 C. K. Liu, G. Wei and W. J. Atwood, J. Virol., 1998, 72, 4643-4649.

193 D. M. Reiter, J. M. Frierson, E. E. Halvorson, T. Kobayashi, T. S. Dermody and T. Stehle, PLoS Pathog., 2011, 7, e1002166.

194 K. Reiss, J. E. Stencel, Y. Liu, B. S. Blaum, D. M. Reiter, T. Feizi, T. S. Dermody and T. Stehle, PLoS Pathog., 2012, 8, e1003078.

195 T. Haselhorst, F. E. Fleming, J. C. Dyason, R. D. Hartnell, X. Yu, G. Holloway, K. Santegoets, M. J. Kiefel, H. Blanchard, B. S. Coulson and M. Von Itzstein, Nat. Chem. Biol., 2009, 5, 91-93.

196 S. M. Cashman, D. J. Morris and R. Kumar-Singh, Virology, 2004, 324, 129-139.

197 E. C. Nilsson, R. J. Storm, J. Bauer, S. M. C. Johansson, A. Lookene, J. Ångström, M. Hedenström, T. L. Eriksson, L. FräCurrency Signngsmyr, S. Rinaldi, H. J. Willison, F. P. Domellöf, T. Stehle and N. Arnberg, Nat. Med., 2011, 17, 105-109.

198 A. Lenman, A. Manuel Liaci, Y. Liu, L. Frängsmyr, M. Frank, B. S. Blaum, W. Chai, I. I. Podgorski, B. Harrach, M. Benko, T. Feizi, T. Stehle and N. Arnberg, Proc. Natl. Acad. Sci. U. S. A., 2018, 115, E4264-E42736.

199 D. X. Liu, J. Q. Liang and T. S. Fung, Encyclopedia of Virology, 2021, vol. 2, pp. 428-440.

200 L. Guruprasad, Prog. Biophys. Mol. Biol., 2021, 161, 39-53.

201 A. H. M. Wong, A. C. A. Tomlinson, D. Zhou, M. Satkunarajah, K. Chen, C. Sharon, M. Desforges, P. J. Talbot and J. M. Rini, Nat. Commun., 2017, 8, 1735.

202 X. Zhao, F. Guo, M. A. Comunale, A. Mehta, M. Sehgal, P. Jain, A. Cuconati, H. Lin, T. M. Block, J. Chang and J. T. Guo, Antimicrob. Agents Chemother., 2015, 59, 206-216.

203 R. J. G. Hulswit, Y. Lang, M. J. G. Bakkers, W. Li, Z. Li, A. Schouten, B. Ophorst, F. J. M. Van Kuppeveld, G. J. Boons, B. J. Bosch, E. G. Huizinga and R. J. De Groot, Proc. Natl. Acad. Sci. U. S. A., 2019, 116, 2681-2690. 
204 W. Li, R. J. G. Hulswit, I. Widjaja, V. S. Raj, R. McBride, W. Peng, W. Widagdo, M. A. Tortorici, B. Van Dieren, Y. Lang, J. W. M. Van Lent, J. C. Paulson, C. A. M. De Haan, R. J. De Groot, F. J. M. Van Kuppeveld, B. L. Haagmans and B. J. Bosch, Proc. Natl. Acad. Sci. U. S. A., 2017, 114, E8508-E8517.

205 M. Örd, I. Faustova and M. Loog, Sci. Rep., 2020, 10, 16944.

206 M. Seyran, K. Takayama, V. N. Uversky, K. Lundstrom, G. Palù, S. P. Sherchan, D. Attrish, N. Rezaei, A. A. A. Aljabali, S. Ghosh, D. Pizzol, G. Chauhan, P. Adadi, T. Mohamed Abd El-Aziz, A. G. Soares, R. Kandimalla, M. Tambuwala, S. S. Hassan, G. K. Azad, P. Pal Choudhury, W. Baetas-daCruz, Á. Serrano-Aroca, A. M. Brufsky and B. D. Uhal, FEBS J., 2021, 288, 5010-5020.

207 M. Awasthi, S. Gulati, D. P. Sarkar, S. Tiwari, S. Kateriya, P. Ranjan and S. K. Verma, Viruses, 2020, 12, 909.

208 L. Pruimboom, Med. Hypotheses, 2021, 146, 110368.

209 E. Milanetti, M. Miotto, L. Di Rienzo, M. Nagaraj, M. Monti, T. W. Golbek, G. Gosti, S. J. Roeters, T. Weidner, D. E. Otzen and G. Ruocco, Front. Mol. Biosci., 2021, 8, 690655.

210 B. Li, L. Wang, H. Ge, X. Zhang, P. Ren, Y. Guo, W. Chen, J. Li, W. Zhu, W. Chen, L. Zhu and F. Bai, Front. Chem., 2021, 9, 659764.

211 V. C. Divya and B. Saravanakarthikeyan, J. Oral Biosci., 2021, DOI: 10.1016/j.job.2021.08.004, In Press.

212 N. Z. Cuervo and N. Grandvaux, eLife, 2020, 9, e61390.

213 W. Hao, B. Ma, Z. Li, X. Wang, X. Gao, Y. Li, B. Qin, S. Shang, S. Cui and Z. Tan, Sci. Bull., 2021, 66, 1205-1214.

214 A. Shajahan, S. Archer-Hartmann, N. T. Supekar, A. S. Gleinich, C. Heiss and P. Azadi, Glycobiology, 2021, 31, 410-424.

215 Q. Yang, T. A. Hughes, A. Kelkar, X. Yu, K. Cheng, S. J. Park, W. C. Huang, J. F. Lovell and S. Neelamegham, eLife, 2020, 9, e61552.

216 H. Chu, B. Hu, X. Huang, Y. Chai, D. Zhou, Y. Wang, H. Shuai, D. Yang, Y. Hou, X. Zhang, T. T. T. Yuen, J. P. Cai, A. J. Zhang, J. Zhou, S. Yuan, K. K. W. To, I. H. Y. Chan, K. Y. Sit, D. C. C. Foo, I. Y. H. Wong, A. T. L. Ng, T. T. Cheung, S. Y. K. Law, W. K. Au, M. A. Brindley, Z. Chen, K. H. Kok, J. F. W. Chan and K. Y. Yuen, Nat. Commun., 2021, 12, 134.

217 C. Dhar, A. Sasmal, S. Diaz, A. Verhagen, H. Yu, W. Li, X. Chen and A. Varki, Glycobiology, 2021, 31, 1068-1071.

218 L. Nguyen, K. A. McCord, D. T. Bui, K. M. Bouwman, E. N. Kitova, M. Elaish, D. Kumawat, G. C. Daskhan, I. Tomris, L. Han, P. Chopra, T.-J. Yang, S. D. Willows, A. L. Mason, L. K. Mahal, T. L. Lowary, L. J. West, S.-T. D. Hsu, T. Hobman, S. M. Tompkins, G.-J. Boons, R. P. de Vries, M. S. Macauley and J. S. Klassen, Nat. Chem. Biol., 2021, DOI: 10.1038/ s41589-021-00924-1.

219 E. Song, C. Zhang, B. Israelow, A. Lu-Culligan, A. Vieites Prado, S. Skriabine, P. Lu, O.-E. Weizman, F. Liu, Y. Dai, K. Szigeti-Buck, Y. Yasumoto, G. Wang, C. Castaldi, J. Heltke, E. Ng, J. Wheeler, M. M. Alfajaro, E. Levavasseur, B. Fontes, N. G. Ravindra, D. V. Dijk, S. Mane, M. Gunel, A. Ring, S. A. J. Kazmi, K. Zhang, C. B. Wilen, T. L. Horvath, I. Plu,
S. Haik, J.-L. Thomas, A. Louvi, S. F. Farhadian, A. Huttner, D. Seilhean, N. Renier, K. Bilguvar and A. Iwasaki, J. Exp. Med., 2021, 218, e20202135.

220 C. M. Salvatore, J.-Y. Han, K. P. Acker, P. Tiwari, J. Jin, M. Brandler, C. Cangemi, L. Gordon, A. Parow, J. DiPace and P. DeLaMora, Lancet Child Adolesc. Health, 2020, 4, 721-727.

221 J. C. Silva-Filho, C. G. F. de Melo and J. L. de Oliveira, Med. Hypotheses, 2020, 144, 110155.

222 R. Uraki and Y. Kawaoka, Nat. Chem. Biol., 2021, DOI: 10.1038/s41589-021-00923-2.

223 T. A. Altalhi, K. Alswat, W. F. Alsanie, M. M. Ibrahim, A. Aldalbahi and H. S. El-Sheshtawy, J. Mol. Struct., 2021, 1228, 129459.

224 P. Colson, J. M. Rolain, J. C. Lagier, P. Brouqui and D. Raoult, Int. J. Antimicrob. Agents, 2020, 55, 105932.

225 C. Prodromos and T. Rumschlag, New Microbes New Infect., 2020, 38, 100776.

226 N. Sinha and G. Balayla, Postgrad. Med. J., 2020, 96, 550-555.

227 J. K. Sun, Y. T. Chen, X. De Fan, X. Y. Wang, Q. Y. Han and Z. W. Liu, Postgrad. Med., 2020, 132, 604-613.

228 M. Wang, R. Cao, L. Zhang, X. Yang, J. Liu, M. Xu, Z. Shi, Z. Hu, W. Zhong and G. Xiao, Cell Res., 2020, 30, 269-271.

229 J. A. Al-Tawfiq, A. H. Al-Homoud and Z. A. Memish, Travel Med. Infect. Dis., 2020, 34, 101615.

230 A. N. Baker, S. J. Richards, C. S. Guy, T. R. Congdon, M. Hasan, A. J. Zwetsloot, A. Gallo, J. R. Lewandowski, P. J. Stansfeld, A. Straube, M. Walker, S. Chessa, G. Pergolizzi, S. Dedola, R. A. Field and M. I. Gibson, ACS Cent. Sci., 2020, 6, 2046-2052.

231 M. Renlund, M. A. Chester, A. Lundblad, P. Aula, K. O. Raivio, S. Autio and S.-L. Koskela, Eur. J. Biochem., 1979, 101, 245-250.

232 L. W. Hancock, M. M. Thaler, A. L. Horwitz and G. Dawson, J. Neurochem., 1982, 38, 803-808.

233 L. W. Hancock, A. L. Horwitz and G. Dawson, Biochim. Biophys. Acta, 1983, 760, 42-52.

234 G. H. Thomas, J. Scocca, C. S. Miller and L. Reynolds, Clin. Genet., 1989, 36, 242-249.

235 G. Strecker, M.-C. Peers, J.-C. Michalski, T. Hondi-Assah, B. Fournet, G. Spik, J. Montreuil, J.-P. Farriaux, P. Maroteaux and P. Durand, Eur. J. Biochem., 1977, 75, 391-403.

236 M. F. Goldberg, E. Cotlier, L. G. Fichenscher, K. Kenyon, R. Enat and S. A. Borowsky, Arch. Intern. Med., 1971, 128, 387-398.

237 T. Yardeni, T. Choekyi, K. Jacobs, C. Ciccone, K. Patzel, Y. Anikster, W. A. Gahl, N. Kurochkina and M. Huizing, Biochemistry, 2011, 50, 8914-8925.

238 C. Tran, L. Turolla, D. Ballhausen, S. C. Buros, T. Teav, H. Gallart-Ayala, J. Ivanisevic, M. Faouzi, D. J. Lefeber, I. Ivanovski, S. Giangiobbe, S. G. Caraffi, L. Garavelli and A. Superti-Furga, Mol. Genet. Metab. Rep., 2021, 28, 100777.

239 L. F. Mollashahi, M. Honarmand, A. Nakhaee and G. Mollashahi, Int. J. High Risk Behav. Addict., 2016, 5, e27969.

240 N. Kurtul and E. Gkpnar, Mediators Inflammation, 2012, 2012, 619293. 
241 N. Waszkiewicz, S. D. Szajda, A. Kȩpka, A. Szulc and K. Zwierz, Biochem. Soc. Trans., 2011, 39, 365-369.

242 J. Romppanen, K. Punnonen, P. Anttila, T. Jakobsson, J. Blake and O. Niemelä, Alcohol.: Clin. Exp. Res., 2002, 26, 1234-1238.

243 P. Ghosh, E. A. Hale and M. R. Lakshman, Alcohol, 2001, 25, 173-179.

244 F. M. Wurst, N. Thon, W. Weinmann, S. Tippetts, P. Marques, J. A. Hahn, C. Alling, S. Aradottir, S. Hartmann and R. Lakshman, Alcohol.: Clin. Exp. Res., 2012, 36, 251-257.

245 B. Cylwik, L. Chrostek, A. Krawiec, Z. Supronowicz, A. Koput and M. Szmitkowski, Alcohol, 2010, 44, 457-462.

246 P. Sillanaukee, M. Pönniö and K. Seppä, Alcohol.: Clin. Exp. Res., 1999, 23, 1039-1043.

247 T. Alam, R. Cherian, P. T. Raman and A. S. Balasubramanian, J. Neurol., Neurosurg. Psychiatry, 1976, 39, 1201-1203.

248 Y. Nagata, A. Hirayama, S. Ikeda, A. Shirahata, F. Shoji, M. Maruyama, M. Kayano, M. Bundo, K. Hattori, S. Yoshida, Y.-I. Goto, K. Urakami, T. Soga, K. Ozaki and S. Niida, Biomark. Res., 2018, 6, 5.

249 J. Yadav, A. K. Verma, R. K. Garg, K. Ahmad, Shiuli, A. A. Mahdi and S. Srivastava, Exp. Gerontol., 2020, 141, 111092.

250 F. Mochel, F. Sedel, A. Vanderver, U. F. H. Engelke, J. Barritault, B. Z. Yang, B. Kulkarni, D. R. Adams, F. Clot, J. H. Ding, C. R. Kaneski, F. W. Verheijen, B. W. Smits, F. Seguin, A. Brice, M. T. Vanier, M. Huizing, R. Schiffmann, A. Durr and R. A. Wevers, Brain, 2009, 132, 801-809.

251 E. Demirci, Y. Guler, S. Ozmen, M. Canpolat and S. Kumandas, Clin. Psychopharmacol. Neurosci., 2019, 17, 415-422.

252 X. Yang, S. Liang, L. Wang, P. Han, X. Jiang, J. Wang, Y. Hao and L. Wu, Brain Res., 2018, 1678, 273-277.

253 M. A. Crook, P. Tutt, H. Simpson and J. C. Pickup, Clin. Chim. Acta, 1993, 219, 131-138.

254 T. Ozben, S. Nacitarhan and N. Tuncer, Ann. Clin. Biochem., 1995, 32, 303-306.

255 J. Roozbeh, A. Merat, F. Bodagkhan, R. Afshariani and H. Yarmohammadi, Int. Urol. Nephrol., 2011, 43, 1143-1148.

256 S. Shahvali, A. Shahesmaeili, M. Sanjari and S. KaramiMohajeri, Diabetol. Int., 2020, 11, 19-26.

257 P. Khalili, J. Sundström, J. Jendle, F. Lundin, I. Jungner and P. M. Nilsson, Prim. Care Diabetes, 2014, 8, 352-357.

258 R. B. Findik, F. M. Yilmaz, G. Yilmaz, H. Yilmaz and J. Karakaya, Arch. Gynecol. Obstet., 2012, 286, 913-916.

259 H. Dogan and H. Pagaoglu, Acta Ophthalmol., 1992, 70, 790-794.

260 I. Zipkin, S. E. Mergenhagen and R. Kass, Biochem. Biophys. Res. Commun., 1961, 4, 76-78.

261 S. R. Rathod, F. Khan, A. P. Kolte and M. Gupta, J. Clin. Diagn. Res., 2014, 8, 19-21.

262 A. Hernández-Cedillo, M. G. García-Valdivieso, A. C. Hernández-Arteaga, N. Patiño-Marín, Á. A. VértizHernández, M. José-Yacamán and H. R. Navarro-Contreras, Oral Dis., 2019, 25, 1627-1633.
263 S. Oktay, Ö. Ö. Bal, L. Kuru, A. Yarat and Ü. Noyan, Niger. J. Clin. Pract., 2020, 23, 603-609.

264 M. Crook, M. Haq, S. Haq and P. Tutt, Angiology, 1994, 45, 709-715.

265 M. N. Li, S. H. Qian, Z. Y. Yao, S. P. Ming, X. J. Shi, P. F. Kang, N. R. Zhang, X. J. Wang, D. S. Gao, Q. Gao, H. Zhang and H. J. Wang, BMC Cardiovasc. Disord., 2020, 20, 404.

266 P. Khalili, J. Sundström, S. S. Franklin, J. Jendle, F. Lundin, I. Jungner and P. M. Nilsson, J. Hypertens., 2012, 30, 1718-1724.

267 L. Zhang, T. T. Wei, Y. Li, J. Li, Y. Fan, F. Q. Huang, Y. Y. Cai, G. Ma, J. F. Liu, Q. Q. Chen, S. L. Wang, H. Li, R. N. Alolga, B. Liu, D. S. Zhao, J. H. Shen, X. M. Wang, W. Zhu, P. Li and L. W. Qi, Circulation, 2018, 137, 1374-1390.

268 M. T. Goodarzi, M. Rezaei, E. Moadel, S. Homayounfar and M. R. Safari, Eur. J. Lipid Sci. Technol., 2008, 110, 302-306.

269 S. Oktay, I. Basar, E. Emekli-Alturfan, E. Malali, E. Elemek, F. Ayan, L. Koldas, U. Noyan and N. Emekli, Pathophysiol. Haemostasis Thromb., 2009, 37, 67-71.

270 L. Råstam, G. Lindberg, A. R. Folsom, G. L. Burke, P. Nilsson-Ehle and A. Lundblad, Int. J. Epidemiol., 1996, 25, 953-958.

271 M. Crook and W. U-test, Clin. Sci., 1992, 83, 593-595.

272 P. A. Larnba, P. K. Pandey, G. S. Sarin and M. D. Mathur, Acta Ophthalmol., 1993, 71, 833-835.

273 M. Altay, M. A. Karakoç, N. Çakır, C. Yılmaz Demirtaş, E. T. Cerit, M. Aktürk, İ. Ateş, N. Bukan and M. Arslan, J. Clin. Lab. Anal., 2017, 31, e22034.

274 R. Baba, K. Yashiro, K. Nagasako and H. Obata, Gastroenterol. Jpn., 1992, 27, 604-610.

275 E. Gruszewska, B. Cylwik, M. Gudowska, A. Panasiuk, R. Flisiak and L. Chrostek, Ann. Clin. Biochem., 2019, 56, 118-122.

276 B. Cylwik, L. Chrostek, B. Zalewski, A. Dabrowski and M. Szmitkowski, Dig. Dis. Sci., 2007, 52, 2317-2322.

277 B. Cylwik, L. Chrostek, A. Panasiuk and M. Szmitkowski, Clin. Chem. Lab. Med., 2010, 48, 137-139.

278 T. Özben, Ann. Clin. Biochem., 1991, 28, 44-48.

279 F. Fuentes, N. Carrillo, K. J. Wilkins, J. Blake, P. Leoyklang, W. A. Gahl, J. B. Kopp and M. Huizing, Kidney360, 2020, 1, 957-961.

280 S. S. Demir, H. Ç. Özcan, Ö. Balat, E. Öztürk, M. G. Uğur, R. Gündüz and S. Taysi, J. Obstet. Gynaecol., 2018, 38, 532-535.

281 F. M. Von Versen-Hoeynck, C. A. Hubel, M. J. Gallaher, H. S. Gammill and R. W. Powers, Am. J. Hypertens., 2009, 22, 687-692.

282 R. O'Kennedy, G. Berns, E. Moran, H. Smyth, K. Carroll, R. D. Thornes, A. O'Brien, J. Fennelly and M. Butler, Cancer Lett., 1991, 58, 91-100.

283 R. Iijima, H. Takahashi, S. Ikegami and M. Yamazaki, Biol. Pharm. Bull., 2007, 30, 580-582.

284 N. Kurtul and B. C. Arikan, Acta Med., 2006, 49, 97-100.

285 A. Cardenas, A. M. Bernard and R. R. Lauwerys, Toxicol. Appl. Pharmacol., 1991, 108, 547-558. 
286 Y. Wang, A. Khan, A. Antonopoulos, L. Bouché, C. D. Buckley, A. Filer, K. Raza, K. P. Li, B. Tolusso, E. Gremese, M. Kurowska-Stolarska, S. Alivernini, A. Dell, S. M. Haslam and M. A. Pineda, Nat. Commun., 2021, 12, 2343.

287 R. E. Taylor, C. J. Gregg, V. Padler-Karavani, D. Ghaderi, H. Yu, S. Huang, R. U. Sorensen, X. Chen, J. Inostroza, V. Nizet and A. Varki, J. Exp. Med., 2010, 207, 1637-1646.

288 L. Le Berre, J. Rousse, P. A. Gourraud, B. M. ImbertMarcille, A. Salama, G. Evanno, G. Semana, A. Nicot, E. Dugast, P. Guérif, C. Adjaoud, T. Freour, S. Brouard, F. Agbalika, R. Marignier, D. Brassat, D. A. Laplaud, E. Drouet, V. Van Pesch and J. P. Soulillou, Clin. Immunol., 2017, 180, 128-135.

289 Y. Chen, L. Pan, N. Liu, F. A. Troy and B. Wang, J. Geophys. Res. Oceans, 2014, 111, 332-341.

290 L. Tolenaars, D. Romanazzi, E. Carpenter, S. Gallier and C. G. Prosser, Int. Dairy J., 2021, 117, 105012.

291 H. Li and X. Fan, Open J. Prev. Med., 2014, 04, 57-63.

292 H. L. Yao, L. P. Conway, M. M. Wang, K. Huang, L. Liu and J. Voglmeir, Glycoconjugate J., 2016, 33, 219-226.

293 M. Hedlund, V. Padler-Karavani, N. M. Varki and A. Varki, Proc. Natl. Acad. Sci. U. S. A., 2008, 105, 18936-18941.

294 A. N. Samraj, H. Läubli, N. Varki and A. Varki, Front. Oncol., 2014, 4, 33.

295 P. R. Sanjay, K. Hallikeri and A. R. Shivashankara, Indian J. Dent. Res., 2008, 19, 288-291.

296 K. S. C. Bose, P. V. Gokhale, S. Dwivedi and M. Singh, J. Nat. Sci., Biol. Med., 2013, 4, 122-125.

297 R. D. Xing, Z. S. Wang, C. Q. Li, Q. Y. Tang, C. B. Jiang and Y. Z. Zhang, Int. J. Biol. Markers, 1994, 9, 239-242.

298 S. Wongkham, C. Boonla, S. Kongkham, C. Wongkham, V. Bhudhisawasdi and B. Sripa, Clin. Biochem., 2001, 34, 537-541.

299 C. Feijoo-Carnero, F. J. Rodríguez-Berrocal, M. Páez de la Cadena, D. Ayude, A. de Carlos and V. S. Martínez-Zorzano, Int. J. Biol. Markers, 2004, 19, 38-45.

300 A. Semczuk, M. Cybulski, A. Paszkowska and H. Berbec, Eur. J. Obstet. Gynecol. Reprod. Biol., 1998, 76, 211-215.

301 S. Inoue, S. L. Lin, T. Chang, S. H. Wu, C. W. Yao, T. Y. Chu, F. A. Troy and Y. Inoue, J. Biol. Chem., 1998, 273, 27199-27204.

302 F. Wang, B. Xie, B. Wang and F. A. Troy, Glycobiology, 2015, 25, 1362-1374.

303 D. Konukoglu, T. Akqay and A. Ergzenci, Cancer Lett., 1995, 94, 97-100.

304 T. Akqay, D. Konukoglua, S. Atausb, A. Dirican and C. Uygur, Cancer Lett., 1994, 78, 7-9.

305 M. Payazdan, S. Khatami, H. Galehdari, N. Delfan, M. Shafiei and S. Heydaran, Gene Rep., 2021, 24, 101218.

306 J. E. Martin, S. W. Tanenbaum and M. Flashner, Carbohydr. Res., 1977, 56, 423-425.

307 Z. C. F. Wong, G. K. L. Chan, K. Q. Y. Wu, K. K. M. Poon, Y. Chen, T. T. X. Dong and K. W. K. Tsim, Food Funct., 2018, 9, 5139-5149.

308 N. H. Jamalluddin, N. A. Tukiran, N. Ahmad Fadzillah and S. Fathi, Food Control, 2019, 104, 247-255.
309 X. Ma, J. Zhang, J. Liang, X. Ma, R. Xing, J. Han, L. Guo and Y. Chen, Food Res. Int., 2019, 125, 108639.

310 N. Daud, S. Mohamad Yusop, A. S. Babji, S. J. Lim, S. R. Sarbini and T. Hui Yan, Food Rev. Int., 2021, 37, 177-196.

311 Y. Dai, J. Cao, Y. Wang, Y. Chen and L. Jiang, Food Res. Int., 2021, 140, 109875.

312 T. Nakano and M. Betti, J. Dairy Res., 2020, 87, 364-367.

313 R. J. McMahon, M. F. Locniskar, S. C. Rumsey, J. C. Anthony and R. Wantanagorn, US7951410B2, 2011.

314 https:/www.thegreenpharmacy.com/sialex-90-caps-p6399. html (Accessed November 2021).

315 https://www.ecologicalformulas.net/ (Accessed November 2021).

316 https://www.ulprospector.com/en/na/Food/Detail/5331/ 190810/Lacprodan-CGMP-10 (Accessed November 2021).

317 S. J. Danishefsky, M. P. DeNinno and S. Hui Chen, J. Am. Chem. Soc., 1988, 110, 3929-3940.

318 C. De Meo and B. T. Jones, in Advances in Carbohydrate Chemistry and Biochemistry, ed. D. C. Baker, Elsevier, 75th edn, 2018, pp. 215-316.

319 N. Komura, K. Kato, T. Udagawa, S. Asano, H. N. Tanaka, A. Imamura, H. Ishida, M. Kiso and H. Ando, Science, 2019, 364, 677-680.

320 A. M. Vibhute, N. Komura, H. N. Tanaka, A. Imamura and H. Ando, Chem. Rec., 2021, 21, 1-31.

321 X. Chen and A. Varki, ACS Chem. Biol., 2010, 5, 163-176.

322 C. C. Yu and S. G. Withers, Adv. Synth. Catal., 2015, 357, 1633-1654.

323 W. Li, J. B. McArthur and X. Chen, Carbohydr. Res., 2019, 472, 86-97.

324 A. S. Kooner, H. Yu and X. Chen, Front. Immunol., 2019, 10, 2004.

325 I. Maru, J. Ohnishi, Y. Ohta and Y. Tsukada, J. Biosci. Bioeng., 2002, 93, 258-265.

326 M. J. Dawson, D. Noble and M. Mahmoudian, USOO6156544A, 2000.

327 U. Kragl, D. Gygax, O. Ghisalba and C. Wandrey, Angew. Chem., Int. Ed. Engl., 1991, 30, 827-828.

328 J. Lee, J. Yi, S. Lee, S. Takahashi and B. Kim, Enzyme Microb. Technol., 2004, 35, 121-125.

329 X. Gao, F. Zhang, M. Wu, Z. Wu and G. Shang, J. Agric. Food Chem., 2019, 67, 6285-6291.

330 V. R. L. J. Bloemendal, S. J. Moons, J. J. A. Heming, M. Chayoua, O. Niesink, J. C. M. Van Hest, T. J. Boltje and F. P. J. T. Rutjes, Adv. Synth. Catal., 2019, 361, 2443-2447.

331 https://www.glycom.com/ (Accessed November 2021).

332 https://www.dsm.com/corporate/home.html (Accessed November 2021).

333 A. Schroven, G. Dekany and I. Vrasidas, WO2013088267Al, 2013.

334 M. Shiba and S. Koizumi, EP1484406B1, 2004.

335 D. Zhu, W. Xiao, L. Zhu and Y. Jiang, J. Ind. Microbiol. Biotechnol., 2019, 46, 125-132.

336 B. Wang, Annu. Rev. Nutr., 2009, 29, 177-222. 
337 B. Wang, Adv. Nutr., 2012, 3, 465-472.

338 J. M. Gil-Robles and G. Zalm, Official Journal of the European Communities, 1997, L43, 1-6.

339 Report of the Scientific Committee on Food on the Revision of Essential Requirements of Infant Formulae and Followon Formulae, 2003.

340 B. Koletzko, S. Baker, G. Cleghorn, U. F. Neto, S. Gopalan, O. Hernell, Q. S. Hock, P. Jirapinyo, B. Lonnerdal, P. Pencharz, H. Pzyrembel, J. Ramirez-Mayans, R. Shamir, D. Turck, Y. Yamashiro and D. Zong-Yi, J. Pediatr. Gastroenterol. Nutr., 2005, 41, 584-599.

$341 \mathrm{~J}$. B. Fontelles and J. Korkeaoja, Official Journal of the European Union, 2007, L12, 3-18.

342 J.-L. Bresson, A. Flynn, M. Heinonen, K. Hulshof, H. Korhonen, P. Lagiou, M. Løvik, R. Marchelli, A. Martin, B. Moseley, H. Przyrembel, S. Salminen, S. (J. J.) Strain, S. Strobel, I. Tetens, H. van den Berg, H. van Loveren and H. Verhagen, EFSA J., 2009, 7, 1277.

343 S. S. H. Choi, N. Baldwin, V. O. Wagner, S. Roy, J. Rose, B. A. Thorsrud, P. Phothirath and C. H. Röhrig, Regul. Toxicol. Pharmacol., 2014, 70, 482-491.

344 J. P. Zimmer and C. M. Butt, US8703716B2, 2014.

345 Glycom A/S, GRAS Exemption Claim for N-Acetyl-Dneuraminic acid (NANA), http:/www.fda.gov/Food/ IngredientsPackagingLabeling/GRAS/NoticeInventory/ default.htm.

346 Food Safety Authority of Ireland, Safety Assessment of N-acetyl-D-neuraminic acid dihydrate (NANA), 2016.

347 ADVISORY COMMITTEE FOR NOVEL FOODS AND PROCESSES, N-Acetyl-D-Neuraminic Acid (NANA, Sialic Acid) DOSSIER 187, https://acnfp.food.gov.uk/sites/default/ files/nana.pdf.

348 EFSA Panel on Dietetic Products, EFSA J., 2017, 15, 4918.

349 S. Peled and Y. D. Livney, Food Hydrocolloids, 2021, 120, 106911.

350 X. Sun, S. Zhang, J. Ren and C. C. Udenigwe, Crit. Rev. Food Sci. Nutr., 2020, 1846157.

351 X. Sun and J. Wu, Trends Food Sci. Technol., 2017, 69, 148-156.

352 K. R. Phipps, Š. Alica, N. J. Baldwin, B. Gilby, B. Lynch, D. R. Stannard, M. H. Mik and C. H. Röhrig, J. Appl. Toxicol., 2019, 39, 1378-1393.

353 K. R. Phipps, Š. Alica, N. J. Baldwin, B. Gilby, B. Lynch, D. R. Stannard, M. H. Mik and C. H. Röhrig, J. Appl. Toxicol., 2019, 39, 1444-1461.

354 Glycom A/S, GRAS Notice for 3' -Sialyllactose, https://www. fda.gov/food/generally-recognized-safe-gras/gras-noticeinventory.

355 Glycom A/S, GRAS Notice for 6 '-Sialyllactose, https://www. fda.gov/food/generally-recognized-safe-gras/gras-noticeinventory.

356 EFSA Panel on Nutrition, EFSA J., 2020, 18, 6098.

357 EFSA Panel on Nutrition, EFSA J., 2020, 18, 6097.

358 https://www.dsm.com/human-nutrition/en/early-lifenutrition/human-milk-oligosaccharides/GlyCare-3SL.html (Accessed November 2021).
359 https://www.dsm.com/human-nutrition/en_AP/early-lifenutrition/human-milk-oligosaccharides/GlyCare-6SL.html (Accessed November 2021).

360 F. Herrmann, A. Nieto-Ruiz, N. Sepúlveda-Valbuena, M. T. Miranda, E. Diéguez, J. Jiménez, R. De-Castellar, M. GarcíaRicobaraza, J. A. García-Santos, M. G. Bermúdez and C. Campoy, J. Funct. Foods, 2021, 83, 104529.

361 J. Ma, S. Gong, Y. He, W. Gao, W. Hao and X. Lan, Lett. Appl. Microbiol., 2021, 73, 20-25.

362 X. Wu, Z. Li, X. X. Chen, J. S. Fossey, T. D. James and Y. B. Jiang, Chem. Soc. Rev., 2013, 42, 8032-8048.

363 H. Otsuka, E. Uchimura, H. Koshino, T. Okano and K. Kataoka, J. Am. Chem. Soc., 2003, 125, 3493-3502.

364 K. Djanashvili, L. Frullano and J. A. Peters, Chem. - Eur. J., 2005, 11, 4010-4018.

365 S. Nishitani, Y. Maekawa and T. Sakata, ChemistryOpen, 2018, 7, 513-519.

366 N. Wellington, S. Macklai and P. Britz-McKibbin, Chem. Eur. J., 2019, 25, 15277-15280.

367 E. L. Hess, J. W. Hahn and W. Ayala, Exp. Biol. Med., 1956, 91, 528-531.

368 E. L. Hess, A. F. Coburn, R. C. Bates and P. Murphy, J. Clin. Invest., 1957, 36, 449-455.

369 L. Svennerholm, Biochim. Biophys. Acta, 1957, 24, 604-611.

370 G. W. Jourdian, L. Dean and S. Roseman, J. Biol. Chem., 1971, 246, 430-435.

371 G. D. Dimitrov, Hoppe-Seyler's Z. Physiol. Chem., 1973, 354, 121-124.

372 M. H. E. Spyridaki and P. A. Siskos, Anal. Chim. Acta, 1996, 327, 277-285.

373 L. Warren, J. Biol. Chem., 1959, 234, 1971-1975.

374 D. Aminoff, Virology, 1959, 7, 355-357.

375 I. E. Horgan, Clin. Chim. Acta, 1981, 116, 409-415.

376 Y. Massamiri, G. Durand, A. Richard, J. Féger and J. Agneray, Anal. Biochem., 1979, 97, 346-351.

377 K. Yao and T. Ubuka, Acta Med. Okayama, 1987, 41, 237-241.

378 J. B. Joicy, N. T. G. de Paula, P. A. B. da Silva, G. C. S. de Souza, A. P. S. Paim and A. F. Lavorante, Microchem. J., 2019, 147, 782-788.

379 T. J. Jayeoye, W. Cheewasedtham, C. Putson and T. Rujiralai, Microchim. Acta, 2018, 185, 409.

380 T. J. Jayeoye, W. Cheewasedtham, C. Putson and T. Rujiralai, J. Mol. Liq., 2019, 281, 407-414.

381 H. Hess and E. Rolde, J. Biol. Chem., 1964, 239, 3215-3220.

382 K. S. Hammond and D. S. Papermaster, Anal. Biochem., 1976, 74, 292-297.

383 J. I. Murayama, M. Tomita, A. Tsuji and A. Hamada, Anal. Biochem., 1976, 73, 535-538.

384 A. K. Shukla and R. Schauer, Hoppe-Seyler's Z. Physiol. Chem., 1982, 363, 255-262.

385 K. Matsuno and S. Suzuki, Anal. Biochem., 2008, 375, 53-59.

386 A. D. A. Alves, M. F. Belian and A. F. Lavorante, Luminescence, 2014, 29, 779-783.

387 Q. Wang, B. Wang, M. Ma and Z. Cai, J. Food Sci., 2014, 79, C2434-C2440. 
388 J. Wang, G. Xu, F. Wei, J. Yang, P. Zhou and Q. Hu, RSC $A d v .$, 2016, 6, 481-488.

389 X. Hao, Q. Zhang, L. Li and L. Zhou, Mater. Lett., 2018, 227, 165-168.

390 S. Xu, S. Che, P. Ma, F. Zhang, L. Xu, X. Liu, X. Wang, D. Song and Y. Sun, Talanta, 2019, 197, 548-552.

391 N. Wang, M. Wang, Y. Yu, G. Yang and X. Su, New J. Chem., 2020, 44, 2350-2356.

392 J. Wang, L. Zhao and B. Yan, ACS Appl. Mater. Interfaces, 2020, 12, 12990-12997.

393 H. Yu, Y. Li and A. Huang, Talanta, 2021, 232, 122434.

394 Y. Zhang, H. Lu and B. Yan, Sens. Actuators, B, 2021, 349, 130736.

395 D. E. Wang, J. Yan, J. Jiang, X. Liu, C. Tian, J. Xu, M. Sen Yuan, X. Han and J. Wang, Nanoscale, 2018, 10, 4570-4578.

396 H. Yue, J. Chen, X. Chen, X. Wang, Y. Zhang and N. Zhou, Sens. Actuators, B, 2021, 344, 130270.

397 Q. Lu, M. Zhan, L. Deng, G. Qing and T. Sun, Analyst, 2017, 142, 3564-3568.

398 X. Wang, S. Qian, D. Wang, C. Wang, H. Qin, L. Peng, W. Lu, Y. Zhang and G. Qing, J. Mater. Chem. B, 2021, 9, 4690-4699.

399 K. Ouchi, C. L. Colyer, M. Sebaiy, J. Zhou, T. Maeda, H. Nakazumi, M. Shibukawa and S. Saito, Anal. Chem., 2015, 87, 1933-1940.

400 J. A. Cabezas, Biochem. J., 1991, 278, 311-312.

401 S. Roseman and D. G. Comb, J. Am. Chem. Soc., 1958, 80, 3166-3167.

402 D. G. Comb and S. Roseman, J. Am. Chem. Soc., 1958, 80, 497-499.

403 D. G. Comb and S. Roseman, J. Biol. Chem., 1960, 235, 2529-2537.

404 A. D. Winer and G. W. Schwert, Science, 1958, 128, 660-661.

405 O. H. Lowry, N. R. Roberts and J. I. Kapphahn, J. Biol. Chem., 1957, 224, 1047-1064.

406 P. Brunetti, A. Swanson and S. Roseman, Methods Enzymol., 1963, 6, 465-473.

407 D. G. Comb and S. Roseman, Methods Enzymol., 1962, 5, 391-394.

408 K. Sugahara, K. Sugimoto, O. Nomura and T. Usui, Clin. Chim. Acta, 1980, 108, 493-498.

409 S. Teshima, K. Tamai, Y. Hayashi and S. Emi, Clin. Chem., 1988, 34, 2291-2294.

410 H. Simpson, G. D. Chusney, M. A. Crook and J. C. Pickup, Br. J. Biomed. Sci., 1993, 50, 164-167.

411 T. Horiuchi and T. Kurokawa, Clin. Chim. Acta, 1989, 182, 117-121.

412 J. P. Johnston, A. G. Ogston and J. E. Stanier, Analyst, 1951, 76, 88-89.

413 L. Svennerholm, Acta Chem. Scand., 1958, 12, 547-554.

414 M. J. Krantz and Y. C. Lees, Anal. Biochem., 1975, 63, 464-469.

415 D. A. Craven and C. W. Gehrke, J. Chromatogr., 1968, 37, 414-421.

416 J. Casals-Stenzel, H.-P. Buscher and R. Schauer, Anal. Biochem., 1975, 65, 507-524.
417 J. P. Kamerling, J. F. G. Vliegenthart, C. Versluis and R. Schauer, Carbohydr. Res., 1975, 41, 7-17.

418 H. K. B. Silver, K. A. Karim, M. J. Gray and F. A. Salinas, J. Chromatogr., 1981, 224, 381-388.

419 A. K. Shukla, N. Scholz, E. H. Reimerdes and R. Schauer, Anal. Biochem., 1982, 123, 78-82.

420 A. K. Shukla and R. Schauer, J. Chromatogr., 1982, 244, 81-89.

421 N. K. Karamanos, B. Wikström, C. A. Antonopoulos and A. Hjerpe, J. Chromatogr., 1990, 503, 421-429.

422 F. Unland and J. Muthing, Biomed. Chromatogr., 1992, 6, 155-159.

423 E. L. Romero, M. F. Pardo, S. Porro and S. Alonso, J. Biochem. Biophys. Methods, 1997, 35, 129-134.

424 S. M. Levonis, J. Pittet, B. C. M. Pointon and S. S. Schweiker, J. Chromatogr., B, 2019, 1104, 130-133.

425 K. Kobayashi, Y. Akiyama, K. Kawaguchi, T. Shinzo and T. Imanari, Anal. Sci., 1985, 1, 81-84.

426 K. Li, J. Chromatogr., 1992, 579, 209-213.

427 S. Honda, S. Iwase, S. Suzuki and K. Kakehi, Anal. Biochem., 1987, 160, 455-461.

428 K. R. Anumula, Anal. Biochem., 1995, 230, 24-30.

429 S. Hara, M. Yamaguchi, Y. Takemori and M. Nakamljra, J. Chromatogr., 1986, 377, 111-119.

430 S. Hara, Y. Takemori, M. Yamaguchi, M. Nakamura and Y. Ohkura, Anal. Biochem., 1987, 164, 138-145.

431 S. Hara, M. Yamaguchi, Y. Takemori, K. Furuhata, H. Ogura and M. Nakamura, Anal. Biochem., 1989, 179, 162-166.

432 P. G. Stanton, Z. Shen, E. A. Kecorius, P. G. Burgon, D. M. Robertson and M. T. W. Hearn, J. Biochem. Biophys. Methods, 1995, 30, 37-48.

433 M. J. Martín, E. Vázquez and R. Rueda, Anal. Bioanal. Chem., 2007, 387, 2943-2949.

434 A. Kawasaki, M. Yasuda, K.-I. Mawatari, T. Fukuuchi, N. Yamaoka, K. Kaneko, R. Iijima, S. Yui, M. Satoh and K. Nakagomi, Anal. Sci., 2018, 34, 841-844.

435 T. Ota, M. Yasuda, R. Iijima, S. Yui, T. Fukuuchi, N. Yamaoka, K. Mawatari, K. Kaneko and K. Nakagomi, J. Chromatogr., B, 2013, 932, 152-157.

436 D. Li, Food Sci. Biotechnol., 2012, 21, 1317-1320.

437 L. Wang, D. Wang, X. Zhou, L. Wu and X. Sun, RSC Adv., 2014, 4, 45797-45803.

438 M. I. Orozco-Solano, F. Priego-Capote and M. D. Luque de Castro, Anal. Chim. Acta, 2013, 766, 69-76.

439 F. Qu, L. Xia, C. Wu, L. Liu, G. Li and J. You, RSC Adv., 2016, 6, 64895-64901.

440 A. E. Manzi, S. Diaz and A. Varki, Anal. Biochem., 1990, 188, 20-32.

441 M. R. Hardy, Methods Enzymol., 1989, 179, 76-82.

442 J. S. Rohrer, J. Thayer, M. Weitzhandler and N. Avdalovic, Glycobiology, 1998, 8, 35-43.

443 R. D. Rocklin, A. P. Clarke and M. Weitzhandler, Anal. Chem., 1998, 70, 1496-1501.

444 C. J. Shaw, H. Chao and B. Xiao, J. Chromatogr. A, 2001, 913, 365-370. 
445 M. van der Ham, B. H. C. M. T. Prinsen, J. G. M. Huijmans, N. G. G. M. Abeling, B. Dorland, R. Berger, T. J. de Koning and M. G. M. de Sain-van der Velden, J. Chromatogr., B, 2007, 848, 251-257.

446 P. Allevi, E. A. Femia, M. L. Costa, R. Cazzola and M. Anastasia, J. Chromatogr. A, 2008, 1212, 98-105.

447 L. A. Hammad, D. Z. Derryberry, Y. R. Jmeian and Y. Mechref, Rapid Commun. Mass Spectrom., 2010, 24, 1565-1574.

448 Y. Shi, X. Xu, M. Fang, M. Zhang, Y. Li, B. Gillespie, S. Yorke, N. Yang, J. C. McKew, W. A. Gahl, M. Huizing, N. Carrillo-Carrasco and A. Q. Wang, J. Chromatogr., B, 2015, 1000, 105-111.

449 C. Li, L. Liu, H. Xie and N. Liu, Int. J. Dairy Technol., 2015, 68, 166-173.

450 S. F. Fernando and B. W. Woonton, J. Food Compos. Anal., 2010, 23, 359-366.

451 T. Hayama, Y. Sakaguchi, H. Yoshida, M. Itoyama, K. Todoroki, M. Yamaguchi and H. Nohta, Rapid Commun. Mass Spectrom., 2010, 24, 2868-2874.

452 A. Tebani, D. Schlemmer, A. Imbard, O. Rigal, D. Porquet and J. F. Benoist, J. Chromatogr., B, 2011, 879, 3694-3699.

453 D. Wang, X. Zhou, L. Wang, S. Wang and X. L. Sun, J. Chromatogr., B, 2014, 944, 75-81.

454 F. Priego-Capote, M. I. Orozco-Solano, M. CalderónSantiago and M. D. Luque de Castro, J. Chromatogr. A, 2014, 1346, 88-96.

455 B. Yesilyurt, U. Sahar and R. Deveci, Mol. Reprod. Dev., 2015, 82, 115-122.

456 F. T. A. Chen, T. S. Dobashi and R. A. Evangelista, Glycobiology, 1998, 8, 1045-1052.

457 F. Y. Che, X. X. Shao, K. Y. Wang and Q. C. Xia, Electrophoresis, 1999, 20, 2930-2937.

458 X. Dong, X. Xu, F. Han, X. Ping, X. Yuang and B. Lin, Electrophoresis, 2001, 22, 2231-2235.

459 K. Strousopoulou, M. Militsopoulou, K. Stagiannis, F. N. Lamari and N. K. Karamanos, Biomed. Chromatogr., 2002, 16, 146-150.

460 A. Taga, M. Sugimura, S. Suzuki and S. Honda, J. Chromatogr. A, 2002, 954, 259-266.

461 K. Ortner and W. Buchberger, Electrophoresis, 2008, 29, 2233-2237.

462 Y. Zheng, T. Wang, J. Kong, Y. Ma, Y. Heng, Y. Ren, J. Ye and Q. Chu, Chin. J. Chem., 2016, 34, 925-930.

463 Y. Wang, J. Kong, Z. Chen, D. Luo, J. Ye and Q. Chu, Food Anal. Methods, 2018, 11, 1105-1112.

464 S. A. M. Marzouk, S. S. Ashraf and K. A. Al Tayyari, Anal. Chem., 2007, 79, 1668-1674.

465 S. A. M. Marzouk, J. D. Haddow and A. Amin, Sens. Actuators, B, 2011, 157, 647-653.

466 A. Fatoni, A. Numnuam, P. Kanatharana, W. Limbut and P. Thavarungkul, Electrochim. Acta, 2014, 130, 296-304.

467 Y. Zhou, H. Dong, L. Liu, J. Liu and M. Xu, Biosens. Bioelectron., 2014, 60, 231-236.

468 Y. Zhou, H. Huangfu, J. Yang, H. Dong, L. Liu and M. Xu, Analyst, 2019, 144, 6432-6437.
469 F. Huang, B. Zhu, H. Zhang, Y. Gao, C. Ding, H. Tan and J. Li, Microchim. Acta, 2019, 186, 1-11.

470 T. V. Shishkanova, G. Broncová, Z. Němečková, V. Vrkoslav, V. Král and P. Matějka, J. Electroanal. Chem., 2019, 832, 321-328.

471 T. Liu, B. Fu, J. Chen, Z. Yan and K. Li, Electrochim. Acta, 2018, 269, 136-143.

472 Y. Lv, Y. Zhou, H. Dong, L. Liu, G. Mao, Y. Zhang and M. $\mathrm{Xu}$, ChemElectroChem, 2020, 7, 922-927.

473 W. Hai, S. Pu, X. Wang, L. Bao, N. Han, L. Duan, J. Liu, T. Goda and W. Wu, Langmuir, 2020, 36, 546-553.

474 S. Ding, S. Cao, Y. Liu, Y. Lian, A. Zhu and G. Shi, ACS Sens., 2017, 2, 394-400.

475 G. Broncová, P. Matějka, Z. Němečková, V. Vrkoslav and T. V. Shishkanova, Electroanalysis, 2018, 30, 672-680.

476 L. Chen, N. Wang, J. Wu, F. Yan and H. Ju, Anal. Chim. Acta, 2020, 1128, 231-237.

477 J. Wang, S. Zhang, H. Dai, H. Zheng, Z. Hong and Y. Lin, Biosens. Bioelectron., 2019, 142, 111567.

478 D. Fang, S. Zhang, H. Dai, Z. Hong and Y. Lin, Electrochim. Acta, 2019, 326, 134956.

479 N. Cao, F. Zhao and B. Zeng, Sens. Actuators, B, 2020, 313, 128042.

480 A. Kugimiya, H. Yoneyama and T. Takeuchi, Electroanalysis, 2000, 12, 1322-1326.

481 S.-J. Duan, X.-W. He, L.-X. Chen and Y.-K. Zhang, Gaodeng Хиехіао Ниахие Хиеbаo, 2012, 33, 464-469.

482 X. Qiu, X. Y. Xu, X. Chen, Y. Wu and H. Guo, Anal. Bioanal. Chem., 2018, 410, 4387-4395.

483 A. Kugimiya and T. Takeuchi, Biosens. Bioelectron., 2001, 16, 1059-1062.

484 S. Li, J. Liu, Y. Lu, L. Zhu, C. Li, L. Hu, J. Li, J. Jiang, S. Low and Q. Liu, Biosens. Bioelectron., 2018, 117, 32-39.

485 E. Vinogradova, A. Tlahuice-Flores, J. J. Velazquez-Salazar, E. Larios-Rodriguez and M. Jose-Yacaman, J. Raman Spectrosc., 2014, 45, 730-735.

486 A. C. Hernández-Arteaga, F. C. Delgado-Nieblas, H. J. OjedaGalván, J. J. Velázquez-Salazar, E. Vinogradova, M. JoséYacamán, R. A. Guirado-López and H. R. Navarro-Contreras, J. Phys. Chem. C, 2017, 121, 21045-21056.

487 A. Hernández-Arteaga, J. de Jesús Zermeño Nava, E. S. Kolosovas-Machuca, J. J. Velázquez-Salazar, E. Vinogradova, M. José-Yacamán and H. R. Navarro-Contreras, Nano Res., 2017, 10, 3662-3670.

488 X. Teng, F. Chen, Y. Gao, R. Meng, Y. Wu, F. Wang, Y. Ying, X. Liu, X. Guo, Y. Sun, P. Lin, Y. Wen and H. Yang, Anal. Chem., 2020, 92, 3332-3339.

489 https://www.elabscience.com/p-sialic_acid_sa_colorimetric_ assay_kit-40365.html (Accessed November 2021).

490 https://www.mybiosource.com/assay-kits/sialic-acid/2540448 (Accessed November 2021).

491 https://www.mybiosource.com/general-assay-kits/sialic-acidsa/2563693 (Accessed November 2021).

492 https://www.biovision.com/sialic-acid-nana-colorimetricfluorometric-assay-kit.html (Accessed November 2021).

493 https://www.bioassaysys.com/Sialic-acid-Assay-Kit-(ESLA100).html (Accessed November 2021). 
494 https://www.lsbio.com/assaykits/sialic-acid-assay-kitcolorimetric-fluorometric-ls-k187/187 (Accessed November 2021).

495 https://www.promocell.com/product/sialic-acid-nana-assaykit/ (Accessed November 2021).

496 https://www.abcam.com/sialic-acid-nana-assay-kit-ab83375. html (Accessed November 2021).

497 https://www.antibodies-online.com/kit/411705/Sialic+Acid +NANA+Colorimetric/Fluorometric+Assay+Kit/ (Accessed November 2021).

498 http://www.cohesionbio.com/goods.php?id=127272 (Accessed November 2021).

499 https://www.mybiosource.com/general-assay-kits/sialic-acid/ 8309610 (Accessed November 2021).

500 https:/www.mybiosource.com/assay-kits/sialic-acid-nana/ 841610 (Accessed November 2021).

501 https://www.usbio.net/kits/S1013-31Q/sialic-acid-assay-kitbioassaytrade-colorimetricfluorometric-high-sensitivity (Accessed November 2021).

502 https://www.usbio.net/kits/A0535-01A/n-acetylneuraminicacid-nana-sialic-acid-bioassaytrade-kit (Accessed November 2021).

503 https://www.creativebiomart.net/sialic-acid-nanacolorimetricfluorometric-assay-kit-463657.htm (Accessed November 2021).

504 https://www.creativebiomart.net/sialic-acid-assay-kit-502969. htm (Accessed November 2021).

505 http://www.abnova.com/products/products_detail.asp? catalog_id=KA1655 (Accessed November 2021).

506 https://www.bioassaysys.com/Sialic-acid-Assay-Kit-(DSLA100).html (Accessed November 2021).

507 https://www.usbio.net/kits/S1013-31P/sialic-acid-assay-kitbioassaytrade-colorimetricfluorometric (Accessed November 2021).

508 https://www.sigmaaldrich.com/IE/en/product/sigma/ mak314? context=product (Accessed November 2021).

509 https:/www.creativebiomart.net/sialic-acid-assay-kit-463740. htm (Accessed November 2021).

510 https://www.assaygenie.com/sialic-acid-assay-kitcolorimetric-or-fluorometric-ba0058/ (Accessed November 2021).

511 https://www.sigmaaldrich.com/IE/en/product/sigma/sialicq? context=product (Accessed November 2021).

512 https:/www.takarabio.com/products/protein-research/ glycobiology/sialic-acid-kit?catalog $=4400$

(Accessed November 2021).

513 https://www.agilent.com/store/productDetail.jsp? catalogId= GKK-407 (Accessed November 2021).
514 https://www.ludger.com/dmb-sialic-acid-analysis/index.php (Accessed November 2021).

515 https://www.agilent.com/store/productDetail.jsp?catalogId= GS24-SAP (Accessed November 2021).

516 W. Song, L. Ding, Y. Chen and H. Ju, Chem. Commun., 2016, 52, 10640-10643.

517 T. Gong, Y. Cui, D. Goh, K. K. Voon, P. P. Shum, G. Humbert, J. L. Auguste, X. Q. Dinh, K. T. Yong and M. Olivo, Biosens. Bioelectron., 2015, 64, 227-233.

518 X. N. He, Y. N. Wang, Y. Wang and Z. R. Xu, Talanta, 2020, 209, 120579.

519 L. Liang, Y. Shen, J. Zhang, S. Xu, W. Xu, C. Liang and B. Han, Anal. Chim. Acta, 2018, 1033, 148-155.

520 S. Shinde, Z. El-Schich, A. Malakpour, W. Wan, N. Dizeyi, R. Mohammadi, K. Rurack, A. Gjörloff Wingren and B. Sellergren, J. Am. Chem. Soc., 2015, 137, 13908-13912.

521 N. Peng, R. Xu, M. Si, A. Victorious, E. Ha, C. Y. Chang and X. D. Xu, RSC Adv., 2017, 7, 11282-11285.

522 Y. Geng, L. Cong, Y. Tian, Z. Huo, Y. Wang, L. Xing, S. Xu, C. Liang and W. Xu, Sens. Actuators, B, 2019, 301, 127074.

523 V. Almeida-Marrero, M. Mascaraque, M. Jesús VicenteArana, Á. Juarranz, T. Torres and A. de la Escosura, Chem. Eur. J., 2021, 27, 9634-9642.

524 X. Yang, L. Zhou, Y. Hao, B. Zhou and P. Yang, Analyst, 2017, 142, 2169-2176.

525 D. Qian, F. Han, W. Li, N. Bao, C. Yu and H. Gu, Microchim. Acta, 2017, 184, 3841-3850.

526 K. Liu, Q. Sun, L. Zhu, C. Feng, J. Zhang, Y. Wang, F. Zhang, Z. Xu and W. Zhang, Anal. Methods, 2015, 7, 3819-3826.

527 L. Zhang, C. Yu, R. Gao, Y. Niu, Y. Li, J. Chen and J. He, Biosens. Bioelectron., 2017, 92, 434-441.

528 A. Matsumoto, S. Osawa, T. Arai, Y. Maejima, H. Otsuka and Y. Miyahara, Bioconjugate Chem., 2021, 32, 239-244.

529 G. Landa, L. G. Miranda-Calderón, V. Sebastian, S. Irusta, G. Mendoza and M. Arruebo, Talanta, 2021, 234, 122644.

530 S. Osawa, A. Matsumoto, Y. Maejima, T. Suzuki, Y. Miyahara and H. Otsuka, Anal. Chem., 2020, 92, 11714-11720.

531 D. Sui, X. Tang, J. Ding, Y. Wang, Y. Qin, N. Zhang, X. Liu, Y. Deng and Y. Song, Int. J. Pharm., 2021, 602, 120552.

532 https://www.biovision.com/ezclicktm-sialic-acid-manazmodified-glycoprotein-assay-kit-facs-microscopy-greenfluorescence.html (Accessed November 2021).

533 https:/www.sartorius.com/en/products/protein-analysis/ biosensors-chips-kits/sialic-acid-glys-kit November 2021). 